T3

> Triiodthyronin, gesamt

\section{T3, freies}

- Triiodthyronin, freies

\section{T4}

- Thyroxin, gesamt

\section{T4, freies}

- Thyroxin, freies

\section{T9}

CD71

\section{Tabak-Alkaloide}

T. Arndt

Synonym(e) Nicotiana-Alkaloide

Englischer Begriff tabacco alkaloids
Definition Tabak-Alkaloide sind im weiteren Sinne Inhaltsstoffe von Pflanzen der Gattung Nicotiana L., im engeren Sinne der Art Nicotiana tabacum L., und sollen hier jene Alkaloide sein, die für die Labordiagnostik des Tabakrauchens von Bedeutung sind.

\section{Struktur Abb. 1.}

Molmasse Nicotin $\left(\mathrm{C}_{10} \mathrm{H}_{14} \mathrm{~N}_{2}\right) 162,23 \mathrm{~g}$, Nornicotin $\left(\mathrm{C}_{9} \mathrm{H}_{12} \mathrm{~N}_{2}\right)$ $148,20 \mathrm{~g}$, Anatabin $\left(\mathrm{C}_{10} \mathrm{H}_{12} \mathrm{~N}_{2}\right) 160,22 \mathrm{~g}$, Anabasin (syn. Neonicotin; $\mathrm{C}_{10} \mathrm{H}_{14} \mathrm{~N}_{2}$ ) 162,23 g; Nicotinmetabolite Cotinin $\left(\mathrm{C}_{10} \mathrm{H}_{12} \mathrm{~N}_{2} \mathrm{O}\right)$ 176,22 $\mathrm{g}$ und 3-OH-Cotinin $\left(\mathrm{C}_{10} \mathrm{H}_{12} \mathrm{~N}_{2} \mathrm{O}_{2}\right)$ $192,21 \mathrm{~g}$.

Synthese - Verteilung - Abbau - Elimination Die aus Südamerika stammende Tabakpflanze (Nicotiana tabacum L.) ist ein Nachtschattengewächs, das heute vorrangig in den subtropischen bis gemäßigten Breiten in China, Nord-, Mittel- und Südamerika, daneben aber auch in Europa kultiviert wird.

Sie enthält bis zu 50 verschiedene Alkaloide, mit einem Gesamtgehalt von $0,5-9 \%$. Die quantitativ wichtigsten Alkaloide sind Nicotin (ca. $95 \%$ ), Norcotinin (ca. $3 \%$ ), Anatabin (ca. $2 \%$ ) und Anabasin (ca. 0,3 \%), wobei sowohl Gesamtgehalt als auch relativer Anteil der einzelnen Alkaloide von der Art und geografischen Herkunft abhängen. So hat z. B. Nicotiana glauca Graham (Tabakbaum) einen etwa 1000-fach höheren Anabasingehalt als N. tabacum L.

Nicotin Nicotin wird von der Tabakpflanze als Abwehrstoff in den Wurzeln erzeugt und in den Blättern angereichert. Seine Wirkungen haben dem Tabak als Genussmittel zu einer großen Verbreitung verholfen. Die Aufnahmeformen reichen vom konventionellen Rauchen bzw. Kauen der getrockneten Blätter bis hin zu transdermaler Zufuhr (Nicotinpflaster) und elektronischen Zigaretten (E-Zigaretten).

Nicotin wird über die Lunge und Schleimhäute schnell resorbiert, wobei der Nicotingehalt des Tabakrauches und 


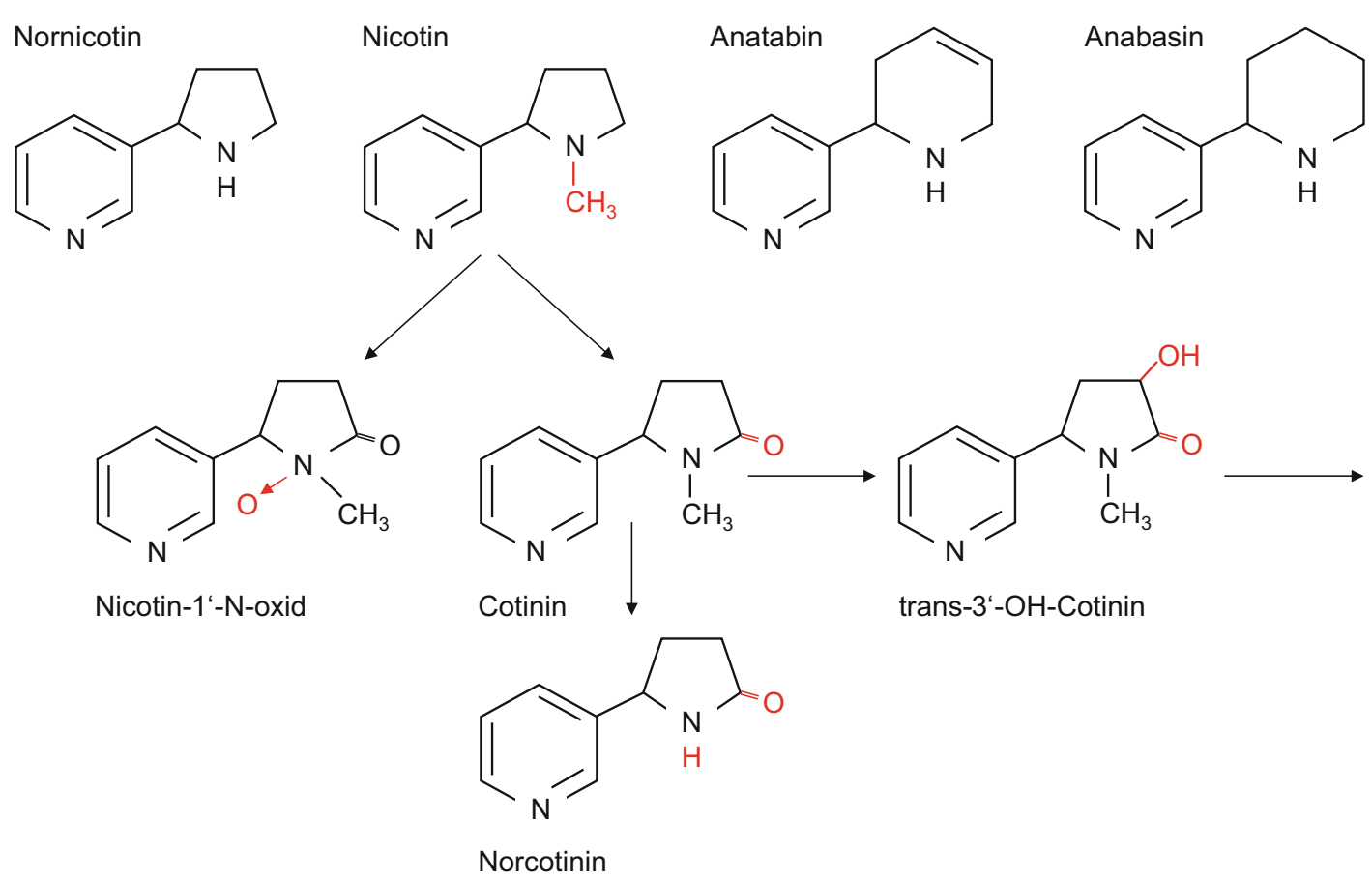

Tabak-Alkaloide, Abb. 1 Strukturen der quantitativ wichtigsten Alkaloide von Nicotiana tabacum L. sowie einiger Nicotinmetabolite. (Nach: Blaschek et al. 2007; Baselt 2014)

damit die resorbierte Nicotinmenge von der Azidität des Tabaks abhängt. Rauch aus zuckerreichem, fermentiertem Tabak liefert sauren Rauch und entsprechend weniger Nicotin als zuckerarmer, unfermentierter Tabak. Die langsamere Resorption von Nicotin aus Kautabak führt man auf ähnliche pH-abhängige Mechanismen zurück (Speichel ist gewöhnlich leicht sauer).

Nicotin wird hauptsächlich in der Leber abgebaut. Der Metabolismus ist komplex mit Oxidation zu Nicotin-1'-NOxid und Cotinin, wobei letzteres zu Norcotinin desmethyliert und $\mathrm{zu}$ trans-3'-OH-Cotinin (syn. 3-OH-Cotinin) hydroxyliert wird. Dieses wiederum unterliegt in einer Folgereaktion einer Ringöffnung. Weitere Metabolite sind Nornicotin (selbst ein Alkaloid von N. tabacum L.), Cotinin-Noxid und N- und O-Glukuronide von Nicotin und den hier genannten Metaboliten (s. Strukturen in Abb. 1).

Nur etwa $5 \%$ der ursprünglich resorbierten Nicotinmenge werden im 24-Stunden-Urin unverändert ausgeschieden (Eliminationshalbwertszeit $\mathrm{t}_{1 / 2} 4,5$ Stunden). Hauptmetabolite im Urin sind Cotinin (ca. $10 \%, \mathrm{t}_{1 / 2} 19$ Stunden), 3-OH-Cotinin (ca. $35 \%, \mathrm{t}_{1 / 2} 22$ Stunden) sowie Nicotin-1'-N-oxid (ca. $4 \%$ ). Die Ausscheidung von Nicotin ist im sauren Urin im Vergleich zu alkalischem Urin beschleunigt.

Anatabin und Anabasin Für den menschlichen Organismus sind, abgesehen von Glukuroniden, bisher keine Anabasin- und Anatabinmetabolite beschrieben. Von einer $2 \mathrm{mg}$ Anabasineinnahme wurden ca. $28 \%$, bei einem sauren Urin bis $70 \%$ Wirkstoff im 24-Stunden-Urin gefunden.
Halbwertszeit Nicotin 30 Minuten bis 2 Stunden im Blut (Plasma), Eliminationshalbwertszeiten s. oben.

Funktion - Pathophysiologie Nicotin entfaltet seine Wirkungen über den sog. nicotinischen Acetylcholinrezeptor, d. h. in den Membranen des Nervensystems und Muskels liegende, durch Nicotin aktivierbare Ionenkanäle. Niedrig dosiert hat Nicotin einen stimulierenden Kurzzeiteffekt. Längere Einwirkung oder eine höhere Dosis führen nach anfänglicher Erregung zu einer anhaltenden Depolarisation der postsynaptischen Membran vegetativer Ganglien. Leichte Intoxikationen führen zu Übelkeit, Erregung und Schwindel, schwere zu Tachykardie, Hypotonie, Krämpfen, Koma bis zu Herz- und Atemstillstand. Eine chronische Nicotinexposition kann sich atherogen, mutagen, karzinogen, reproduktionstoxisch und sensibilisierend (Kontaktallergie, Asthma) auswirken. Wirkung und Toxikologie der Nebenalkaloide von $N$. tabacum sind noch nicht hinreichend bekannt.

Untersuchungsmaterial - Entnahmebedingungen Spontanurin (normaler Postversand möglich).

Probenstabilität Nicotin, Cotinin, 3-OH-Cotinin, Anabasin: Raumtemperatur 48 Stunden, Kühlschrank 14 Tage, $-20{ }^{\circ} \mathrm{C} 6$ Monate; 3 Auftau-/Einfrierzyklen (noch unpublizierte Daten).

Präanalytik Keine Patientenvorbereitung. 
Untersuchungsmaterial Urin (längeres Nachweiszeitfenster als in Blut).

Analytik Immunoassay (Cotinin); HPLC, GC; LC-MS/MS mit chromatographischer Trennung der Konstitutionsisomeren bzw. Isobaren ( $\triangleright$ Isobare) Nicotin und Anabasin.

Konventionelle Einheit $\mu \mathrm{g} / \mathrm{L}$.

Internationale Einheit nmol/L.

Umrechnungsfaktor zw. konv. u. int. Einheit $\mu \mathrm{g} \times$ Faktor=nmol: Nicotin und Anabasin 6,164; Nornicotin 6,747; Anatabin 6,241; Cotinin 5,674; 3-OH-Cotinin 5,202.

Referenzbereich - Entscheidungsgrenzen Nicotin im Plasma (Schulz et al. 2012): therapeutisch 50-300 $\mu \mathrm{g} / \mathrm{L}$ (Nicotinpflaster), toxisch ab $400 \mu \mathrm{g} / \mathrm{L}$, komatös-letal ab $5000 \mu \mathrm{g} / \mathrm{L}$.

Vorläufige Entscheidungsgrenzen für Differenzierung Nichtraucher vs. Raucher vs. Passivraucher (aus: Moyer et al. 2002; von Weymarn et al. 2016*):

\begin{tabular}{l|l|l|l} 
& $\begin{array}{l}\text { Nichtraucher } \\
(\mu \mathrm{g} / \mathrm{L})\end{array}$ & $\begin{array}{l}\text { Raucher } \\
(\mu \mathrm{g} / \mathrm{L})\end{array}$ & $\begin{array}{l}\text { Passivraucher } \\
(\mu \mathrm{g} / \mathrm{L})\end{array}$ \\
\hline Serum & $<2$ & $30-50$ & $<2$ \\
\hline Nicotin & $<2$ & $200-800$ & $<8$ \\
\hline Cotinin & $<2$ & $100-500$ & $<2$ \\
\hline 3-OH-Cotinin & k.A. & k.A. & k.A. \\
\hline Anabasin & k.A. & k.A. & k.A. \\
\hline Anatabin & & & \\
\hline Urin & $<2$ & $1000-5000$ & $<20$ \\
\hline Nicotin & $<5$ & $1000-8000$ & $<20$ \\
\hline Cotinin & $<50$ & $3000-25000$ & $<50$ \\
\hline 3-OH-Cotinin & $<2$ & $30-900$ & $<2$ \\
\hline Norcotinin & $<2$ & $10-500$ & $<2$ \\
\hline Anabasin & $<2 *$ & n.n. $-58^{*}$ & k.A.* \\
\hline Anatabin & $<2$ & &
\end{tabular}

\section{Indikation}

- Erfassung Raucher-/Nichtraucherstatus (z. B. Versicherungsmedizin)

- Einschätzung der Belastung durch Passivrauchen (z. B. Arbeitsmedizin)

- Monitoring bei Nicotinsubstitutionstherapie (z. B. Suchtmedizin, Nicotinpflaster)

- Verdacht auf Intoxikation mit Tabak-Alkaloiden (Landwirtschaft: Tabaklauge gegen Ektoparasiten, Nicotin zur Schädlingsbekämpfung; Tabakindustrie: inhalativ, transdermal z. B. beim Zigarrenrollen (erhöhtes Abortrisiko bei Schwangeren und Schädigungen der Säuglinge von stillenden Müttern)
Interpretation Die Detektion von Nicotin(metaboliten) und zunehmend auch Tabak-Nebenalkaloiden in Urin (Serum oder Haaren) gilt als Nachweis einer Nicotinaufnahme.

Die Angaben zu den Eliminationshalbwertszeiten von Nicotin und Cotinin und damit von deren Nachweisbarkeitsdauer im Urin schwanken u. a. in Abhängigkeit vom Alter und dem Raucherstatus (Nicotin 30-60 Minuten Raucher, bis 120 Minuten Nichtraucher; Cotinin 16 Stunden).

Da Anatabin und Anabasin kaum in Nicotinpflastern, wohl aber in der Tabakpflanze vorliegen, könnte deren Nachweis im Urin eine Therapiekontrolle, z. B. unter Raucherentwöhnungstherapie, möglich machen.

Allgemein akzeptierte Entscheidungsgrenzen zur Differenzierung zwischen Nichtrauchern, Rauchern und Passivrauchern basierend auf valide erhobenen Referenzintervallen fehlen noch, insbesondere für die Nebenalkaloide Norcotinin, Anatabin und Anabasin.

Die Bedeutung von Spuren von Begleitalkaloiden in Nicotinpräparaten wie Nicotinpflastern, Nicotinkaugummi und E-Zigaretten auf der Basis eines aus Tabakmaische gewonnenen Nicotindestillats für die Interpretation von TabakAlkaloidkonzentrationen im Urin ist noch unklar.

Unzureichend untersucht sind die quantitativen Zusammenhänge zwischen Nicotingehalt des Tabaks, Rauchverhalten (Quantität, Intensität) und der Ausscheidung von Nicotin und seinen Metaboliten sowie von Nicotiana-Nebenalkaloiden im Urin.

Diagnostische Wertigkeit Es handelt sich um einen Parameter mit derzeit noch nicht vollständig erfasstem diagnostischen Potenzial im Übergang aus dem experimentellen Stadium in die klinische Anwendung. Dies betriff insbesondere die Differenzierung und Quantifizierung von Nicotin(metaboliten) und Tabak-Nebenalkaloiden wie Anatabin und Anabasin mit LC-MS/MS.

\section{Literatur}

Baselt RC (2014). Disposition of toxic drugs and chemicals in man, 10. Aufl. Biomedical Publications, Seal Beach, S 133-134 und 1452-1456

Blaschek W, Ebel S, Hackenthal E, Holzgrabe U, Keller K, Reichling J, Schulz V (Hrsg) (2007) Hagers Enzyklopädie der Arzneistoffe und Drogen, Bd 11, 6. Aufl. Wissenschaftliche Verlagsgesellschaft -Springer, Stuttgart/Heidelberg, S 431-444

Moyer TP, Charlson JR, Enger RJ, Dale LC, Ebbert JO, Schroeder DR, Hurt RD (2002) Simultaneous analysis of nicotine, nicotine metabolites, and tobacco alkaloids in serum or urine by tandem mass spectrometry, with clinically relevant metabolic profiles. Clin Chem 48:1460-1471

Schulz M, Iwersen-Bergmann S, Andresen H, Schmoldt A (2012) Therapeutic and toxic blood concentrations of nearly 1000 drugs and other xenobiotics. Crit Care 16:R136

von Weymarn LB, Thomson NM, Donny EC, Hatsukami DK, Murphy SE (2016) Quantification of the minor tobacco alkaloids nornicotine, anatabine, and anabasine in smokers' urine by high throughput liquid chromatography-mass spectrometry. Chem Res Toxicol 29:390-397 


\section{Tac-Antigen}

$>\mathrm{CD} 25$

\section{Tacrolimus}

H.-D. Haubeck

\section{Synonym(e) FK-506}

\section{Englischer Begriff tacrolimus}

Definition Makrolid-Antibiotikum aus dem Pilz Streptomyces tsukubaensis mit potenter immunsuppressiver Wirkung.

Strukturformel:<smiles>C=CCC(/C=C(\C)CC(C)CC(OC)C1OC(O)(C(=O)C(=O)N2CCCCC2C(=O)OC(/C(C)=C/C2CCC(O)C(OC)C2)C(C)C(O)CC(=O)C(C)CC(C)C)C(C)CC1OC)C(=O)O</smiles>

Molmasse $804,04 \mathrm{~g}$.

Synthese - Verteilung - Abbau - Elimination Die orale Bioverfügbarkeit von Tacrolimus ist mit $6-56 \%$ sehr variabel. Tacrolimus wird durch Cytochrom P450 3A (CYP3A) metabolisiert. Die pharmakologische Bedeutung der Tacrolimusmetabolite ist noch nicht vollständig geklärt. Induktion von CYP3A, z. B. durch $\triangleright$ Phenytoin, \ Carbamazepin etc., führt zu erniedrigten Tacrolimuskonzentrationen im Blut. Bei Gabe von Substanzen, die ebenfalls über CYP3A abgebaut werden z. B. Ketokonazol, Erythromycin etc., steigt die Tacrolimuskonzentration. Die Elimination erfolgt nach der hepatischen Metabolisierung überwiegend durch biliäre Ausscheidung.

Halbwertszeit 9-16 Stunden im Plasma.

Funktion - Pathophysiologie Die immunsuppressive Wirkung von Tacrolimus beruht auf einer Hemmung der Aktivie- rung und Proliferation von T-Lymphozyten. Tacrolimus bindet intrazellulär zunächst an das Immunophilin FKBP12 (FK-506 Bindungsprotein 12). Dieser Komplex bindet dann mit hoher Affinität an den Calcineurin-Calmodulin- $\mathrm{Ca}^{2+}$ Komplex, hemmt die Serin-Threonin-Phosphatasea-Aktivität des Calcineurins und dadurch die Dephosphorylierung von NF-AT (,nuclear factor of activated t-cells"). Hierdurch wird die Produktion von Interkeukin 2 (IL-2), das für die Aktivierung und Proliferation von T-Lymphozyten notwendig ist, aber auch von weiteren proinflammatorischen $>$ Zytokine wie Interferon- $\gamma$ und TNF- $\alpha$ sowie von Protoonkogenen wie ras, myc und rel gehemmt. Andererseits wird die Expression des profibrotischen TGF- $\beta$ stimuliert.

Klinische Wertigkeit Die immunsuppressive Wirksamkeit ist stärker als die von $>$ Ciclosporin. Dementsprechend wird Tacrolimus auch zur Rescue-Therapie bei Abstoßungsreaktionen unter Ciclosporin eingesetzt. Während bei der Häufigkeit akuter Abstoßungsreaktionen Tacrolimus dem Ciclosporin klar überlegen ist, gibt es beim Patienten- und Transplantatüberleben keine signifikanten Unterschiede.

Bei den Nebenwirkungen des Tacrolimus steht wie beim Ciclosporin die Nephrotoxizität im Vordergrund. Daneben sind die dosisabhängige Neurotoxizität, die Hypertonie und die Entwicklung eines insulinpflichtigen Posttransplantationsdiabetes von Bedeutung.

Untersuchungsmaterial - Entnahmebedingungen Da über $90 \%$ des Tacrolimus im Blut intraerythrozytär vorliegt, wird EDTA-Blut als Probenmaterial eingesetzt. Zur Bestimmung der $>$ Talkonzentration erfolgt die Blutentnahme unmittelbar vor der nächsten Einnahme.

Analytik Für die Bestimmung der Tacrolimuskonzentrationen stehen aktuell mehrere Immunoassays sowie massenspektrometrische Methoden ( $\triangleright$ LC-MS und LC-MS/MS) zur Verfügung.

Indikation Aufgrund des relativ engen therapeutischen Bereichs von Tacrolimus, der bei der Nierentransplantation durch eine deutlich erhöhte Frequenz von akuten AbstoBungsreaktionen bei Talkonzentrationen von $\leq 3,5 \mu \mathrm{g} / \mathrm{L}$ und durch die ausgeprägte Dosisabhängigkeit der Nebenwirkungen (s. o.) bedingt ist, ergibt sich die Notwendigkeit eines therapeutischen Drug-Monitoring (s. Tabelle).

Konzentrationen bei initialer und Erhaltungstherapie:

\begin{tabular}{l|l|l|}
\hline & \multicolumn{2}{|l}{ Talkonzentration im Blut $(\mu \mathrm{g} / \mathrm{L})$} \\
\cline { 2 - 3 } Initiale Therapie & Erhaltungstherapie \\
\hline Lierentransplantation & $10-15$ & $5-10$ \\
\hline Hebertransplantation & $10-15$ & $5-10$ \\
\hline
\end{tabular}


Diagnostische Wertigkeit Angesichts unbefriedigender Präzision und Richtigkeit der Immunoassays, insbesondere im niedrigen Konzentrationsbereich ( $\mathrm{VK} \geq 15 \%$ ) bei einer unteren Nachweisgrenze von $1,5 \mu \mathrm{g} / \mathrm{L}$ für die Immunoassays, sollten trotz initial hoher Investitionskosten wenn möglich die massenspektrometrischen Methoden eingesetzt werden.

\section{Literatur}

Armstrong VW, Schütz E, Oellerich M (1999) Drug Monitoring nach Organtransplantation. In: Bruhn HD, Fölsch UR (Hrsg) Lehrbuch der Labormedizin. Schattauer, Stuttgart, S 124-131

Taylor PJ, Jones A, Balderson GA et al (1996) Sensitive, specific quantitative analysis of tacrolimus (FK506) in blood by liquid chromatography-electrospray tandem mass spectrometry. Clin Chem 42:279-285

\section{TAFI}

Fibrinolyseinhibitor, Thrombin-aktivierbarer

\section{TAG}

Tennessee-Antigen

\section{Tagesende}

O. Colhoun

Englischer Begriff daily conclusion

Definition Funktion der $>$ Labor-EDV zur Anzeige des aktuellen Standes aller offenen Befunde nach bestimmten Kriterien.

Beschreibung Das sind die Befunde, welche am aktuellen Tag bearbeitet wurden, aber noch nicht vollständig sind. Beim Durchsehen der Befunde im Tagesende können diese ergänzt, kommentiert und/oder zum Druck als Vorabbefunde freigegeben werden. Die Definition der Kriterien für die Anzeige als ,offen“ in der Tagesendemaske erfolgt in den $>$ Stammdaten der $\triangleright$ Labor-EDV.

\section{Tagesinformation}

Laborstatus

\section{Tagesnummer}

W. G. Guder

Synonym(e) Nummer, serielle; Probennummer

Englischer Begriff sample number; serial number

Definition Zur Charakterisierung der analytischen Proben verwendete Nummerierung entsprechend der Reihenfolge der Proben im analytischen Prozess.

Beschreibung Mit größer werdenden Probennummern wurde es notwendig, die Proben in einer analytischen Serie zu identifizieren. Dies wurde zunächst durch Führen eines Buches mit fortlaufender Nummerierung für jeden Tag bewerkstelligt, bei dem die Nummer jeweils auf die zu analysierende Sekundärprobe übertragen wurde. Da diese Nummerierung täglich wieder von „1-“ begonnen wurde, setzte sich die Bezeichnung Tagesnummer im Alltag durch. Dies Verfahren ist durch Einführung der Verwendung von Barcodes ( $\triangleright$ Barcodetypen) und anderen Identifikationsmöglichkeiten überflüssig geworden, wenn die Identifikation des Patienten an jedem Arbeitsplatz gewährleistet ist.

\section{TAK}

- Autoantikörper gegen Thyreoglobulin

- Autoantikörper gegen Thyreoperoxidase

\section{Takata-Ara-Reaktion}

- Takata-Reaktion

\section{Takata-Reaktion}

A. M. Gressner und O. A. Gressner

Synonym(e) Takata-Ara-Reaktion

Englischer Begriff Takata-reaction; Takata-Ara-reaction

Definition Die von den Japanern Maki Takata und Kiyoshi Ara im Jahr 1925 entwickelte, heute diagnostisch obsolete 
Trübungsreaktion des Serums durch Zugabe von Quecksilberchlorid dient dem Nachweis von Dysproteinämien durch Verschiebungen des Albumin-Globulin-Konzentrationsverhältnisses bei chronischen Entzündungen.

Beschreibung Die zu den unspezifischen $>$ SerumproteinLabilitätsreaktionen gehörende, heute verlassene Trübungsreaktion ( $\triangleright$ Trübung) dient dem qualitativen Nachweis einer $\gamma$-Globulinerhöhung bei chronischen Entzündungen. Das mit einer Lösung von Natriumcarbonat-Natriumchlorid verdünnte Serum wird mit einer Quecksilberchloridlösung $(0,25 \%$ ige wässrige Lösung von Sublimat; $>$ Sublimation) tropfenweise versetzt, die auftretende Trübung visuell bewertet oder semiquantitativ turbidimetrisch gemessen. Je nach Grad der pathologischen Erhöhung der $\gamma$-Globuline oder Abnahme von - Albumin erfolgt eine verschieden starke Trübung. Positiver Ausfall bei schweren akuten und chronischen Lebererkrankungen, Nierenerkrankungen, Tumoren, Plasmozytomen und febrilen Zuständen, die alle mit einer Veränderung des Albumin- $\gamma$-Globulin-Verhältnisses einhergehen.

\section{Literatur}

Hallmann L (1980) Klinische Chemie und Mikroskopie, 11. Aufl. Georg Thieme Verlag, Stuttgart/New York

\section{Talinolol}

- $\beta$-Rezeptorenblocker

\section{Talkonzentration}

C. Vidal und W.-R. Külpmann

Synonym(e) Talspiegel

Englischer Begriff trough concentration

Definition Niedrigste Plasmakonzentration eines Pharmakons während eines Dosierungsintervalls bei intermittierender Applikation.

Beschreibung Die Talkonzentration findet sich in der Regel unmittelbar vor der Gabe der nächsten Dosis. Bei verzögerter Freisetzung des Pharmakons aus dem verabreichten Präparat kann jedoch die Talkonzentration noch nach der nächsten Dosis erreicht werden. Für $>$ Therapeutisches Drug Monitoring werden gewöhnlich Talkonzentrationen gemessen, auf die sich meist die therapeutischen Bereiche ( $\triangleright$ Therapeutischer Bereich) beziehen (s. a. \ C2-Monitoring ).

\section{Literatur}

Taylor WJ, Diers Caviness MH (1986) A textbook for the clinical application of therapeutic drug monitoring. Abbot, Irving

\section{Talspiegel}

- Talkonzentration

\section{Ta/Ma2-Antikörper}

- Autoantikörper gegen neuronale Antigene

\section{Tamm-Horsfall-Glykoprotein}

- Tamm-Horsfall-Protein

\section{Tamm-Horsfall-Protein}

W. G. Guder, K. Kleesiek, C. Götting, J. Diekmann, J. Dreier und M. Schmidt

Synonym(e) Sda; Sid-Antigen; Tamm-Horsfall-Glykoprotein; Uromodulin

Englischer Begriff Tamm-Horsfall mucoprotein; TammHorsfall protein; Tamm-Horsfall glycoprotein

Definition Von Igor Tamm (1922-1995) und Frank Horsfall (1906-1971) im Jahr 1952 beschriebenes Protein aus dem Urin, das später als luminales Oberflächenprotein der Epithelien des dicken aufsteigenden Teils der Henle-Schleife erkannt wurde.

Beschreibung Im Jahr 1952 beschrieben die amerikanischen Virologen Tamm und Horsfall ein Protein aus Urin, das in der Lage ist, immunmodulatorisch in der Abwehr von infektiösen Viren zu wirken. Das Protein in seiner monomeren Form (ca. $90 \mathrm{kDa}$ ) ist kohlenhydratreich und bildet bei saurem $\mathrm{pH}$, höherer Salzkonzentration und anderen sich im distalen Tubulus bildenden Bedingungen Polymere $\leq 70.000 \mathrm{kDa}$, die McQueen im Jahr 1962 als Basis der $>$ Zylinder im Urin erkannte. Tamm-Horsfall-Protein ist in der monomeren Form löslich im Urin, in der polymeren Form unlöslich und bildet einen Hauptbestandteil des normalen Harnsediments. Mit 
einer Ausscheidung von über $200 \mathrm{mg}$ pro Tag bildet es den Hauptteil der Urinproteine ( $\triangleright$ Protein, gesamt im Urin), wird aber von den meisten Methoden zur Proteinquantifizierung im Urin nicht erfasst. Seine Quantifizierung wurde als möglicher Indikator einer distal tubulären Schädigung z. B. bei Abstoßungsreaktionen beschrieben, wenn die Menge des immunologisch messbaren Tamm-Horsfall-Proteins absinkt. Wegen der nur teilweisen Löslichkeit und der großen biologischen Streuung ließ sich jedoch eine gültige Entscheidungsgrenze schwer festlegen. Interessant und von möglicher zukünftiger diagnostischer Bedeutung ist die Beobachtung von Janssens, dass dysmorphe, d. h. aus renalen Ursachen der Proteinurie stammende Erythrozyten mit Tamm-Horsfall-Antikörpern charakterisiert werden können.

In der Transfusionsmedizin ist das Tamm-Horsfall-Glykoprotein als Sid-Antigen bekannt, das zu den hochfrequenten erythrozytären Antigenen gehört, aber nicht auf neonatalen Erythrozyten exprimiert wird. Die Expressionsstärke des SdaAntigens variiert stark auf Erythrozyten. Anti-Sda-haltige Seren reagieren meist nur schwach, wobei Agglutinate klein und labil sind. Die große Variationsbreite in der Reaktionsstärke mit verschiedenen Testerythrozyten und Mischblutbilder sind charakteristisch für Antikörper der Spezifität Anti-Sda. Antikörper gegen Sda sind in der Regel vom IgM-Typ, komplementbindend und haben eine geringe transfusionsmedizinische Bedeutung.

\section{Literatur}

Janssens PMV, Kornaat N, Tielemann R et al (1992) Localizing the site of hematuria by immunochemical staining of erythrocytes in urine. Clin Chem 38:216-222

McQueen EG (1962) The nature of urinary casts. J Clin Pathol 15:367-373

Reid ME, Lomas-Francis C (2004) The blood group antigen facts book, 2. Aufl. Elsevier, New York

Serafini-Cessi F, Malagolini N, Cavallone D (2003) Tamm-horsfall glycoprotein: biology and clinical relevance. Am J Kidney Dis $42: 658-676$

Tamm I, Horsfall FL (1952) A mucoprotein derived from human urine which reacts with influenca, mumps, and Newcastle disease viruses. J Exp Med 95:71-96

\section{Tandem Repeats}

J. Arnemann

Synonym(e) Tandem-artig wiederholte DNA-Sequenzen

Englischer Begriff tandem repeats

Definition Mit Tandem Repeats beschreibt man die direkte, d. h. tandemartige Aufeinanderfolge einer identischen Nukleotidabfolge.
Beschreibung Die Repeats, also die Nukleotidfolgen, werden nach Anzahl weitergehend unterteilt, wie z. B. Dinukleotidrepeats bei 2 Nukleotiden oder Trinukleotidrepeats bei 3 Nukleotiden. Abfolgen von bis zu 10 Nukleotiden werden als Mikrosatelliten oder $>$ Short Tandem Repeat (STR) beschrieben, während Repeats von 10-60 Nukleotiden als Minisatelliten bezeichnet werden.

Die Anzahl der aufeinanderfolgenden Repeats können zum Teil individuell variieren und werden dann als VNTRs (,variable nucleotide tandem repeats") bezeichnet, die aufgrund des individuellen Musters auch bei Kopplungsanalysen oder beim DNA-Fingerprinting zur Typisierung eingesetzt werden.

\section{Literatur}

Weissenbach J (1993) Microsatellite polymorphisms and the genetic linkage map of the human genome. Curr Opin Genet Dev 3:414-417

\section{Tandem-artig wiederholte DNA- Sequenzen}

- Tandem Repeats

\section{Tandemkonjugate}

H. Baum

Englischer Begriff tandem conjugates

Definition Fluoreszenzfarbstoffkombination zur Verschiebung der Emission eines Lichtquants zu längeren Wellenlängen bei Mehrfachfluoreszenzanwendungen.

Beschreibung Tandemkonjugate sind Verbindungen zweier > Fluoreszenz-Farbstoffe, wobei ein Farbstoff Licht einer definierten Wellenlänge absorbiert und nach Emission das Lichtquant quantitativ an den zweiten, gekoppelten Fluoreszenzfarbstoff abgibt, ohne es selbst zu emittieren. Der Emissionsbereich des ersten Farbstoffes liegt dabei im Absorptionsmaximum des zweiten Farbstoffes. Anschließend emittiert der zweite Farbstoff das Lichtquant bei einer noch höheren Wellenlänge. Dieses Lichtquant wird dann von einer > Photozelle aufgefangen. Tandemkonjugate kommen bei der Multiparameteranalyse in der $>$ Durchflusszytometrie zum Einsatz, da hier meist nur eine Anregungswellenlänge zur Verfügung steht (Argonlaser mit $488 \mathrm{~nm}$ Anregungswellenlänge). 
Ein Beispiel für ein Tandemkonjugat ist die Verbindung zwischen R-Phycoerythrin (PE) und Cy5. R-Phycoerythrin absorbiert bei $488 \mathrm{~nm}$ und emittiert in einem weiten Bereich bis $625 \mathrm{~nm}$. Cy5 absorbiert das von > R-Phycoerythrin emittierte Lichtquant und emittiert es wieder bei $674 \mathrm{~nm}$.

\section{Literatur}

Raffael A, Nebe T, Valet G (1994) Grundlagen der Durchflusszytometrie. In: Schmitz G, Rothe G (Hrsg) Durchflusszytometrie in der klinischen Zelldiagnostik. Schattauer Verlag, Stuttgart, S 11

\section{Tandem-LC-MS/MS}

LC-MS

\section{Tandem-Massenspektrometrie}

$>$ LC-MS

$\checkmark$ Massenspektrometrie

\section{T-Antigen}

K. Kleesiek, C. Götting, J. Diekmann, J. Dreier und

M. Schmidt

\section{Synonym(e) Kryptantigen T}

\section{Englischer Begriff $\mathrm{T}$ antigen}

Definition Durch bakterielle Neuraminidasen generiertes erythrozytäres Antigen, das zur $\triangleright$ T-Polyagglutinabilität mit AB0-Blutgruppen-kompatiblen Seren führt.

Beschreibung Das $>$ Kryptantigen $\mathrm{T}$ ist ein Kohlenhydratantigen auf der Erythrozytenoberfläche, das als antigene Determinante im Normalfall nicht präsent ist bzw. maskiert vorliegt und erst nach Behandlung mit $>$ Neuraminidase als Antigen auftritt. Infektionen mit Neuraminidase-bildenden Bakterien und Viren führen zu einer Freisetzung des Enzyms Neuraminidase in der Blutzirkulation. Die Neuraminidase spaltet die endständigen Neuraminsäurezucker auf Glykoproteinen auf der Erythrozytenoberfläche ab, wodurch das normalerweise verdeckte T-Antigen entsteht. Das T-Antigen besteht aus den unverzweigten Zuckerresten Galaktose- $\beta$ 1,3-N-Acetylgalaktosamin, die über eine $\alpha$-glykosidische Bindung mit den Aminosäuren Serin oder Threonin von
Glykoproteinen auf der Erythrozytenoberfläche verbunden sind. Aufgrund der Immunogenität des T-Antigens und der hohen Frequenz von Infektionen mit Neuraminidaseproduzierenden Viren und Bakterien sind Antikörper gegen das T-Antigen in annähernd allen Seren von Erwachsenen zu finden. Die Freilegung des T-Antigens durch Neuraminidasen bei Infektionen mit Neuraminidase-produzierenden Pathogenen ist ein transientes Ereignis, das jedoch zu autoimmunhämolytischen Anämien (s. > Autoimmunhämolytische Anämie) und Problemen bei der $\triangleright$ Blutgruppenbestimmung führen kann.

\section{Literatur}

Mueller-Eckhardt C, Kiefel V (Hrsg) (2004) Transfusionsmedizin: Grundlagen - Therapie - Methodik, 3. Aufl. Springer, Berlin/Heidelberg/New York

Strobel E (2000) Erworbene Veränderungen der erythrozytären Merkmale. Infus Ther Transfus Med 27:80-89

\section{TAP}

- Trypsinogen-Aktivierungspeptid

\section{Taq-DNA-Polymerase}

> Taq-Polymerase

\section{Taqman-Sonden}

\section{J. Arnemann}

Synonym(e) Fluoreszenzmarkierte Hybridisierungssonde

\section{Englischer Begriff Taqman probes}

Definition Der Einsatz von Taqman-Sonden in einem PCRExperiment ( $\triangleright$ PCR (Polymerase-Kettenreaktion)) ermöglicht nicht nur eine Verfolgung der Fluoreszenzsignale der einzelnen PCR-Zyklen in Echtzeit (als Realtime-PCR), sondern auch eine sichere Quantifizierung der resultierenden PCR-Produkte.

Beschreibung Taqman-Sonden sind eine definierte Form von fluoreszenzmarkierten Hybridisierungssonden, die in einem PCR-Experiment eingesetzt werden. Kern dieser Sonden ist ein Oligonukleotid mit Sequenzhomologie zu dem zu amplifizierenden DNA-Abschnitt, d. h. mit optimal 1-2 Basen Abstand zu den eigentlichen PCR-Primern, und einer 
Schmelztemperatur (Tm), die oberhalb der Werte der PCRPrimer liegen sollte. Dieses Oligonukleotid enthält weiterhin an seinem 5'-Ende ein Donorfluorochrom, auch Reporter genannt, sowie am 3'-Ende ein Akzeptorfluorochrom, bei Taqman-Sonden auch ,dark quencher“ genannt. Der Wirkung der Taqman-Sonde liegt das Prinzip des Förster-Resonanzenergietransfers (FRET) zugrunde, das besagt, dass ein durch Lichtenergie angeregtes Donorfluorochrom einen Teil seiner Energie an ein in begrenzter Nähe befindliches Akzeptorfluorochrom abgibt. Bei der Taqman-Sonde handelt es sich beim Akzeptor um einen sog. ,dark“ oder Black-Hole-Quencher, der die Anregungsenergie des Donors absorbiert und als Hitze abgibt und nicht, wie sonst bei Akzeptormolekülen üblich, die Anregungsenergie in Form von Licht abgibt. Vergrößert sich der Abstand zwischen Donor und Akzeptor, wird der Quencher-Effekt reduziert und die Akzeptorenergie wird als Fluoreszenzlicht freigesetzt.

Bei der PCR-Reaktion kommt es zu einem Annealing der PCR-Primer sowie der Taqman-Sonde an die reziproke Sequenz des DNA-Fragments. Bei der Synthese des neuen Strangs hat die DNA-Polymerase eine zusätzliche $5^{\prime}$ - $3^{\prime}$-Exonukleaseaktivität, mit der sie die gebundene Taqman-Sonde vom 5 -Ende her abbaut. Durch diesen Abbauprozess werden Reporter und „,dark quencher“ voneinander räumlich getrennt, sodass das Reportermolekül seine Energie als Fluoreszenzlicht emittieren und so detektiert werden kann. Eine Zunahme des Fluoreszenzsignals ist somit direkt proportional zur Synthese der PCR-Produkte und erlaubt damit auch eine genaue Quantifizierung.

\section{Literatur}

Applied Biosystems StepOne Real-time-PCR systems; Part Number 4379704 TM Rev E; 06/2010

Kessler Y et al (2009) Quantitative TaqMan ${ }^{\circledR}$ real-time PCR assays for gene expression normalisation in feline tissues. BMC Mol Biol 10:106-120

\section{Taq-Polymerase}

\section{J. Arnemann}

Synonym(e) Taq-DNA-Polymerase

\section{Englischer Begriff Taq DNA polymerase}

Definition Die Taq-Polymerase ist eine thermostabile DNAPolymerase aus dem Bakterium Thermus aquaticus und die wesentliche DNA-Polymerase zur diagnostischen Durchführung zyklischer DNA-Synthesen ( $\triangleright$ PCR (PolymeraseKettenreaktion)).
Beschreibung Die Taq-DNA-Polymerase wurde aus dem Bakterium Thermus aquaticus isoliert, das in über $70{ }^{\circ} \mathrm{C}$ heißen Geysiren vorkommt. Im Gegensatz zu DNAPolymerasen anderer Organismen wird diese thermostabile DNA-Polymerase durch diese hohen Temperaturen nicht denaturiert, sondern synthetisiert einen komplementären DNA-Strang ohne Einschränkungen. Die Taq-DNA-Polymerase übersteht $u$. a. auch Temperaturerhöhungen auf $98^{\circ} \mathrm{C}$ für 10 Minuten unbeschadet, bei denen doppelsträngige DNA bereits in einzelsträngige DNA denaturiert wird.

Das als Taq-Polymerase kommerziell verfügbare Enzym verliert durch die hohen Temperaturen einer Hitzedenaturierung nicht seine Aktivität und kann daher zur Vervielfältigung von DNA-Fragmenten eingesetzt werden in einem sich zyklischen wiederholenden Prozess aus

1. Hitzedenaturierung der doppelsträngigen DNA

2. Annealing (Hybridisierung), d. h. Anbindung der synthetischen Primer an einen DNA-Strang

3. Elongation (Verlängerung) des Gegenstrangs mittels der Taq-DNA-Polymerase

Die Extensionsrate wird mit 2-4,5 kb pro Minute angegeben.

Die Taq-Polymerase besitzt keine $3^{\prime}-5^{\prime}$ Exonukleaseaktivität und damit auch keine Proofreading-Aktivität, was bei der Synthese zu einer Fehlerrate führt, die in unterschiedlichen Publikationen von 1:4,5 kb über $1: 10 \mathrm{~kb}$ bis hin $\mathrm{zu}$ $1: 125 \mathrm{~kb}$ angegeben wird. Die neueren, gentechnisch hergestellten Taq-Polymerasen besitzen eine hinzugefügte Proofreading-Aktivität, was die Fehlerrate stark reduziert hat.

Die Aktivität der Taq-Polymerase wird in Units angegeben und 1 Unit als die Enzymmenge definiert, die in 30 Minuten bei $72{ }^{\circ} \mathrm{C} 10 \mathrm{nmol}$ dNTP in eine säureunlösliche Form überführt.

\section{Literatur}

Mullis KB, Ferré F, Gibbs RA (Hrsg) (1994) The polymerase chain reaction (PCR). Birkhäuser Verlag AG, Basel

Target-Zelle

H. Baum

Synonym(e) Kokardenzelle; Leptozyt; Schießscheibenzelle

\section{Englischer Begriff target cell}

Definition Erythrozyt mit im Ausstrichpräparat ringförmiger Anordnung des Hämoglobins. 
Beschreibung Die Target-Zelle ist ein Erythrozyt ( $\downarrow$ Erythrozyten) mit einer in Ringen angeordneten intrazellulären - Hämoglobin-Verteilung, die an eine Schießscheibe erinnert. Der Nachweis der Target-Zellen im Ausstrichpräparat ist ein allgemeiner Hinweis auf eine gestörte Erythropoese ( $\triangleright$ Erythropoese, ineffektive). Häufig können Target-Zellen zusammen mit anderen Zeichen einer gestörten Erythropoese bei Eisenmangelanämie, Hämoglobinopathien sowie nach Splenektomie nachgewiesen werden.

Die Abbildung zeigt Target-Zellen (Pfeile) mit der typischen ringförmigen intrazellulären Verteilung des Hämoglobins $(1000 \times$, May-Giemsa-Grünwald-Färbung):

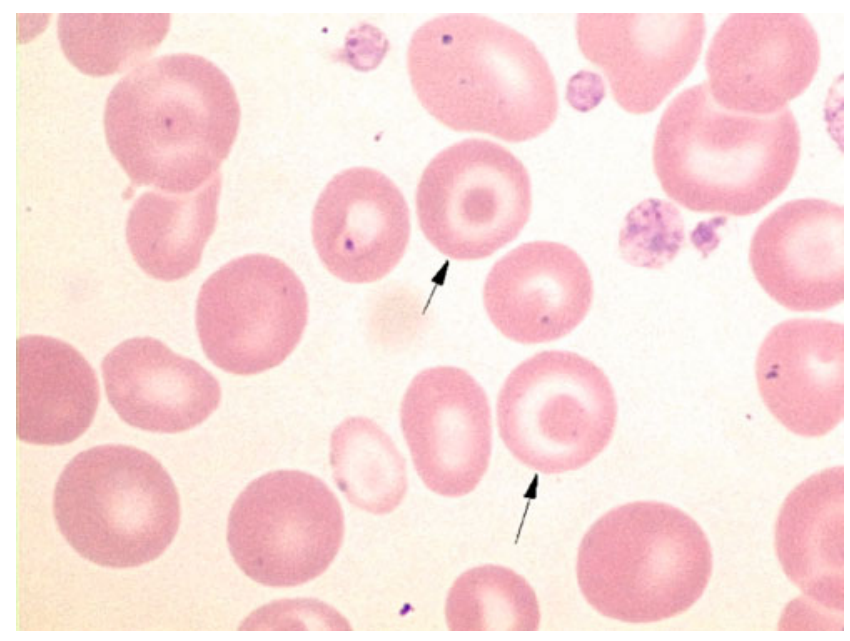

\section{Literatur}

Koeppen KM, Heller S (1991) Differentialblutbild (panoptische Färbung). In: Boll I, Heller S (Hrsg) Praktische Blutzelldiagnostik. Springer, Berlin/Heidelberg/New York, S 173-174

\section{Tarifwerke}

O. Colhoun

Synonym(e) Abrechnungskataloge

Englischer Begriff standard catalogues

Definition In der $>$ Labor-EDV hinterlegte Leistungskataloge als Grundlage der Zuordnung einer erbrachten Laborleistung zu einer Abrechnungsziffer.

Beschreibung Standardisierte Tarifwerke sind z. B. Gebührenordnung für Ärzte (GOÄ) oder $>$ Einheitlicher Bewertungsmaßstab (EBM). Eigene Tarifwerke und Bewertungsziffern können hinterlegt werden. In den Analysenstammdaten erfolgt die Zuordnung der Messgrößen (s. \ Messgröße) zu den Tarifziffern der jeweiligen Tarifwerke.

\section{TAT}

- Thrombin-Antithrombin-Komplex

> Turnaround-Time

\section{Tau}

> Taurin

\section{Tau-Globulin im Liquor cerebrospinalis (CSF)}

> Liquor-Asialotransferrin

\section{Tauopathien}

T. O. Kleine

Synonym(e) Protein-Fehlfaltungs-Erkrankungen (tau, alphaSynuclein, Polyglutamin, Huntingtin, Transthyretin)

Englischer Begriff tauopathies; protein-missfolding disesses with tau proteins

Definition Tauopathien entstehen hauptsächlich durch Zusammenlagerung von überphosphorylierten tau-Proteinen ( $\triangleright$ Liquor-tau-Protein, phosphoryliert) und mutierten tauProteinen ( $\triangleright$ Liquor-tau-Proteine, gesamt; Molekulargewicht 55-66 kDa), Mikrotubuli-assoziiert.

Beschreibung Zwei überphosphorylierte tau-Dupletten von 64, $69 \mathrm{kDa}$ aggregieren intrazytoplasmatisch und verursachen kortikale Degeneration, Siberkornkrankheit, progressive supranukleäre Blick-Parese. Drei sich wiederholende überphosphorylierte tau-Dupletten von $60,64,68 / 69 \mathrm{kDa}$ verursachen Pick-Krankheit, Alzheimer-Krankheit. Überphosphorylierte Duplets, Triplets und pathologische tau-Proteine lagern sich in Doppelhelix-artigen unlöslichen Filamenten mit $\beta$-Faltblattstruktur in Nervenzellen ab (sog. paarige helikale Filamente, PHF, ,tangles“); Vorstufen ,pretangles“ ohne Faltblattstruktur sind toxisch. 


\section{Literatur}

Cowan CM, Mudher A (2013) Are tau aggregates toxic or protective in tauopathies? Front Neurol Neurodegeneration 4:1-13. Article 114

Kirschner DA, Abraham C, Selkoe DJ (1986) X-ray diffraction from intraneuronal paired helical filaments and extraneuronal amyloid fibers in Alzheimer disease indicates cross- $\beta$ conformation. Proc Natl Acad Sci USA 83:503-507

\section{Taurin}

\section{A. C. Sewell}

$\operatorname{Synonym(e)~Tau~}$

\section{Englischer Begriff taurine}

Definition Eine natürlich vorkommende Sulphonsäure, keine Aminosäure per se. Benannt nach Taurus (Fel tauri, Ochsengalle), da Taurin erstmals im Jahr 1827 aus Stiergalle durch Friedrich Tiedemann (1781-1861) und Leopold Gmelin (1788-1853) isoliert wurde.

\section{Struktur}

$$
\mathrm{HO}-\underset{\mathrm{I}}{\mathrm{I}} \mathrm{O}-\mathrm{CH}_{2}-\mathrm{CH}_{2}-\mathrm{NH}_{2}
$$

Molmasse $125,14 \mathrm{~g}$.

Synthese - Verteilung - Abbau - Elimination Taurin wird in Leber und Gehirn synthetisiert.

Funktion - Pathophysiologie Taurin ist kein Bestandteil von Proteinen. Zusammen mit Chenodeoxycholsäure und Cholsäure bildet es die Salze der Gallensäure ( $\triangleright$ Gallensäuren). Taurin wird in hohen Konzentrationen in der Muttermilch gefunden und ist für die Entwicklung des kindlichen Gehirns von großer Bedeutung. Katzen können kein Taurin bilden und müssen es über die Nahrung aufnehmen (Taurinmangel führt zur dilatativen Kardiomyopathie und Retinadegeneration). Forscher der Universität Glasgow haben beobachtet, dass bestimmte Vogelarten (z. B. Blaumeisen) ihre Jungen mit taurinreicher Kost (z. B. Spinnen) füttern, wodurch die Jungvögel mutiger und lernfähiger werden sollen. Energy-Drinks (z. B. Red Bull) enthalten zusätzlich Taurin (ca. $441 \mathrm{mg} / 100 \mathrm{~g}$ ) zur Bekämpfung von Erschöpfungszuständen und zur Steigerung der Muskelkraft.

Untersuchungsmaterial - Entnahmebedingungen Plasma, Serum, Liquor, Urin.
Analytik Aminosäuren.

Referenzbereiche Aminosäuren.

Indikation Sulphitoxidase-Molybdän-Kofaktormangel.

\section{Literatur}

Duran M (2008) Amino acids. In: Blau N, Duran M, Gibson KM (Hrsg) Laboratory guide to the methods in biochemical genetics. Springer, Berlin, S 53-90

Morris JH, Rogers OR (1992) The metabolic basis for the taurine requirements of cats. Adv Exp Med Biol 315:33-44

Oja SS, Saransaari P (2005) Pharmacology of taurine. Proc West Pharmacol Soc 50:8-15

\section{Taurocholat-Absorptionstest, ${ }^{14} \mathrm{C}$ -} oder ${ }^{3} \mathrm{H}$-markiert

A. M. Gressner und O. A. Gressner

Synonym(e) ${ }^{14} \mathrm{C}$ - oder ${ }^{3} \mathrm{H}$-Taurocholat-Absorptionstest

Englischer Begriff taurocholate resorption test

Definition Nuklearmedizinischer Funktionstest zur Diagnostik einer Gallensäuremalabsorption, bei dem nach oraler Applikation der radioaktiv markierten konjugierten Gallensäure Taurocholsäure deren fäkale Ausscheidungsmenge nach 24 Stunden gemessen wird.

Die am Cholsäurerest ${ }^{14} \mathrm{C}$ - oder ${ }^{3} \mathrm{H}$-markierte Taurocholsäure wird oral in Verbindung mit einer Testmahlzeit verabreicht. Es erfolgt im terminalen Ileum eine aktive Resorption und Reexkretion durch die Leber im Rahmen des enterohepatischen Kreislaufs. Die in 24 Stunden fäkal ausgeschiedene Menge der radioaktiven Gallensäure ( $\triangleright$ Gallensäuren) wird bestimmt. Eine fäkale Ausscheidung $>30 \%$ der applizierten Menge spricht für eine Gallensäuremalabsorption.

\section{Literatur}

Stein J, Wehrmann T (Hrsg) (2002) Funktionsdiagnostik in der Gastroenterologie. Springer, Heidelberg

\section{Taurocholsäure}

- Gallensäuren 


\section{Taurocholsäure-Absorptionstest,}

${ }^{14} \mathrm{C}$ - oder ${ }^{3} \mathrm{H}$-markiert

- Taurocholat-Absorptionstest, ${ }^{14} \mathrm{C}$ - oder ${ }^{3} \mathrm{H}$-markiert

\section{Taxon}

C. Vidal und W.-R. Külpmann

\section{Englischer Begriff taxon}

Definition Größenart, die eine nicht nummerische Bewertung von Entitäten mit Einbindung in eine systematisierte Taxonomie anzeigt.

Beschreibung Auf vielen Gebieten, wie z. B. Mikrobiologie, aber auch Klinische Chemie oder Toxikologie ergeben sich Resultate, die zu einer $>$ Nominalskala gehören. Verschiedene Begriffe wurden für die zugehörige Merkmalsart überlegt, wie z. B. „gefunden“, ,anwesend“, „nachgewiesen“. Im $\triangleright$ C-NPU-System wird universell stattdessen Taxon verwendet für Nominalmerkmale innerhalb einer systematisierten Taxonomie, s. dazu folgende Tabelle:

\begin{tabular}{|c|c|c|}
\hline System & Bestandteile & $\begin{array}{l}\text { Merkmalsart mit Beispiel } \\
\text { (in Klammern) }\end{array}$ \\
\hline $\begin{array}{l}\text { Abszess } \\
\text { (Spezifikation) }\end{array}$ & Bakterium & $\begin{array}{l}\text { Taxon } \\
(\text { Verfahren })=(\text { Staphylococcus } \\
\text { aureus })\end{array}$ \\
\hline Plasma & M-Komponente & Taxon $=($ Immunglobulin $\mathrm{G} \kappa)$ \\
\hline Urin & Benzodiazepine & $\begin{array}{l}\text { Taxon } \\
(\text { Verfahren })=(\text { Lorazepam })\end{array}$ \\
\hline
\end{tabular}

\section{Literatur}

Soares de Araujo P, Zingales B, Alia-Ramos P et al (2004) Properties and units in the clinical laboratory sciences. Part XVIII. Properties and units in clinical molecular biology. Pure Appl Chem 76:1799-1807

\section{TBARS}

\ Thiobarbitursäure-reaktive Substanzen

\section{TBG}

- Thyroxin-bindendes Globulin
TBI

- Thyroxinbindungskapazität

\section{TBK}

\ Thyroxinbindungskapazität

\section{TBPE-Test auf basische Substanzen im Urin}

C. Vidal und W.-R. Külpmann

\section{Englischer Begriff TBPE test}

Definition Nachweis basischer Substanzen (insbesondere Pharmaka) im Urin durch Reaktion mit Tetrabromphenolphthalein-Ethylester (TBPE) zu einem Farbkomplex.

Bewertung Viele basische Pharmaka, wie z. B. zentralwirksame Analgetika, Psychopharmaka, Antihistaminika, Calciumantagonisten, $\beta$-Blocker und Muskelrelaxanzien reagieren mit TBPE unter Bildung eines Farbkomplexes. Das Verfahren ist so empfindlich, dass vielfach die Substanzen bereits in Konzentrationen $\geq 10 \mathrm{mg} / \mathrm{L}$ nachweisbar sind. Es werden je nach vorliegender(n) Substanz(en) ganz unterschiedliche Farben beobachtet: rot, grün, violett, orange. Das TBPEVerfahren kann als Screening-Verfahren im Rahmen der Vergiftungsdiagnostik eingesetzt werden.

\section{Literatur}

Lappenberg-Pelzer M (2009) Tetrabromophenolphthalein ethyl ester. In: Külpmann WR (Hrsg) Clincial toxicological analysis. Wiley-VCH, Weinheim, S 175-187

\section{TCA}

- Antidepressiva, trizyklische 


\section{TCP/IP}

O. Colhoun

Synonym(e) Transmission Control Protocol/Internet Protocol

\section{Englischer Begriff TCP/IP}

Definition Gruppe von Protokollen für die Datenübertragung in Weitbereichsnetzen (WAN) und lokalen Netzen (LAN, Intranet).

Beschreibung TCP/IP wurde bereits mit dem Internetvorläufer ARPANet entwickelt und liegt heute allen Internetübertragungen zugrunde. Es ist als Standard zur Vernetzung heterogener Systeme auch Bestandteil einiger UNIXVarianten.

Das Internet Protocol (IP) regelt die Organisation, Adressierung und Weiterleitung der Daten; vor allem teilt es die zu übermittelnden Daten in einzelne Pakete auf. Jedes Datenpaket enthält neben den eigentlichen Nutzdaten auch einen Header mit Verwaltungsdaten (Absender- und Empfängeradresse, Kontrolldaten etc.). Bei Bedarf, etwa bei geringer Übertragungsbandbreite, lassen sich die Datenblöcke in kleinere Einheiten unterteilen, die dann jeweils einen eigenen Header erhalten. Für die Adressierung der Datenpakete benutzt IP die sog. IP-Adressen.

TD 50

- Toxische Dosis

\section{TDM}

- Therapeutisches Drug Monitoring
TEAC

> Antioxidative Kapazität

TEG

- Thrombelastographie

\section{Teicoplanin}

C. Vidal und W.-R. Külpmann

Englischer Begriff teicoplanin

Definition Glykopeptid-Antibiotikum aus Actinoplanes teichomyceticus.

Molmasse 1564,3-1907,7 g.

Synthese - Verteilung - Abbau - Elimination Es handelt sich nicht um eine einheitliche Substanz, sondern um ein Gemisch 9 verschiedener Substanzen, die sich bei gemeinsamem Glykopeptidgerüst bezüglich der Substituenten R (s. Strukturformel Abb. 1) unterscheiden (s. Molmasse). Teicoplanin wird i.v. appliziert und zu über $80 \%$ glomerulär filtriert und unverändert im Urin ausgeschieden.

Halbwertszeit Terminale Halbwertszeit: 70-100 Stunden (Plasma).

Funktion - Pathophysiologie Teicoplanin ist nahe mit - Vancomycin verwandt. Wie Vancomycin hemmt es die Membransynthese von Bakterien. Es kann ebenfalls zu interstitieller Nephritis, Reduktion des Hörvermögens und Schwindel führen sowie zu anaphylaktoiden Reaktionen.

Untersuchungsmaterial - Entnahmebedingungen Serum (S), Plasma (P).

Analytik Immunoassay, LC-MS/MS.

Indikation Therapeutisches Drug Monitoring.

TDP

- Vitamin $\mathrm{B}_{1}$ 
Teicoplanin,

Abb. 1 Strukturformel

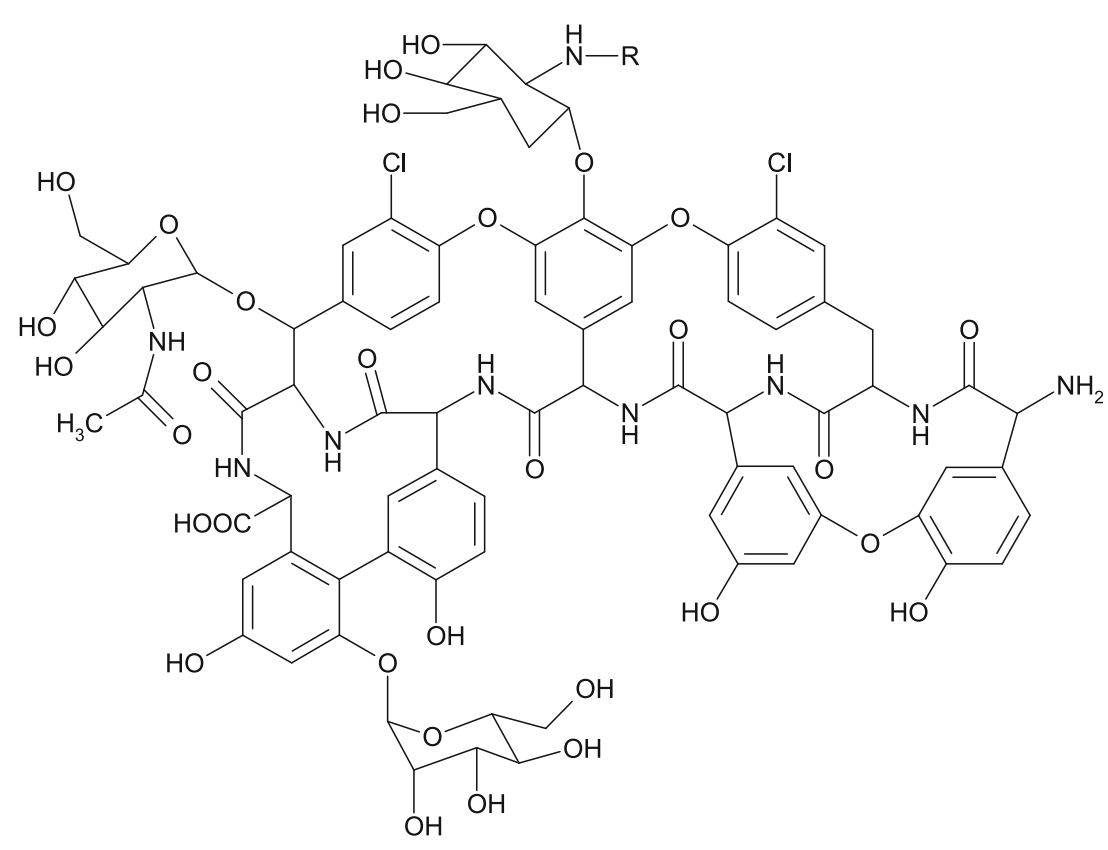

Interpretation Therapeutischer Bereich (S, P): 15-20 mg/L; toxisch: $>200 \mathrm{mg} / \mathrm{L}$; komatös-letal: unbekannt.

Bei Niereninsuffizienz kommt es zur Kumulation. Deswegen muss in diesem Fall die Dosis reduziert werden.

\section{Literatur}

Wellhöner HH (1997) Pharmakologie und Toxikologie, 6. Aufl. Springer, Berlin/Heidelberg/New York

\section{Teilbefund}

O. Colhoun

Synonym(e) Vorbefund

\section{Englischer Begriff report part}

Definition Befundausgabe der Labor-EDV eines unvollständig bearbeiteten Laborauftrags.

Beschreibung Entsprechend der Definition der Analyten in den $>$ Stammdaten der $>$ Labor-EDV kann die Ausgabe eines Teilbefunds für einen Auftrag an den Einsender getriggert werden (beispielsweise in der Funktion $>$ Tagesende). Sinnvoll ist dies vor allem bei umfangreichen Laboraufträ- gen, die eine größere Anzahl von Anforderungen unterschiedlicher Bearbeitungsdauer oder einzelne, besonders eilige Analyten enthalten, die auch bei Fehlen der weiteren noch in Bearbeitung befindlichen Parameter bereits an den Einsender ausgegeben werden sollen (z. B. kardiale Marker). Teilbefunde werden für jede Befundart in den jeweiligen Stammdaten einzeln generiert.

\section{Teilstornierung}

O. Colhoun

Englischer Begriff partly cancellation

Definition Stornierung eines Teils des Rechnungsbetrags für Laboraufträge in der Labor-EDV.

Beschreibung Teil der Abrechnungsfunktionalität des $>$ Labor-EDV-Systems. Die Funktion erlaubt das Kürzen eines Rechnungsbetrags um eine bestimmte Summe der Beträge für bestimmte Leistungen oder Aufträge.

\section{Tein}

$\checkmark$ Coffein 


\section{Telefonliste}

O. Colhoun

Englischer Begriff calling list

Definition Aus der Labor-EDV stets aktuell abrufbare Auflistung von Messergebnissen, die aufgrund entsprechender Stammdatendefinition als dem Einsender telefonisch mitzuteilen gekennzeichnet und noch nicht als ,durchgesagt“ quittiert wurden.

Beschreibung In den Analysenstammdaten wird für bestimmte, therapeutisch besonders zeitkritische oder diagnostisch dringend mitzuteilende Messergebnisse ( $>$ Messergebnis) der Status ,auf die Telefonliste zu setzen“ definiert, und zwar für bestimmte Messergebnisse außerhalb der Referenzbereiche, nur für bestimmte Einsender oder auch generell jedes Messergebnis für bestimmte Einsender. Nach dem Telefonat für die Wertedurchsage wird das Ergebnis als ,telefoniert“" quittiert und verschwindet von der aktuellen Telefonliste. Die Telefonliste wird komplett oder nach Laborbereich, Material (Notfallproben) oder Einsender gefiltert in der $>$ Labor-EDV abgerufen.

\section{Tele-Laboratoriumsmedizin}

\section{A. M. Gressner und O. A. Gressner}

Synonym(e) Laborergebnis-Begutachtung; LaborergebnisFerninterpretation

Englischer Begriff tele laboratory medicine

Definition Tele-Laboratoriumsmedizin (TLM) ist ein Teilgebiet der Telemedizin, das sich vorwiegend mit der Interpretation von (digitalisierten) morphologischen und komplexen quantitativen Laborergebnissen, die über elektronische Medien entsprechendem Fachpersonal zugeleitet werden, befasst.

Beschreibung TLM ist ein Teilbereich der Telemedizin, die der „Erbringung konkreter medizinischer Dienstleistungen in Überwindung räumlicher Entfernungen durch Zuhilfenahme moderner Informations- und Kommunikationstechnologien“ dient (DGTelemed 2011). Sie wiederum ist ein Spezialgebiet der im Gesundheitswesen wirksamen Telematik (Fusion von Telekommunikation und Informatik). Die Telemedizin setzt elektronische Medien (z. B. Internet) im Gesundheitssystem ein, wie elektronische Gesundheitskarten, Patientenakten, Arztbriefe u. a. In diesem Rahmen befasst sich die TLM mit der Interpretation komplexer morphologischer (z. B. Blutbild [ $\triangleright$ Blutbild, großes, $>$ Blutbild, kleines], $>$ Knochenmarkausstrich, $>$ Knochenmarkzytologie, Liquorzytologie [ $>$ LiquorDifferenzialzellbild]) und der alle Bereiche der quantitativen Laboranalytik umfassenden labormedizinischen Ergebnisse durch zuständiges Fachpersonal. Neben der Erstellung eines auf die Patientenangaben abgestellten Befundes ( $\triangleright$ Befund, - Befundkommentierung) aus den Teilbereichen der Laboratoriumsmedizin (z. B. Hämatologie, Gerinnung, Klinische Chemie, Immunologie, Infektiologie/Mikrobiologie, Toxikologie, Molekulardiagnostik, Transfusionsmedizin und Immunhämatologie) werden, falls erforderlich, Hinweise auf die Auswahl geeigneter labordiagnostischer Kenngrößen ( $\triangleright$ Indikation einer Laboruntersuchung), die Präanalytik ( $\triangleright$ präanalytische Phase) und Analytik ( $>$ Analyse) gegeben sowie ggf. weiterführende Untersuchungen vorgeschlagen ( $\triangleright$ Befunderstellung, Teilschritte). In Videokonferenzschaltungen mit Fachvertretern anderer medizinischer Teilgebiete können multidisziplinäre Fachgespräche zu Therapie und weiteren Aspekten geführt werden. Wie in anderen Bereichen der Telemedizin wird auch mit der TLM medizinisches Fachwissen der Spezialisten zu konkreten Themen/Fragestellungen weltweit verfügbar. Somit kann die TLM einen wichtigen Beitrag zur Qualitätsverbesserung, -sicherung und -standardisierung ( $>$ Qualitätsmanagement, $>$ Qualität, extraanalytische) der medizinischen Versorgung sowie zur Weiterbildung von medizinischem Fachpersonal dort leisten, wo lokale Ressourcen beschränkt sind.

\section{Literatur}

Bartmann FJ, Blettner M, Heuschmann PU (2012) Telemedizinische Methoden in der Patientenversorgung. Deutscher Ärzteverlag, Köln Deutsche Gesellschaft für Telemedizin (DGTelemed) e.V. Blenheimstr.

24, 12685 Berlin; info@dgtelemed.de,www.dgtelemed.de www.e-health-com.eu

\section{Telomer-flankierender Bereich}

- Subtelomer-Region

\section{Temperatur}

C. Vidal und W.-R. Külpmann

Englischer Begriff temperature 
Definition Thermodynamische Temperatur (Kelvin) [K]: Die thermodynamische Temperatur gründet sich auf die Beziehung zwischen Wärme und mechanischer Arbeit und ist unabhängig von den Eigenschaften irgendeiner speziellen Substanz, wie z. B. Quecksilber oder Alkohol.

Beschreibung In der Klinischen Chemie wird überwiegend mit Zustimmung der Conférence générale des poids et mesures (CGPM) die Nicht-SI-Temperatur Celsius $\left[{ }^{\circ} \mathrm{C}\right]$ benutzt.

Umrechnung: $0{ }^{\circ} \mathrm{C}$ entspricht $273,15 \mathrm{~K}$.

\section{Temperaturumrechnung, Blutgase}

> Body Temperature and Ambient Pressure, Fully Saturated

\section{Tenascin}

H.-D. Haubeck

Synonym(e) Cytotactin; Restrictin

\section{Englischer Begriff tenascins}

Definition Tenascine bilden eine Familie komplexer Glykoproteine der Extrazellulärmatrix.

Beschreibung Die Familie der Tenascine, großer multimerer Proteine der Extrazellulärmatrix (ECM), umfasst die 4 Mitglieder Tenascin-C, -R, -X und -W. Jedes dieser Tenascine besitzt ein spezifisches Expressionsmuster. Im Gegensatz zu vielen anderen ECM-Proteinen haben Tenascine antiadhäsive Eigenschaften. Tenascine besitzen eine komplexe Struktur mit einer $N$-terminalen Cystein-reichen Domäne, zahlreichen EGF-ähnlichen Repeats, einigen Fibronectin-Typ-III-ähnlichen Repeats und einer carboxyterminalen globulären Domäne. Tenascine assoziieren zu Trimeren und Hexameren über Bindungsstellen (,heptad repeats") in der Cystein-reichen Domäne. Für die verschiedenen Tenascine existieren darüber hinaus alternative Splice-Formen. Zahlreiche Liganden von Tenascin wurden beschrieben, u. a. verschiedene Integrine, Axonin, Neurofascin, $>$ Fibronectin und zahlreiche $>$ Proteoglykane wie Neurocan, Phosphacan, Versican und Heparin/Heparansulfat-Proteoglykane. Die verschiedenen Tenascine besitzen nicht nur wichtige Funktionen in der Embryogenese, sondern auch im adulten Organismus. Tenascin-R (Restrictin) wird fast ausschließlich im Zentralnervensystem (ZNS) exprimiert und ist an der Regelung des Neuritenwachstums beteiligt. Dementsprechend zeigen Tenascin-R-defiziente Mäuse Störungen im ZNS. Tenascin-C zeigt eine größere Verbreitung als Tenascin- $\mathrm{R}$ und wird vor allem bei der Wundheilung und Reparaturprozessen verstärkt exprimiert. Darüber hinaus wird Tenascin im Stroma von verschiedenen Tumoren, z. B. kolorektalen Karzinomen, Melanomen und Fibrosarkomen, verstärkt exprimiert. Dabei können die antiadhäsiven Eigenschaften von Tenascin-C das invasive Wachstum und die Metastasierung der Tumoren fördern. Tenascin-X-defiziente (Knock-out-)Mäuse zeigen wie entsprechende Patienten mit einer Form des EhlersDanlos-Syndroms charakteristische Symptome: erhöhte Elastizität der Haut, Überstreckbarkeit der Gelenke, brüchige Blutgefäße und Wundheilungsstörungen. Diese Patienten exprimieren kein Tenascin und weisen in der Haut Störungen der Elastinfaserbildung und einen verminderten Kollagengehalt auf.

Eine Bewertung der bei unterschiedlichen Krankheitsbildern, u. a. verschiedenen Lebererkrankungen, chronisch-entzündlichen Darmerkrankungen, kolorektalen Tumoren und Melanomen, gemessenen Tenascin-C-Serumkonzentrationen ist wegen der unterschiedlichen Erfassung der alternativen Splice-Formen von Tenascin-C z. Zt. kaum möglich.

\section{Literatur}

Burch GH, Gong Y, Liu W et al (1997) Tenascin-X deficiency is associated with Ehlers-Danlos syndrome. Nat Genet 17:5-7

Dueck M, Riedl S, Hinz U et al (1999) Detection of tenascin-C isoforms in colorectal mucosa, ulcerative colitis, carcinomas and liver metastases. Int J Cancer 82:477-483

\section{Tennessee-Antigen}

S. Holdenrieder und P. Stieber

$\operatorname{Synonym(e)~TAG~}$

Englischer Begriff Tennessee antigen

Definition Aus Adenokarzinomen des Kolons isoliertes Glykoprotein.

Synthese - Verteilung - Abbau - Elimination In erhöhten Konzentrationen wurde das Tennessee-Antigen beim Magen-, Kolon- und Pankreaskarzinom beschrieben, außerdem bei verschiedenen benignen gastrointestinalen Erkrankungen.

Untersuchungsmaterial - Entnahmebedingungen Serum, Plasma.

Analytik Hämagglutinationshemmtest.

Indikation Historisch. 
Interpretation Aufgrund der geringen Trennschärfe zwischen benignen und malignen Erkrankungen des Gastrointestinaltrakts hat das Tennessee-Antigen in der klinischen Anwendung keine diagnostische Bedeutung erlangt.

\section{Literatur}

Sampson J, Wong L, Harris OD (1982) The role of Tennessee antigen in the diagnosis of gastrointestinal malignancy. Aust N Z J Surg 52:39-41

\section{Terasaki-Test}

- Lymphozytotoxischer Test

\section{Terminal}

O. Colhoun

Definition Datenstation mit Zugriff auf den Labor-EDVServer.

Beschreibun Ein Terminal ist eine Station zur Eingabe (Tastatur) und Ausgabe (Bildschirm) von Daten an den und vom $>$ Labor-EDV-Server. Ein reines Terminal verfügt weder über Speicher noch Prozessor und ist nicht in der Lage, Daten selbst zu verarbeiten. Labor-EDV-Systeme werden nicht mehr von Terminals aus bedient, sondern von Personal Computern oder vom $>$ Thin Client mit einer grafischen Programmoberfläche (Client-Software).

\section{Terpenalkaloide}

$\checkmark$ Alkaloide

\section{Test}

A. M. Gressner und O. A. Gressner

Synonym(e) Prüfung (des Untersuchungsgutes)

Englischer Begriff test, assay

Definition International nicht verbindlich geführte Bezeichnung für einen geplanten, zweckgerichteten Prozess zur Gewinnung relevanter ärztlicher Informationen.
Beschreibung Klinisch-chemische Tests zielen auf die qualitative ( $\triangleright$ Nachweisverfahren) oder quantitative (Bestimmungsverfahren) Ermittlung von Stoffeigenschaften und Stoffkonzentrationen (z. B. Substrate, Enzyme, Zellen, Gase) in Körpermaterialien (z.B. Blut, Urin, Liquor, Faezes, Punktionsflüssigkeiten) des Patienten ( $\triangleright$ Test, diagnostischer).

\section{Literatur}

Stamm D, Büttner J (1995) Klinisch-chemische Untersuchungen und Befunde als Grundlage ärztlicher Handlungen. In: Greiling A, Gressner AM (Hrsg) Lehrbuch der Klinischen Chemie und Pathobiochemie, 3. Aufl. Schattauer Verlag, Stuttgart

\section{Test, diagnostischer}

R.-D. Hilgers, N. Heussen und S. Stanzel

\section{Englischer Begriff diagnostic test}

Definition Ein diagnostischer Test ist ein Verfahren, das zur Klassifizierung bzw. Differenzierung zwischen 2 Zuständen üblicherweise krank oder gesund - führt.

Beschreibung Ein wesentlicher Teil medizinischer Entscheidungsprozesse besteht darin, eine spezielle Erkrankung auf der Basis von Symptomen, Befunden und den Resultaten eines (diagnostischen) Tests zu erkennen.

Bei der Interpretation der Ergebnisse eines solchen (diagnostischen) Tests ist zu beachten, dass ein positives Resultat üblicherweise mit dem Vorliegen der Krankheit assoziiert ist und entsprechend ein negatives Testresultat mit dem Nichtvorliegen der Krankheit. Ferner gilt es zu berücksichtigen, dass der Test (zumindest theoretisch) positiv ausfallen kann, wenn der Patient tatsächlich erkrankt ist, aber auch wenn der Patient tatsächlich nicht erkrankt ist. Entsprechend kann der Test negativ ausfallen, wenn der Patient tatsächlich nicht erkrankt ist, aber auch wenn der Patient tatsächlich erkrankt ist. (s. Tabelle im Stichwort $>$ Vierfeldertafel).

Liefert der Test bei wiederholter Anwendung nicht dasselbe Ergebnis ( $\triangleright$ Reproduzierbarkeit), so erscheint der Test wenig nützlich.

\section{Literatur}

Armitage P, Colton T (1998) Encyclopedia of biostatistics. Wiley, New York 


\section{Test, multipler diagnostischer}

\section{R.-D. Hilgers, N. Heussen und S. Stanzel}

Englischer Begriff multiple diagnostic testing

Definition Man spricht von einem multiplen diagnostischen Test, wenn mehrere unterschiedliche diagnostische Tests $(\triangleright$ Test, diagnostischer) nacheinander oder gleichzeitig durchgeführt werden, um eine gemeinsame diagnostische Aussage zu treffen.

Beschreibung Bei der mehrfachen Anwendung diagnostischer Tests kann vereinfachend zunächst zwischen parallelen $(\triangleright$ Test, paralleler diagnostischer) und seriellen Tests ( $\triangleright$ Test, serieller diagnostischer) unterschieden werden. In der Praxis liegen häufig Mischformen dieser Teststrategien vor. Der Formulierung einer Entscheidungsregel, die die Grundlage für die Diagnose auf der Basis aller Einzeltestergebnisse bildet, kommt eine besondere Bedeutung zu. Dabei sind sowohl unterschiedliche Gewichtungen, etwa hinsichtlich der Sicherheit, Kosten oder Falschdiagnosen, als auch unterschiedliche Reihenfolgen denkbar. Eine detaillierte Analyse der einzelnen Tests, insbesondere deren Konsequenzen bildet die Grundlage für einen „diagnostischen“ Entscheidungsbaum.

\section{Literatur}

Hilgers R-D, Bauer P, Scheiber V (2002) Einführung in die Medizinische Statistik. Springer, Berlin/Heidelberg/New York

Test, paralleler diagnostischer

R.-D. Hilgers, N. Heussen und S. Stanzel

Englischer Begriff parallel diagnostic testing

Definition Unter einem parallelen diagnostischen Test versteht man die gleichzeitige Durchführung mehrerer Einzeltests.

Beschreibung Bei der streng parallelen, also gleichzeitigen Durchführung mehrerer diagnostischer Tests $(\triangleright$ Test, diagnostischer) gilt die Diagnose üblicherweise schon dann als bestätigt, wenn lediglich einer der Tests positiv ausfällt. Die parallele Durchführung wird meist angewandt, wenn eine schnelle Beurteilung erforderlich ist. Die parallele Durch- führung erhöht im Allgemeinen die Sensitivität ( $\triangleright$ Sensitivität, diagnostische) und damit den negativen Vorhersagewert $(\triangleright$ Vorhersagewert, negativer) bei gegebener Prävalenz der Krankheit über die negativen Vorhersagewerte der einzelnen Tests hinaus. Andererseits werden Spezifität ( $\triangleright$ Spezifität, diagnostische) und positiver Vorhersagewert ( $\triangleright$ Vorhersagewert, positiver) verringert. Somit ist ein Übersehen der Krankheit weniger wahrscheinlich, aber die Wahrscheinlichkeit für eine falsch-positive Diagnose erhöht.

\section{Literatur}

Hilgers R-D, Bauer P, Scheiber V (2002) Einführung in die Medizinische Statistik. Springer, Berlin/Heidelberg/New York

\section{Test, serieller diagnostischer}

\section{R.-D. Hilgers, N. Heussen und S. Stanzel}

Englischer Begriff serial diagnostic testing

Definition Unter einem seriellen diagnostischen Test versteht man die nacheinander geschaltete Durchführung mehrerer diagnostischer Tests ( $\vee$ Test, diagnostischer), d. h., der Folgetest wird erst durchgeführt, wenn die Resultate der vorangegangenen Tests feststehen.

Beschreibung Im Rahmen der Durchführung multipler diagnostischer Tests ( $\triangleright$ Test, multipler diagnostischer) ist grundsätzlich anzumerken, dass der Entscheidungsregel eine besondere Bedeutung zukommt. Ein vielfach praktiziertes Verfahren beruht auf dem „Believe the positive“-Prinzip. Dabei müssen alle in streng konsekutiver Abfolge durchgeführten Einzeltests ein positives Resultat für die zu ermittelnde Diagnose liefern, um die Diagnose zu bestätigen. Hingegen wird der diagnostische Prozess bei Auftreten eines negativen Ergebnisses beendet. Die serielle Durchführung wird meist angewandt, wenn eine schnelle Beurteilung nicht primär erforderlich ist oder die Tests zu teuer oder risikoreich sind. Gegenüber den Einzeltests erhöht die serielle Durchführung im Allgemeinen die (Gesamt-)Spezifität ( $\triangleright$ Spezifität, diagnostische) und damit den positiven Vorhersagewert ( $\vee$ Vorhersagewert, positiver), verringert jedoch die (Gesamt-)Sensitivität ( $\vee$ Sensitivität, diagnostische) und den negativen Vorhersagewert $(\triangleright$ Vorhersagewert, negativer). Daraus resultiert insgesamt ein erhöhtes Risiko, die Krankheit zu übersehen, bei gleichzeitig erhöhter Sicherheit für eine Bestätigung der Krankheit durch ein positives Testresultat. 
Das $\triangleright$ a posteriori odds eines seriellen diagnostischen Tests lässt sich aus dem $\triangleright$ a priori odds bei Kenntnis der Sensitivitäten und Spezifitäten der Einzeltests ermitteln durch Multiplikation der einzelnen positiven Likelihood Ratios ( $\triangleright$ Likelihood Ratio, positives).

\section{Literatur}

Hilgers R-D, Bauer P, Scheiber V (2002) Einführung in die Medizinische Statistik. Springer, Berlin/Heidelberg/New York

\section{Test, statistischer}

\section{R.-D. Hilgers, N. Heussen und S. Stanzel}

Synonym(e) Hypothesentest; statistischer Signifikanztest

\section{Englischer Begriff statistical test}

Definition Ein statistischer Test ist ein Entscheidungsverfahren zur Prüfung einer wissenschaftlichen Hypothese aufgrund von Daten aus einer oder mehreren Stichproben (s. - Stichprobe).

Beschreibung Im medizinisch-biologischen Bereich können wissenschaftliche Hypothesen meist nicht direkt bewiesen werden, da unbekannte Faktoren eventuell vorhandene Gesetzmäßigkeiten stören.

Die Gültigkeit einer wissenschaftlichen Hypothese wird überprüft, indem ein konkretes Experiment benutzt wird, um die Vereinbarkeit der Hypothese mit der Realität zu erklären. Wird beispielsweise die Hypothese untersucht, ob eine bestimmte Operationsmethode die Blutzuckerkonzentration beeinflusst, muss zusätzlich die Tatsache berücksichtigt werden, dass mehrfache Blutzuckerbestimmungen beim gleichen Patienten zufällige (biologische) Schwankungen aufweisen. Auch bei fehlendem Einfluss der Operationsmethode werden die Messungen der Blutzuckerwerte eines Patienten vor und nach der Operation voneinander abweichen. Sind die beobachteten Blutzuckerveränderungen jedoch ausschließlich durch Zufallsschwankungen bedingt, so kann man erwarten, dass diese Differenzen im Mittel ( $\triangleright$ Mittelwert, arithmetischer) sehr klein sind, dass sie also nur zufällig vom erwarteten Wert Null abweichen. Auf dieser Tatsache basiert die Konstruktion von Beurteilungskriterien für die Gültigkeit der Hypothese.

Eine Hypothese der Art „Es besteht kein Unterschied“ oder „Beobachtete Unterschiede weichen nur zufällig von Null ab“ werden in der Statistik als $>$ Nullhypothese $\left(\mathrm{H}_{0}\right)$ bezeichnet. Die komplementäre Aussage heißt Alternativhypothese $\left(\mathrm{H}_{1}\right)$.
Die zentrale Bedeutung der Nullhypothese ist, dass sie Annahmen zur Formulierung eines Wahrscheinlichkeitsmodells festlegt. Lassen sich die tatsächlichen Beobachtungen ( $\triangleright$ Beobachtung) durch das so festgelegte Modell nur unzulänglich erklären, wird die ursprüngliche Annahme in der Form der Gültigkeit von $\mathrm{H}_{0}$ als unhaltbar verworfen. Unter der Annahme der Richtigkeit der Nullhypothese ist man in der Lage, die Verteilung ( $\triangleright$ Verteilung, statistische) der $\triangleright$ Prüfgröße vor Beginn des Versuchs zu spezifizieren. So können Aussagen über das voraussichtliche Versuchsergebnis gemacht werden. Es wird ein Bereich angegeben, in dem die Realisation der Prüfgröße mit einer bestimmten (hohen), vor Versuchsbeginn festzulegenden Wahrscheinlichkeit zu finden sein wird (z. B. 95 oder 99 \%). In den komplementären Bereich fällt unter der Annahme der Gültigkeit der Nullhypothese die Realisation der Prüfgröße nur mit einer geringen Wahrscheinlichkeit von $\alpha=0,05$ (5\%) bzw. 0,01 (1\%), der sog. Irrtumswahrscheinlichkeit ( Irrtumswahrscheinlichkeit $\alpha$, \ Irrtumswahrscheinlichkeit $\beta$ ). Fällt die Realisation der Prüfgröße in diesen - Ablehnbereich, ist ein Ereignis eingetreten, dem bei Zutreffen der Nullhypothese nur eine geringe Wahrscheinlichkeit zukommt. In diesem Falle wird man sich daher dafür entscheiden, die Nullhypothese zu verwerfen und die Alternative anzunehmen, eine solche Testentscheidung nennt man ,signifikant“.

Fällt die Realisation der Prüfgröße nicht in den Ablehnbereich, sondern in den $>$ Annahmebereich, hat das Experiment keine gewichtigen statistischen Gründe geliefert, die Nullhypothese anzuzweifeln und die Nullhypothese wird nicht verworfen. Die entsprechende Testentscheidung wird „nicht signifikant" genannt.

Die Auswahl eines speziellen Testverfahrens hängt nicht nur von den zu prüfenden Hypothesen ab, sondern darüber hinaus von den Informationen über die vorliegende(n) Stichprobe(n). Testverfahren lassen sich nach der Zielsetzung des Tests (Vergleich von Erwartungswerten, Varianzen oder Häufigkeiten), der Anzahl der Stichproben (ein, zwei oder mehr als zwei), der Art der Stichproben (unabhängig, abhängig) sowie der Verteilung der Prüfgröße ( $\triangleright$ Binomialverteilung, - Normalverteilung, andere oder auch unbekannt) klassifizieren. Die Tabelle fasst häufig verwendete Testverfahren für Ein- und Zweistichprobensituationen in Hinblick auf die Zielsetzung des Tests zusammen:

\begin{tabular}{|c|c|c|}
\hline Zielsetzung & Stichprobe & Testverfahren \\
\hline $\begin{array}{l}\text { Vergleich eines Anteils } \\
\text { mit einem festen Wert }\end{array}$ & Eine & Binomialtest \\
\hline Vergleich zweier Anteile & $\begin{array}{l}\text { Zwei, } \\
\text { unabhängig }\end{array}$ & $\chi^{2}$-Test \\
\hline $\begin{array}{l}\text { Vergleich eines } \\
\text { Mittelwertes mit einem } \\
\text { festen Wert }\end{array}$ & Eine & (Einstichproben) t-Test \\
\hline $\begin{array}{l}\text { Vergleich zweier } \\
\text { Mittelwerte }\end{array}$ & $\begin{array}{l}\text { Zwei, } \\
\text { abhängig }\end{array}$ & Verbundener $\mathrm{t}$-Test \\
\hline
\end{tabular}

(Fortsetzung) 


\begin{tabular}{l|l|l|}
\hline Zielsetzung & Stichprobe & Testverfahren \\
\hline $\begin{array}{l}\text { Vergleich zweier } \\
\text { Mittelwerte }\end{array}$ & $\begin{array}{l}\text { Zwei, } \\
\text { unabhängig }\end{array}$ & Unverbundener t-Test \\
\hline $\begin{array}{l}\text { Vergleich zweier } \\
\text { Verteilungen }\end{array}$ & $\begin{array}{l}\text { Zwei, } \\
\text { abhängig }\end{array}$ & $\begin{array}{l}\text { Wilcoxon-Vorzeichen- } \\
\text { Rangtest }\end{array}$ \\
\hline $\begin{array}{l}\text { Vergleich zweier } \\
\text { Verteilungen }\end{array}$ & $\begin{array}{l}\text { Zwei, } \\
\text { unabhängig }\end{array}$ & $\begin{array}{l}\text { Wilcoxon- } \\
\text { Rangsummentest, Mann- } \\
\text { Whitney-U-Test }\end{array}$ \\
\hline
\end{tabular}

\section{Literatur}

Hilgers R-D, Bauer P, Scheiber V (2002) Einführung in die Medizinische Statistik. Springer-Verlag, Berlin/Heidelberg/New York

\section{Test auf klonale Lymphozytenpopulationen}

> Klonalitätsanalyse

\section{Test auf Molybdän-Cofaktor-Defizienz}

- Sulfit-Test

\section{Testeffizienz}

- Effizienz, diagnostische

\section{Testergebnis, falsch-negatives}

\section{R.-D. Hilgers, N. Heussen und S. Stanzel}

Synonym(e) Falsch-negativer Test

Englischer Begriff false-negative test; false-negative test result

Definition Ein falsch-negatives Testergebnis eines diagnostischen Tests liegt vor, wenn tatsächlich Erkrankte ein negatives Testergebnis aufweisen.

Beschreibung Ein falsch-negatives Testergebnis stellt eine der beiden möglichen Fehlentscheidungen eines diagnostischen Tests ( $\vee$ Test, diagnostischer) dar. In Analogie zum statistischen Test bezeichnet man zuweilen ein falschnegatives Testergebnis auch als einen $>$ Fehler 2. Art. Anhand der Rate der falsch-negativen Testergebnisse lässt sich die Genauigkeit ( $\triangleright$ Accuracy, diagnostische) des Tests bewerten. Die Anzahl falsch-negativer Testergebnisse wird üblicherweise durch den Wert $c$ bestimmt (Bezeichnungen s. Tabelle im Stichwort $>$ Vierfeldertafel).

\section{Literatur}

Hilgers R-D, Bauer P, Scheiber V (2002) Einführung in die Medizinische Statistik. Springer, Berlin/Heidelberg/New York

\section{Testergebnis, falsch-positives}

R.-D. Hilgers, N. Heussen und S. Stanzel

Synonym(e) Falsch-positiver Test

Englischer Begriff false-positive test; false-positive test result

Definition Ein falsch-positives Testergebnis eines diagnostischen Tests liegt vor, wenn tatsächlich Gesunde ein positives Testergebnis aufweisen.

Beschreibung Ein falsch-positives Testergebnis stellt eine der beiden Fehlentscheidungen des diagnostischen Tests ( $\vee$ Test, diagnostischer) dar. In Analogie zum statistischen Test ( $\triangleright$ Test, statistischer) bezeichnet man zuweilen ein falsch-positives Testergebnis auch als einen $\triangleright$ Fehler 1. Art. Anhand der Rate der falsch-positiven Testergebnisse lässt sich die Genauigkeit ( $\triangleright$ Accuracy, diagnostische) des Tests bewerten. Die Anzahl falsch-positiver Testergebnisse wird üblicherweise durch den Wert $b$ bestimmt (Bezeichnungen s. Tabelle im Stichwort $>$ Vierfeldertafel).

\section{Literatur}

Hilgers R-D, Bauer P, Scheiber V (2002) Einführung in die Medizinische Statistik. Springer, Berlin/Heidelberg/New York

\section{Testergebnis, richtig-negatives}

R.-D. Hilgers, N. Heussen und S. Stanzel

Synonym(e) Richtig-negativer Test 
Englischer Begriff true-negative test; true-negative test result

Definition Ein richtig-negatives Ergebnis eines diagnostischen Tests ( $\triangleright$ Test, diagnostischer) liegt vor, wenn tatsächlich Gesunde ein negatives Testergebnis aufweisen.

Beschreibung Richtig-negative Testergebnisse beschreiben die korrekten Testergebnisse für das Nichtvorliegen der Krankheit. Die Anzahl richtig-negativer Testergebnisse wird durch den Wert $d$ geschätzt (Bezeichnungen s. Tabelle im Stichwort $>$ Vierfeldertafel).

\section{Literatur}

Hilgers R-D, Bauer P, Scheiber V (2002) Einführung in die Medizinische Statistik. Springer, Berlin/Heidelberg/New York

\section{Testergebnis, richtig-positives}

R.-D. Hilgers, N. Heussen und S. Stanzel

Synonym(e) Richtig-positiver Test

Englischer Begriff true positiv test; true positiv result result

Definition Ein richtig-positives Ergebnis eines diagnostischen Tests ( $\triangleright$ Test, diagnostischer) liegt vor, wenn tatsächlich Kranke ein positives Testergebnis aufweisen.

Beschreibung Richtig-positive Testergebnisse beschreiben die korrekten Testergebnisse für das Vorliegen der Krankheit. Die Anzahl richtig-positiver Testergebnisse wird durch den Wert $a$ geschätzt (Bezeichnungen s. Tabelle im Stichwort $\checkmark$ Vierfeldertafel).

\section{Literatur}

Hilgers R-D, Bauer P, Scheiber V (2002) Einführung in die Medizinische Statistik. Springer, Berlin/Heidelberg/New York

\section{Testfelder für Urin}

- Urinteststreifen

\section{Testosteron}

M. Bidlingmaier

$\operatorname{Synonym(e)~4-Androsten-17\beta -ol-3-on;~} 17 \beta$-Hydroxyandrost4-en-3-on

Englischer Begriff testosterone; Androst-4-en-17 $\beta$-ol-3-one

Definition C-19-Steorid, Hauptandrogen beim Mann.

Struktur C-19-Steroid, $\mathrm{C}_{19} \mathrm{H}_{28} \mathrm{O}_{2}$.

Molmasse 288,42 Da.

Synthese - Verteilung - Abbau - Elimination Testosteron wird beim Mann hauptsächlich in den Leydig-Zellen des Hodens, bei der Frau im Ovar und bei beiden Geschlechtern in geringerem Umfang auch in der Nebennierenrinde produziert. Bei der schwangeren Frau gibt es zudem eine plazentare Testosteronsynthese. In der Steroidbiosynthese entsteht Testosteron durch Reduktion der Ketogruppe an C17 des Androstendions ( $\triangleright$ Androstendion) durch die 17ß-Hydroxysteroid-Dehydrogenase. Eigentlich wirksames Androgen ist jedoch auf zellulärer Ebene das $>$ Dihydrotestosteron, das durch Reduzierung des Testosterons unter Einwirkung der 5- $\alpha$-Reduktase in den androgensensitiven Zielzellen entsteht. Ein weiterer Abbauweg des Testosterons ist die Konversion zu $>$ Estradiol durch die Aromatase, die sich u. a. im Fettgewebe findet. Die „Nettowirkung“ des Testosterons ist daher - je nach Gewebsexpression von 5- $\alpha$-Reduktase und Aromatase - die Summe von Testosteron-, Dihydrotestosteron- und Estradioleffekten. Im Blut zirkuliert Testosteron nur zu ca. 1-2 \% in der freien Form, der größte Teil liegt gebunden an $>$ SHBG und Albumin vor. Wie andere Androgene wird auch das Testosteron vor allem in der Leber glukuronidiert bzw. sulfatiert, zudem erfolgt eine Metaboliserung zum Androsteron und Etiocholanolon. Die Ausscheidung erfolgt dann vornehmlich renal, teilweise auch biliär. Nur ein sehr geringer Teil $(<2 \%)$ des Testosterons im Urin ist unverändert, hauptsächlich erscheint es in Form der 17-Ketosteroide.

Pathophysiologie Beim Mann wird die Testosteronsynthese der Leydig-Zellen vor allem durch das hypophysäre luteinisierende Hormon (LH, > Luteinisierendes Hormon) geregelt. Umgekehrt inhibiert das Testosteron die hypothalamische Gonadotropin-releasing-Hormon-Freisetzung sowie die hypophysäre LH-Freisetzung. Störungen der HypothalamusHypophysen-Gonaden-Achse sind auf allen Ebenen möglich. Dementsprechend wird beim Hypogonadismus eine primäre Form, bei der die Störung in den Gonaden selbst lokalisiert 
ist, von einer sekundären (hypophysären) und tertiären (hypothalamischen) Form abgegrenzt. Die Wirkung der Androgene wird über den nukleären Androgenrezeptor vermittelt, Störungen der Bindung bzw. Mutationen im Rezeptor führen zur Androgeninsensitivität. Eine massive Überproduktion des Testosterons spielt vor allem bei angeborenen Störungen der Steroidbiosynthese (z. B. beim adrenogenitalen Syndrom) eine Rolle, zudem gibt es die seltenen androgenproduzierenden Tumoren (z. B. der Nebennierenrinde). Auch Stoffwechselstörungen wie das polyzystische Ovarsyndrom (PCOS) gehen mit erhöhten Androgenkonzentrationen einher.

Das Testosteron kommt zwar in niedrigen Konzentrationen auch bei der Frau vor und hat dort auch physiologische Effekte, es ist aber primär das wichtigste männliche Sexualhormon und - direkt oder nach Reduzierung zu Dihydrotestosteron - verantwortlich für die Ausbildung und Erhaltung des normalen männlichen Phänotyps. Testosteron beeinflusst bereits pränatal die Ausbildung der Geschlechtsmerkmale (Differenzierung der Wolff-Gänge) sowie der Geschlechtsidentität. Später reguliert es das Wachstum der Knochen und der Muskulatur, ist essenziell für die Pubertätsentwicklung und fördert die Spermienreifung. Der Einfluss auf die Mineralisierung des Knochens erfolgt auch bei Männern indirekt über die Aromatisierung zu Estradiol. Darüber hinaus hat Testosteron eine Vielzahl weiterer Effekte auf diverse Organe. Bekannt sind z. B. die Wirkung auf Haarfollikel und Talgdrüsen, aber auch auf das Zentralnervensystem, wo unter anderem kognitive Effekte beschrieben sind. Entsprechend der Vielzahl der Wirkungen gibt es auch eine Vielzahl von Erkrankungen, bei denen eine reduzierte oder erhöhte Testosteronkonzentration eine Rolle spielen kann. Beim Mann ist der Testosteronmangel eine wichtige Differenzialdiagnose $u$. a. in der Abklärung der verzögerten Pubertät sowie von Infertilität, Potenz- und Libidoverlust und erektiler Dysfunktion. Erniedrigte Testosteronkonzentrationen finden sich allerdings auch assoziiert mit viszeraler Adipositas, metabolischem Syndrom, was die Abgrenzung vom primären Testosteronmangel erforderlich macht. Bei der Frau stehen in der Pathophysiologie meist die Konsequenzen zu hoher Testosteronkonzentrationen im Vordergrund. Hierbei kommt es durch die Testosteronwirkung auf die entsprechend sensitiven Geweben zu Virilisierungserscheinungen.

Untersuchungsmaterial Serum, Plasma, Urin.

Probenstabilität Bis 24 Stunden bei Raumtemperatur, eingefroren $\left(-20^{\circ} \mathrm{C}\right)$ mehrere Jahre.

Präanalytik Abnahmeuhrzeit notieren! Die Sekretion des Testosterons zeigt einen zirkadianen Verlauf. Die höchsten Werte finden sich am frühen Morgen, die niedrigsten am späten Nachmittag. Dies ist bei der Interpretation zu berücksichtigen, da die meisten Referenzbereiche sich auf den Blutentnahmezeitpunkt am frühen Vormittag beziehen.
Bei Frauen wird die Blutentnahme in der frühen Follikelphase (2.-5. Zyklustag) empfohlen.

Analytik Immunoassay, Gas- oder Flüssigkeitschromatographie-gekoppelte Massenspektrometrie, Flüssigkeitschromatographie-gekoppelte Tandem-Massenspektrometrie.

Konventionelle Einheit $\mu \mathrm{g} / \mathrm{L}$.

Internationale Einheit $\mathrm{nmol} / \mathrm{L}$.

Umrechnungsfaktor zw. konv. u. int. Einheit $1 \mu \mathrm{g} / \mathrm{L}=$ $3,47 \mathrm{nmol} / \mathrm{L}$.

Referenzbereich - Erwachsene Die Messergebnisse verschiedener Testosteronimmunoassays unterscheiden sich deutlich. Zudem besteht die Möglichkeit der Interferenz von Bindungsproteinen. Insbesondere im Bereich niedriger, bei der Frau häufig vorkommender Werte sind Präzision und Richtigkeit der Immunoassays oft schlecht. Neuere, massenspektrometrische Verfahren sind hier deutlich überlegen.

Methodenspezifische Referenzbereiche sind nötig, folgende Angaben können als grobe Orientierung gelten:

- Frauen: $<0,6 \mu \mathrm{g} / \mathrm{L}(<2,1 \mathrm{nmol} / \mathrm{L})$

- Männer: 3,5-8,6 $\mu \mathrm{g} / \mathrm{L}(12-30 \mathrm{nmol} / \mathrm{L})$

Referenzbereich - Kinder Knaben vor der Pubertät: $0,3-1,2 \mu \mathrm{g} / \mathrm{L}(1-4 \mathrm{nmol} / \mathrm{L})$. Alter bzw. Pubertätsentwicklung beachten!

\section{Indikation}

Beim Kind:

- Unklares Genitale beim Neugeborenen

- Kryptorchismus

- Störungen der Pubertätsentwicklung

Beim Mann:

- Verdacht auf Hypogonadismus

- Erektile Dysfunktion, Libido- und Potenzverlust

- Therapiemonitoring bei Hypogonadismus

- Hodentumoren

- Tumoren der Nebennierenrinde

- Hypophysentumoren

Bei der Frau:

- Virilisierungserscheinungen, Hirsutismus, Akne, Alopezie

- PCO-Syndrom

- Ovarialtumoren

- Tumoren der Nebennierenrinde 
Interpretation S. Pathophysiologie und Referenzbereiche.

Diagnostische Wertigkeit Testosteron ist der wichtigste Parameter zur Beurteilung der Hodenfunktion, Konzentrationen unter $3 \mu \mathrm{g} / \mathrm{L}(10 \mathrm{nmol} / \mathrm{L})$ sind sicher pathologisch und erfordern die Abklärung möglicher Ursachen eines Hypogonadismus. Bei der Frau erfordern erhöhte Testosteronwerte die differenzialdiagnostische Abklärung, die klinische Aussagekraft erniedrigter Testosteronwerte bei der Frau ist nicht zuletzt aufgrund der messtechnischen Limitationen vieler Assays umstritten. Grundsätzlich ist ein Testosteronwert nur in Zusammenschau mit dem klinischen Bild zu interpretieren.

Die parallele Messung von SHBG ( $\triangleright$ Sexualhormonbindendes Globulin) stellt eine Möglichkeit zur Abschätzung der freien Androgene dar. Hierzu können komplexere Algorithmen unter Verwendung der Konzentrationen von Testosteron, SHBG und Albumin verwendet werden (z. B. mit der Formel nach Vermeulen). Im klinischen Alltag ist jedoch vielerorts auch der einfachere freie Androgenindex (Testosteron-SHBG-Quotient) im Einsatz.

\section{Literatur}

Kaufman JM, Vermeulen A (2005) The decline of androgen levels in elderly men and its clinical and therapeutic implications. Endocr Rev 26(6):833-876

Tavita N, Greaves RF (2017) Systematic review of serum steroid reference intervals developed using mass spectrometry. Clin Biochem pii: S0009-9120(17)30582-9

Tran TS, Center JR, Seibel MJ, Eisman JA, Kushnir MM, Rockwood AL, Nguyen TV (2015) Relationship between serum testosterone and fracture risk in men: a comparison of RIA and LC-MS/MS. Clin Chem 61(9):1182-1190

\section{Testosteron-Stimulation}

- HCG-Test

\section{Teststatistik}

> Prüfgröße

\section{Teststreifen}

W. G. Guder

Synonym(e) Schnelltest; Streifentest

Englischer Begriff test strips; dipsticks; urine dipsticks; lateral flow assay
Definition Teststreifen sind Träger von Reagenzien für chemische, immunologische oder physikalisch-chemische Reaktionen zum Nachweis von Analyten in Körperflüssigkeiten.

Beschreibung Teststreifen entstanden, als man versuchte, die qualitativen chemischen Nachweise des 19. Jahrhunderts auf einen Träger zu binden, um das Verfahren jedermann, z. B. auch beim Arztbesuch zu Hause oder zur Verwendung von Laien zu ermöglichen. 1850 entwickelte der Chemiker Maumené in Paris in Merinowolle imprägniertes Zinkchlorid und nannte dies Teststreifen. Bei seiner Anwendung in Urin konnte man durch Erhitzen an der Schwarzfärbung $>$ Glukose nachweisen. Über Testtabletten wurde dann 1883 eine Serie von „Urinary Test Papers“ von Oliver aus London vorgestellt, die > Albumin und Zucker nachweisen konnten. Diese wurden als „Olivers Reagenzpapiere“ von Geßler aus Dresden ab 1883 auch in Deutschland bekannt gemacht. Es folgten Testpapiere für den Blutnachweis mit Benzidin ( $\triangleright$ Benzidinprobe) durch die Brüder Adler und weitere Verfahren bis zum ersten Mehrfeldteststreifen „Urocit“, der im Jahr 1938 schon 8 Testfelder enthielt. Durch Entwicklungen der Nachkriegszeit in USA (Miles, Ames) und Deutschland (Boehringer Mannheim) entstanden die noch heute gebräuchlichen Methoden des Leukozyten-, Blut- und Glukosenachweises mit Teststreifen ( $\triangleright$ Urinstatus; $\triangleright$ Urinteststreifen). Neu entwickelt wurden Streifen für $>$ Phenylalanin, Schwangerschaftstests auf der Basis von Gonadotropintests sowie spezifische Tests für Albumin ( $\triangleright$ Albumin im Urin), \ Kreatinin und $>\alpha_{1}$-Mikroglobulin im Urin. Diese Methodik wurde verwendet, um die gesamte Diagnostik auch des Blutes auf $\triangleright$ Trockenchemie umzustellen (Kodak, Rochester, USA; Boehringer Mannheim, Deutschland), bei denen die Teststreifen nach Auftragen eines Tropfens Blut in ein Messgerät gestellt wurden. Daraus wiederum sind die modernen Teststreifen für die $\vee$ patientennahe Sofortdiagnostik (POCT) und die Patientenselbstkontrolle entstanden.

\section{Literatur}

Maumené EJ (1850) Sur un nouveau réactif pour distinguer la présence $\mathrm{du}$ sucre dans certain liquides. C R Hebd Seances Acad Sci 30:314-315

Oliver G (1883) On bedside urine testing. Lancet I 1883(139-140):190-192 Voswinckel P (1994) A marvel of color and ingredients. The story of urine test strips. Kidney Int 46(Suppl) 47:3-7

\section{Tetanus}

W. Stöcker

Englischer Begriff tetanus 
Beschreibung des Erregers Clostridium tetani ist ein weltweit verbreitetes, grampositives, obligat anaerobes, bewegliches Stäbchenbakterium aus der Familie der Bacillaceae. Es bildet Sporen, die sehr widerstandsfähig gegen Hitze, Austrocknung und Desinfektionsmittel sind. Nach Infektion vermehrt sich Clostridium tetani im sauerstoffarmen Wundmilieu sehr schnell und produziert 2 Exotoxine, das hämolytische Tetanolysin und das hochpotente neurotoxische Tetanospasmin $\left(\mathrm{LD}_{50}\right.$ ca. $1-2 \mathrm{ng} / \mathrm{kg}$ ). Letzteres verhindert die Freisetzung inhibierender $>$ Neurotransmitter und blockiert somit die Hemmung spinaler Motoneuronen. Es resultieren Erhöhung des Muskeltonus, Übererregbarkeit der Muskulatur sowie Krämpfe.

Erkrankungen Tetanus (Wundstarrkrampf) geht von Wundinfektionen aus. Insbesondere in feuchtwarmen Ländern mit niedrigen Impfraten sowie schlechter medizinischer Versorgung sind Morbidität und Letalität hoch. Weltweit verursacht die Erkrankung über eine Million Todesfälle pro Jahr. In Deutschland treten jährlich 10-15 Fälle auf, überwiegend bei Erwachsenen. Der Erreger (Clostridium tetani) kommt ubiquitär im Darm vieler Tiere vor, aber auch in Erdboden und Staub, und gelangt über Wunden jeder Art in die Haut, z. B. über Holzsplitter, Nägel, Dornen oder durch Bissverletzungen, Sekundärinfektion nach Verbrennungen und über den Nabel. Die Inkubationszeit beträgt 3 Tage bis 3 Wochen, in Einzelfällen auch mehrere Monate. Kurze Inkubationszeiten (hohe Toxinmengen) sind typisch für schwere Verläufe und eine hohe Letalität.

Beim generalisierten Tetanus findet man Spasmen der mimischen Gesichtsmuskulatur (Risus sardonicus), der Kiefermuskulatur (Trismus) sowie der Nacken- und Rückenmuskulatur (Opisthotonus). Es treten schmerzhafte tonischklonische Krampfanfälle auf, die durch geringfügige Reize ausgelöst und bei vollem Bewusstsein erlebt werden. Die Lähmung des Zwerchfells und der Interkostalmuskulatur kann zum Erstickungstod führen. Ohne Behandlung ist die Letalität sehr hoch, sie kann aber durch adäquate Therapie auf 10-20\% reduziert werden. Die seltenere lokale Form des Tetanus führt nur im Verletzungsbereich zu Muskelstarre, nicht aber zu allgemeinen Krämpfen. Bei Neugeborenen unzureichend immunisierter Mütter führen Nabelinfektionen zu Tetanus neonatorum.

Nach Ausbruch eines Tetanus wird schnellstmöglich Tetanus-Immunglobulin in hoher Dosierung verabreicht, um zirkulierendes Toxin zu neutralisieren. Zusätzlich erfolgen Wundexzision, antibiotische Behandlung und aktive Immunisierung. Häufig ist eine Intensivtherapie (Sedierung, Muskelrelaxation, künstliche Beatmung) erforderlich. Als wichtigste Präventionsmaßnahme gilt die aktive Immunisierung mit Tetanustoxoid. Bei negativem oder unklarem Impfstatus wird nach Verletzungen eine gleichzeitige aktive und passive Immunisierung empfohlen. Es besteht keine Meldepflicht für Tetanus.
Analytik Clostridium tetani stellt sich mikroskopisch als grampositives, bewegliches Stäbchen mit terminal gelagerten Endosporen (Trommelschlegel) dar. Die Untersuchung mikroskopischer Direktpräparate ist in der Tetanusdiagnostik allerdings nicht zielführend. Der kulturelle Erregernachweis gelingt nur selten und ist für die Diagnostik praktisch ebenfalls ohne Bedeutung. Die Anzucht erfolgt auf supplementierten Nährmedien (Leber-/Thioglykolatbouillon, Blutagar) unter anaeroben Bedingungen bei $37^{\circ} \mathrm{C}$.

Die Diagnose stützt sich auf den Toxinnachweis mittels eines In-vivo-Neutralisationstests im Tierversuch (Maus). Dazu wird Mäusen Wundmaterial, Patientenserum oder Kulturfiltrat injiziert. Das Toxin führt innerhalb weniger Tage zu typischen Erscheinungen (Starrkrampf der Hinterbeine) und zum Tod der nicht vorbehandelten Maus, während immunisierte Vergleichstiere bei sonst identischer Behandlung keine Symptome zeigen.

In der Serologie werden Antikörper gegen das TetanusToxin mittels Enzyme-linked Immunosorbent assay (ELISA) bestimmt, zum Beispiel zur Kontrolle des Impfstatus.

Untersuchungsmaterial - Probenstabilität Direktnachweis, Kultur und Toxin-Nachweis: Untersucht werden Wundmaterial und Serum. Das Material sollte bis zur Weiterverarbeitung bei +4 bis $+8{ }^{\circ} \mathrm{C}$ aufbewahrt werden. Direktnachweise sind innerhalb von 24 Stunden durchzuführen, Kulturen innerhalb von 6 Stunden anzulegen. Bei längerer Transportzeit ist das Material einzufrieren.

Serologie: Serum oder Plasma für den Nachweis der Antikörper sind bei $+4^{\circ} \mathrm{C}$ bis zu 2 Wochen lang beständig, Liquor nur eine Woche, bei $-20^{\circ} \mathrm{C}$ über Monate und Jahre hinweg. Zur Tiefkühlkonservierung des IgM kann man den Proben $80 \%$ gepuffertes Glyzerin beifügen.

Diagnostische Wertigkeit Die Diagnose eines Tetanus erfolgt in erster Linie durch das klinische Bild sowie die Verletzungs- und Impfanamnese. Zur Diagnoseabsicherung ist der Toxinnachweis im Tierversuch (noch) die Methode der Wahl. Die quantitative Bestimmung von IgG-Antikörpern gegen das Tetanus-Toxin mittels ELISA gilt als standardisiertes Testverfahren und dient vorrangig der Kontrolle des Immunstatus. Differenzialdiagnostisch sind hyperkalziämische Tetanie, Tollwut, Meningitis, Hirntumoren und Strychninvergiftung zu berücksichtigen.

\section{Literatur}

Hahn H, Falke D, Kaufmann SHE, Ullmann U (Hrsg) (2005) Medizinische Mikrobiologie und Infektiologie, 5. Aufl. Springer, Berlin/Heidelberg/New York, S 339-348

Köhler W, Eggers HJ, Fleischer B, Marre R, Pfister H, Pulverer G (Hrsg) (2001) Medizinische Mikrobiologie, 8. Aufl. Urban \& Fischer Verlag, München, S 395-398 


\section{Tetracarboxyporphyrin}

> Porphyrine

\section{Tetracosansäure}

Lignocerinsäure

\section{Tetrahydro-Aldosteron}

W. Hubl

Synonym(e) $3 \alpha, 5 \beta$-Tetrahydro-Aldosteron; $\quad(3 \alpha, 5 \beta, 11 \beta)-$ 11,18-Epoxy-3,18,21-trihydroxypregnan-20-one; $11 \beta, 18$ Epoxy-3 $\alpha, 18,21$-Trihydroxy-5 $\beta$-pregnan-20-one

Englischer Begriff tetrahydro-aldosterone

Definition Metabolit des Mineralokortikosteroids Aldosteron.

Struktur $\mathrm{C}_{21} \mathrm{H}_{32} \mathrm{O}_{5}$.<smiles>O=C(CO)C1CCC2C3CCC4C[C@@H](O)CCC4C3C3CC12C(O)O3</smiles>

Molmasse $364,5 \mathrm{~g}$.

Synthese - Verteilung - Abbau - Elimination TetrahydroAldosteron wird durch den Abbau von $>$ Aldosteron in der Leber (40 \%) gebildet. Hierbei wird die Doppelbindung im A-Ring des Aldosterons mit dem Enzym 5 $\beta$-Reduktase reduziert. Im weiteren Stoffwechselverlauf werden ca. $50 \%$ des Tetrahydro-Aldosterons in der C3-Position zum Glukuronid konjugiert und ca. 5-25\% zum 3-Oxo-Konjugat abgebaut und im Urin ausgeschieden.

Funktion - Pathophysiologie $>$ Aldosteron.

Untersuchungsmaterial - Entnahmebedingungen 24Stunden-Sammelurin.
Probenstabilität 24 Stunden im Kühlschrank stabil. Bei längerer Aufbewahrung: $1 \mathrm{~g}$ Borsäure pro $100 \mathrm{~mL}$ Urin zusetzen.

Präanalytik Erhöhungen bei: Einnahme von Diuretika, Spironolactone, Natriumentzug, natriumarme Kost, Gravidität. Erniedrigungen bei Natriumzufuhr, natriumreicher Kost.

Analytik Radioimmunoassay; - GaschromatographieMassenspektrometrie.

Konventionelle Einheit $\mu \mathrm{g} / 24 \mathrm{~h}$.

Internationale Einheit $\mathrm{nmol} / 24 \mathrm{~h}$.

Umrechnungsfaktor zw. konv. u. int. Einheit

$\mu \mathrm{g} / 24 \mathrm{~h} \times 2,74=\mathrm{nmol} / 24 \mathrm{~h}$.

Referenzbereich - Erwachsene 27,4-192 nmol/L.

\section{Indikation}

- Hypertonie, Nebennierenrindenerkrankungen

- Primärer und sekundärer Hyperaldosteronismus

- Hypoaldosteronismus

- Adrenogenitales Syndrom

\section{Interpretation}

- Erhöht: Hyperaldosteronismus

- Abgrenzung des Hyperaldosteronismus von der essenziellen Hypertonie

- Erniedrigt: Hypoaldosteronismus, Nebennierenrindeninsuffizienz, adrenogenitales Syndrom mit Salzverlust

- Ergänzende Untersuchungen: > Renin, > OrthostaseTest, ACTH-Test bei Verdacht auf eine NNRInsuffizienz, $>$ Aldosteron-Renin-Quotient.

Diagnostische Wertigkeit Basisdiagnostik des Hyper- bzw. Hypoaldosteronismus; diagnostische Sensitivität/Spezifität für Adenomdiagnostik 99,9\%/82,1\%; diagnostische Sensitivität/Spezifität für Abgrenzung Aldosteron-produzierendes Adenom zu essenzieller Hypertonie 96 \%/95 \%.

\section{Literatur}

Hubl W, Thomas L (2005) Renin-Angiotensin-Aldosteron-System. In: Thomas L (Hrsg) Labor und Diagnose, 6. Aufl. TH-Books, Frankfurt am Main, S 1406-1425

McQuarrie EP, Freel EM, Mark PB et al (2013) Urinary sodium excretion is the main determinant of mineralocorticoid excretion rates in patients with chronic kidney disease. Nephrol Dial Transplant $28(\mathrm{~S}): 1526-1532$ 


\section{$3 \alpha, 5 \beta$-Tetrahydro-Aldosteron}

> Tetrahydro-Aldosteron

\section{Tetrahydrocannabinol}

> Cannabinoide

\section{Tetrahydrofolsäure}

> Folsäure

\section{2,3,4,5-Tetrahydropicolinsäure}

$\Delta^{1}$-Piperidin-6-carbonsäure

\section{Tetraiodthyronin}

- Thyroxin, gesamt

\section{Tetraiodthyronin, freies}

> Thyroxin, freies

\section{Textarin-Zeit}

\section{T. Stief}

\section{Englischer Begriff textarin time}

Definition Textarin ist eine Serinproteinase aus dem Gift der Pseudonaja textilis (,brown snake"), das > Prothrombin in Abhängigkeit von $>$ Gerinnungsfaktor $\mathrm{V}, \mathrm{Ca}^{2+}$ und gerinnungsaktiven Phospholipiden (PL) zu $\triangleright$ Thrombin aktiviert. Die Textarinzeit ist ein sehr sensitiver Test zum Nachweis eines Lupus-Antikoagulans (Phospholipidantikörper).

Beschreibung Die Textarin-Zeit ist bei einem LupusAntikoagulans ( $\triangleright$ Autoantikörper gegen Phospholipide) wegen der Abhängigkeit der Textarin-Aktivität von PL verlängert. Die Textarin-Zeit fällt falsch positiv aus, wenn ein GerinnungsfaktorII-Mangel, Antikörper gegen Gerinnungsfaktor V oder ein Gerinnungsfaktor-V-Mangel vorliegt. Ein Gerinnungsfaktor-VMangel oder ein Hemmkörper gegen den Gerinnungsfaktor $\mathrm{V}$ sollte daher ausgeschlossen werden.

Im Gegensatz zu Textarin ist die Aktivität von Ecarin, eine Serinproteinase der Echis carinatus, nicht abhängig von PL. Daher verlängert ein Lupus-Antikoagulans die TextarinZeit, während die PL-unabhängige $>$ Ecarin-Zeit unbeeinflusst ist. Von diagnostischem Interesse ist der Quotient (Ratio) aus Textarin-Zeit und Ecarin-Zeit.

Normalbereich Textarin-Ecarin-Ratio $=$ ca. 0,8 ; eine Ratio größer 1,3 ist pathologisch.

\section{Literatur}

Triplett DA, Stocker KF, Unger GA, Barna LK (1993) The Textarin/ Ecarin ratio: a confirmatory test for lupus anticoagulants. Thromb Haemost 70:925-931

\section{Textbausteine}

\section{$\checkmark$ Texte}

\section{Texte}

\section{O. Colhoun}

Synonym(e) Befundtexte; Ergebnistexte; Textbausteine

\section{Englischer Begriff texts; t-notes}

Definition Textstrings als Messergebnis oder an Stelle eines Messwerts, Kommentartextbausteine und Befundtextbausteine der $\triangleright$ Labor-EDV.

Beschreibung Einfachste Form der Textergebnisse sind qualitative Analysenergebnisse (positiv, negativ, +++ etc.). Anstelle eines Messwerts erscheinen Texte beispielsweise in Form eines Hinweises wie „Material geronnen“ oder „siehe Befundbericht“. Umfangreichere Texte erscheinen auf dem Laborbefund in Form von Textbausteinen als Erläuterung und Interpretation von Ergebniskonstellationen. Die Notwendigkeit des Gebrauchs von Expertensystemen (s. D Expertensystem) ergibt sich bei komplexer werdenden Parameterkonstellationen. 


\section{Texterkennung}

$\triangle \mathrm{OCR}$

\section{TF}

> Tissue Factor

TFC

> Turbulent-flow-Chromatographie

\section{TFPI-1}

- Tissue factor pathway inhibitor

\section{TG}

\section{> Thyreoglobulin}

\section{TGF- $\beta$}

- Transforming Growth Factor $\beta$

TGF- $\beta 1$

- Transforming Growth Factor $\beta$

TGF- $\beta 2$

- Transforming Growth Factor $\beta$

\section{TGF- $\beta 3$}

- Transforming Growth Factor $\beta$

\section{TGFBR3}

- Betaglykan

\section{Thallium}

C. Vidal und W.-R. Külpmann

Englischer Begriff thallium

Definition Schwermetall (III. Hauptgruppe).

Molmasse Relative Atommasse: 204,383.

Synthese - Verteilung - Abbau - Elimination Nach oraler Zufuhr verteilt sich Thallium (Tl) rasch in den Geweben, in das Zentralnervensystem wird es allerdings langsam aufgenommen. $\mathrm{Tl}$ wird langsam renal eliminiert.

Halbwertszeit 2-4 Tage (Plasma).

Funktion - Pathophysiologie Die akute Vergiftung ist häufig bedingt durch die orale Zufuhr von Thalliumsulfat (Rodentizid). Als tödlich gelten Dosen ab $8 \mathrm{mg} / \mathrm{kg} \mathrm{KG}$. Es wird vermutet, dass die Thalliumionen sulfhydrylhaltige Enzyme hemmen. Bei der Vergiftung tritt zunächst Erbrechen auf. Nach einem 2- bis 4-tägigen symptomfreien Intervall treten Obstipation, neuralgiforme Schmerzen, Hyperästhesie und Sehstörungen, später und bei chronischer Intoxikation büschelförmiger Haarausfall und die Mees-Bänder an den Nägeln auf.

Untersuchungsmaterial - Entnahmebedingungen Urin, Blut.

Analytik - Atomabsorptionsspektrometrie, inverse Voltammetrie (s. Voltammetrie, zyklische und inverse, fotometrische Bestimmung nach Farbreaktion.

Indikation Verdacht auf akute oder chronische Vergiftung. Die fotometrische Bestimmung erfasst nur toxische Konzentrationen.

Interpretation Referenzbereich (Urin): $<2 \mu \mathrm{g} / \mathrm{L}$; toxisch: $>250 \mu \mathrm{g} / \mathrm{L}$.

\section{Literatur}

Degel F, Gibitz HJ, Aderjan R, Daldrup T (2009) Thallium. In: Külpmann WR (Hrsg) Clincial toxicological analysis. Wiley-VCH, Weinheim, S 664-678 


\section{THC}

$\checkmark$ Cannabinoide

\section{Thebain, in Opium}

$>$ Mohn

\section{Theca-Zell-Antikörper}

- Autoantikörper gegen Steroidhormon-produzierende Zellen

\section{T4-Helfer/T8-Suppressor-Quotient im} Liquor

> Liquor-CD4/CD8-Quotient

\section{T4-Helfer-Zelle}

$>\mathrm{CD} 4$

\section{Theobromin}

$\checkmark$ Alkaloide

\section{Theophyllin}

C. Vidal und W.-R. Külpmann

Englischer Begriff theophylline

Definition Broncholytikum.

Strukturformel:<smiles>Cn1c(=O)c2nc[nH]c2n(C)c1=O</smiles>

Molmasse $180,17 \mathrm{~g}$.

Synthese - Verteilung - Abbau - Elimination Theophyllin wird hepatisch zu 3-Methylxanthin bzw. 1,3-Dimethylharnsäure und weiter zu 1-Methylharnsäure metabolisiert, sodass sich im Urin im Wesentlichen Abbauprodukte finden. Bei Neugeborenen (Indikation: Apnoebehandlung) wird Theophyllin zusätzlich zu $\triangleright$ Coffein methyliert.

Halbwertszeit Im Plasma Erwachsener 6-9 Stunden, von Kindern und Rauchern 4 Stunden, von Frühgeborenen 30 Stunden.

Funktion - Pathophysiologie Akute Vergiftung mit Übelkeit, Krampfanfällen, Tachykardie, Atemstillstand.

Untersuchungsmaterial - Entnahmebedingungen Serum (S), Plasma (P), Urin.

Analytik Immunoassay, GC-MS, LC-MS/MS.

Indikation Therapeutisches Drug Monitoring.

Interpretation Bei Frühgeborenen ist wegen des Metabolismus neben der Theophyllin- auch die Coffeinkonzentration zu überwachen.

Therapeutischer Bereich (S, P): 8-20 mg/L (Erwachsene), 6-11 mg/L (Frühgeborene); toxisch: $>20 \mathrm{mg} / \mathrm{L}$ (Erwachsene), $>15 \mathrm{mg} / \mathrm{L}$ (Frühgeborene); komatös-letal: $>50 \mathrm{mg} / \mathrm{L}$ (Erwachsene), unbekannt (Frühgeborene).

\section{Literatur}

Külpmann WR (Hrsg) (2009) Bronchodilators. In: Clinical toxicological analysis. Wiley-VCH, Weinheim, S 313-316

\section{Theranostik}

A. M. Gressner und O. A. Gressner

Synonym(e) Therapie-Diagnostik

Englischer Begriff theranostics; (personalized medicine)

Definition Theranostik ist ein Therapiekonzept, dem eine auf den jeweiligen, individuellen Patienten ausgerichtete spezifische und zeitgerechte Behandlung zugrunde liegt.

Beschreibung Die Theranostik ist eine individualisierte, therapiebegleitende labormedizinische, molekularbiologische 
oder bildgebende Diagnostik, deren Ergebnisse die Grundlage für eine spezifische Therapie ist. So erfolgt eine therapeutische Anpassung an das Krankheitsstadium, an genetische Prädispositionen und an die Wirksamkeit des Medikamentes. Theranostikprinzipien sind bisher erfolgreich angewendet worden bei der individuellen Chemotherapie maligner Erkrankungen, z. B. Mammakarzinom. Die weitere Entwicklung des Theranostikkonzeptes in Verbindung mit den Erkenntnissen der molekularen Medizin bleibt abzuwarten.

\section{Literatur}

Warner S (2004) Diagnostics and therapy (theranostics). The Scientist 18:38-39

\section{Therapeutischer Bereich}

C. Vidal und W.-R. Külpmann

\section{Englischer Begriff therapeutic range}

Definition Bereich der Plasmakonzentration eines Pharmakons, bei dem ein therapeutischer Effekt bei der Mehrzahl der Patienten beobachtet wird.

Beschreibung Der therapeutische Bereich ist nur dann für den individuellen Patienten gültig, wenn dieser vergleichbar ist mit der untersuchten $\triangleright$ Referenzpopulation. Der therapeutische Bereich hat stets nur orientierende Bedeutung. Je nach Indikation für ein Medikament können unterschiedliche therapeutische Bereiche gelten (z. B. Acetylsalicylsäure).

\section{Literatur}

Arndt T (2016) Therapeutische und toxische Bereiche - Zur Transversalbeurteilung in der Labordiagnostik Teil 2. Toxichem Krimtech 83:115-120

Külpmann WR (1991) Drug monitoring. Diagnose und Labor 41:55-62

\section{Therapeutischer Index}

C. Vidal und W.-R. Külpmann

Englischer Begriff therapeutic index
Definition $L D_{5} / E D_{95}$.

$E D_{95}$ : Dosis, die bei $95 \%$ der Probanden die erwünschte Wirkung hervorruft.

$L D_{5}$ : Dosis, die $5 \%$ der Organismen tötet.

Beschreibung Der therapeutische Index soll ein Maß sein für die potenzielle Gefahr bei Applikation eines Pharmakons. Für diesen Zweck ist er dem therapeutischen Quotienten meist überlegen.

\section{Literatur}

Wellhöner HH (1997) Pharmakologie und Toxikologie, 6. Aufl. Springer, Berlin/Heidelberg/New York

\section{Therapeutischer Quotient}

C. Vidal und W.-R. Külpmann

Englischer Begriff therapeutic ratio

Definition $L D_{50} / E D_{50}$

$E D_{50}$ : Dosis, die bei $50 \%$ der Probanden die erwünschte Wirkung hervorruft.

$L D_{50}$ : Dosis, die $50 \%$ der Organismen tötet.

Beschreibung Der therapeutische Quotient soll ein Maß sein für die potenzielle Gefährdung bei Applikation eines Pharmakons, das jedoch leicht zu Fehlschlüssen verleitet.

\section{Literatur}

Wellhöner HH (1997) Pharmakologie und Toxikologie, 6. Aufl. Springer, Berlin/Heidelberg/New York

\section{Therapeutisches Drug Monitoring}

C. Vidal und W.-R. Külpmann

\section{$\operatorname{Synonym(e)}$ TDM}

Englischer Begriff therapeutic drug monitoring

Definition Überwachung der Plasmakonzentration von Arzneistoffen zur Therapiesteuerung. 
Beschreibung Für das TDM kommen infrage:

- Arzneistoffe, deren Wirkung nicht auf einfache Weise erfassbar ist

- Arzneistoffe mit engem therapeutischen Bereich ( $\triangleright$ Therapeutischer Bereich)

- Verdacht auf Abweichung von der charakteristischen Pharmakokinetik

- Überprüfung der Compliance

Es muss eine enge Beziehung zwischen Plasmakonzentration und pharmakologischer Wirkung bestehen. Bei Pharmaka mit kurzer Halbwertszeit wird eine $>$ Probe zum Zeitpunkt der erwarteten Maximalkonzentration entnommen (häufig etwa 1-2 Stunden nach Zufuhr; > C2-Monitoring), eine zweite zum Zeitpunkt der Minimumkonzentration (unmittelbar vor Gabe der nächsten Dosis). Bei Pharmaka mit langer Halbwertszeit genügt es, eine Probe im Dosierungsintervall jeweils zur gleichen Zeit zu entnehmen (bevorzugt vor der nächsten Dosis).

\section{Literatur}

Arndt T (2016) Therapeutische und toxische Bereiche - Zur Transversalbeurteilung in der Labordiagnostik Teil 2. Toxichem Krimtech $83: 115-120$

Külpmann WR (1991) Drug monitoring. Diagn Labor 41:55-62

\section{Therapie-Diagnostik}

> Theranostik

\section{Thermogenin (für UCP1)}

Entkopplungsproteine

\section{Thermospray}

B. Güssregen

\section{Englischer Begriff thermospray}

Beschreibung Bei Thermospray handelt es sich um eine - Atmospheric pressure ionisation-(API-)Methode in der - Massenspektrometrie. Aus einer geheizten Kapillare wird das LC-Fließmittel in eine beheizte Desolvatisierungskammer (oft Quelle genannt) versprüht, von der aus möglichst reproduzierbare Anteile die generierten Ionen in den unter Vakuum stehenden Massenanalysator gesogen werden.

\section{Thiamin}

$>$ Vitamin $\mathrm{B}_{1}$

\section{Thiamin(pyrophosphat) und Thiamintriphosphat}

Vitamin $\mathrm{B}_{1}$

\section{Thin Client}

O. Colhoun

Definition Thin Client (bezogen auf $>$ Client-ServerArchitektur) bezeichnet eine Anwendung oder einen Computer als Endgerät ( $>$ Terminal) eines Netzwerkes, dessen funktionale Ausstattung alleine auf die Ein- und Ausgabe beschränkt ist.

\section{Thioalkohole}

Mercaptane

\section{Thiobarbitursäure-reaktive} Substanzen

K. J. Lackner und D. Peetz

\section{Synonym(e) TBARS}

Englischer Begriff thiobarbituric acid reactive substances; TBARS

Definition Substanzen, die mit Thiobarbitursäure bei saurem pH reagieren; meist Aldehyde. Deshalb werden TBARS auch als Surrogatparameter für die Lipidoxidation verwendet.

\section{Literatur}

Meagher EA, FitzGerald GA (2000) Indices of lipid peroxidation in vivo: strengths and limitations. Free Radic Biol Med 28:1745-1750 


\section{Thiopental}

> Barbiturate

\section{Thioredoxine}

\section{A. M. Gressner und O. A. Gressner}

Englischer Begriff thioredoxine

Definition Ubiquitär exprimierte Familie von Oxidoreduktasen

Beschreibung Thioredoxine wirken antioxidativ ( $\triangleright$ Stress, oxidativer), indem sie die Reduktion anderer Proteine durch Cystin-Thiol-Disulfid-Austausch katalysieren. Sie fungieren als Elektronendonatoren für Peroxidasen und Ribonukleotidreduktasen. Zahlreiche In-vitro-Substrate für Thioredoxine konnten identifiziert werden, so z. B. Ribonuklease, Choriogonadotropine ( $\triangleright$ Choriongonadotropin, humanes), $\triangleright$ Gerinnungsfaktoren, Glukokortikoidrezeptoren oder $>$ Insulin.

Die Thioredoxin-katalysierte Reduktion von Insulin mit dadurch präzipitierenden freien Insulin- $\beta$-Ketten wird spektrophotometrisch bei $650 \mathrm{~nm}$ gemessen und in der Regel als Assay zur Aktivitätsbestimmung verwendet. Zusätzliche Funktionen betreffen ihre Rolle bei der DNA-Synthese und AntiApoptose.

\section{Literatur}

Holmgren A, Lu J (2010) Thioredoxin and thioredoxin reductase: current research with special reference to human disease. Biochem Biophys Res Commun 396:120-124

\section{Thomas-Plot}

T. Arndt

Synonym(e) Eisenstoffwechselplot nach Thomas

\section{Englischer Begriff Thomas plot}

Definition Diagnostisches Diagramm zur Beurteilung des Eisenstatus eines Patienten.

Beschreibung Im Thomas-Plot werden Kenngrößen des Eisenstoffwechsels graphisch so angeordnet, dass sich in der durch die X- und Y-Achse aufgespannten Fläche 4 Quadranten mit je einer Differenzialdiagnose zum Eisenhaushalt ergeben (s. Abbildung).

Diagnostisches Diagramm zur Beurteilung des Eisenstatus:

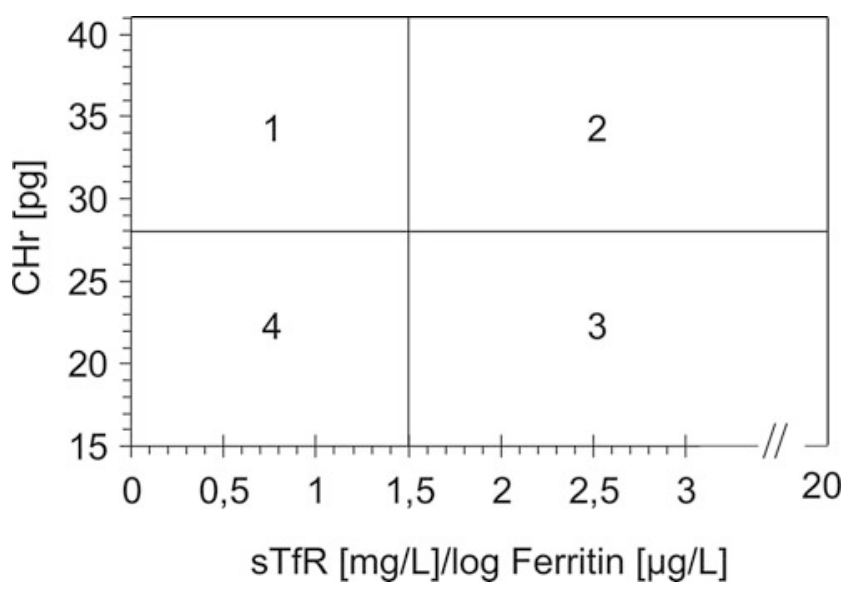

Auf der X-Achse ist der Quotient aus der Konzentration des löslichen Transferrinrezeptors ( $\triangleright$ Transferrinrezeptor, löslicher) und dem Logarithmus der $\gg$ Ferritin-Konzentration im Serum (Plasma) des Patienten, d. h. der sog. Ferritin-Index sTfR $[\mathrm{mg} / \mathrm{L}] / \log$ Ferritin $[\mu \mathrm{g} / \mathrm{L}]$, aufgetragen, auf der Y-Achse der Hämoglobingehalt der Retikulozyten $\mathrm{CHr}$ (,content of hemoglobin of reticulocytes") [pg]. Die Differenzialdiagnose für den Patienten wird erhalten, indem man ausgehend vom Messwert $\mathrm{CHr}$ eine Waagerechte nach rechts und ausgehend vom sTfR/log Ferritin-Quotienten eine Senkrechte nach oben zieht. Der Schnittpunkt beider Linien findet sich in einem der 4 Quadranten mit der entsprechenden Differenzialdiagnose.

Der Ferritin-Index (sTfR/log Ferritin) ist ein Marker des Eisenangebots, $\mathrm{CHr}$ eine Kenngröße des Eisenbedarfs der Erythropoese (sog. Funktionseisen).

Interpretation sTfR/log Ferritin $>1,5$ : Ausdruck mangelnden Eisenangebots, $\mathrm{CHr}<28 \mathrm{pg}$ Zeichen funktionellen Eisenmangels.

Quadrant 1: Speichereisenreserve gefüllt, normale Erythropoese.

Quadrant: 2: Speichereisenreserve vermindert, noch kein Funktionseisenmangel, normaler Hämoglobingehalt der Erythrozyten.

Quadrant 3: Speichereisenreserve vermindert, Funktionseisenmangel, hypochrome rote Blutzellen.

Quadrant 4: Speichereisenreserve gefüllt, Funktionseisenmangel, hypochrome rote Blutzellen.

Patienten mit Anämie infolge chronischer Erkrankungen sind in mehr als $95 \%$ der Fälle durch Quadrant 1 oder 4 repräsentiert, Patienten mit leichtem Eisenmangel durch Quadrant 2 und solche mit ausgeprägtem Eisenmangel durch Quadrant 3. 


\section{Literatur}

Thomas C, Thomas L (2002) Biochemical markers and hematologic indices in the diagnosis of functional iron deficiency. Clin Chem 48:1066-1076

\section{Thoma-Zählkammer}

- Erythrozytenzählung

- Thrombozytenzählung

> Zählkammer

\section{Thormählen-Probe}

> Thormählen-Test

\section{Thormählen-Test}

\section{A. M. Gressner und O. A. Gressner}

Synonym(e) Melanogennachweis nach Thormählen; Thormählen-Probe

\section{Englischer Begriff Thormälen's test}

Definition Heute obsoletes, von Johannes Thormählen (1860-1892) im Jahr 1887 eingeführtes, semiquantitatives kolorimetrisches Nachweiverfahren von Melanogenen (Melaninvorstufen) im Urin zur Diagnostik des (metastasierenden) Melanoms.

Beschreibung Melanogene (5,6-Dihydroxyindolester) werden im alkalischen Milieu $(\mathrm{NaOH})$ durch NitroprussidNatrium zu Indolchinon oxidiert und zu Melanin (hochmolekulare, amorphe Indolchinonpolymere) polymerisiert. Die im Melanogen-haltigen Harn auftretende Rotviolettfärbung schlägt bei Ansäuern durch Zusatz von Essigsäure in Blau um. Positiver Ausfall deutet auf fortgeschrittenes Stadium hin, nicht geeignet zur Frühdiagnose. Interferenz mit hohem Urobilinogen- und Ascorbinsäuregehalt (Blaugrünfärbung). Heute nicht mehr in Gebrauch.

\section{Literatur}

Voswinckel P (1989) Zum Abschied von der Thormählen-Reaktion beim Melanom. Neue Kenntnisse über den frühverstorbenen Dr. med. Johannes Thormählen (1860-1892). J Clin Chem Clin Biochem 27:253-259

\section{Thorn-Test}

W. Hubl

\section{Englischer Begriff Thorn test}

Definition Der heute obsolete Thorn-Test dient zur Funktionsprüfung der Nebennierenrinde durch Messung des Abfalls der eosinophilen Leukozyten nach Injektion des adrenokortikotropen Hormons ( $\triangleright$ Adrenokortikotropes Hormon; ACTH).

Indikation Ausschluss einer Nebennierenrindeninsuffizienz.

\section{Durchführung}

- Erste Blutentnahme zur Bestimmung der Eosinophilenzahl

- Gabe von 25 I.E. ACTH über 8 Stunden i.v.

- Danach zweite Blutentnahme zur Bestimmung der Eosinophilenzahl

Referenzbereich Ein Abfall um mindestens $50 \%$ zeigt eine normale Nebennierenrindenfunktion an.

Interpretation Ein Abfall der Eosinophilen um weniger als $50 \%$ des Ausgangswertes deutet auf eine Nebennierenrindeninsuffizienz hin.

Vor Einführung der Kortisolbestimmung ( $\triangleright$ Kortisol) be$\mathrm{sa} ß$ der Thorn-Test eine diagnostische Bedeutung; heute ist er angesichts seiner geringeren diagnostischen Relevanz obsolet.

\section{Literatur}

Beishuizen A, Vermes I (1999) Relative eosinophilia (Thorn test) as a bioassay to judge the clinical relevance of cortisol values during severe stress. J Clin Endocrinol Metab 84:3400. https://doi.org/ 10.1210/jcem.84.9.6011-2. First Published Online: 22.04.2011

Thorn W (1949) Cortisone acetate in Addison disease. Recent Prog Horm Res 4:229

Thr

> Threonin

\section{THRB-Genmutation}

- Schilddrüsenhormon-Rezeptor $\beta$-Genmutation 


\section{Threonin}

A. C. Sewell

Synonym(e) Thr

Englischer Begriff threonine

Definition Essenzielle $\alpha$-Aminosäure.

Struktur $\triangleright$ Aminosäuren.

Molmasse 119,1 g.

Synthese - Verteilung - Abbau - Elimination Thr wird ausgehend von Aspartat über Aspartylsemialdehyd und Homoserin synthetisiert. Thr wird zu Pyruvat mittels Threonindehydrogenase oder zu $\alpha$-Ketobutyrat und Succinyl-CoA abgebaut.

Untersuchungsmaterial - Entnahmebedingungen Plasma, Serum, Liquor, Urin, Trockenblut.

Analytik $\triangleright$ Aminosäuren.

Referenzbereich - Erwachsene $>$ Aminosäuren.

\section{Literatur}

Duran M (2008) Amino acids. In: Blau N, Duran M, Gibson KM (Hrsg) Laboratory guide to the methods in biochemical genetics. Springer, Berlin, S 53-90

\section{Thrombelastographie}

\section{T. Stief und P. Kiefer}

Synonym(e) Rotationsthrombelastographie; TEG

Englischer Begriff thromboelastography; thromboelastometry

Definition Die Thrombelastographie ist eine Methode, um in Nativblut (oder Citratblut) die Hämostase unter niedrigen Scherstressbedingungen dynamisch zu messen. Die Gerinnselfestigkeit wird kontinuierlich aufgezeichnet.
Physikalisch-chemisches Prinzip In der klassischen Methode nach Hartert (im Jahr 1948) wird eine Küvette mit Nativblut gefüllt und ein mit einem Torsionsdraht verbundener Kolben in die Probe eingeführt. Anschließend bewegt sich die Küvette um den Kolben in einem kleinen Winkel vor und zurück. Der Torsionsdraht wird mit einem Lichtzeiger (optische Messung) oder einem magnetischen Detektor verbunden, und die Bewegung des Kolbens wird auf einem Film registriert. Mit zunehmender Gerinnselbildung werden Scherkräfte auf den Kolben wirksam und die Drehung der Küvette überträgt sich auf den Kolben, wodurch dieser entsprechend ausgelenkt wird. Die Zeit bis zum Beginn der Auslenkung des Kolbens wird als Reaktionszeit (r-Zeit) und die Zeit vom Beginn der Auslenkung des Kolben bis zu einer festgelegten Amplitude (z. B. $60 \%$ der Maximalamplitude) wird als Fibrinbildungszeit (k-Zeit) bezeichnet. Nachfolgend ist die TEG unter verschiedenen Hämostasebedingungen dargestellt.

Normal
Aggregationshemmer,
Thrombozytopenie
Hyperfibrinolyse
Hyperkoagulation
Verbrauchskoagulopathie
Stadium 1
Stadium 2
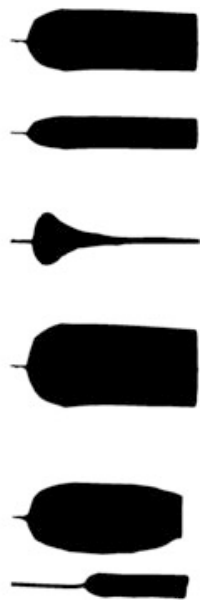

Einsatzgebiet Als Globaltest der Bluthämostase im Zentrallabor oder gegebenenfalls als POCT-Gerät im operativen Bereich.

Untersuchungsmaterial Citratblut oder Nativblut.

\section{Instrumentierung ROTEM.}

Fehlermöglichkeit Problematisch ist, Nativblut standardisiert in die Küvette zu bringen (unterschiedliche Entnahmebedingungen, unterschiedliche Entnahmesysteme, unterschiedliche Stauzeiten); die Küvettenwand gehört zur Probenmatrix (= alles was F12/PK umgibt) und kann unterschiedlich die intrinsische Gerinnung starten.

Praktikabilität - Automatisierung - Kosten Als POCTMethode ( $\triangleright$ Patientennahe Sofortdiagnostik) bedingt geeignet, Durchführung in Zentrallabor durch geschultes Personal valider als Durchführung in der Hektik der Notaufnahme/oder des OP. 
Bewertung - Methodenhierarchie Globaltest. Durch die Anwendung aktivierter Analysen wird die Messung beschleunigt, sodass ca. 15 min nach der Entnahme der Probe eine Aussage über Fibrinbildung und Thrombozytenfunktion zur Verfügung steht. Der Test ist allerdings bei starker intrinsischer oder extrinsischer Aktivierung so grob wie die APTT oder die Prothrombinzeit. Moderne ultraspezifische Teste der Thrombingenerierung wie INCA (,intrinsic coagulation activity assay") oder EXCA (,extrinsic coagulation activity assay“) sind der TEG weit überlegen. Der RECA (,recalcified coagulation activity assay") ist mehr als 1000-fach empfindlicher als die nicht aktivierte TEG. Zur direkten Erfassung einer Hyperfibrinolyse ist die sofortige Zentrallaborbestimmung von Plasmininhibitor/Plasminogen/Fibrinogen/D-Dimer dem TEG vorzuziehen.

\section{Literatur}

Calatzis A, Heesen M, Spannagl M (2003) Patientennahe Sofortdiagnostik von Hämostaseveränderungen in der Anästhesie und Intensivmedizin. Anaesthesist 52:229-237

\section{Thrombin}

T. Stief

Englischer Begriff thrombin, F2a

Definition Thrombin (F2a) ist die humane Serinprotease (His $\cdots$ Asp $\cdots$ Ser im katalytischen Zentrum), die Fibrinogen zu Fibrin umwandelt, indem es primär 2 Fibrinopeptid A-Moleküle von den beiden symmetrischen alpha-Ketten der zentralen E-Domäne des Fibrinogens abspaltet, das entstehende Fibrin-Monomer polymerisiert bereits (sekundär kann Thrombin zusätzlich 2 Fibrinopeptid B-Moleküle von den beiden symmetrischen beta-Ketten der EDomäne(N-Terminus) abspalten). Thrombin entsteht aus dem Proenzym Prothrombin (F2) nach limitierter Spaltung durch den Gerinnungsfaktor 10a (F10a), katalytische Mengen an Thrombin können auch durch die Wirkung von Kallikrein auf F2 entstehen. Die Generierung von Thrombin ist das zentrale Ereignis der Aktivierung der Hämostase.

Beschreibung Thrombin schneidet bevorzugt an Argininresten (die freie negativ geladene Carboxylgruppe von Asp im katalytischen Zentrum bindet die positiv geladene Guanidinogruppe von Arg im Substrat), wobei die Substratspezifität durch die Bindung an ,exosites“ außerhalb des katalytischen Zentrums bestimmt wird. Thrombin ist einer der $>$ Vitamin K-abhängigen Gerinnungsfaktoren (F2, F7, F9, F10, PC, PS). Neben seiner Hauptfunktion in der Umwandlung von
- Fibrinogen zu $\triangleright$ Fibrin aktiviert Thrombin eine Reihe von - Gerinnungsfaktoren wie F5 ( F5a ist einbedeutender Gerinnungs-Beschleuniger), F8, F11, F13 oder von Inhibitoren der Gerinnung wie $>$ Protein $\mathrm{C}$ und ,thrombin-activatable fibrinolysis inhibitor“ (TAFI). Wenn Thrombin an das membranständige Thrombomodulin bindet, verliert es seine Reaktivität für Fibrinogen. Der Thrombin-Thrombomodulin-Komplex aktiviert Protein C und TAFI. An Thrombomodulin gebundenes Thrombin wird auch vom wichtigsten Inaktivator von Thrombin, dem $>$ Antithrombin-3, inaktiviert. Daneben spaltet Thrombin eine Reihe zellulärer Rezeptoren (,protease activated receptor", PAR-1, PAR-3 und PAR-4), der neue N-Terminus, imitiert durch das Peptid TRAP (,thrombin receptor activator peptide“) aktiviert die Zelle. PAR-1 und PAR-4 scheinen die wesentlichen Thrombinrezeptoren für die Aktivierung von humanen Thrombozyten durch Thrombin zu sein. Die Aktivierung von Thrombozyten - PAR-1 durch Thrombin scheint auch für den Synergismus von primärer und sekundärer Hämostase bei Kollagen-induzierter Hämostaseaktivierung verantwortlich zu sein. Die Präsenz von Thrombinrezeptoren auf Zellen wie T-Lymphozyten, Endothelzellen, Monozyten und Megakaryozyten erklärt die Vielzahl der Effekte von Thrombin.

\section{Literatur}

Ofosu FA (2003) Protease activated receptors 1 and 4 govern the responses of human platelets to thrombin. Transfus Apher Sci 28:265-268

Stief TW, Jeske WP, Walenga J, Schultz C, Kretschmer V, Fareed J (2001) Singlet oxygen inhibits agonist-induced P-selectin expression and formation of platelet aggregates. Clin Appl Thromb Hemost 7:219-224

Stief TW (2013) Clinical biochemistry of thrombin. Hemostasis Laboratory 6: 1-11. https://www.novapublishers.com/catalog/pro duct_info.php?products_id $=42107$

\section{Thrombin-aktivierbarer Fibrinolyseinhibitor}

- Fibrinolyseinhibitor, Thrombin-aktivierbarer

\section{Thrombinaktivitåt in Plasma}

T. Stief

Englischer Begriff thrombin activity in plasma

Definition Aktivität (akut oder chronisch) des zentralen Enzyms der Hämostase in Plasma. Physiologisch/pathophysiologisch bedeutend ist sowohl die In-vivo-Aktivität von Throm- 
bin im systemisch zirkulierenden Blut als auch die In-vitroAktivität von Thrombin in neuen ultraspezifischen Testen der Thrombingenerierung. Die Thrombinaktivität wird in internationalen Einheiten (IE) pro $\mathrm{mL}(\mathrm{IE} / \mathrm{mL})$ oder milliinternationalen Einheiten pro $\mathrm{mL}(\mathrm{mIE} / \mathrm{mL})$ angegeben. Analog der Antithrombin-3 Aktivität kann die Thrombin-Aktivität auch in \% der Norm angegeben werden.

Beschreibung Thrombin (F2a) entsteht durch intrinsische oder extrinsische Aktivierung der Hämostase. Die sekundäre Hämostase (plasmatische Gerinnung) ist klinisch sehr wichtig, weswegen im Krankenhaus prophylaktisch gegen die Entstehung von Mikro- oder Makrothromben hauptsächlich Antikoagulanzien vom Typ der niedermolekularen Heparine $(\mathrm{NMH})$ eingesetzt werden. Systemisch zirkulierendes freies Thrombin reagiert sofort mit Fibrinogen, Antithrombinen und konstant zu ca. $10 \%$ mit $\alpha 2$-Makroglobulin (vgl. Abb. unten). Im $\alpha 2$-Makroglobulin-Schutzkäfig (wie der „Taucher im Haifischkäfig") bleibt die Thrombinaktivität von EDTAPlasma erhalten. Kleine Substrate (wie das farblose chromogene Substrat HD-CHG-Ala-Arg-pNA) können in den Schutzkäfig hinein diffundieren, wo sie vom Enzym Thrombin schnell amidolytisch gespalten werden. Das freigesetzte gelbe Para-Nitro-Anilid (pNA) kann so beispielsweise bei $405 \mathrm{~nm}$ gemessen werden und ist ein direktes Maß für die systemische Thrombinaktivität. Das Ergebnis des Thrombintests wird (wie beim AT3) in \% der Norm angegeben. 5,5 $\mathrm{mIE} / \mathrm{mL}$ Thrombin entsprechen $100 \%$ der Norm. Der Normalbereich ist $100 \pm 20 \%$ (Mittelwert \pm 1 Standardabweichung). Die systemische (amidolytische) Thrombinaktivität $(\mathrm{F} 2 \mathrm{a} \cdot \alpha 2 \mathrm{M}$; Blut-HWZ = ca. $0,5 \mathrm{~h}$; Clearance über robuste Gewebsmakrophagen, nicht wie beim ,sprunghaften“ TATKomplex über sensible Hepatozyten) ist ein bedeutender Biomarker für die systemische Gerinnungsaktivierung.

\section{Untersuchungsmaterial - Entnahmebedingungen EDTA- Plasma.}

Präanalytik Proben sollten frisch sein $(<2 \mathrm{~h}$ alt, gelagert bei Raumtemperatur) oder 1+1-stabilisiert mit 2,5 M Arginin, pH 8,6 (bis zu einem Tag Raumtemperatur valide oder mit Arginin stabilisiert eingefroren). Es gilt:

- 80-120\%: Normalbereich (NIC)

- 121-150 \%: Vorphase der pathologischen systemischen Gerinnungsaktivierung (PIC-0); bereits vital gefährdend (sehr häufig)

- 151-200 \%: pathologische systemische Gerinnungsaktivierung (PIC-1); unmittelbar vital gefährdend (häufig)

- $>200 \%$ : Am stärksten pathologische, systemische Gerinnungsaktivierung (PIC-2), oft mit Faktorenverbrauch; (INR > 1.15); extrem vital gefährdend (selten)
Dieser Biomarker reflektiert eine akut oder chronisch erhöhte In-vivo-Thrombingenerierung. Erhöhte Aktivitäten von systemischem Thrombin können durch viele Erkrankungen (z. B. Sepsis, Polytrauma, Atherosklerose, Diabetes mellitus, Ischämie), Metabolite (Glukose, Laktat, Cholesterin, Triglyzeride, Ketonkörper) oder Medikamente/ Toxine (z. B. Valproinsäure, Asparaginase, Antibiotika, Immunsuppressiva/ Äthanol) insbesondere durch Abänderung der Blutmatrix (Umgebung von Faktor 12/Präkallikrein) entstehen. Das klinisch sehr wichtige intrinsische (,altered blood matrix") Gerinnungssystem ist in nachfolgender Abb. 1 dargestellt (modifiziert nach Stief 2012; mit freundlicher Genehmigung von Nova Science Publishers).

Die erniedrigte Thrombingenerierung in Citratplasma bei Therapie mit NMH (oder bei NMH-Unverträglichkeit mit Hirudin), d. h. die Effizienz von Anti-F10a- oder Anti-F2aMedikamenten, wird besser mit einem ultra-spezifischen Invitro-F10a/F2a-Generierungstest gemessen.

EXCA (,extrinsic coagulation activity assay“), INCA (,intrinsic coagulation activity assay“) und RECA (,recalcified coagulation activity assay") sind die 3 ultraspezifischen plasmatischen F10a/F2a - Generierungsteste (ohne Zusatz von Phospholipiden (PL)). Im Gegensatz zu herkömmlichen Thrombingenerierungstesten wird hier nach einer ersten Inkubationsphase der Thrombingenerierung (,coagulation reaction time“, CRT) eine supra-1-molare finale Konzentration an Arginin zugesetzt, die die Protein-ProteinInteraktionen bei der Hämostaseaktivierung stoppt, nicht quervernetztes Fibrin (Antithrombin-1) depolymerisiert und den chromogenen spezifischen Nachweis von Thrombin (nicht aber Kallikrein!) ermöglicht.

Bei allen 3 Testen wird Citratplasma (ggf. sogar EDTAPlasma) in möglichst reinen Polystyren-Mikrotiterplatten (z. B. pure grade Brand, Wertheim) im Verhältnis 10:1 mit $250 \mathrm{mM} \mathrm{CaCl}_{2}$ versetzt, d. h., die Gerinnung läuft in nahezu unverdünntem Plasma ab. Die 3 Teste unterscheiden sich hinsichtlich des Triggers, der die Gerinnungskaskade verstärkt auslöst:

- EXCA: $\gg$ Tissue Factor (TF) $\left(\mathrm{mit}^{\mathrm{Ca}^{2+}}\right)$ und zwar in einer Endkonzentration von nur ca. $0,1 \mathrm{ng} / \mathrm{mL}$, was etwa 1000 fach niedriger liegt als die TF-Konzentration in der Thromboplastinzeit (,prothrombin time“, PT).

- INCA: ein Oberflächenaktivator wie $\mathrm{SiO}_{2}$ oder Ellagsäure $\left(\mathrm{mit} \mathrm{Ca}^{2+}\right)$ in final niedriger Konzentration.

- RECA: Lediglich $\mathrm{Ca}^{2+}$ wird zugesetzt (kein zusätzlicher Trigger), weshalb nur die Plasmamatrix (Plasma selbst und die Wand des Reaktionsgefäßes) die Thrombingenerierung auslöst.

Bei den Globaltesten der ,,alten“ Gerinnung PT und APTT bedingt durch unphysiologisch starke Aktivierung entstehen Thrombinaktivitäten von ca. $1-10 \mathrm{IE} / \mathrm{mL}$ im Normalplasma 
Thrombinaktivität in Plasma, Abb. 1 Intrinsic (altered blood matrix) coagulation. Eine unphysiologische MikroUmgebung faltet F12 oder Präkallikrein in F12a oder Kallikrein, die intrinsische Tenase (F8a-F9a-Ca-PL) mit F9a als dem Enzym wird generiert. F10a aktiviert Prothrombin zu Thrombin (F2a), ca. $10 \%$ des in vivo entstehenden $\mathrm{F} 2 \mathrm{a}$ wird inhibiert and transportiert durch $\alpha 2$-Makroglobulin wo es gemessen werden kann als systemisch zirkulierende amidolytische Thrombin Aktivität, ein guter Biomarker der systemischen GerinnungsAktivierung. Gezeichnet von T. Stief und C. Müller

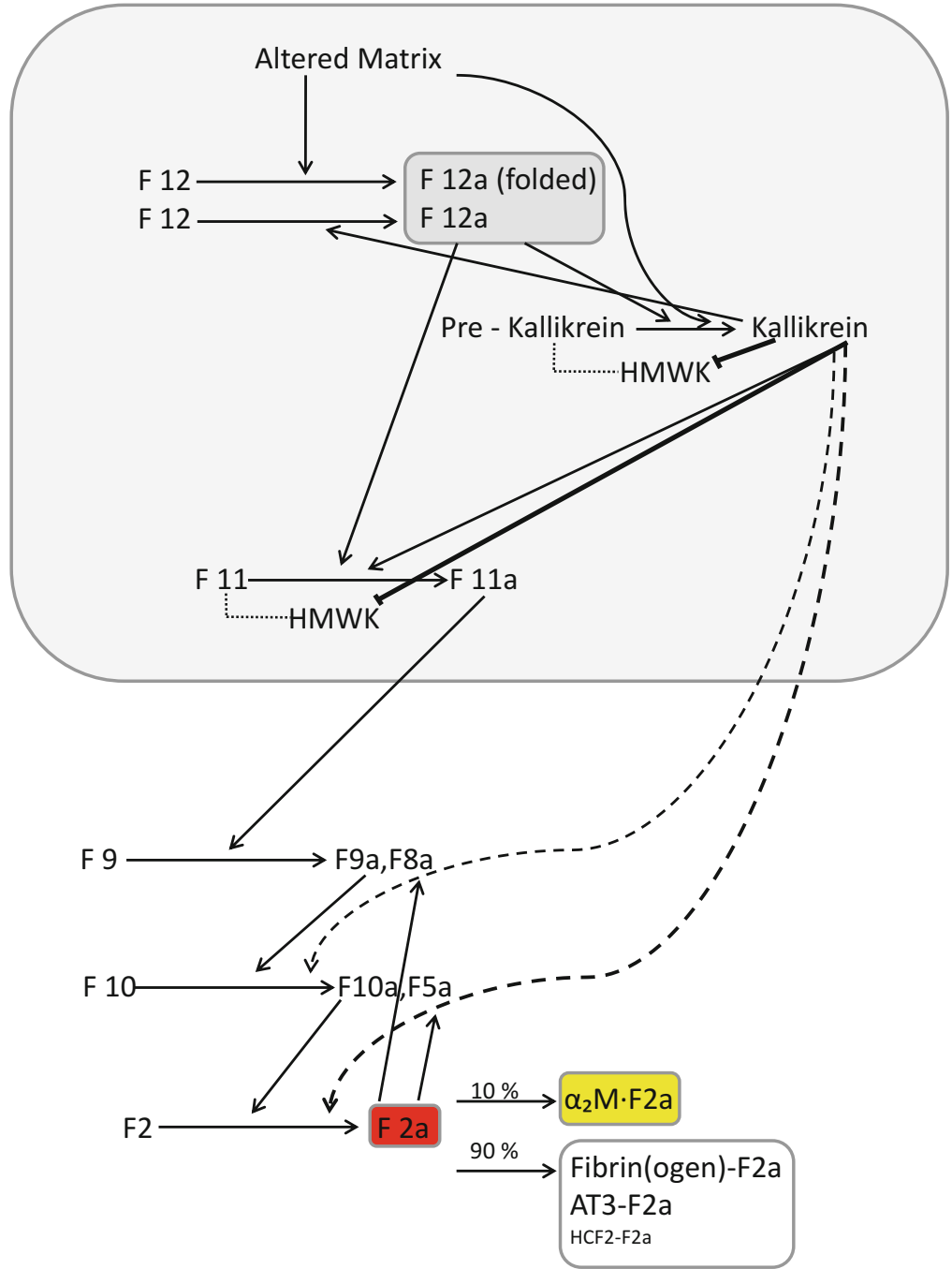

binnen 10-30 s $\left(37{ }^{\circ} \mathrm{C}\right)$. Dagegen entstehen im ,neuen“ RECA nach ca. $20 \min \left(37^{\circ} \mathrm{C}\right)$ weniger als $0,1 \mathrm{IE} / \mathrm{mL}$ Thrombin in Normalplasma. Die Hauptinkubationszeit im EXCA beträgt ca. $1 \mathrm{~min}\left(37^{\circ} \mathrm{C}\right)$, die Hauptinkubationszeit im INCA ist ca. 3-4 $\min \left(37^{\circ} \mathrm{C}\right)$. Die neuen Thrombingenerierungsteste sollten möglichst mit einer höheren Inkubationszeit kontrolliert werden, d. h. beispielsweise EXCA bei 2 min, INCA bei 5 min und RECA bei $25 \mathrm{~min}$, um zu kontrollieren, dass am ersten Messzeitpunkt (Hauptwert) keine signifikanten Mengen an quervernetztem Fibrin (Antithrombin-1) entstanden sind, die das generierte Thrombin inhibiert haben. Valide ist: Hauptwert dividiert durch Kontrollwert = kleiner 1. Alternativ kann auch die basale Plasmatrübung gemessen werden, die bei Abwesenheit von entstandenem Fibrin nicht signifikant ansteigt.

EXCA und INCA messen insbesondere die therapeutisch oder auch pathologisch erniedrigte plasmatische Thrombingenerierung; 10-20\% der normalen EXCA-Aktivität ist der Zielwert für die therapeutische plasmatische Antikoagulation, $20-40 \%$ der normalen EXCA-Aktivität ist der Zielwert für die prophylaktische plasmatische Antikoagulation. RECA misst insbesondere die prothrombotische Kapazität von Plasma.

\section{Literatur}

Stief TW (2006) Specific determination of plasmatic thrombin activity. Clin Appl Thromb Hemost 12:324-329

Stief TW (2008) The laboratory diagnosis of the pre-phase of pathologic disseminated intravascular coagulation. Hemost Lab 1:2-20

Stief TW (2010) Circulating thrombin activity in unselected routine plasmas. Hemost Lab 3:7-16

Stief TW (2012) Thrombin: function and pathophysiology. Nova Science Publishers, New York

Thrombin-Antithrombin-Komplex

T. Stief

Synonym(e) TAT 
Englischer Begriff thrombin-antithrombin complex; TAT

Definition $>$ Thrombin bildet mit $>$ Antithrombin-3 (AT-3) einen 1:1-Komplex, sowohl Thrombin als auch AT-3 verlieren dabei ihre Aktivität.

Beschreibung Ähnlich wie die Messung des Prothrombinfragments $1+2$ soll mit der Bestimmung des TAT-Komplexes eine gesteigerte Thrombinbildung nachgewiesen werden. Hepatozyten entziehen den Komplex der Zirkulation und zerstören ihn. Die Halbwertszeit beträgt wenige Minuten. Der Serinprotease-Serpin-Komplex hat noch hormonale Wirkung auf die Zellaktivität von beispielsweise Hepatozyten oder neutrophilen Granulozyten. Erhöhte TAT-Komplexe werden gefunden bei Thrombosen, Polytrauma, Sepsis, Präeklampsie oder fibrinolytischer Therapie. Problematisch ist die Abhängigkeit der TAT-Konzentration von der Hepatozytenfunktion oder von der Therapie mit sulphatierten Glykosaminoglykanen (SGAG), was die TAT-Konzentration „sprunghaft“ ansteigen lässt, ohne dass eine gesteigerte Gerinnungsaktiverung vorliegt. Der neue Biomarker systemische amidolytische Thrombinaktivität ist dem Parameter TAT bei Diagnose und Staging einer Hämostaseaktivierung klar überlegen.

Zum TAT-Nachweis werden Enzymimmunoassays nach dem Sandwich-Prinzip eingesetzt, wobei zunächst der TATKomplex durch einen Thrombin-spezifischen Antikörper fixiert wird. In einer zweiten Reaktion bindet ein mit Peroxidase konjugierter Antikörper, der gegen AT-3 gerichtet ist, an das fixierte TAT. Es finden sich mittlere TAT-Konzentrationen von $1,5 \mu \mathrm{g} / \mathrm{L}(1,0-4,1 \mu \mathrm{g} / \mathrm{L})$ im Normalplasma (idealerweise EDTA-Plasma oder Arginin-stabilisiertes EDTA-Plasma).

\section{Literatur}

Stief TW (2008) Arginine conserves the hemostasis activation state of plasma even against freezing/thawing. Int J Med Biol Front 14:275-288

Stief TW, Kurz J (2012) The natural anti-inflammatory agent PAI-2 suppresses the oxidative state of human blood. Hemost Lab 5:145-159

Stief TW, Ijagha O, Weiste B, Herzum I, Renz H, Max M (2007) Analysis of hemostasis alterations in sepsis. Blood Coagul Fibrinolysis 18:179-186

Stief TW, Ulbricht K, Max M (2009) Circulating thrombin activity in sepsis. Hemost Lab 2:293-306

\section{Thrombininhibitoren}

T. Stief

Synonym(e) Direkte Thrombininhibitoren; DTI; Neue direkte orale Antikoagulanzien (NOAK, DOAK)
Englischer Begriff thrombin inhibitors

Definition Thrombin ist das zentrale Enzym der Gerinnung. Thrombin besitzt wie alle Serinproteasen ein katalytisches Zentrum (His $\cdots$ Asp $\cdots$ Ser) und wichtige Bindungsregionen für Fibrinogen (Exosite 1) und Heparin (Exosite 2). Direkte Thrombininhibitoren hemmen Thrombin durch Bindung an die Exosite 1 oder an das katalytische Zentrum.

Beschreibung Die Enzymaktivität von Thrombin wird durch Bindung von Kofaktoren und/oder Substraten an Exosites an der Oberfläche der Protease gesteuert. So beschleunigt Thrombomodulin (TM) die Aktivierung von $>$ Protein $\mathrm{C}$ durch Thrombin um das 1500-Fache. DTI wie Hirudin (oder die rekombinanten Analoga Bivalirudin und Lepirudin) binden nicht nur an die katalytische Region von Thrombin, sondern auch an die Fibrinogenbindungsstelle (Exosite 1).

Niedermolekulare Inhibitoren wie Argatroban (ein synthetisches L-Argininderivat; parenteral zu verabreichen) oder orale direkte Thrombininhibitoren, wie Dabigatran (dem $\alpha$-NAPAP [N-alpha-(2-Naphthylsulfonylglycyl)-4-Amidinophenylalaninpiperidid] strukturverwandt), hemmen das katalytische Zentrum von Thrombin. Die Prodrug Dabigatranetexilat wurde durch Einführung hydrophober Seitenketten oral absorbierbar. Ximelagatran, der erste orale DTI, wurde wegen seiner Hepatotoxizität zurückgezogen. Dabigatran gehört wie die neuen oralen F10aInhibitoren Rivaroxaban, Apixaban und Edoxaban zur Klasse der neuen direkten oralen Antikogulanzien (NOAK, DOAK). Zunächst wurde gehofft, dass die NOAK ohne das übliche Monitoring wie bei den Cumarinen auskommen könnten. Es zeigte sich jedoch, dass die Gefahr der Überdosierung mit schweren Blutungen (z. B. zerebralen Blutungen) besteht. Außerdem können die Seitenketten der NOAK intrinsisch Thrombin generieren. Es besteht klinischer Bedarf, alle plasmatischen Antikoagulanzien mit demselben F10a/F2a - Generierungstest zu monitoren. Der Bereich 10-20 \% der normalen Thrombingenerierung bei EXCA (,extrinsic coagulation activity assay“) oder INCA (,intrinsic coagulation activity assay") dürfte der therapeutische Bereich sein, $20-40 \%$ der prophylaktische Bereich; Werte unter $10 \%$ bedeuten Blutungsrisiko, Werte über $40 \%$ bedeuten Thromboserisiko.

\section{Literatur}

Stief TW (2007) The efficiency of anti-factor Xa and anti-factor IIa anticoagulants. Blood Coagul Fibrinolysis 18:265-269

Stief TW (2012) Determination of the anti-F10a or anti-F2a generation action of rivaroxaban or dabigatran. Blood Coagul Fibrinolysis 23:619-621

Stief TW, Ajib S, Renz H (2008) The sensibility of individual plasma to heparins. Hemost Lab 1:143-157 


\section{Thrombinzeit}

T. Stief und P. Kiefer

Synonym(e) Plasma-Thrombinzeit; TZ

Englischer Begriff thrombin time

Definition Bestimmung der Gerinnungszeit des letzten Schritts der Gerinnungskaskade, der Aktivierung von - Fibrinogen zu Fibrinmonomeren. Die Thrombinzeit ist Heparin-sensitiv und verlängert bei niedrigen Fibrinogenkonzentrationen, Dysfibrinogenämien und hohen Konzentrationen an $>$ Fibrin(ogen)abbauprodukten. Das Prinzip der Thrombin-/Reptilasezeit ist nachfolgend dargestellt.

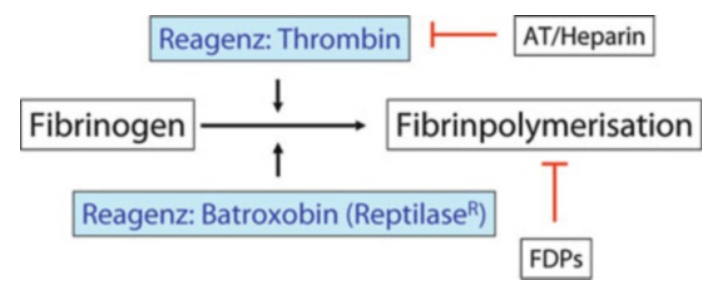

Physikalisch-chemisches Prinzip Humanes oder Rinderthrombin wird dem Patientenplasma zugesetzt und die Bildung eines Fibringerinnsels in Sekunden gemessen. $>$ Thrombin spaltet die Fibrinopeptide A und B von $>$ Fibrinogen ab. Die Fibrinmonomere aggregieren spontan zu einem Gerinnsel aus Fibrin. Die Fibrinbildung kann mechanisch oder optisch erfasst werden.

Normbereich $14-20 \mathrm{~s}$.

Einsatzgebiet Zusammen mit der Reptilasezeit (unabhängig vom Heparin) zur Diagnose einer Dysfibrinogenämie, Monitoring der Heparintherapie.

\section{Untersuchungsmaterial Citratplasma.}

Instrumentierung Großgeräte, Vollautomaten, Einzelbestimmungen.

Fehlermöglichkeit Antikörper gegen Thrombin, wenn z. B. Patienten lokal mit Rinderthrombin behandelt wurden, können die TZ verlängern. Selten wird von Heparin-ähnlichen Antikoagulanzien bei malignen Erkrankungen berichtet, die die TZ, nicht jedoch die Reptilasezeit verlängern.

Praktikabilität-Automatisierung-Kosten Applikationsprotokolle für alle gängigen Gerinnungsautomaten.
Bewertung - Methodenhierarchie Gruppentest.

\section{Literatur}

Barthels M, von Depka M (2003) Das Gerinnungskompendium. Georg Thieme Verlag, Stuttgart/New York

\section{$\beta$-Thromboglobulin}

> Plättchen-spezifische (Release-)Faktoren

\section{Thrombokrit}

A. M. Gressner und O. A. Gressner

Synonym(e) PCT; Plättchenkrit

Englischer Begriff thrombocrit

Definition Prozentualer Anteil des Volumens aller Thrombozyten am gesamten Blutvolumen.

Beschreibung Der Thromobokrit (PCT) bezeichnet den Volumenanteil (\%) aller $>$ Thrombozyten am Vollblutvolumen. Er wird aus den Messgrößen PLT (= Thrombozytenzahl im EDTA-Vollblut) und mittleres Thrombozytenvolumen (MPV, Referenzbereich 9,0-13,0 fL) nach folgender Formel berechnet:

$$
\mathrm{PCT}=(\mathrm{PLT} \times \mathrm{MPV}) \times 10^{-1}
$$

und beträgt $0,17-0,35 \%$ (altersabhängig, geringe Geschlechtsdifferenzen). Abweichungen ergeben sich bei Größen- oder Zellzahlveränderungen der Thrombozyten (Thrombozytose/ Thrombozythämie, Thrombozytopenie) und starken Veränderungen des Verteilungsvolumens (Hämokonzentration, -dilution; \ Hämatokrit). Der klinische Stellenwert des Thrombokrits ist beschränkt.

\section{Thrombomodulin}

T. Stief und P. Kiefer

Synonym(e) TM 
Englischer Begriff thrombomodulin

Definition Thrombomodulin (TM) ist ein endotheliales, transmembranes Bindungsprotein für $>$ Thrombin. TM-gebundenes Thrombin interagiert nicht mehr mit Fibrinogen, stattdessen aktiviert es Protein C.

Beschreibung TM ist ein Typ-1-transmembranes Glykoprotein, das nach Abspaltung des Signalpeptids eine Länge von 559 Aminosäuren hat (ca. $58 \mathrm{kDa}$ ). TM ist ein spezifisches endotheliales Protein und bildet einen 1:1-Komplex mit Thrombin. Es ist ein wesentlicher Regulator der Aktivierung von Protein $\mathrm{C}$. TM bindet Thrombin mit einer $\mathrm{Kd}$ von ca. 1-10 nmol/L (in Abhängigkeit von verfügbarem Chondroitinsulfat). Wegen der hohen Konzentration auf den Endothelzellen der Kapillaren sequestriert TM Thrombin aus den kleinen Gefäßen und antagonisiert so die prokoagulatorische Aktivität von Thrombin. Durch die Protein-C-Aktivierung fördert der TM-Thrombin-Komplex die Hemmung der Gerinnung.

\section{Literatur}

Esmon CT (2003) The protein C pathway. Chest 124:26S-32S

\section{Thromboplastin}

$>$ Tissue Factor

\section{Thromboplastine, partielle}

- Thromboplastinzeit, partielle aktivierte

\section{Thromboplastinzeit}

T. Stief und P. Kiefer

Synonym(e) TPZ; Quick-Test

Englischer Begriff thromboplastin time; prothrombin time (PT); tissue factor (TF)-induced coagulation time

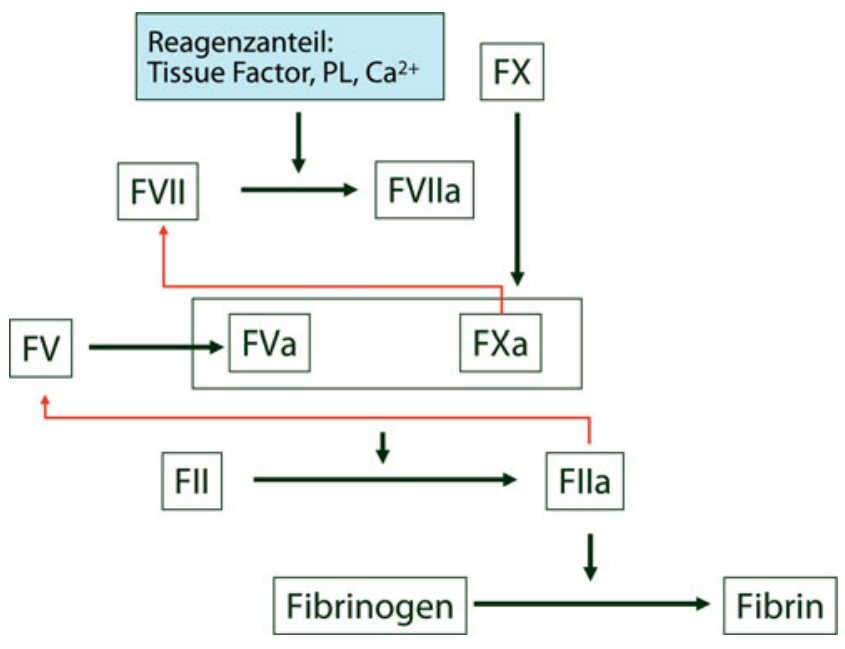

Definition Der Thromboplastinzeit-Test misst die Gerinnungszeit vom Zeitpunkt des Zusatzes des Reagenzes, welches Faktor VII (F7) aktiviert bis zur Bildung eines Gerinnsels. Damit bestimmt dieser Test das ExtrinsicSystem und die gemeinsame Endstrecke der Gerinnungskaskade. Das Prinzip der Thomboplastinzeit ist oben dargestellt (verglichen mit TF ist F10a allerdings ein schwacher F7-Aktivator).

Physikalisch-chemisches Prinzip Thromboplastin (TF), Phospholipide und Calcium-Ionen werden dem Patientenplasma zugesetzt und die Zeit bis zur Bildung eines Fibringerinnsels gemessen. Thromboplastin kann aus Gewebsextrakten verschiedener Organe (Hirn, Lunge, Plazenta) gewonnen werden, dem Extrakt kann Calciumchlorid zugesetzt sein (,plain thromboplastin“), oder es kann zusätzlich mit Gerinnungsfaktor I und V angereichert sein (,combined thromboplastin“). Heute werden immer mehr Thromboplastine mit rekombinantem Tissue Factor (TF) und mit einem chemisch definierten Phospholipidanteil eingesetzt. Die verschiedenen Thromboplastine weisen eine unterschiedliche Empfindlichkeit für Faktorenmangel (insbesondere F7, F2) auf. TF aktiviert F7 zu F7a. Die gemessene Gerinnungszeit verhält sich invers zu der Aktivität der Faktoren II, V, VII, $\mathrm{X}(2,5,7,10)$ und nur bedingt $\mathrm{zu}$ der Fibrinogenkonzentration. Die heutigen Tests weisen eine hohe Präzision auf (Variationskoeffizienten 1-3\%). Das Ergebnis des TPZ-Tests kann in verschiedenen Einheiten erfasst werden, und die Normwerte sind abhängig von dem benutzten Gerät und dem eingesetzten Reagenz:

- Der Quick-Wert ( $>$ Quick, Armand James) wird in Relativprozent (\%) der Gerinnungsaktivität Gerinnungsgesunder angegeben und lässt sich der Aktivität der einzelnen Gerinnungsfaktoren leichter zuordnen. Der Referenzbereich liegt zwischen 70-130 \%.

- Die TPZ (PT) wird in Sekunden angegeben. 
- Prothrombin-Time-Ratio (PR) ist der Quotient gebildet aus der TPZ des Patientenplasma und der eines Normalplasmapools.

- International Normalized Ratio (INR) korrigiert die PR durch den International Sensitivity Index (ISI), ein geräteabhängiger, chargenspezifischer Korrekturfaktor des jeweiligen Thromboplastins, der im Vergleich zu einer WHO-Referenzpräparation ermittelt wurde. Der Referenzbereich liegt zwischen 1,17 und 0,84 .

Einsatzgebiet Überwachung der oralen Antikoagulation mit Cumarinen, Gruppentest der Gerinnungsaktivität zur Erfassung von Blutungsneigungen, zur Beurteilung der Lebersyntheseleistung, zur Diagnose bei „consumption-coagulopathy“.

Untersuchungsmaterial Citratplasma, Citratblut, Kapillarvollblut (In Point-of-care-TPZ-Testmethoden wird die Bestimmung mit einem einzigen Tropfen Kapillarvollblut durchgeführt; $>$ Patientennahe Sofortdiagnostik).

Instrumentierung Der Quick-Test lässt sich auf verschiedene Geräte (Großgeräte und Vollautomaten) adaptieren und mit verschiedenen Messprinzipien durchführen: mechanische Messung mit der Häkchenmethode oder Kugelmethode in einem Koagulometer, durch Trübungsmessung, chromogene Messung oder Kombination einer optischen mit einer mechanischen Messung zur Erfassung der Fibrinbildung.

Spezifität Bestimmt im Wesentlichen die Integrität des Extrinsic-Systems und die Aktivität der Faktoren 1, II, V und FX der gemeinsamen Endstrecke der Gerinnungsaktivierung. Zusatz von Rinderfibrinogen und -FV erhöht die Spezifität für die Aktivität der Vitamin-K-abhängigen Faktoren II, VII und X (,Hepato-Quick“).

Sensitivität In Abhängigkeit vom gewählten Thromboplastin muss bei einem singulären Faktormangel die Aktivität des Faktors in der Regel unter $45 \%$ fallen, bevor er in der TPZ erfasst wird. Bedingt durch extrem starke Aktivierung der Probe durch TF ist die TPZ ist ein relativ grober Test, viele Patienten mit normaler TPZ (oder APTT) haben Störungen im extrinsischen (oder intrinsischen) Gerinnungs-System, die nur mit einem neuen F10a/Thrombin-Generierungstests wie dem EXCA (,extrinsic coagulation activity assay“) (oder dem INCA = ,intrinsic coagulation activity assay“ bzw. dem RE$\mathrm{CA}=$,recalcified coagulation activity assay“) diagnostiziert werden können.

Fehlermöglichkeit Höhere Plasmakonzentrationen an nicht fraktioniertem Heparin ( $>1 \mathrm{IE} / \mathrm{ml}$ ) können gegebenenfalls den Test beeinflussen, da dann das Polyanion Heparin nicht durch das Polykation Polybren im TF-Reagenz neutralisiert wird. Lupus-Antikoagulans kann die TPZ verlängern, beson- ders, wenn ein rekombinantes Thromboplastin eingesetzt wird. Die meisten Gewebsextrakte enthalten jedoch einen Überschuss an Phospholipiden, sodass ein Lupus-Antikoagulans nicht zur TPZ-Verlängerung führt.

Praktikabilität - Automatisierung - Kosten Die TPZ kann mit verschiedenen Geräten und mit verschiedenen Messprinzipien durchgeführt werden. Geringe Kosten.

Bewertung - Methodenhierarchie Gruppentest.

\section{Literatur}

Barthels M, Depka M (2003) Gerinnungskompendium. Georg Thieme Verlag, Stuttgart

Stief TW (2011) $20 \%$ EXCA (0.1 IU/ml thrombin) - the ideal anticoagulant target value. Hemostasis. Laboratory 4:275-280

Stief TW (2012) LMWH - action-monitoring for all patients. Acta Paediatr 101:e314. https://doi.org/10.1111/j.1651-2227.2012.02712.x

\section{Thromboplastinzeit, partielle aktivierte}

T. Stief

\section{$\operatorname{Synonym(e)~aPTT~}$}

Englischer Begriff activated partial thromboplastin time; APTT

Definition Die aPTT misst die Gerinnungszeit von Beginn der Aktivierung von $>$ Gerinnungsfaktor XII (F12)/Präkallikrein zu F12a/Kallikrein bis zur Bildung eines Fibringerinnsels. Damit bestimmt der Test das intrinsische System und die gemeinsame Endstrecke der Gerinnungskaskade (vgl. Abb. im Eintrag $>$ Thrombinaktivität in Plasma).

Physikalisch-chemisches Prinzip Das PTT-Reagenz enthält nur die Phospholipide (PL), daher der Name ,partielles Thromboplastin“, da der \ Tissue Factor (wie im PT-Reagenz) nicht enthalten ist. Inkubation von Plasma mit einem Oberflächenaktivator (z. B. Kaolin oder Ellagsäure) aktiviert das Kontaktsystem, nach Rekalzifizierung wird die gesamte Gerinnungskaskade ausgelöst. Die Zeit bis zur Bildung eines Fibringerinnsels wird gemessen. Die aPTT erfasst deutlich sensitiver einen Gerinnungsfaktorenmangel des intrinsischen Systems $(8,9,11,12$, $>$ Präkallikrein und $\triangleright$ High-MolecularWeight Kininogen) als einen Faktorenmangel der gemeinsamen Endstrecke der Gerinnung (Fibrinogen, 2, 5, 10). 
Das Ergebnis des aPTT-Tests wird in Sekunden angegeben; selten als Ratio bezogen auf die Gerinnungszeit gemessen an einem Normalplasmapool.

Ein Faktorenmangel oder pathologische Antikörper (Lupus-Antikoagulans, Antikörper gegen Gerinnungsfaktoren) können zu einer Verlängerung der aPTT führen. Beim Plasmamischtest (Plasmatauschversuch; nach Ausschluss von Antikoagulanzien) wird die Patientenprobe 1+1 mit Normalplasma gemischt und die aPTT direkt gemessen (oder nach 60-minütiger Inkubation zur Diagnose progressiv wirksamer Inhibitoren). Der Test ist positiv, wenn sich die Gerinnungszeit im 1+1-Ansatz um $>5 \mathrm{~s}$ verlängert.

Einsatzgebiet Als Gruppentest zur Erfassung von Gerinnungsstörungen, insbesondere der Hämophilie A und B. Zur Überwachung von unfraktioniertem Heparin. Als Screeningmethode zur Erfassung von Inhibitoren.

\section{Untersuchungsmaterial Citratplasma.}

Instrumentierung Die aPTT lässt sich auf verschiedene Großgeräte und Vollautomaten adaptieren und mit verschiedenen Messprinzipen durchführen: mechanische Messung mit der Häkchenmethode oder Kugelmethode in einem Koagulometer, durch Trübungsmessung oder Kombination einer optischen mit einer mechanischen Messung zur Erfassung der Fibrinbildung.

Referenzbereich Reagenzabhängig zwischen $25-40 \mathrm{~s}$ für die meisten automatisierten Methoden.

Spezifität Bestimmt im Wesentlichen die Aktivitäten des intrinsischen Systems.

Sensitivität Die unterschiedlichen aPTT-Reagenzien weisen erhebliche Unterschiede in der Empfindlichkeit für Faktormangel auf. In Abhängigkeit vom Faktor muss die Faktoraktivität unter 15-45 \% liegen, bevor die aPTT verlängert ist. Ebenso reagieren die einzelnen aPTT-Reagenzien unterschiedlich auf die Anwesenheit eines Lupus-Antikoagulans. Bedingt durch extrem starke intrinsische Aktivierung der Probe ist die aPTT ein relativ grober Test, viele Patienten mit normaler aPTT haben Störungen im intrinsischen System, die nur durch Durchführung eines neuen Thrombingenerierungstests wie dem INCA (,intrinsic coagulation activity assay“) oder dem RECA (,recalcified coagulation activity

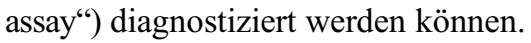

Fehlermöglichkeit Die aPTT-Reagenzien sind nicht standardisiert, sodass es erhebliche Abweichungen in ihrer Faktor- und Inhibitorsensitivität gibt.
Praktikabilität - Automatisierung - Kosten Die aPTT kann mit verschiedenen Geräten und mit verschiedenen Messprinzipien durchgeführt werden. Geringe Kosten.

Bewertung - Methodenhierarchie Gruppentest, Routinetest.

\section{Literatur}

Barthels M (2004) Gerinnungsdiagnostik Hämostaseologie 24:123-135 Barthels M, Depka M (2002) Gerinnungskompendium. Georg ThiemeVerlag, Stuttgart

Stief TW (2009) Ellagic acid as a stable INCA-trigger. Hemost Lab 2:23-32

\section{Thrombopoetin}

H. Baum

$\operatorname{Synonym}(e)$ TPO

Englischer Begriff thrombopoietin

Definition Glykoprotein, das die Thrombopoese stimuliert sowie einen Einfluss auf die Selbsterneuerung der hämatopoetischen Stammzelle hat.

Beschreibung Thrombopoetin ist ein Glykoprotein, das in Leber, Nieren und Knochenmark-Stromazellen als 353 Aminosäuren langes Präkursorprotein synthetisiert wird und die Thrombopoese stimuliert. Zusätzlich ist das TPO ein wichtiger Faktor in der Selbsterneuerung und Expansion der hämatopoetischen Stammzelle. Es bindet dabei über einen spezifischen Rezeptor (Mpl). Eine Thrombozytopenie ist der Stimulus für die Synthese von TPO. Aber auch bei entzündlichen Geschehen und hämatologischen Erkrankungen mit einer Thrombozytose sind erhöhte Konzentrationen von TPO nachweisbar.

\section{Literatur}

Kausshansky K (2003) Thrombopoietin: a tool for the understanding thrombopoiesis. J Thromb Haemost 1:1587-1592

\section{Thrombospondin-5}

$\checkmark$ COMP 


\section{Thrombospondine}

H.-D. Haubeck

Synonym(e) TSP

Englischer Begriff thrombospondins (released in response to activation of platelets by thrombin)

Definition Thrombospondine bilden eine Familie von Glykoproteinen der Extrazellulärmatrix, die an zahlreichen wichtigen Prozessen, wie der Wundheilung und Angiogenese, beteiligt sind.

Beschreibung Thrombospondine (TSP) bilden eine Familie von sezernierten > Glykoproteine der Extrazellulärmatrix (matrizelluläre Proteine) und besitzen einen modularen Aufbau. TSP1 und TSP2 bilden eine Unterfamilie und lagern sich zu Trimeren zusammen (Molmasse von ca. $145 \mathrm{kDa} / \mathrm{Kette}$ ). Im Gegensatz hierzu bilden die Mitglieder einer zweiten Unterfamilie (TSP3-5) Pentamere aus kleineren Ketten (ca. $100 \mathrm{kDa}$ ). Die Funktion der Thrombospondine wurde bisher erst teilweise aufgeklärt.

Thrombospondin (TSP-1) wurde zuerst in den $\alpha$-Granula von Thrombozyten identifiziert und ist nach der Freisetzung im Rahmen der Thrombozytenaktivierung an der Thrombozytenaggregation beteiligt. TSP, die außer von Thrombozyten auch von zahlreichen weiteren Zelltypen produziert werden, zeigen vielfältige Interaktionen mit verschiedenen Plasmaproteinen (u. a. Fibrinogen, Plasminogen), Zelloberflächenproteinen, Komponenten der Extrazellulärmatrix (u. a. $\checkmark$ Kollagene, L Laminine, $>$ Heparansulfat-Proteoglykane und $\triangleright$ Fibronectin), aber auch $>$ Zytokine und Wachstumsfaktoren (z. B. TGF- $\beta$ ). Im Gegensatz zu Fibronectin und Laminin, die die Zelladhäsion fördern, besitzen TSP z. T. auch antiadhäsive Eigenschaften. Darüber hinaus wirken TSP1 und TSP2 als starke Chemokine und sind bei Verletzungen u. a. durch die Rekrutierung von $>$ Makrophagen, Fibroblasten etc. an der Wundheilung beteiligt. Von Bedeutung ist hierbei auch die Beteiligung von TSP1 an der Konversion des latenten TGF- $\beta 1$ in die aktive Form. TSP 1 und TSP 2 sind aber nicht nur an der Wundheilung beteiligt, sondern auch an der Kontrolle von Tumorwachstum und Metastasierung. Hierbei dürfte vor allem die antiangiogene Wirkung von TSP1 und TSP2 u. a. über die Hemmung der Proliferation glatter Muskelzellen, aber auch über die Inhibition der Wirkung der Wachstumsfaktoren bFGF (,,basic fibroblast growth factor") und VEGF (,vascular endothelial cell growth factor") eine Rolle spielen. Darüber hinaus weisen eine Reihe von Publikationen auch auf die Bedeutung von Punktmuta- tionen bzw. Polymorphismen in den TSP-Genen für verschiedene Krankheiten (z. B. bei bestimmten Formen des Myokardinfarkts) hin.

\section{Literatur}

Adams JC, Lawler J (2004) The thrombospondins. Int J Biochem Cell Biol 36:961-968

Bornstein P (2001) Thrombospondins as matricellular modulators of cell function. J Clin Invest 107:929-934

\section{Thromboxan}

A. M. Gressner und O. A. Gressner

Synonym(e) Thromboxan A2; TXA2

Englischer Begriff thromboxane

Definition Thromboxan (TXA2) ist ein Gewebshormon, das in den Thrombozyten aus den Prostaglandinen G2 und $\mathrm{H} 2$ gebildet wird und an der Regulation der Blutzirkulation, der Nierendurchblutung und der Gerinnung beteiligt ist.

Beschreibung TXA2 gehört $\mathrm{zu}$ den Eicosanoiden. Es wird aus dem Prostaglandin G2 sowie H2 unter Vermittlung des Enzyms Thromboxan-Synthase gebildet. Biosynthese und Metabolismus sind in der Abbildung im Eintrag Prostaglandine zusammengefasst. Die Zyklooxygenase-1 (COX 1) hat eine dominierende Rolle bei der Synthese des Thromboxan A2 und der stabilen inaktiven Form Thromboxan B2. TXA2 hat eine Halbwertszeit von 30 Sekunden.

Es bewirkt im Herz-Kreislauf-System eine Vasokonstriktion und stimuliert die Thrombozytenaggregation. Diurese, Natriurese und Nierendurchblutung werden gehemmt.

Acetylsalicylsäure (ASS, Aspirin) hemmt die Thromboxansynthese, und dadurch werden die Thrombozyten inaktiviert. Hierin liegt die außergewöhnliche Bedeutung der Acetylsalicylsäure für die Prophylaxe des Herzinfarkts und thromboembolischer Erkrankungen.

Der Gegenspieler des Thromboxans ist das Prostazyklin ( $\triangleright$ Prostaglandine).

Die Thromboxanbildung der Thrombozyten wird im Rahmen eines Thrombozytenfunktionstests durch die Aggregationsprüfung nach Zugabe von Arachidonsäure (Eicosa- 
tetraensäure) erfasst ( Thrombozytenaggregation und -aktivierung). Daneben kann Thromboxan A2 auch direkt bestimmt werden.

\section{Literatur}

Yagami T, Koma H, Yamamoto Y (2016) Pathophysiological roles of cyclooxygenases and postaglandines in the central nervous system. Mol Neurobiol 53(7):4754-4771

\section{Thromboxan A2}

$>$ Thromboxan

\section{Thrombozyten}

H. Baum

Synonym(e) Blutplättchen

Englischer Begriff thrombocytes; platelets

Definition Kernlose, vom Megakaryozyten des Knochenmarks abstammende Zellelemente des peripheren Blutes mit kardinalen Funktionen in der primären Hämostase (s. Abbildung, Pfeile; 1000×, May-Giemsa-Grünwald-Färbung):

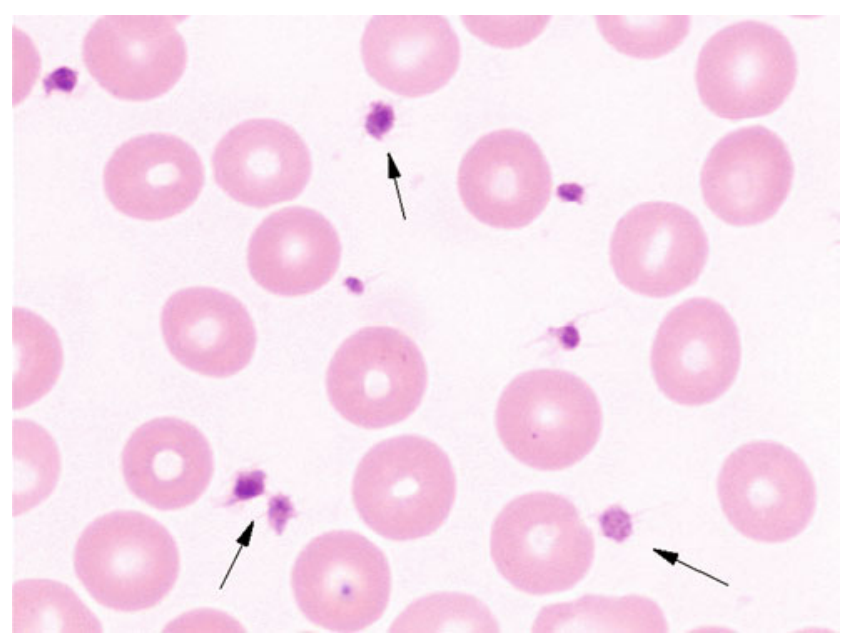

Synthese - Verteilung - Abbau - Elimination Thrombozyten entstehen im Knochenmark durch Zytoplasmaabschnürungen der $>$ Megakaryozyten und direkter Freigabe in die Sinus des Knochenmarks. Die Thrombozyten sind normalerweise nur im Blut nachweisbar und werden von der Milz eliminiert.
Halbwertszeit 10 Tage.

Funktion - Pathophysiologie Die Thrombozyten sind die Effektorzellen der Megakaryopoese. Sie sind entscheidend an der primären Hämostase beteiligt. Nach der Verletzung eines Blutgefäßes lagern sich die Thrombozyten an die freigelegten subendothelialen Strukturen an, bilden Aggregate und induzieren die plasmatische Gerinnung.

Untersuchungsmaterial - Entnahmebedingungen EDTABlut, in speziellen Situationen (z. B. bei EDTA-bedingter Pseudothrombopenie) auch Citrat- oder Heparinblut.

Probenstabilität Bei Raumtemperatur bis zu 24 Stunden.

Präanalytik Bei der Blutentnahme ist darauf zu achten, dass keine Aktivierung der Thrombozyten erfolgt (v. a. schnelle Mischung des Blutes mit dem Antikoagulans, Kontaktzeit mit Fremdoberfläche minimieren).

Präanalytik Thrombozytenzählung.

Konventionelle Einheit $\mu \mathrm{L}$.

Internationale Einheit G/L.

Umrechnungsfaktor zw. konv. u. int. Einheit $1 \mu \mathrm{L}: 1000$ $=1 \mathrm{G} / \mathrm{L}$.

Referenzbereich - Erwachsene 100-300 G/L.

Referenzbereich - Kinder S. Erwachsene.

\section{Indikation}

- Unklare Blutungen

- Ausschluss einer Blutungsneigung

- V. a. Erkrankungen des Knochenmarks

- Bei Zytostatika- und Strahlentherapie

- V. a. peripheren Verbrauch

- V. a. Thrombozytosen

Interpretation Thrombozytosen:

- Primäre Thrombozytosen. Als Ursache liegt ein Defekt der megakaryozytären Progenitorzelle vor. Dies ist assoziiert mit der Polycythaemia vera, essenzielle Thrombozytose, chronisch myeloische Leukämie, primäre Osteomyelofibrose. Die klinische Symptomatik reicht dabei in Abhängigkeit von der Funktionsfähigkeit der Thrombozyten von Blutungen bis zu Thrombosen.

- Sekundäre Thrombozytosen. Ursächlich liegt eine Überproduktion vor bei Stimulation der Megakaryozyten im 
Knochenmark durch einen peripherer Verlust oder eine Freisetzung aus dem Milzpool z. B. bei körperlicher Anstrengung, Stress.

Thrombozytopenien:

- Verminderte Bildung

- Hereditäre Ursachen (selten)

- Erworbene Ursachen, wie z. B. aplastische Anämie, Leukosen, nach Bestrahlung oder Chemotherapie

- Vermehrte Thrombozytenzerstörung und Verbrauch

- Immunthrombozytopenie bei verstärkter Clearance durch Thrombozyten-assoziierte IgG- und Komplementaktivierung (Auto- oder Alloantikörper) oder Medikamenteninduziert

- Erhöhter peripherer Verbrauch bei dissiminierter intravasaler Gerinnung, Sepsis, Schock, intraoperativ und nach Transfusionen

- Heparin-assoziierte Thrombozytopenie (HIT)

Diagnostische Wertigkeit Die Bestimmung der Thrombozyten gehört zu den Basisuntersuchungen der Hämatologie. Sie erlaubt eine orientierende Einteilung in Thrombozytopenie oder Thrombozytose. Allerdings sagt die Thrombozytenzahl nichts über die Funktionsfähigkeit der Thrombozyten aus (z. B. Thrombastenie). Diese muss durch Thrombozytenfunktionsteste nachgewiesen werden.

\section{Literatur}

Thomas L (Hrsg) (1998) Thrombozytenzahl. In: Labor und Diagnose, 5. Aufl. TH Books Verlagsgesellschaft, Frankfurt, S 509-516

\section{Thrombozytenadhäsion}

\section{T. Stief}

Synonym(e) (Blut-)Plättchenadhäsion

Englischer Begriff platelet adhesion

Definition Die im fließenden Blut befindlichen $>$ Thrombozyten müssen für die primäre Hämostase zunächst an einer Gefäßverletzung gestoppt werden, um sich dann anzuheften. Hierzu bindet der Glykoprotein-Ib/V/IX-Komplex der Thrombozytenoberfläche an den $>$ Von-Willebrand-Faktor (VWF) gebunden (und konformationsverändert) am Subendothel der verletzten Gefäßwand.
Beschreibung In der direkten Folge einer Gewebs- oder Gefäßschädigung bilden zirkulierende Blutplättchen eine adhäsive Interaktion mit dem durch den Endothelschaden entstandenen freiliegenden Subendothel. Konformationsveränderter VWF bindet sowohl an das Kollagen des Subendothels als auch an den Glykoprotein(GP)-Ib/V/IX-Komplex der Plättchenoberfläche. Eine hohe Scherrate begünstigt die Interaktion des VWF (A1-Domäne) mit GPIb $\alpha$. Bei niedrigen Scherraten kann eine stabile Adhäsion auch ohne initiale VWF-GPIb $\alpha$ Interaktion erfolgen, wobei dann die Thrombozyten direkt über GPIa-IIa $(\alpha 2 \beta 1)$ an das subendotheliale Kollagen binden. Die Aktivierung der Thrombozyten durch Adhäsion führt zur Aktivierung des GPIIb-IIIa-( $\alpha$ IIb $\beta 3-)$ Komplexes, an den Liganden wie $>$ Fibrinogen oder $>$ Fibrin binden können, wodurch die Thrombozyten sich untereinander binden (aggregieren) und sich über den Endotheldefekt ausbreiten können. Die Aktivierung der Thrombozyten ist gekennzeichnet durch

- den Formwandel des Thrombozyten von der diskoiden („,Rugby-Ball ähnliche“) Form des ruhenden Thrombozyten zum Sphärozyten, der Pseudopodien ausbildet;

- die Aktivierung des Glykoproteinrezeptorkomplexes GPIIbIIIa $(\alpha \operatorname{IIb} \beta 3)$, der dann lösliches Fibrinogen binden kann und die Thrombozyten über eine Fibrinogenbrücke miteinander verbindet;

- die Induktion einer prokoagulatorischen Oberfläche für die plasmatische Gerinnung.

Der aktivierte Thrombozyt setzt seinerseits ADP, Serotonin und Thromboxan A2 frei zur weiteren Aktivierung ruhender Thrombozyten in der Umgebung.

\section{Literatur}

Kehrel BF (2003) Blutplättchen: Biochemie und Physiologie. Hämostaseologie 4:149-158

Ruggeri ZM (2000) Old concepts and new developments in the study of platelet aggregation. J Clin Invest 105:699-701

Stief TW, Feek U, Ramaswamy A, Kretschmer V, Renz H, Fareed J (2001) Singlet Oxygen (1O2) disrupts platelet aggregates. Thrombosis Research 104(5):361-370

\section{Thrombozytenaggregation und} -aktivierung

T. Stief

Synonym(e) Plättchenaggregation und -aktivierung; Thrombozytenfunktionstest 


\section{Englischer Begriff platelet aggregation}

Definition Aggregation ist die Verklumpung von aktivierten Thrombozyten über die Ausbildung von Fibrinogenbrücken, die durch die Bindung von $>$ Fibrinogen an den aktivierten Thrombozyten-Rezeptor GPIIb-IIIa ( $\alpha$ IIb $\beta 3$ ) entstehen.

Beschreibung Die Thrombozytenaggregate bilden sich durch Aktivierung von GPIb-IX-V, insbesondere aber von GPIIa-IIIa $(\alpha \operatorname{Ilb} \beta 3)$. $\alpha \operatorname{Ilb} \beta 3$ bindet nicht nur Fibrinogen, Fibrin ( $\triangleright$ Heparin und Heparinoide), sondern auch VonWillebrand-Faktor (VWF), Fibronektin, Vitronektin und Thrombospondin. Aktivierte Thrombozyten ändern ihre Konformation (,shape change“) von diskoid glatt (,Rugby-Ball“) zu Pseudopodien-ausbildend.

Agonisten wie ADP (Adenosin-5'-Diphosphat) und - Thrombin etc. bewirken ein sogenanntes Inside-out-Signaling oder Integrinaktivierung, die zu einer Konformationsänderung des $\alpha$ IIb $\beta 3$-Heterodimers führen, sodass die Fibrinogenbindungsdomäne exponiert wird und der aktivierte Rezeptor nun auch Fibrinogen binden kann. Inside-out-Signaling kann durch eine Vielzahl von Agonisten, die an ihre Rezeptoren in der Plättchenmembran binden, ausgelöst werden. Weitere Agonisten-Beispiele Adrenalin (Epinephrin), Thromboxan A2, Bindung von Kollagen an GPVI oder GPIa-IIa und die Bindung von VWF an GPIb-V-IX unter hohem Scherstress. Die Serin-Threoninkinase Proteinkinase C (PKC) und die Phosphatidylinosid-3OH-Kinase (PI3K) sind wesentliche Second Messenger in der Aktivierung des $\alpha$ IIb $\beta 3$-Integrins.

Thrombin ist der potenteste Aktivator der Thrombozyten in vivo. Der ,proteinase-activated receptor 1“ (PAR1) ist aufgrund seines Expressionslevels (ca. 2000 Kopien pro Plättchen) und Sensitivität für Thrombin der primäre thrombozytäre Rezeptor für Thrombin. Thrombin spaltet den Rezeptor zwischen den Aminosäureresten Arg41 und Ser42, wodurch ein neuer N-Terminus entsteht, der Ligandenfunktion hat. Ein Peptid aus den ersten 5 Aminosäureresten des neuen N-Terminus (,thrombin receptor activator peptide“ $=$ TRAP) imitiert die gleiche Aktivierung des Rezeptors wie die Spaltung durch Thrombin.

Die Signaltransduktion erfolgt über heterotrimere G-Proteine (Gi). Stimulation von Plättchen mit Thrombin $(<10 \mathrm{IE} / \mathrm{ml})$ invitro bewirkt Phosphoinositol-Hydrolyse durch Phospholipase C (PLC), \ Thromboxan-A2-(TXA - -)Bildung, Erhöhung des freien zytosolischen $\mathrm{Ca}^{2+}$ und Hemmung der Adenylatzyklase, wodurch die Bildung von cAMP unterdrückt wird.

Thrombozyten haben $\alpha 2$-adrenerge Rezeptoren, die die Adenylatzyklase hemmen und die Thrombozytenaggregation verstärken können. Die PLC - Aktivierung ist von der Bildung von $\mathrm{TXA}_{2}$ abhängig und kann durch Aspirin unterdrückt werden.

ADP wird in den dichten Granula („,dense granules“) zusammen mit $>$ Serotonin $(5-\mathrm{HAT})$ und ATP gespeichert.
Bei der Aktivierung der Thrombozyten wird der Inhalt der Speicherpools freigesetzt. ADP bindet an 2 Rezeptortypen: P2X (Kationenkanal-gekoppelt; $\mathrm{Ca}^{2+}$ abhängig) und P2Y (G-Protein-gekoppelt).

Drei verschiedene Rezeptoren können direkt an Kollagen binden: $\alpha 2 \beta 1$ (GPIa-IIa), GPVI und GPIV (CD36). GPVI scheint der wichtigste signaltransduzierende Kollagenrezeptor zu sein. Kollagen aktiviert Thrombozyten über PLC (Phosphoinositol-Hydrolyse), TXA 2 -Bildung und Erhöhung des freien zytosolischen $\mathrm{Ca}^{2+}$. Zyklooxygenase-Inhibitoren verzögern die Antwort der Thrombozyten auf Kollagen.

Nach der Aktivierung der Thrombozyten durch TXA $_{2}$ steigt die zytosolische Konzentration an $\mathrm{Ca}^{2+}$ als Kombination aus Freisetzung von $\mathrm{Ca}^{2+}$ aus dem dichten Tubularsystem (,dense tubular system“) und durch Einstrom durch die Plasmamembran an. Letzterer wird nach Bindung von ADP an den PX2-ADP-Rezeptor (einem ligandengesteuerten Kationenkanal) reguliert. Die Freisetzung von $\mathrm{Ca}^{2+}$ aus dem dichten Tubularsystem hingegen ist von der Aktivierung von Inositol-1,4,5-Triphosphat-Rezeptoren abhängig. Durch die Mobilisierung von freiem $\mathrm{Ca}^{2+}$ wird die Phospholipase A2 aktiviert, die die Freisetzung von Arachidonsäure aus den Phospholipiden der Plättchenmembran (Phosphatidylcholin, Phosphatidylserin, Phosphatidylinositol) katalysiert. Die Zyklooxygenase (COX-1) oxidiert Arachidonsäure zu den Zwischenprodukten Prostaglandin (PG) PGG2 und PGH2. Aus den Zwischenprodukten bildet die Thromboxansynthase Thromboxan A2. Aspirin hemmt COX-1 irreversibel durch Acetylierung eines Serinrestes am C-Terminus. Indomethacin und andere nicht steroidale Antiphlogistika hemmen COX-1 ohne kovalente Modifizierung des Enzyms.

Seit seiner Einführung durch Gustav Born im Jahr 1962 ist die In-vitro-Thrombozytenaggregation ein wichtiger Test zur Quantifizierung von Funktionsstörungen der Thrombozyten. Thrombozyten-angereichertes Plasma (Citratblut zentrifugiert für $15 \mathrm{~min}$ bei $150 \mathrm{~g}$ ) wird in einer Küvette zwischen eine Lichtquelle und eine Photozelle platziert und definierte Mengen an Aggreganzien werden zugesetzt (Born-Test). Wenn die Thrombozyten aggregieren, steigt die Lichtdurchlässigkeit an und wird mit einem angeschlossen Schreiber erfasst. Das Probenmaterial sollte nicht älter als $2 \mathrm{~h}$ sein. Die wichtigsten Aggreganzien sind: ADP, Kollagen, Arachidonsäure, Adrenalin, Thrombin, Ristocetin. Wichtiges Antiaggregans ist „singlet (spin state) molecular oxygen“ (wird von dem Neutrophilenprodukt Taurin-Chloramin generiert).

Die Inaktivierung der Thrombozytenaggregation durch Singulett-Sauerstoff-generierendes Chloramin $\mathrm{T}$ ist in der nachfolgenden Abbildung dargestellt. $400 \mu \mathrm{L}$ Plättchenreiches Plasma (PRP; 15 min Zentrifugation bei $150 \mathrm{~g}$ ) wurden mit $50 \mu \mathrm{l}$ Chloramin $\mathrm{T}(0-2 \mathrm{mM}$ finale Konzentration) für $10 \mathrm{~min}$ bei $37^{\circ} \mathrm{C}$ inkubiert. Dann wurden $50 \mu \mathrm{ADP}(20 \mathrm{mM}$ finale Konzentration) zugesetzt, und die Thrombozytenaggregation nach $3 \mathrm{~min}$ wurde durch einen PAP-4-Analyzer 
(BioData) gemessen (VK $<5 \%$ ). Die ungefähre IC50 (50\% „,inhibitory concentration“) beträgt 0,9 mM Chloramin. AuBer der optischen Erfassung der Thrombozytenaggretation kann diese auch über eine Änderung der Impedanz sogar im Vollblut gemessen werden.

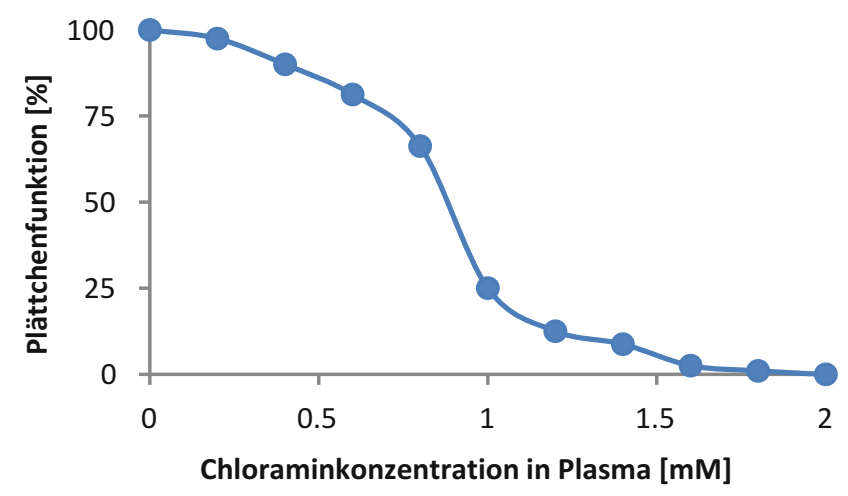

\section{Literatur}

Kehrel BE (2003) Blutplättchen: Biochemie und Physiologie. Hamostaseologie 4:149-158

Polanowska-Grabowska R, Wallace K, Field JJ, Chen L, Marshall MA, Figler R, Gear AR, Linden J (2010) P-selectin-mediated plateletneutrophil aggregate formation activates neutrophils in mouse and human sickle cell disease. Arterioscler Thromb Vasc Biol 30:2392-2399

Stief TW, Feek U, Ramaswamy A, Kretschmer V, Renz H, Fareed J (2001) Singlet oxygen (1O2) disrupts platelet aggregates. Thromb Res 104(5):361-369

\section{Thrombozyten-Antigene}

K. Kleesiek, C. Götting, J. Diekmann, J. Dreier und M. Schmidt

Synonym(e) HPA; Humane Plättchen-Antigene

Englischer Begriff human platelet antigens

Definition Glykoproteinkomplexe auf der Oberfläche von Thrombozyten, gegen die Antikörper nachgewiesen werden können.

Beschreibung Thrombozyten-Antigene werden von polymorphen Bereichen der Glykoproteinkomplexe Ia/IIa, Ib/IX, IIb/IIIa und der Glykoproteine IV und V auf der Thrombozytenmembran gebildet. Bislang sind 15 verschiedene Antigene identifiziert worden, die in unterschiedlicher Frequenz auftreten.

Die meisten Antigene trägt der Glykoprotein-IIb/IIIaKomplex (GPIIb/IIIa), der als Fibrinogenrezeptor eine zentrale Rolle in der Plättchenphysiologie spielt. Mutationen, die die Expression dieses Rezeptors verhindern, führen bei normalen
Thrombozytenzahlen zum Krankheitsbild der Thrombasthenie Glanzmann. Der Glykoprotein-Komplex Ia/IIa hat die Funktion eines Kollagenrezeptors, der Komplex Ib/IX besitzt als Rezeptor für den $>$ Von-Willebrand-Faktor eine wichtige Funktion im Rahmen der primären Hämostase. Glykoprotein $\mathrm{V}$ ist ein Substrat für die Proteinase $\triangleright$ Thrombin. Eine durch Mutationen bedingte fehlende oder verminderte Expression der Glykoproteine Ib/IX und V geht mit einer massiven Störung der primären Hämostase einher. Das resultierende Krankheitsbild wird als Bernard-Soulier-Syndrom bezeichnet. Ein Fehlen des thrombozytären Glykoproteins IV, das vor allem in ostasiatischen Populationen beobachtet wird, ist offenbar nicht mit Defekten der primären Hämostase verbunden.

Die Nomenklatur der Thrombozyten-Antigene ist seit 1990 einheitlich definiert. Dem Begriff HPA wird eine Nummer entsprechend der Reihenfolge der Entdeckung des Antigens zugeteilt. Das häufigere Allel trägt den Zusatz „a“, die seltenere Variante „, 1a und HPA-5b, gegen die am häufigsten Antikörper gebildet werden. Alloantikörper gegen HPA-1a und HPA-5b sind z. B. für die Auslösung der neonatalen und fetalen Alloimmunthrombozytopenie verantwortlich und werden bei Patientinnen mit posttransfusioneller Purpura gefunden. Sie finden sich auch bei einem Teil derjenigen Patienten, die nach einer längerdauernden Transfusionstherapie febrile Transfusionsreaktionen und ein Refraktärverhalten gegenüber Thrombozytentransfusionen aufweisen. In seltenen Fällen verursachen thrombozytäre Alloantikörper Thrombozytopenien nach Transplantationen.

\section{Literatur}

Curtis BR, McFarland JG (2014) Human platelet Antigens-2013. Vox Sang 106:93-102

\section{Thrombozyten-Antikörper}

- Autoantikörper gegen Thrombozyten

\section{Thrombozytenfunktionstest}

- Thrombozytenaggregation und -aktivierung

\section{Thrombozytenverteilungsbreite}

A. M. Gressner und O. A. Gressner

Synonym(e) PDW 
Englischer Begriff platelet distribution width

Definition Prozentuale oder absolute Häufigkeit der Volumenverteilung der Thrombozyten.

Beschreibung Die mit dem Impedanzverfahren (Widerstandsmessverfahren) oder optischer (Laser-)Streulichtmethode gemessene Volumenverteilung der $\$ Thrombozyten im EDTAVollblut (Breite des Histogramms 9,0-17,0 fL) gibt Auskunft über die relative (\%) oder absolute (Umrechnung auf Zahl der Thrombozyten) Häufigkeit der Thrombozyten in den einzelnen Volumenklassen. Abweichungen (Mikro-, Makrothrombozyten) sind durch Links- oder Rechtsverschiebungen im Histogramm sichtbar. Die klinische Bedeutung ist beschränkt.

\section{Thrombozytenzählung}

H. Baum

Englischer Begriff platelet count

Definition Bestimmung der Thrombozytenzahl pro Volumeneinheit.

\section{Physikalisch-chemisches Prinzip}

- Manuelle Kammerzählung z. B. in einer Neubauer- oder Thoma- $\triangleright$ Zählkammer mit einer verdünnten Blutprobe.

- Mechanisierte Zählung.

- Impedanzmessung: Messung der Widerstandsänderung zwischen 2 Elektroden bei Durchtritt der Thrombozyten durch eine Kapillare im elektrischen Feld. Die in einer isotonen Salzlösung suspendierten Thrombozyten führen beim Durchtritt durch die Kapillare zu einer Änderung des Widerstandes, da ihre elektrische Leitfähigkeit im Vergleich zur Salzlösung geringer ist. Die Höhe der Widerstandänderung ist dabei proportional der Größe ( $\triangleright$ Coulter-Prinzip der Zellzählung).

- Streulichtmessung im kontinuierlichen Durchfluss (optisches Dunkelfeldprinzip): Die Thrombozyten passieren einzeln eine Kapillare. Ein durch diese Kapillare geleiteter monochromatischer Lichtstrahl wird an den Thrombozyten gestreut. Das auf einer $>$ Photozelle auftreffende Streulicht ist dabei proportional des Zellgröße, die Anzahl der Impulse proportional der Zellzahl.

Einsatzgebiet Die Thrombozytenzählung erfolgt im Rahmen der Bestimmung des kleinen Blutbildes.

Untersuchungsmaterial EDTA-Blut, Citratblut, Kapillarblut (bei manueller Kammerzählung).

\section{Fehlermöglichkeit}

- EDTA-Blut nicht genügend gemischt.

- Falsche Verdünnung (bei Handzählung).

- Die Handzählung ist mit einem größeren Variationskoeffizient $>10 \%$ behaftet als die mechanisierte Zählung.

- Bei der automatisierten Messung werden die Thrombozyten und die Erythrozyten gleichzeitig in einem Messkanal gemessen. Nur anhand ihrer unterschiedlichen Größen werden die gezählten Ereignisse den Thrombozyten oder Erythrozyten zugeordnet. Dies führt beim Vorhandensein von Thrombozytenaggregaten und Riesenthrombozyten zu einem falsch niedrigen Ergebnis. Kleine Erythrozyten (Mikrozyten) können dagegen bei der Thrombozytenzählung miterfasst werden und führen zu einem falsch hohen Messwert.

Praktikabilität - Automatisierung - Kosten Die Handmethode wird nur noch in besonderen Fällen durchgeführt, in denen die Analysengeräte zur automatischen Zellzählung keine korrekte Zählung durchführen können, wie z. B. bei einer ausgeprägten Mikrozytose der Erythrozyten oder bei Riesenthrombozyten mit gleichzeitiger Thrombozytopenie. Die automatisierten Methoden sind schnell durchzuführen, präzise und gelten als Standardmethode.

Die Kosten der Untersuchung sind insgesamt gering.

Bewertung - Methodenhierarchie (allg.) Die Bestimmung der Thrombozytenzahl gehört zu den Basisuntersuchungen und wird gleichzeitig mit den Parametern des kleinen Blutbilds ( $\triangleright$ Blutbild, kleines) durchgeführt.

\section{Literatur}

Witt I (1995) Hämostase- und Fibrinolysesystem - Primäre Hämostase und Thrombozytenfunktion. In: Greiling H, Gressner AM (Hrsg) Lehrbuch der Klinischen Chemie und Pathobiochemie, 3. Aufl. Schattauer Verlag, Stuttgart, S S 932-S 933

\section{Thrombozytenzählung nach Fonio}

H. Baum

Englischer Begriff Fonio method of counting platelets

Definition Abschätzung der Thrombozytenzahl mithilfe eines Blutausstrichs.

Beschreibung Aus der Anzahl der $\gg$ Thrombozyten im Verhältnis zur Anzahl der Erythrozyten im • Blutausstrich kann 
die Thrombozytenkonzentration abgeschätzt werden. Normalerweise werden etwa 40-60 Thrombozyten auf 1000 Erythrozyten gefunden. Unter Berücksichtigung der absoluten Erythrozytenzahl kann die Thrombozytenzahl näherungsweise berechnet werden:

Thrombozytenzahl $(/ \mu \mathrm{L})=$ Thrombozyten auf 1000 Erythrozyten $\times$ Erythrozytenzahl $(/ \mu \mathrm{L}) / 1000$

Angesichts ihrer sehr großen Streubreite eignet sich diese Methode allerdings nicht für eine genaue Thrombozytenzählung und wird heute routinemäßig nicht mehr eingesetzt.

\section{THSD7A-Autoantikörper}

- Autoantikörper gegen THSD7A (thrombospondin type 1 domain containing 7A)

\section{THT}

> Thrombokrit

\section{Th/To-Antikörper}

> Autoantikörper gegen Zellkerne

\section{3-Thujanon}

$>$ Absinth

\section{Thymidinkinase}

S. Holdenrieder und P. Stieber

\section{$\operatorname{Synonym(e)~TK~}$}

Englischer Begriff thymidine kinase

Definition Die Serum-Thymidinkinase ist ein Enzym, das für die Phosphorylierung von Desoxythymidin zu Desoxythymidin-Monophosphat verantwortlich ist.

Struktur Es sind 3 Isoenzyme der Thymidinkinase in menschlichen Zellen bekannt. Das Isoenzym I kommt in hoher Konzentration in proliferierenden Zellen und Tumorzellen vor, nicht jedoch in ruhenden Zellen.

Synthese - Verteilung - Abbau - Elimination Die Thymidinkinase spielt in der DNA-Synthese eine wichtige Rolle und ist deshalb in schnell proliferierenden Zellen in hohen Konzentrationen vorhanden. Im Serum werden erhöhte Konzentrationen insbesondere bei lymphatischen Erkrankungen wie Non-Hodgkin-Lymphomen einschließlich chronisch lymphatischer Leukämien und dem multiplen Myelom beobachtet.

Funktion - Pathophysiologie Die wesentliche klinische Bedeutung der Thymidinkinase-Bestimmungen liegt in der Verlaufskontrolle während Therapie und der frühzeitigen Rezidiverkennung von malignen lymphatischen Erkrankungen. Hohe bzw. ansteigende Konzentrationen gehen zudem häufig mit einer ungünstigen Prognose einher.

Untersuchungsmaterial - Entnahmebedingungen Serum, Körperflüssigkeiten.

Analytik $>$ Radioimmunoassay.

\section{Konventionelle Einheit U/L.}

Referenzbereich - Erwachsene Empfohlener Referenzbereich im Serum: $<10 \mathrm{U} / \mathrm{L}$ (methodenabhängig).

Indikation Prognose, Therapiekontrolle und Nachsorge bei lymphoiden Neoplasien, insbesondere bei Non-HodgkinLymphomen, Hodgkin-Lymphomen und beim Plasmozytom.

Interpretation Die derzeit erhältlichen Assays für die Bestimmung der Thymidinkinase sind für die Anwendung im Serum ausgetestet.

Die Thymidinkinase ist ein allgemeiner Proliferationsmarker insbesondere bei Erkrankungen mit Einbeziehung des lymphatischen Systems. Erhöhte Werte findet man beim multiplen Myelom, beim Morbus Hodgkin, bei der chronisch lymphatischen Leukämie und bei anderen malignen NonHodgkin-Lymphomen. Außerdem werden erhöhte Konzentrationen bei einigen soliden Tumorerkrankungen und bei Beeinträchtigungen der Nierenfunktion beobachtet. Ein möglicher Einsatz von Thymidinkinase 1 zur Unterstützung der Diagnose und Prognoseabschätzung bei verschiedenen soliden Tumorarten wird diskutiert.

\section{Diagnostische Wertigkeit}

- Multiples Myelom: Prognose, Therapiekontrolle und Nachsorge 
- Non-Hodgkin-Lymphome: Prognose, Therapiekontrolle und Nachsorge

- Hodgkin-Lymphome: Prognose, Therapiekontrolle und Nachsorge

\section{Literatur}

Hallek M, Wanders L, Strohmeyer S et al (1992) Thymidine kinase: a tumor marker with prognostic value for on-Hodgkin's lymphoma and a broad range of potential clinical applications. Ann Hematol 65:1-5

Stieber P, Heinemann V (2008) Sinnvoller Einsatz von Tumormarkern. J Lab Med 32:339-360

Zhou J, He E, Skog S (2013) The proliferation marker thymidine kinase 1 in clinical use. Mol Clin Oncol 1:18-28

\section{Thymol-Trübungstest}

\section{A. M. Gressner und O. A. Gressner}

Synonym(e) Mac-Lagan-Test

\section{Englischer Begriff Mac Lagan's test}

Definition Heute obsoleter, mit gesättigter Thymollösung (2-Isopropyl-5-Methyl-Phenol) durchgeführter Proteinfällungstest des Serums zum Nachweis von Dysproteinämien bei chronischen Entzündungen.

Beschreibung Der zu den unspezifischen Labilitätsreaktionen des Serums ( $\triangleright$ Serumprotein-Labilitätsreaktionen) gehörende, heute nicht mehr gebräuchliche Test verwendet gesättigte Thymollösung ( $\mathrm{pH} 7,5$ ), deren Zugabe zum Serum eine > Trübung durch Proteinpräzipitation erzeugt, wenn eine pathologische Erhöhung der $\beta$ - und $\gamma$-Globuline (IgG, IgM) vorliegt. Die Trübung kann entweder visuell beurteilt oder turbidimetrisch semiquantitativ ausgewertet werden. Positive Reaktionen bei akuten und chronischen Lebererkrankungen, rheumatoider Arthritis, Sepsis, Pneumonie und weiteren chronischen Entzündungen.

\section{Literatur}

Hallmann L (1980) Klinische Chemie und Mikroskopie, 11. Aufl. Georg Thieme Verlag, Stuttgart/New York

\section{Thyreocalcitonin}

$>$ Calcitonin

\section{Thyreoglobulin}

M. Bidlingmaier

Synonym(e) TG

Englischer Begriff thyroglobulin; Tg

Definition Spezifisch von den Follikelzellen der Schilddrüse synthetisiertes, iodhaltiges Glykoprotein.

Struktur TG liegt als Homodimer aus 2 jeweils 2749 Aminosäuren langen Peptidketten vor. Das Molekül enthält ca. 130 Tyrosinreste.

\section{Molmasse $660 \mathrm{kDa}$.}

Synthese - Verteilung - Abbau - Elimination TG wird in den Follikelzellen der Schilddrüse gebildet und in das Follikellumen sezerniert. Die TG-Bildung wird durch - Thyreoidea-stimulierendes Hormon (TSH) stimuliert. TG macht ungefähr $50 \%$ des Kolloids der Schilddrüse aus. Durch Iodierung von Tyrosinresten werden am TG die Schilddrüsenhormone Thyroxin (T4), Triiodthyronin (T3) und reverses T3 gebildet. Im TG des Follikellumens gespeichert werden sie - nach Wiederaufnahme des TG in Thyreozyten - durch Hydrolyse freigesetzt und sezerniert. Das TG wird in der Schilddrüse wiederverwertet, teilweise auch in der Leber metabolisiert. Die zirkulierenden Konzentrationen werden von der Rate der Neubildung (TSH-Stimulation), aber auch von der nach Therapie verblieben Masse funktionellen Schilddrüsengewebes bestimmt. Die Kinetik des Abfalls der messbaren Konzentrationen von TG ist daher bei Therapieformen, die erst mit einer gewissen Verzögerung zur kompletten Destruktion des Schilddrüsengewebes führen, anders als z. B. bei der kompletten Thyreoidektomie. Dies erklärt die teilweise sehr diskrepanten Angaben zur Halbwertszeit des TG in der Literatur.

Halbwertszeit Ca. 30 Stunden (Serumkonzentration nach totaler Thyreoidektomie).

Pathophysiologie Unter physiologischen Bedingungen erfüllt TG seine Funktion gänzlich in der Schilddrüse und ist in Zirkulation meist nur in verhältnismäßig geringen Konzentrationen nachweisbar. Bei benignen Schilddrüsenerkrankungen, wie z. B. bei Struma nodosa, akuter und subakuter Thyreoiditis, können sich genauso wie bei malignen Erkrankungen, wie dem follikulären und papillären Schilddrüsenkarzinom, erhöhte TG-Konzentrationen finden. In der Diagnostik des Schilddrüsenkarzinoms ist die TG-Bestimmung daher unspezifisch. Da TG jedoch nur in der Schilddrüse hergestellt wird, eignet es sich hervorragend als spezifischer 
Marker zum Nachweis von Schilddrüsengewebe. Dies spielt einerseits in der Diagnostik bei Verdacht auf Athyreose bei Neugeborenen eine Rolle - messbares TG spricht für das Vorhandensein von Schilddrüsengewebe. Andererseits ist das TG ein sensitiver und spezifischer Marker, um bei Patienten mit Schilddrüsenkarzinom nach schilddrüsenablativer Therapie den Therapieerfolg nachzuweisen bzw. ein Rezidiv frühzeitig zu entdecken. Nach erfolgreicher totaler Thyreoidektomie ist TG nicht mehr messbar, während messbare TG-Konzentrationen auf verbliebenes Schilddrüsengewebe verweisen. Im Verlauf sind die TG-Konzentrationen dann bestimmt durch die Masse des malignen Gewebes, abhängig auch vom Grad der Differenzierung der neoplastischen Zellen und von der Stimulation der Zellen durch TSH.

Exogen zugeführte Schilddrüsenhormone supprimieren die TSH-Sekretion und inhibieren damit auch die TG-Synthese. Dies kann bei der Diagnose einer Hyperthyreosis factitia hilfreich sein.

Untersuchungsmaterial Serum, Plasma.

Probenstabilität Bis 24 Stunden bei Raumtemperatur, eingefroren $\left(-20^{\circ} \mathrm{C}\right)$ ein Jahr.

Analytik Immunoassays. Neuerdings auch Flüssigkeitschromatographie-Tandemmassenspektrometrie.

Es muss berücksichtigt werden, dass die absoluten Konzentrationen, die mit verschiedenen Messverfahren erhalten werden, sich drastisch unterscheiden. Daher sollte in der postoperativen Verlaufskontrolle idealerweise stets dieselbe Messmethode eingesetzt werden.

- Autoantikörper gegen Thyreoglobulin sind bei einer Reihe von Schilddrüsenerkrankungen häufig. Diese Autoantikörper können die TG-Bestimmung stören und so zu falsch negativen Befunden führen. Daher sollte regelhaft entweder die Wiederfindung für TG oder aber die Konzentration von Anti-TG-Antikörpern bestimmt werden. Es ist jedoch $\mathrm{zu}$ beachten, dass auch diese Messverfahren nicht alle Ursachen falsch negativer TG-Befunde detektieren können.

Konventionelle Einheit $\mu \mathrm{g} / \mathrm{mL}$.

Referenzbereich Methodenspezifische Referenzbereiche erforderlich!

Orientierend:

- Schilddrüsengesunde: $<35 \mu \mathrm{g} / \mathrm{L}$

- Nach kompletter Thyreoidektomie: $<3 \mu \mathrm{g} / \mathrm{L}$

\section{Indikation}

- Erfolgskontrolle und Verlaufsbeobachtung bei der Therapie des papillären und follikulären und Schilddrüsenkarzi- noms, insbesondere nach Thyreoidektomie und Radioiodtherapie.

- Verdacht auf angeborene Athyreose

- Verdacht auf Hyperthyreosis factitia

Interpretation S. Pathophysiologie und Referenzbereich.

Diagnostische Wertigkeit Die Bestimmung von TG eignet sich nicht zur Diagnose von Schilddrüsenerkrankungen. TG wird im Sinne eines Tumormarkers in der Verlaufskontrolle verwendet. Die Unterschiede zwischen den verschiedenen existierenden Messmethoden sind bei der Beurteilung ebenso zu berücksichtigen wie die Möglichkeit einer Störung der Messung durch interferierende Anti-TG-Antikörper.

\section{Literatur}

Persoon ACM, Links TP, Wilde J, Sluiter WJ, Wolffenbuttel BHR, van den Ouweland JMW (2006) Thyroglobulin (Tg) recovery testing with quantitative Tg antibody measurement for determining interference in serum $\mathrm{Tg}$ assays in differentiated thyroid carcinoma. Clin Chem 52(6):1196-1199

Ringel MD, Nabhan F (2013) Approach to follow-up of the patient with differentiated thyroid cancer and positive anti-thyroglobulin antibodies. J Clin Endocrinol Metab 98(8):3104-3110

Spencer C, Fatemi S (2013) Thyroglobulin antibody (TgAb) methods - strengths, pitfalls and clinical utility for monitoring TgAb-positive patients with differentiated thyroid cancer. Best Pract Res Clin Endocrinol Metab 27(5):701-712

\section{Thyreoglobulin-Antikörper}

- Autoantikörper gegen Thyreoglobulin

Thyreoidea-stimulierendes Hormon

$\rightarrow$ Thyreotropin

\section{Thyreoliberin}

- Thyreotropin-Releasing-Hormon

\section{Thyreoperoxidase}

T. Arndt

Synonym(e) Schilddrüsenperoxidase; TPO 
Englischer Begriff thyroperoxidase; thyroid peroxidase

Definition Die Thyreoperoxidase stimuliert die Synthese der Schilddrüsenhormone an der Membran der follikulären Zellen der Schilddrüse.

Beschreibung Die Thyreoperoxidase (TPO) ist ein membrangebundenes Hämoprotein mit einer Molmasse von $100 \mathrm{kDa}$. Es besitzt eine physiologische Funktion im Rahmen der Synthese der Schilddrüsenhormone bei der Iodination der Tyrosinreste aus dem Thyreoglobulin einerseits und der oxidativen Kopplung von 2 Tyrosinresten mithilfe von Wasserstoffperoxid und Iodid andererseits.

Patienten mit autoimmunen Schilddrüsenerkrankungen bilden $>$ Autoantikörper gegen Thyreoperoxidase. Erhöhte Antikörperkonzentrationen im Blutserum führen dabei zu erheblichen Störungen bei der quantitativen TPO-Bestimmung mit einem $>$ Immunoassay.

Andererseits zeigen die im Blut gemessenen TPO-Konzentrationen bei zahlreichen Patienten keine signifikante Korrelation zu Schilddrüsenerkrankungen und besitzen damit keine klinische Relevanz bei diesen Erkrankungen.

\section{Literatur}

Herbig J, Lange D, Elser H, Georgi P (1996) Methodical evaluation of immunoluminometric determination of thyroid peroxidase in serum. Nuklearmedizin 35:94-98

Ohtaki S, Nakagawa H, Nakamura M, Kotani T (1996) Thyroid peroxidase: experimental and clinical integration. Endocr J 43:1-14

\section{Thyreoperoxidase-Antikörper}

- Autoantikörper gegen Thyreoperoxidase

\section{Thyreotropes Hormon}

- Thyreotropin

\section{Thyreotropin}

W. Hubl

Synonym(e) Thyreoidea-stimulierendes Hormon; Thyreotropes Hormon; TSH

Englischer Begriff thyroid stimulating hormone; thyrotropin
Definition Das Thyreoidea-stimulierende Hormon (TSH) stellt ein Proteohormon dar und wird im Hypophysenvorderlappen gebildet. Die wichtigste Funktion des TSH ist die Regulation der Synthese der Schilddrüsenhormone.

Struktur Thyreotropin besteht aus einer unspezifischen $\alpha$-Untereinheit, die mit anderen Proteohormonen (LH, FSH, HCG) identisch ist, und einer TSH-spezifischen $\beta$-Untereinheit.

Molmasse Ca. $28 \mathrm{kDa}$.

Synthese - Verteilung - Abbau - Elimination Thyreotropin wird in den basophilen, thyreotropen Zellen des Hypophysenvorderlappens gebildet. Die Synthese wird durch TRH ( $\triangleright$ Thyreotropin-Releasing-Hormon) einerseits und über den Feedbackmechanismus durch erniedrigte Schilddrüsenhormon-Konzentrationen andererseits stimuliert.

Halbwertszeit 50 Minuten.

Funktion - Pathophysiologie Thyreotropin steuert die Schilddrüsenfunktion über die Bindung an die TSHRezeptoren der thyreoidalen Follikelzellen. Hierbei werden die Adenylatzyklase und die $>$ Phospholipase $\mathrm{C}$ aktiviert, die Funktion und Wachstum der Schilddrüse kontrollieren. Der TSH-Rezeptor wird durch ein einzelnes Gen kodiert, das über 60 Kilobasen lang ist. Mutationen dieses Gens verbunden mit einer klonalen Expansion scheinen für die chronische Stimulation verantwortlich zu zeichnen, die zu toxischen Follikeladenomen führen.

Untersuchungsmaterial - Entnahmebedingungen Serum, Plasma, 1 Blutstropfen für das Neugeborenen-Screening.

Probenstabilität Blut auf Filterpapier (Neugeborenenscreening): $20-25{ }^{\circ} \mathrm{C} 7$ Tage; Serum, Plasma: $20-25{ }^{\circ} \mathrm{C} 1 \mathrm{Tag}$, $4-8{ }^{\circ} \mathrm{C} 7$ Tage, $-20{ }^{\circ} \mathrm{C} 6$ Monate.

Präanalytik Medikamenteneinflüsse: erhöht unter Thyreostatika, Metoclopramid, Psychopharmaka, erniedrigt unter Schilddrüsenhormone, Glukokortikoide, Dopamin, L-Dopa.

Analytik $>$ Immunoassay.

Qualitätskriterien für einen TSH-Test (Leitlinien):

\begin{tabular}{l|l|}
\hline TSH-Test-Qualitätskriterien & $<0,1 \mathrm{mIU} / \mathrm{L}$ \\
\hline $\begin{array}{l}\text { Funktionelle Assay-Sensitivität } \\
\begin{array}{l}\text { Messung von WHO- oder Medical-Research- } \\
\text { Council-(MRC-)Standards }\end{array}\end{array}$ & $+5 \%$ \\
\hline $\begin{array}{l}\text { Sichere Trennung von euthyreoten und } \\
\text { hyperthyreoten Patienten. Überlappung }\end{array}$ & $<1 \%$ \\
\hline Kein Highdose-Hook-Effekt & $\geq 300 \mathrm{mIU} / \mathrm{L}$ \\
\hline & (Fortsetzung)
\end{tabular}




\section{TSH-Test-Qualitätskriterien}

Parallelität von Verdünnungskurven der

$+10 \%$

Patientenseren zur Standardkurve

Kreuzreaktionen mit anderen Proteohormonen

$<0,01 \%$

\section{Konventionelle Einheit $\mathrm{mU} / \mathrm{L}$.}

Internationale Einheit $\mathrm{mIU} / \mathrm{L}$.

\section{Referenzbereich - Erwachsene}

\begin{tabular}{|l|l|l|}
\hline Median & Frauen $(\mathrm{mIU} / \mathrm{L})$ & Männer $(\mathrm{mIU} / \mathrm{L})$ \\
\hline Gesamtbereich & 1,101 & 1,101 \\
\hline Schwangerschaft - 1. Drittel & $0,170-4,23$ & $0,170-4,23$ \\
\hline Schwangerschaft - 2. Drittel & $0,4-2,5$ & \\
\hline Schwangerschaft - 3. Drittel & $0,4-3,5$ &
\end{tabular}

Referenzbereich - Kinder Neugeborene und Kleinkinder:

\begin{tabular}{|c|c|c|}
\hline Alter & $\begin{array}{l}\text { TSH } \\
(\mathrm{mIU} / \mathrm{L})\end{array}$ & $\begin{array}{l}\text { Ratio: TSH Kind/ } \\
\text { Erwachsene }\end{array}$ \\
\hline $\begin{array}{l}\text { Neugeboren } \\
\text { (Nabelschnurblut) }\end{array}$ & $1,3-20$ & 4,49 \\
\hline Geburt & $1,3-19$ & 4,28 \\
\hline 3. Lebenstag & $1,1-17$ & 3,66 \\
\hline 10 Wochen & $0,6-10$ & 2,13 \\
\hline 14 Monate & $0,4-7,0$ & 1,4 \\
\hline
\end{tabular}

Kinder (KIGGS-Studie):

\begin{tabular}{|l|l|l|}
\hline Alter & $\begin{array}{l}\text { TSH }(\mathrm{mIU} / \mathrm{L}) \\
\text { Jungen }\end{array}$ & $\begin{array}{l}\text { TSH }(\mathrm{mIU} / \mathrm{L}) \\
\text { Mädchen }\end{array}$ \\
\hline 4 Jahre & $1,2-5,1$ & $1,1-4,3$ \\
\hline 5 Jahre & $1,1-5,1$ & $1,1-4,5$ \\
\hline 6 Jahre & $1,1-5,0$ & $1,1-4,7$ \\
\hline 7 Jahre & $1,1-5,0$ & $1,1-4,8$ \\
\hline 8 Jahre & $1,1-4,9$ & $1,1-4,8$ \\
\hline 9 Jahre & $1,1-4,8$ & $1,1-4,8$ \\
\hline 10 Jahre & $1,1-4,7$ & $1,0-4,7$ \\
\hline 11 Jahre & $1,0-4,6$ & $1,0-4,6$ \\
\hline 12 Jahre & $1,0-4,5$ & $0,9-4,3$ \\
\hline 13 Jahre & $1,0-4,3$ & $0,9-4,1$ \\
\hline 14 Jahre & $0,9-4,2$ & $0,8-3,9$ \\
\hline 15 Jahre & $0,9-4,0$ & $0,8-3,8$ \\
\hline 16 Jahre & $0,9-3,8$ & $0,7-3,6$ \\
\hline 17 Jahre & $0,8-3,6$ & $0,7-3,6$
\end{tabular}

\section{Indikation}

- Ausschluss einer Schilddrüsenfunktionsstörung

- Diagnostik einer primären Hyper- oder Hypothyreose

- Screening einer angeborenen Hypothyreose
- Therapiekontrolle bei Schilddrüsenerkrankungen

- Schilddrüsenhormonresistenz (Kombination mit FT4, $>$ Thyroxin, freies)

- Diagnostik einer sekundären Hypothyreose (Kombination mit FT4)

- Hyperprolaktinämie

\section{Interpretation}

- TSH normal: primäre Schilddrüsenfunktionsstörung ausgeschlossen

- TSH erniedrigt: manifeste primäre Hyperthyreose, subklinische Hyperthyreose bei normalen Schilddrüsenhormonwerten

- TSH erhöht: manifeste primäre Hypothyreose, subklinische Hypothyreose bei normalen Schilddrüsenhormonwerten

- TSH erhöht >50 mIU/L: Neugeborenenscreening: angeborene Hypothyreose

Diagnostische Wertigkeit Die TSH-Bestimmung stellt den empfindlichsten Parameter sowohl zum Nachweis als auch zum Ausschluss einer Schilddrüsenfunktionsstörung dar.

Normale TSH-Konzentrationen schließen eine primäre Schilddrüsenfunktionsstörung aus. Zur früheren Diagnostik einer subklinischen Hypothyreose insbesondere in Iodmangelgebieten schlägt die National Academy of Clinical Biochemistry eine Absenkung der oberen TSH-Referenzwertgrenze auf 2,5 mIU/L vor. Andere Untersuchungen empfehlen einen Grenzwert im Bereich von 2,5-3,0 mIU/L. Zur Vermeidung einer Übertherapie sollten jedoch weitere Studien abgewartet werden, die einen eventuell positiven klinischen Effekt einer Therapie ab 2,5 mIU/L ausreichend belegen. In der Schwangerschaft gilt diese niedrigere TSH-Grenzwertgrenze von 2,5-3,5 mIU/L aufgrund des höheren Bedarfs an Schilddrüsenhormonen als gesichert (s. Tabelle unter „Referenzbereich - Erwachsene“).

Im Rahmen des Neugeborenenscreenings werden angeborene Hypothyreosen bei TSH-Konzentrationen von 50-100 $\mathrm{mIU} / \mathrm{L}$ mit einer diagnostischen Sensitivität von $97 \%$ und über $100 \mathrm{mIU} / \mathrm{L}$ von $100 \%$ erfasst. Die diagnostische Spezifität liegt bei TSH-Konzentrationen unter $50 \mathrm{mIU} / \mathrm{L}$ bei $100 \%$.

\section{Literatur}

Brabant G, Luster M, Schmid KW et al (2015) Diagnostik von Schilddrüsenerkrankungen. In: Lehnert H (Hrsg) Rationelle Diagnostik und Therapie in Endokrinologie, Diabetologie und Stoffwechsel. ThiemeVerlag, Stuttgart, S 98-105

Garber JR, Cobin RH, Gharib H et al (2012) Clinical practice guidelines for hypothyroidism in adults: cosponsored by the American Association of Clinical Endocrinologists and the American Thyroid Association. Thyroid 22:1200-1235 
Kratzsch J, Fiedler GM, Leichtle A et al (2005) New reference intervals for thyrotropin and thyroid hormones based on National Academy of Clinical Biochemistry criteria and regular ultrasonography of the thyroid. Clin Chem 51(8):1480-1486

Publikationsliste zur Studie zur Gesundheit von Kindern und Jugendlichen in Deutschland (KiGGS) (2009) Bevölkerungsbezogene Verteilungswerte ausgewählter Laborparameter aus der Studie zur Gesundheit von Kindern und Jugendlichen in Deutschland (KiGGS). Robert Koch-Institut/TSH, Berlin, S 54-57

Thomas L (Hrsg) (2012) Schilddrüsenfunktion. In: Labor und Diagnose. Indikation und Bewertung von Laborbefunden für die medizinische Diagnostik. TH-Books Verlagsgesellschaft mbH, Frankfurt am Main, 8. Aufl., 1718-1752

\section{Thyreotropin-Releasing-Hormon}

W. Hubl

Synonym(e) Protirelin; Thyreoliberin; TRH

Englischer Begriff thyrotropin-releasing hormone; thyreotropin releasing factor

Definition Das Thyreotropin-releasing-Hormon (TRH) aus dem Hypothalamus kontrolliert die TSH-Freisetzung in der Hypophyse. TRH ist ein Tripeptid (L-Pyroglutamyl-L-Histidyl-L-Prolinamid) mit einer Molmasse von $362 \mathrm{~g}$.

Beschreibung TRH wird im Hypothalamus gebildet und stimuliert die Thyreotropin(TSH)-Synthese und -Freisetzung. Dieser Effekt wird im TRH-Funktionstest ( $>$ TRH-Test) ausgenutzt und dabei die Funktion der TSH-Sekretionsleistung des Hypophysenvorderlappens überprüft.

Andererseits stimuliert TRH auch die $>$ Prolaktin-Freisetzung. Bei Patienten mit einer Hypothyreose werden über einen Rückkopplungsmechanismus mit erhöhten TRH-Konzentrationen neben erhöhten TSH- auch erhöhte Prolaktinkonzentrationen beobachtet, die zur Infertilität führen können.

Der seltene TRH-Mangel führt zur tertiären Hypothyreose.

\section{Literatur}

Joseph-Bravo P, Jaimes-Hoy L, Uribe RM et al (2015) 60 years of neuroendocrinology: TRH, the first hypophysiotropic releasing hormone isolated: control of the pituitary-thyroid axis. J Endocrinol 226: $\mathrm{T} 85-\mathrm{T} 100$

\section{Thyreotropin-Releasing-Hormon-Test}

- TRH-Test

\section{Thyroliberin}

- Thyreotropin-Releasing-Hormon

\section{Thyroxin, freies}

W. Hubl

Synonym(e) FT4; T4, freies; Tetraiodthyronin, freies

Englischer Begriff free thyroxine

Definition Das freie Thyroxin wird in der Schilddrüse gebildet und gehört zu den lebenswichtigen Hormonen, da es gemeinsam mit dem freien Triiodthyronin den Stoffwechsel nahezu sämtlicher Körperorgane reguliert. Auf zellulärer Ebene steigern sie den Sauerstoffverbrauch und die Wärmeproduktion. Sie zeichnen für die geistige und körperliche Entwicklung und das Wachstum des gesamten Organismus verantwortlich.

Struktur 3,3',5,5'-Tetraiodo-D-Thyronin, $\mathrm{C}_{15} \mathrm{H}_{11} \mathrm{I}_{4} \mathrm{NO}_{4}$.

Molmasse $776,9 \mathrm{~g}$.

Synthese-Verteilung-Abbau-Elimination Biosynthese: Das mit der Nahrung aufgenommene Iod wird im Dünndarm als Iodid resorbiert. Über die Blutbahn gelangt das Iodid in die Schilddrüse. Dieser Iodidtransport in die Schilddrüse kann durch hochdosierte Iodapplikationen gehemmt werden (Wolff-Chaikoff-Effekt). Zum anderen kann dieser Iodidtransport auch kompetitiv im Rahmen der Therapie durch Perchlorat gehemmt werden.

In der Schilddrüse wird das Iodid mit Hilfe der Schilddrüsenperoxidase (TPO, $>$ Thyreoperoxidase) und $\mathrm{H}_{2} \mathrm{O}_{2}$ oxidiert und in Tyrosylreste des Thyreoglobulins eingebaut.

Es entstehen inaktive Hormonvorläufer, das 3-Monoiodtyrosin und das 3,5-Diiodtyrosin. Durch Kopplung dieser beiden Substanzen über eine oxidative Kondensation entstehen die Schilddrüsenhormone Thyroxin (Tetraiodthyronin, T4) und das Triiodthyronin (T3). Während das T4 komplett in der Schilddrüse synthetisiert wird, kommt das T3 nur zu $20 \%$ aus der Schilddrüse und der Rest wird in extraglanduären Geweben durch enzymatische Abspaltung eines Iodatoms gebildet.

Die Schilddrüse ist in der Lage, Schilddrüsenhormone bis zu zwei Monate zu speichern als Anpassung an eine unregelmäßige Iodaufnahme. 
Transport: Die Schilddrüsenhormone werden in das Blut abgegeben und unmittelbar an folgende Transportproteine mit abfallender Affinität gebunden: - Thyroxin-bindendes Globulin (TBG), T4-bindendes $>$ Präalbumin (Transthyretin, TTR), - Albumin und in geringem Maße das > High Density Lipoprotein. Nur 0,03 \% der Schilddrüsenhormone liegen in freier, ungebundener Form vor. Dieser freie Anteil ist biologisch aktiv und korreliert deshalb deutlich besser mit der aktuellen Stoffwechsellage als die Gesamtkonzentrationen.

Durch die Proteinbindung der Schilddrüsenhormone wird eine rasche Ausscheidung verhindert. Die biologische Halbwertszeit für T4 beträgt 5-8 Tage und für T3 19 Stunden. Das biologisch inaktive reverse-T3 besitzt eine biologische Halbwertszeit von 4 Stunden.

Metabolismus: Im Rahmen des Stoffwechsels in den Zellen wird vom $\mathrm{T} 4 \mathrm{zu}$ ca. $30 \%$ ein Iodatom abgespalten (Monodeiodierung) und es entsteht daraus T3. Daneben wird durch eine spezielle Monodeiodierung an der Position 5 des inneren T4-Rings ein Iodatom abgespalten, wodurch das sogenannte reverse T3 (rT3) entsteht, dass biologisch inaktiv ist.

Durch weitere Abspaltungen von Iodatomen entstehen schließlich iodfreie Thyroninkerne.

Die einzelnen Monodeiodierungen benötigen verschiedene Deiodinasen. Das Isoenzym I aus der Leber und der Niere bewirkt die Konversion des T4 zum T3. Diese Deiodase wird durch die Schilddrüsenhormone, durch Selen und TSH stimuliert, und gehemmt durch Fasten, schwere Erkrankungen sowie Zytokine.

Die Typ-II-Deiodase bildet T3 in der Hypophyse, im Zentralnervensystem, der Plazenta und im Fettgewebe, Typ III kommt im ZNS vor

Ein anderer Stoffwechselweg $(20 \%$ der Schilddrüsenhormone) ist die Konjugation von T4 und T3 mit Glukuronat und Sulfat in der Leber. Diese Konjugate werden über die Galle ausgeschieden oder weiter deiodiert.

Halbwertszeit Das Thyroxin ist im Blut zu 99,9\% an Transportproteine gebunden, wodurch die biologische Halbwertszeit 6-10 Tage beträgt. Für das freie Thyroxin liegen keine verlässlichen Angaben vor.

Funktion - Pathophysiologie Die Schilddrüsenhormone besitzen auf Grund ihrer zahlreichen Wirkungen auf zentrale Stoffwechselvorgänge eine herausragende Bedeutung.

- Die Schilddrüsenhormone zeichnen für ein normales Wachstum verantwortlich. Bereits in der Fetalzeit kann eine Unterfunktion der Schilddrüse zu einer verminderten Gehirnreifung führen, die bei unbehandeltem Schilddrüsenhormonmangel in der Neugeborenenphase einen irreversiblen Kretinismus entwickeln kann
- Umgekehrt führt eine Überangebot an Schilddrüsenhormonen in der Neugeborenenphase zu einem verstärktem Wachstum mit einem verspätetem Schluss der Epiphysenfugen

- Innerhalb des Kohlenhydratstoffwechsels bewirken Schilddrüsenhormone sowohl eine Steigerung der Glukoneogenese als auch einem gesteigerten Kohlenhydratabbau. Zum anderen ziehen Schilddrüsenhormone eine ansteigenden Insulinbedarf nach sich.

- Im Fettstoffwechsel führen erhöhte Schilddrüsenhormone zu einem beschleunigten Abbau von Speicherfetten und einem Cholesterinabfall

- Erhöhte Schilddrüsenhormonwerte bewirken im Proteinstoffwechsel einen verstärkten Proteinabbau

- Im Knochenstoffwechsel spielen Schilddrüsenhormone für eine normale Skelettreifung eine primäre Rolle. Eine Unterfunktion der Schilddrüse bewirkt eine verzögerte Skelettreifung

- Am Herzmuskel bewirken die Schilddrüsenhormone eine Steigerung der Kontraktilität des Myokards, ein erhöhtes Schlagvolumen mit einer erhöhten Schlagfrequenz. Im Rahmen der Schilddrüsenüberfunktion können sich Extrasystolen, Vorhofflimmern und Angina pectoris entwickeln

- Abnorme Schilddrüsenhormonkonzentrationen können zu Gonadenfunktionsstörungen führen

- Im zentralen Nervensystem können abnormale Schilddrüsenhormone zu Veränderungen der Sehnenreflexe führen

- Die Angriffspunkte für die Wirkungen der Schilddrüsenhormone liegen: im Zellkern mit zwei funktionellen T3-Rezeptoren, hTRalpha und hTRbeta, an den Mitochondrien und an der Zellmembran.

Untersuchungsmaterial - Entnahmebedingungen Serum oder Plasma.

Probenstabilität Blut, Serum, Plasma: $20-25{ }^{\circ} \mathrm{C} 2$ Tage; Serum, Plasma: $4-8{ }^{\circ} \mathrm{C} 8$ Tage, $-20{ }^{\circ} \mathrm{C} 3$ Monate.

Präanalytik Medikamenteneinflüsse: erhöht unter Heparin, Schilddrüsenhormone, hochdosierten Iodgaben, Salicylaten, Furosemid, erniedrigt unter Thyreostatika, Barbituraten, Rifampicin.

Analytik - Immunoassay.

Konventionelle Einheit ng/L.

Internationale Einheit $\mathrm{pmol} / \mathrm{L}$.

Umrechnungsfaktor zw. konv. u. int. Einheit ng/L $\times 1,287=\mathrm{pmol} / \mathrm{L}$.

Referenzbereich - Erwachsene $10-23 \mathrm{pmol} / \mathrm{L}$ FT4. 
Referenzbereich - Kinder Säuglinge und Kleinkinder:

\section{Alter}

1.-2. Tag FT4 (pmol/L)

3.-30. Tag

21-49

1. -12 . Monat

14-23
Kinder (KIGGS-Studie):

\begin{tabular}{|l|l|l|}
\hline Alter & $\begin{array}{l}\text { FT4 }(\mathrm{pmol} / \mathrm{L}) \\
\text { Jungen }\end{array}$ & $\begin{array}{l}\text { FT4 }(\mathrm{pmol} / \mathrm{L}) \\
\text { Mädchen }\end{array}$ \\
\hline 4 Jahre & $12,9-18,7$ & $12,6-19,7$ \\
\hline 5 Jahre & $12,9-18,7$ & $12,7-19,4$ \\
\hline 6 Jahre & $12,7-18,8$ & $12,6-19,2$ \\
\hline 7 Jahre & $12,7-18,9$ & $12,6-19,0$ \\
\hline 8 Jahre & $12,6-18,9$ & $12,5-19,0$ \\
\hline 9 Jahre & $12,6-18,9$ & $12,4-18,9$ \\
\hline 10 Jahre & $12,2-19,9$ & $12,0-18,7$ \\
\hline 11 Jahre & $12,5-18,9$ & $11,8-18,3$ \\
\hline 12 Jahre & $12,1-18,7$ & $11,5-17,9$ \\
\hline 13 Jahre & $11,7-18,1$ & $11,3-17,9$ \\
\hline 14 Jahre & $11,2-18,0$ & $11,6-18,3$ \\
\hline 15 Jahre & $11,5-18,7$ & $11,8-18,5$ \\
\hline 16 Jahre & $11,8-19,6$ & $12,0-18,7$ \\
\hline 17 Jahre & $12,2-20,2$ & $12,0-18,7$
\end{tabular}

\section{Indikation}

- Nachweis einer manifesten, primären Hypothyreose

- Nachweis einer manifesten, primären Hyperthyreose
- Therapiekontrolle der T4-Substitution bei Hypothyreose

- Therapiekontrolle bei Hyperthyreose (TSH kann noch monatelang nach Therapiebeginn supprimiert sein)

- Schilddrüsenhormonresistenz (Kombination mit TSH)

- Diagnostik einer sekundären Hypothyreose (Kombination mit TSH)

Interpretation Befundinterpretation:

\begin{tabular}{|c|c|c|c|}
\hline TSH & FT4 & FT3 & Befund \\
\hline $\mathrm{n}$ & & & $\begin{array}{l}\text { Ausschluss einer } \\
\text { Schilddrüsenfunktionsstörung }\end{array}$ \\
\hline- & + & + & Manifeste primäre Hyperthyreose \\
\hline+ & - & $-, \mathrm{n},+$ & Manifeste primäre Hypothyreose \\
\hline+ & & & $\begin{array}{l}\text { Neugeborenen-Screening auf angeborene } \\
\text { Hypothyreose }(\mathrm{TSH}>50 \mathrm{mIU} / \mathrm{L})\end{array}$ \\
\hline
\end{tabular}

Diagnostische Wertigkeit FT4 besitzt insbesondere gemeinsam mit TSH eine hohe klinische Relevanz zur Erkennung von Schilddrüsenfunktionsstörungen. Lediglich Patienten mit subklinischer Hyper- bzw. Hypothyreose zeigen noch normale FT4-Konzentrationen, sodass FT4-Untersuchungen allein für generelle Screeninguntersuchungen ungeeignet erscheinen.

Diagnostische Sensitivität/Spezifität für Hyperthyreose (außer T3-Hyperthyreose) $100 \% / 99 \%$, diagnostische Sensitivität/Spezifität für Hypothyreose $94 \% / 98 \%$.

Thyroxin, freies, Tab. 1 Weitere Befundinterpretationen

\begin{tabular}{|c|c|c|c|c|}
\hline TSH & FT4 & FT3 & Mögliche Ursache & Aktivitäten \\
\hline+ & $\mathrm{n}$ & $\mathrm{n}$ & $\begin{array}{l}\text { Subklinische Hypothyreose } \\
\text { Thyroxintherapie: Dosis zu niedrig oder mangelnde Compliance } \\
\text { Persistierende TSH-Erhöhung in den ersten } 6-8 \text { Wochen der Thyroxin- } \\
\text { Therapie bei Hypothyreose } \\
\text { HAMA-Störung }\end{array}$ & $\begin{array}{l}\text { Schilddrüsen-Antikörper: }+ \text { ? } \\
\text { T4-Dosis erhöhen bzw. Compliance verbessern } \\
\text { TSH-Wiederholungsmessung nach } 2-4 \\
\text { Wochen } \\
\text { Anderen TSH-Testkit wählen (ohne HAMA- } \\
\text { Störung) }\end{array}$ \\
\hline+ & + & + & TSH-produzierendes Hypophysenadenom & $\begin{array}{l}\text { Hypophysenuntersuchung mit bildgebenden } \\
\text { Verfahren, TRH-Test }\end{array}$ \\
\hline $\mathrm{n}$ & + & + & $\begin{array}{l}\text { Thyroxin-Therapie } \\
\text { Antikörper-Interferenzen: T4- bzw. T3-Antikörper, Rheumafaktor }\end{array}$ & $\begin{array}{l}\text { Therapiekontrolle mit TSH } \\
\text { T4- bzw. T3-AK-Bestimmung }\end{array}$ \\
\hline $\mathrm{n}$ & - & - & $\begin{array}{l}\text { Zentrale Hypothyreose (Hypophyseninsuffizienz) } \\
\text { Verringerte Bioaktivität des TSH } \\
\text { Schwangerschaft: } 2 \text {. und 3. Trimester }\end{array}$ & $\begin{array}{l}\text { Bildgebende Untersuchung } \\
\text { TRH-Test (TSH-Anstieg }<200 \% \text { ) } \\
\text { Verwendung schwangerschaftsspezifischer } \\
\quad \text { Referenzwerte }\end{array}$ \\
\hline- & $\mathrm{n}$ & $\mathrm{n}$ & $\begin{array}{l}\text { Subklinische Hyperthyreose } \\
\text { In den ersten 2-3 Monaten nach Therapiebeginn der Hyperthyreose } \\
\text { Medikamentenstörung: Glukokortikoide, Dopamin }\end{array}$ & $\begin{array}{l}\text { Bildgebende Verfahren: Autonomie? } \\
\text { Verwendung von FT4 und FT3 zur } \\
\text { Therapiekontrolle } \\
\text { Absetzen der Medikamente, wenn möglich }\end{array}$ \\
\hline- & - & + & Überdosierung mit T3-haltigen Medikamenten (T3-Thyreotoxikose) & Dosisanpassung mit TSH-Kontrolle \\
\hline
\end{tabular}

$\mathrm{n}=$ normal; $+=$ erhöht $;-=$ erniedrigt 


\section{Literatur}

Brabant G, Luster M, Schmid KW et al (2015) Diagnostik von Schilddrüsenerkrankungen. In: Lehnert H (Hrsg) Rationelle Diagnostik und Therapie in Endokrinologie, Diabetologie und Stoffwechsel. Thieme-Verlag, Stuttgart, S 98-105

Demers LM, Spencer CA (2002) National Academy of Clinical Biochemistry, Washington (NACB) - Laboratory Medicine Practice Guideluines (LMPG) - laboratory support for the diagnosis and monitoring of thyroid disease. AACC Press, Washington DC. http://www.nacb.org/

Kratzsch J, Fiedler GM, Leichtle A et al (2005) New reference intervals for thyrotropin and thyroid hormones based on National Academy of Clinical Biochemistry criteria and regular ultrasonography of the thyroid. Clin Chem 51(S):1480-1486

Thomas L (Hrsg) (2012) Schilddrüsenfunktion. In: Labor und Diagnose. Indikation und Bewertung von Laborbefunden für die medizinische Diagnostik, 8. Aufl. TH-Books, Frankfurt am Main S 1718-1752

\section{Thyroxin, gesamt}

W. Hubl

Synonym(e) T4; Tetraiodthyronin

\section{Englischer Begriff thyroxine}

Definition Thyroxin wird in der Schilddrüse gebildet und gehört zu den lebenswichtigen Hormonen, da es gemeinsam mit dem Triiodthyronin ( $\triangleright$ Triiodthyronin, gesamt) den Stoffwechsel nahezu sämtlicher Körperorgane reguliert. Auf zellulärer Ebene steigern sie den Sauerstoffverbrauch und die Wärmeproduktion. Sie zeichnen für die geistige und körperliche Entwicklung und das Wachstum des gesamten Organismus verantwortlich.

Schilddrüsenfunktionsstörungen werden vom freien Thyroxin (FT4; - Thyroxin, freies) mit einer deutlich höheren diagnostischen Sensitivität angezeigt, sodass Bestimmungen des Gesamt-Thyroxins als obsolet gelten.

Struktur 3,3',5,5'-Tetraiod-D-Thyronin, $\mathrm{C}_{15} \mathrm{H}_{11} \mathrm{I}_{4} \mathrm{NO}_{4}$.

Molmasse $776,9 \mathrm{~g}$.

Synthese - Verteilung-Abbau-Elimination $>$ Thyroxin, freies.

Das Thyroxin wird im Blut zu 99,97 \% an folgende Transportproteine mit abfallender Affinität gebunden: Thyroxinbindendes Globulin (TBG), T4-bindendes Präalbumin (Transthyretin, TTR), Albumin und in geringem Maße an High Density Lipoprotein und $\triangleright$ Sexualhormon-bindendes Globulin (SHBG).

Die besonders hohe Affinität des Thyroxins zum TBG verhindert einen schnellen Abbau, sodass die biologische Halbwertszeit für Thyroxin 5-8 Tage beträgt.
Halbwertszeit 6-10 Tage.

Funktion - Pathophysiologie $>$ Thyroxin, freies.

Untersuchungsmaterial- Entnahmebedingungen Serum, Plasma.

Probenstabilität Blut, Serum, Plasma: $20-25{ }^{\circ} \mathrm{C} 2$ Tage; Serum, Plasma: $4-8{ }^{\circ} \mathrm{C} 8$ Tage, $-20{ }^{\circ} \mathrm{C} 3$ Monate.

Präanalytik Thyroxin (gesamt) ggf. erhöht unter: orale Kontrazeptiva, Gravidität, angeborene TBG-Vermehrung, akute Hepatitis, familiäre dysalbuminämische Hyperthyroxinämie, Amiodaron; erniedrigt unter: Nulldiät, Leberzirrhose, diabetische Ketoazidose, Azetylsalizylsäure, Phenytoin, Phenobarbital, Carbamazepin.

Analytik - Immunoassay.

Konventionelle Einheit $\mu \mathrm{g} / \mathrm{L}$.

Internationale Einheit $\mathrm{nmol} / \mathrm{L}$.

Umrechnungsfaktor zw. konv. u. int. Einheit $\mu \mathrm{g} / \mathrm{L}$ $\times 1,287=\mathrm{nmol} / \mathrm{L}$.

Referenzbereich - Erwachsene $77-142 \mathrm{nmol} / \mathrm{L}$.

\section{Referenzbereich - Kinder}

\begin{tabular}{|l|l|}
\hline Alter & Thyroxin (T4) $\mathrm{nmol} / \mathrm{L}$ \\
\hline Nabelschnurblut & $77-167$ \\
\hline 1. +2. Tag & $138-332$ \\
\hline 3.-30. Tag & $100-254$ \\
\hline 1.-12. Monat & $69-178$ \\
\hline 1.-7. Jahr & $68-158$ \\
\hline 7.-13. Jahr & $77-143$ \\
\hline 13.-18. Jahr & $63-138$ \\
\hline
\end{tabular}

\section{Indikation}

- Nachweis einer Hypothyreose nach erhöhten TSH-Werten

- Nachweis einer Hyperthyreose nach erniedrigten TSHWerten

- Kontrolle der Hyperthyreosetherapie, während TSH in den ersten Monaten noch erniedrigt sein kann

- Kontrolle der Compliance einer Thyroxintherapie.

\section{Interpretation}

- Normalbefund: Euthyreose, Iodmangelstruma, latente Hypo- oder Hyperthyreose, Isolierte T3-Hyperthyreose 
- Gesamt-Thyroxin erhöht: Hyperthyreose

- Gesamt-Thyroxin erniedrigt: Hypothyreose, extremer Iodmangel

Diagnostische Wertigkeit Das Thyroxin wird in ausgeprägtem Ausmaß (noch stärker als T3) von der Konzentration der Bindungsproteine beeinflusst und hinsichtlich seiner Aussage zur Schilddrüsenfunktionsdiagnostik verfälscht.

Aus diesem Grund wurde die Gesamt-T4-Bestimmung durch den FT4-Assay ersetzt. Gesamt-T4 gilt als obsolet.

\section{Literatur}

Brabant G, Luster M, Schmid KW et al (2015) Diagnostik von Schilddrüsenerkrankungen. In: Lehnert H (Hrsg) Rationelle Diagnostik und Therapie in Endokrinologie, Diabetologie und Stoffwechsel. Thieme-Verlag, Stuttgart, S 98-105

Thomas L (Hrsg) (2012) Schilddrüsenfunktion. In Labor und Diagnose. Indikation und Bewertung von Laborbefunden für die medizinische Diagnostik, 8. Aufl. TH-Books, 1718-1752, T4 S 1735-1738

\section{Thyroxin-bindendes Globulin}

\author{
W. Hubl
}

\section{$\operatorname{Synonym(e)~TBG~}$}

Englischer Begriff thyroxine-binding globulin

Definition Das Thyroxin-bindende Globulin bindet und speichert die Schilddrüsenhormone, insbesondere Thyroxin $(\triangleright$ Thyroxin, freies) und Triiodthyronin ( $\triangleright$ Triiodthyronin, freies), mit hoher Affinität und zeichnet für den Transport dieser Hormone im Blut verantwortlich.

Beschreibung Das TBG setzt sich aus 395 Aminosäuren zusammen. Es besitzt eine Molmasse von ca. $54 \mathrm{kDa}$.

Die besonders hohe Affinität des Thyroxins zu TBG verhindert einen schnellen Abbau, sodass die biologische Halbwertszeit für Thyroxin 5-8 Tage beträgt. Das Triiodthyronin besitzt eine 10- bis 20-fach geringere Affinität zu TBG, woraus eine kürzere Halbwertszeit von 19 Stunden resultiert. Die geringste Affinität zu TBG besitzt das reverse T3 ( $\triangleright$ Triiodthyronin, reverses) mit einer Halbwertszeit von lediglich 4 Stunden.

Durch zahlreiche Einflussfaktoren können die TBG-Konzentrationen im Blut verändert werden. Erhöhte TBG-Konzentrationen werden beobachtet bei Patienten mit Lebererkrankungen, wie akuter Hepatitis, kompensierter Leberzirrhose sowie Porphyrie, bei Schwangeren sowie bei Einnahme zahlreicher Medikamente, wie $\triangleright$ Estrogene, Ovulationshemmer, Tam- oxifen, Opiate etc. Im Gegensatz hierzu werden erniedrigte TBG-Werte gemessen bei Patienten mit dekompensierter Leberzirrhose, mit nephrotischem Syndrom, Akromegalie sowie während der Medikamentenapplikation mit Glukokortikoiden und Androgenen ( $\triangleright$ Androgene).

Im Zusammenhang mit diesen deutlichen Veränderungen der TBG-Konzentrationen verändern sich parallel hierzu auch die Konzentrationen der Gesamt-Schilddrüsenhormon-Konzentrationen, obwohl eine gesunde Schilddrüsenfunktion vorliegen kann. Das heißt, dass die Bestimmungen der Gesamthormone bei diesen Zuständen falsch positive oder falsch negative Befunde liefern. Die klinische Bedeutung der TBGBestimmung lag in der Korrektur der Gesamt-Thyroxinbestimmung über den T4/TBG-Quotienten ( $\triangleright$ Thyroxin-Index, freier) zur Abschätzung der freien Hormonkonzentration.

Heute sind die Bestimmungen der Gesamt-Schilddrüsenhormone Thyroxin und Triiodthyronin verlassen worden zugunsten der freien, nicht proteingebundenen T4- bzw. T3-Bestimmungen.

Analytik: Zur TBG-Bestimmung im Blutserum werden - Radioimmunoassay und Lumineszenzimmunoassay eingesetzt.

Referenzbereiche: Erwachsene 220-510 nmol/L (13-30 $\mathrm{mg} / \mathrm{L})$; Kinder bis 15 Jahre: $340-510 \mathrm{nmol} / \mathrm{L}$ (20-30 mg/L).

Umrechnungsfaktor: $\mathrm{mg} / \mathrm{L} \times 17=\mathrm{nmol} / \mathrm{L}$.

Die TBG-Bestimmung wird heute nur noch bei speziellen Erkrankungen benötigt, wie beim erblichen Mangel des Thyroxin-bindenden Globulins, der durch eine Mutation in dem SERPINA7-Gen (früher: TBG-Gen), lokalisiert auf dem X-Chromosom (Xq22.2), verursacht werden kann. Erworbene Erniedrigungen der TBG-Konzentrationen werden weiterhin bei Erkrankungen mit Eiweißverlusten beobachtet, wie beim nephrotischen Syndrom oder bei Leberfunktionsstörungen, die zu einer TBG-Synthesestörung führen können.

In relativ seltenen Fällen ist auch ein TBG-Exzess beschrieben worden. Die Prävalenz des TBG-Exzess wird auf 1:25.000 geschätzt. Erhöhte TBG-Konzentrationen sind häufig mit erhöhten Gesamt-Thyroxinwerten verbunden. Die Konzentration des freien Thyroxins liegt dabei jedoch in der Regel im Referenzbereich, sodass keine Therapie der Schilddrüsenfunktion erforderlich ist.

\section{Literatur}

Fritz KS, Wilcox B, Nelson JC (2007) Quantifying spurious free T4 results attributable to thyroxine-binding proteins in serum dialysates and ultrafiltrates. Clin Chem 53:985-988

Jin HY (2016) Thyroxine binding globulin excess detected by neonatal screening. Ann Pediatr Endocrinol Metab 21:105-108

Thomas L (Hrsg) (2012) Schilddrüsenfunktion. In: Labor und Diagnose. Indikation und Bewertung von Laborbefunden für die medizinische Diagnostik, 8. Aufl. TH-Books, Frankfurt am Main, 1718-1752, TBG S 1740-1741 


\section{Thyroxinbindungs-Index}

- Thyroxinbindungskapazität

\section{Thyroxinbindungskapazität}

W. Hubl

Synonym(e) TBI; TBK; Thyroxinbindungs-Index; T-Uptake

Englischer Begriff thyroxine-binding capacity; TBC; T3-/ T4-uptake

Definition Die Bestimmung der Thyroxinbindungskapazität dient zur Bestimmung der freien Thyroxinbindungsstellen im Blut im Rahmen der Schilddrüsen-Funktionsdiagnostik.

Beschreibung Das Thyroxin wird mit hoher Affinität an - Thyroxin-bindendes Globulin, mit geringerer Affinität an Präalbumin und Albumin gebunden. Die Bestimmung des Gesamt-Thyroxins ( $\triangleright$ Thyroxin, gesamt) erlaubt deshalb nur dann eine richtige Bewertung, wenn die Thyroxinbindungskapazität im Blutserum im Referenzbereich liegt. Bei erhöhter oder erniedrigter Thyroxinbindungskapazität kann es zu falsch positiven oder falsch negativen Gesamt-Thyroxin-Resultaten kommen, obwohl die Konzentration der freien Schilddrüsenhormone im euthyreoten Bereich liegt.

Aus diesem Grund wurden Versuche unternommen, diese Störmöglichkeit zu vermindern. Eine Möglichkeit stellt die Bestimmung der Thyroxinbindungskapazität dar. Mithilfe einer Quotientenbildung aus dem Gesamt-Thyroxin ( $\triangleright$ Thyroxin, gesamt) und der Thyroxinbindungskapazität kann der freie Thyroxin-Index ( $\vee$ Thyroxin-Index, freier) berechnet werden, der Veränderungen der Schilddrüsenbindungsproteine berücksichtigt.

Bei der Bestimmung der Thyroxinbindungskapazität konkurrieren ein zum Blutserum zugesetzter Triiodthyronin(T3-)Antikörper mit den endogenen Transportproteinen im Serum um einen ebenfalls zugesetzten T3-Tracer. Die endogenen Schilddrüsenhormone müssen bei dieser Methode sorgfältig entfernt werden, damit keine Verfälschung an den Bindungsstellen des Thyroxin-bindenden Globulins eintreten kann. Die Thyroxinbindungskapazität wird bei diesen Immunoassays automatisch als Thyroxinbindungs-Index (TBI) ausgewertet.

Analytik $\gg$ Radioimmunoassay, $\triangleright$ Enzymimmunoassay.

Referenzbereiche $0,85-1,34$.
Die modernen Methoden zur Erfassung der freien Schilddrüsenhormone haben diesen Test jedoch heute weitgehend verdrängt.

\section{Literatur}

Abraham K, Rösler-Englhardt A, Kessler AC et al (1980) Erfahrungen mit einem Enzymimmunoassay zur Bestimmung der Thyroxin-Bindungskapazität. LaboratoriumsMedizin 4:235-239

Sapin R (2001) Serum thyroxine binding capacity-dependent bias in five free thyroxine immunoassays: assessment with serum dilution experiments and impact on diagnostic performance. Clin Biochem 34:367-371

Vogt W (1995) Schilddrüsenhormone. In: Greiling H, Gressner AM (Hrsg) Lehrbuch der Klinischen Chemie und Pathobiochemie, 3. Aufl. Schattauer, Stuttgart/New York, S 1011

\section{Thyroxin-Index, freier}

W. Hubl

Synonym(e) Freier T4-Index; FT4I; FTI

Englischer Begriff free thyroxine index; FTI

Definition Der Freie Thyroxin-Index stellt ein Maß für das Verhältnis von freien, nicht proteingebundenen zu proteingebundenem Thyroxin dar. Hiermit gelingt es, eine Abschätzung des freien, biologisch aktiven Thyroxins vorzunehmen, um im Zusammenhang mit der Bestimmung des GesamtThyroxins die Funktion der Schilddrüse besser zu beurteilen.

Beschreibung Bei den traditionellen Bestimmungen der Gesamt-Schilddrüsenhormone, die aufgrund der Abhängigkeit von der Konzentration der Bindungsproteine sehr störanfällig sind, wurde der Versuch unternommen, Kriterien für eine Einschätzung der Konzentration der freien Hormone zu erlangen. Eine Möglichkeit war der Freie Thyroxin-Index, der mit der Konzentration des freien Thyroxins korreliert.

Dieser Index wird aus dem Quotienten der GesamtThyroxinbestimmung sowie einem Parameter zur Abschätzung der Proteinbindung, z. B. durch direkte Bestimmung von $>$ Thyroxin-bindendes Globulin oder einem indirekten Bindungstest, wie dem T3- oder T4-Uptake-Test ( $\triangleright$ Thyroxinbindungskapazität), berechnet.

Durch die Einführung des Freien Thyroxin-Index wurde die Schilddrüsen-Funktionsdiagnostik deutlich verbessert mit einer Steigerung der diagnostischen Sensitivität für Schilddrüsenerkrankungen.

Analytik: Zur Bestimmung mit der Indexmethode im Blutserum werden Radioimmunoassay ( $\triangleright$ Radioimmunoassay) 
bzw. Enzymimmunoassays ( $>$ Enzymimmunoassay) eingesetzt.

Referenzbereiche:

\begin{tabular}{l|l}
\hline Frauen: & $73-154 \mathrm{nmol} / \mathrm{L}$ \\
\hline Männer: & $72-147 \mathrm{nmol} / \mathrm{L}$ \\
\hline $\begin{array}{l}\text { Kinder und Jugendliche: } \\
0-6 \text { Tage: }\end{array}$ & $65-268 \mathrm{nmol} / \mathrm{L}$ \\
\hline$>6$ Tage -3 Monate: & $71-232 \mathrm{nmol} / \mathrm{L}$ \\
\hline 3-12 Monate: & $73-216 \mathrm{nmol} / \mathrm{L}$ \\
\hline >1-6 Jahre: & $77-179 \mathrm{nmol} / \mathrm{L}$ \\
\hline $11-20$ Jahre: & $76-170 \mathrm{nmol} / \mathrm{L}$
\end{tabular}

Nach Einführung der direkten Bestimmungen für die freien Schilddrüsenhormone hat der Freie Thyroxin-Index heute an Bedeutung verloren.

\section{Literatur}

Bourcigaux N, Lepoutre-Lussey C, Guéchot J (2010) Thyroid function at the third trimester of pregnancy in a Northern French population. Ann Endocrinol (Paris) 71:519-524

Hörmann R (2007) Schilddrüsenkrankheiten - Leitfaden für Praxis und Klinik. ABW Wissenschaftsverlag, S 50/93

Vogt W (1995) Schilddrüsenhormone. In: Greiling H, Gressner AM (Hrsg) Lehrbuch der Klinischen Chemie und Pathobiochemie, 3. Aufl. Schattauer, Stuttgart/New York, S 1011

TIC

Totalionenstrom

\section{Tiefgefrorene Proben}

- Einfrieren der Proben

Tiglylglyzin

G. F. Hoffmann, C.-D. Langhans und A. Schulze

Englischer Begriff tiglylglycine

Definition Das Glyzinkonjugat der Tiglinsäure entsteht als pathologischer Metabolit bei Störungen im katabolen Stoffwechsel der Aminosäure > Isoleucin.

Struktur $\mathrm{C}_{7} \mathrm{H}_{11} \mathrm{NO}_{3}$; Strukturformel:<smiles>CC=C(C)C(=O)NCC(=O)O</smiles>

Molmasse $157,17 \mathrm{~g}$.

Synthese - Verteilung - Abbau - Elimination Im Stoffwechsel der Aminosäure Isoleucin wird das Transaminierungsprodukt 2-Oxo-3-Methylvaleriansäure oxidativ zu 2Methylbutyryl-CoA decarboxyliert. Dieses wird durch das Enzym 2-Methylbutyryl-CoA-Dehydrogenase weiter abgebaut zu Tiglyl-CoA. Aus diesem entsteht durch Wasseranlagerung und nachfolgender Oxidation 2-Methyl-3-Oxobutyryl-CoA (2-Methylacetoacetyl-CoA), das wiederum durch die 3-Oxothiolase-Reaktion in Acetyl-CoA und PropionylCoA gespalten wird.

Tiglylglyzin wird effizient renal ausgeschieden.

Funktion - Pathophysiologie Bei Defekten der 2-Methyl3-Hydroxy-Butyryl-CoA-Dehydrogenase oder der Oxothiolase kommt es zu Sekundärreaktionen der sich anstauenden Vorstufen. Unter anderem bildet Tiglyl-CoA mit Glyzin das Konjugat Tiglylglyzin. Die Bildung von Tiglylglyzin stellt einen wichtigen Entgiftungs- und Eliminationsweg für sich anstauendes Tiglyl-CoA dar.

\section{Untersuchungsmaterial - Entnahmebedingungen Urin.}

\section{Präanalytik}

- Durch > Flüssig-Flüssig-Extraktion im sauren Medium mittels Ethylacetat oder Diethylether

- Mittels Gaschromatographie-Massenspektrometrie ( $\vee \mathrm{GC}$ MS) als Mono- und Di-Trimethylsilylester

Als Mono-Trimethylsilylester

- Retentionsindex RI:1571

- $\mathrm{M}+(\mathrm{m} / \mathrm{z}): 229$

- Quant Ion (m/z): 229

- Conf. Ion (m/z): 214

- Retentionsindex RI:1564

- $\mathrm{M}+(\mathrm{m} / \mathrm{z}): 301$

- Quant Ion (m/z): 286

- Conf. Ion (m/z): 184

Internationale Einheit $\mathrm{mmol} / \mathrm{mol}$ Kreatinin (Urin).

Referenzbereich - Kinder $<2 \mathrm{mmol} / \mathrm{mol}$ Kreatinin. Pathologischer Bereich: 
- $2-1000 \mathrm{mmol} / \mathrm{mol}$ Kreatinin ( $\beta$-Ketothiolasemangel)

- $13-497 \mathrm{mmol} / \mathrm{mol} \mathrm{Kreatinin} \mathrm{(Propionazidämie)}$

Indikation Metabolische Ketoacidose, Hypoglykämien, progrediente psychomotorische Retardierung.

Interpretation Erhöhte Ausscheidungen von Tiglylglyzin neben 2-Methyl-3-Hydroxybuttersäure kennzeichnen einen 2-Methyl-3-Hydroxy-Butyryl-CoA-Dehydrogenasemangel. Wird zusätzlich vermehrt 2-Methylacetessigsäure nachgewiesen, liegt ein 3-Oxothiolasemangel vor, auch 2-Methylacetoacetyl-CoA-Thiolasemangel oder $\beta$-Ketothiolasemangel genannt. Bei diesem Defekt neigen die Patienten zu ketoacidotischen Entgleisungen.

Des Weiteren wird Tiglylglyzin auch bei einer Propionazidämie neben anderen diagnostischen Metaboliten wie Propionylglycin und 3-Hydroxysäuren vermehrt im Urin ausgeschieden.

Diagnostische Wertigkeit Erhöhte Urinausscheidungen von Tiglylglyzin sind ein sicherer Hinweis auf einen Defekt im Isoleucinstoffwechsel. Die weitere Differenzierung erfordert Kenntnisse über die o.g. weiteren Metabolite bzw. die enzymatische oder molekularbiologische Bestätigungsdiagnostik.

\section{Literatur}

Blau N, Duran M, Gibson KM, Dionisi-Vici C (Hrsg) (2014) Physician's guide to the diagnosis, treatment, and follow-up of inherited metabolic diseases. Springer, Berlin/Heidelberg

\section{Tilidin}

C. Vidal und W.-R. Külpmann

\section{Englischer Begriff tilidine}

Definition Opioidanalgetikum.

Strukturformel:

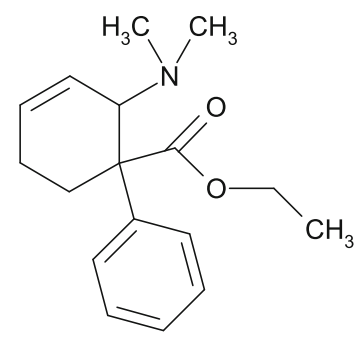

Molmasse $273,38 \mathrm{~g}$.

Synthese - Verteilung - Abbau - Elimination Tilidin wird oral appliziert und rasch enteral resorbiert (Bioverfügbarkeit
$98 \%$ ). Als First-pass-Effekt wird es vollständig zu NorTilidin bzw. Bis-Nor-Tilidin metabolisiert. Weniger als $2 \%$ der Dosis erscheinen unverändert im Urin.

Halbwertszeit 2-3 Stunden (Plasma).

Funktion - Pathophysiologie Tilidin ist Prodrug. Wirksam ist der Metabolit Nor-Tilidin als Agonist an $\mu$-Opioid-Rezeptoren. Bei Intoxikation werden Angstzustände und Halluzinationen beobachtet, in schweren Fällen Ateminsuffizienz bis zum Atemstillstand.

Untersuchungsmaterial-Entnahmebedingungen Plasma (P), Serum (S), Urin.

Analytik HPLC zur quantitativen Bestimmung im Plasma, - GC-MS zum Nachweis von Tilidin-Metaboliten im Urin. Opiat-Immunoassays erfassen Tilidin/-Metabolite nicht.

Indikation Verdacht auf Intoxikation.

Interpretation Therapeutischer Bereich (S, P): Tilidin 0,05-0,12 $\mathrm{mg} / \mathrm{L}$, Nor-Tilidin unbekannt; toxisch: Tilidin und Nor-Tilidin unbekannt; komatös-letal: Tilidin $1,7 \mathrm{mg} / \mathrm{L}$ (Einzelfall), Nor-Tilidin 4,4 mg/L (Einzelfall).

Tilidin hat nur geringe Bedeutung in der Drogenszene: Das handelsübliche Präparat (Valoron) enthält den Opiatantagonisten Naloxon, was den Abusus stark erschwert. Wegen des häufigen klinischen Einsatzes ist eine Intoxikation eher iatrogen bedingt.

\section{Literatur}

Binscheck T (2009) Tilidine. In: Külpmann WR (Hrsg) Clincial toxicological analysis. Wiley-VCH, Weinheim, S 257-262

\section{Time of flight}

- Massenspektrometrie

Time-resolved Fluorescence Immunoassay

W. Stöcker und C. Krüger

Synonym(e) DELFIA; TR-FIA; Zeitaufgelöste Fluoreszenz

Englischer Begriff time-resolved fluorescence immunoassay (TR-FIA); delayed emission lanthanide fluorescent immunoassay (DELFIA) 
Definition Der Time-Resolved Fluorescence Immunoassay (TR-FIA) ist ein $>$ Sandwich-Assay, bei dem die für die Markierung ( $\triangleright$ Fluoreszenzmarkierung) verwendeten Fluorophore das Emissionslicht zeitversetzt abgeben und das Messsignal zur Reduktion von Störsignalen nach impulsartiger Anregung nur während der Emissionsphase erfasst wird.

Physikalisch-chemisches Prinzip Beim TR-FIA werden als Fluorophore z. B. Chelate aus Diketonen und den Lanthaniden Europium und Terbium verwendet. Bei der impulsartigen Anregung des Metallchelates absorbiert das Diketon die Anregungsenergie und gibt sie an das Lanthanid weiter, das dann, bedingt durch den Umweg zeitversetzt, ein Lichtquant niedrigerer Energie abstrahlt. Auch die fotometrische Erfassung des emittierten Fluoreszenzlichtes erfolgt zeitversetzt. Dadurch werden im Vergleich zu den üblichen Fluoreszenzimmuntests Untergrundfluoreszenz und Streulicht reduziert, da sich diese Störeinflüsse normalerweise nur unmittelbar nach der Anregung bemerkbar machen: Die Lanthanid-Chelate haben Fluoreszenzabklingzeiten von $10-1000 \mathrm{~ms}$, man misst die Lanthanid-Fluoreszenz nachdem Störungen durch gestreutes Anregungslicht und die kurzlebigen Fluoreszenzen (1-20 ns) der biologischen Proben abgeklungen sind (s. a. > Fluoreszenz, zeitaufgelöste).

Weitere messtechnisch günstige Eigenschaften der Lanthanid-Chelate sind die sehr starke Stokes-Verschiebung von etwa $340 \mathrm{~nm}$ nach $613 \mathrm{~nm}$ und die sehr schmale Emissionsbande mit einer Halbintensitätsbreite von etwa $10 \mathrm{~nm}$. Die Bestimmung wird dadurch zusätzlich empfindlich und reproduzierbar, die Messung beeinflusst biologische Eigenschaften wenig. Der TR-FIA wird meist als Sandwich-Assay mit zwei Antikörpern durchgeführt.

Einsatzgebiet Antigenbestimmungen.

Untersuchungsmaterial Serum, Plasma.

Sensitivität Die analytische Sensitivität der TR-FIA liegt bei $10^{-18}-10^{-20} \mathrm{~mol} / \mathrm{L}$.

Praktikabilität - Automatisierung - Kosten Der TR-FIA weist gleich hohe Empfindlichkeit, Reproduzierbarkeit und Genauigkeit wie der $>$ Radioimmunoassay auf und wäre im Prinzip hinsichtlich Geschwindigkeit der Testdurchführung und breiter Anwendbarkeit dem $\triangleright$ Enzymimmunoassay ebenbürtig. Einige TR-FIA sind als manuelle sowie automatisierte Immunoassays verfügbar.

\section{Literatur}

Wild D (2001) The immunoassay handbook. Nature Publishing Group, New York, S 167-168

\section{TIMP-1}

- Tissue inhibitor of metalloproteinase-1

Tiselius, Arne Wilhelm Kaurin

A. M. Gressner und O. A. Gressner

Lebensdaten Schwedischer Wissenschaftler, geboren am 10. August 1902 in Stockholm, gestorben am 29. Oktober 1971 in Uppsala.

Verdienste Tiselius studierte an der Universität Uppsala Physik, Chemie und Mathematik und wurde anschließend (1925) Assistent im Arbeitskreis von Theodor Svedberg ( $\triangleright$ Svedberg, Theodor; $>$ Svedberg-Einheit), wo er mit dem Arbeitsgebiet der Proteintrennungsmethodik in Kontakt kam. Die Beschäftigung mit elektrophoretischen Untersuchungen von Proteinen führte im Jahr $1930 \mathrm{zu}$ seiner Promotion mit dem Thema ,The moving boundary method for studying the electrophoresis of proteins“. Nach einem Forschungsaufenthalt in den USA nahm Tiselius in Uppsala seine elektrophoretischen Forschungsarbeiten wieder auf, die zur Konstruktion der „Tiselius-Elektrophoreseapparatur“ (1937) führten. Apparatur und Methodik erlaubten eine wesentlich schnellere Separation der Proteine, die mit der Schlierenmethode nach August Toepler (1864) sichtbar gemacht und für biochemische Untersuchungen eingesetzt werden konnten. Im Schlierendiagramm beschrieb Tiselius erstmals 5 Banden: $>$ Albumin, $\alpha-1-, \alpha-2-, \beta$ - und $\gamma$ - $>$ Globuline ( $>$ Serumprotein-Elektrophorese). Für die in der Folgezeit weiter ausgebaute und verfeinerte Methode, z. B. für die Trennung der humanen Plasmaproteine, erhielt Tiselius zahlreiche Auszeichnungen darunter im Jahr 1948 den Nobelpreis für Chemie, 12 Ehrendoktorate und die Präsidentschaft der Nobel-Stiftung (s. a. $>$ Elektrophorese).

\section{Literatur}

Tiselius A (1937) A new apparatus for electrophoretic analysis of colloidal mixtures. Trans Faraday Soc 33:524-531

\section{Tissue Factor}

T. Stief

Synonym(e) CD142; Gerinnungsfaktor III; Gewebsfaktor; Thromboplastin; TF 


\section{Englischer Begriff tissue factor; TF}

Definition Tissue Factor (TF) ist Kofaktor für F7/F7a. Wichtigstes Substrat des TF-F7a-Komplexes (extrinsische Tenase) ist F10.

Beschreibung TF ist ein ca. $45 \mathrm{kDa}$ großes Typ-I-integrales Membranprotein, dessen extrazellulärer Teil aus zwei > Fibronectin-Typ-III-Domänen besteht. TF besitzt eine nur aus 23 Aminosäuren bestehende zytoplasmatische Domäne, deren Funktion nicht bekannt ist, jedoch wohl keine prokoagulatorische Funktion besitzt. Unter normalen Bedingungen wird TF nicht auf Zellen gefunden, die in einem direkten Kontakt mit der Zirkulation sind. Erst eine Schädigung des Zellverbandes führt zu einer Exposition von TF auf der Zelloberfläche. Der TF wird dort sehr hoch exprimiert gefunden, wo eine Blutung fatale Folgen hätte, z. B. in Gehirn, Nierenglomeruli, Plazenta. TF ist allosterischer Aktivator von F7/F7a. Inhibiert werden die TF-7a-Komplexe durch den „tissue factor pathway inhibitor“ (TFPI). Tissue Factor wird im Thromboplastinreagenz für den Quick-Test ( $\triangleright$ Thromboplastinzeit) verwendet. Thromboplastine können aus Hirngewebe, Lunge oder Plazenta verschiedener Spezies gewonnen oder rekombinant in eukaryontischen oder prokaryontischen Expressionssystemen hergestellt werden. Tissue Factor ist ein interessanter Biomarker für extrinsische Gerinnungsaktivierung wie z. B. bei Sepsis. Intensivpflichtige Patienten mit schwerer Sepsis haben ca. 4-fach erhöhte Plasmakonzentrationen an TF.

Normbereich $140 \pm 42 \mathrm{pg} / \mathrm{mL}$; Patienten mit schwerer Sepsis haben $568 \pm 225 \mathrm{pg} / \mathrm{mL}$.

Messtechnik Enzymimmunoassay. EDTA-Plasma sollte mit 1,25 M Arginin, pH 8,7 stabilisiert sein. In der CaptureAntibody-Antigen-Reaktion sollten 400-600 mM Arginin anwesend sein, um eine unspezifische Zerstörung des Antigens (hier: TF) zu verhindern.

\section{Literatur}

Morrissey JH (2004) Tissue factor: a key molecule in hemostatic and nonhemostatic systems. Int J Hematol 79:103-108

Stief TW, Ijagha O, Weiste B, Herzum I, Renz H, Max M (2007) Analysis of hemostasis alterations in sepsis. Blood Coagul Fibrinolysis 18:179-186

Stief TW, Ulbricht K, Max M (2010) ICAM-1, tissue factor, protein C, and AT3 dynamic in severe sepsis. Hemost Lab 3:239-249

Tissue factor pathway inhibitor

T. Stief und P. Kiefer

Synonym(e) TFPI-1
Englischer Begriff tissue factor pathway inhibitor

Definition TFPI ist ein Kunitz-Typ-Proteinaseinhibitor (wie Aprotinin), der den Faktor-VIIa-Tissue-Factor-Komplex inhibiert. Nachfolgend ist die TFPI-Komplexbildung mit FVII und FX dargestellt (modifiziert nach Ehsan und Plumbley 2002 (die Inhibition von FIXa (F9a) ist noch Gegenstand der Forschung)).

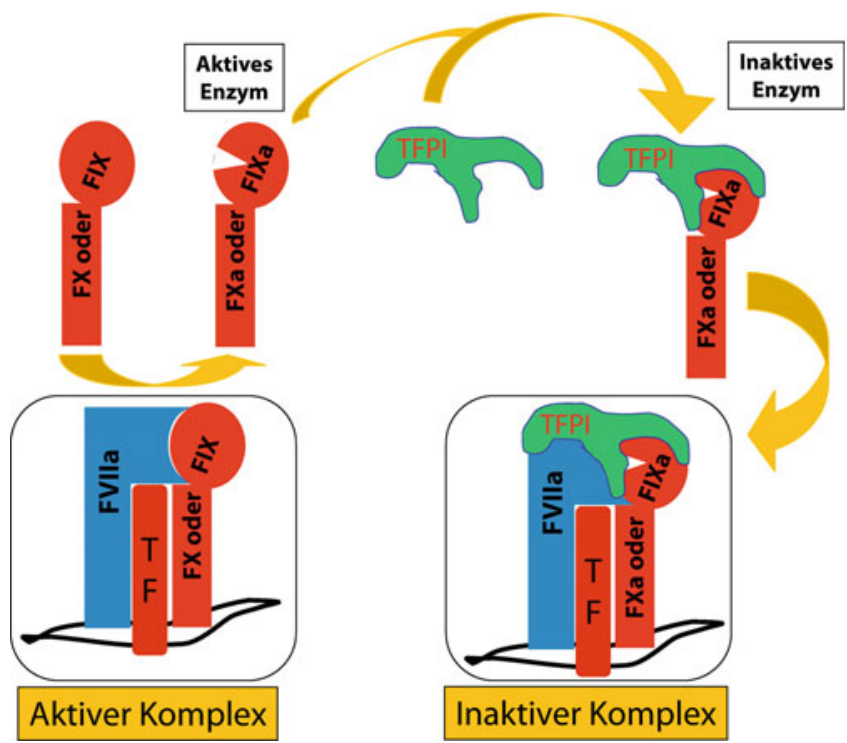

Beschreibung TFPI-1 ist ein $36 \mathrm{kDa}$ großes Glykoprotein, das primär in mikrovaskulären Endothelzellen produziert wird. Größtenteils findet sich TFPI an den Gefäßzellen gebunden, $10 \%$ sind im Plasma an Lipoproteine gebunden und nur ein kleiner Teil findet sich in den $>$ Thrombozyten. Die normale Konzentration von TFPI ist ca. $100 \mu \mathrm{g} / \mathrm{L}$. Gebundenes TFPI kann durch $>$ Heparin und Heparinoide ins Plasma freigesetzt werden oder durch die Aktivierung von Thrombozyten. TFPI enthält 3 tandemartig angeordnete Kunitz-Inhibitordomänen, wobei die erste mit $>$ Tissue Factor-(TF-)FVIIa interagiert. Die dritte Kunitz-Domäne und die C-terminale Region von TFPI enthalten die Heparinbindende Domäne. Die erste Kunitz-Domäne reagiert mit der aktiven Seite des FVIIa, jedoch nur, wenn FVIIa an den TF gebunden ist. Die Affinität zu dem FVIIa-TF-Komplex wird durch Heparin verstärkt. Die zweite Kunitz-Domäne bindet an die aktive Seite des Faktor Xa. Sobald dieser Komplex gebildet ist, bindet der Inhibitor mit hoher Affinität an FVIIa im TF-VIIa-Komplex, um den eigentlichen tetramolekularen Inhibitorkomplex aus TF:VIIa:TFPI:Xa zu bilden.

\section{Literatur}

Ehsan A, Plumbley JA (2002) Introduction to thrombosis and anticoagulant therapy. In: Hammening DM (Hrsg) Clinical hematology and fundamentals of hematostasis. F.A. Davis Company Philadelphia, 534-562

Price GC, Thompson SA, Kam PCA (2004) Tissue factor and tissue factor pathway inhibitor. Anaesthesia 59:483-492 


\section{Tissue inhibitor of metalloproteinase-1}

\section{S. Holdenrieder und P. Stieber}

\section{Synonym(e) TIMP-1}

Englischer Begriff tissue inhibitor of metalloproteinases 1

Definition TIMP-1 ist ein $28 \mathrm{kDa}$ schweres Glykoprotein und Vertreter einer Proteinaseninhibitor-Familie. Er liegt in löslicher Form vor und bindet an die Matrix-Metalloproteinase 9 ( $\triangleright$ Matrix-Metalloproteinasen).

Struktur Die Familie der ,tissue inhibitors of metalloproteinases" besteht aus derzeit 4 Mitgliedern (TIMP 1-4): Sie besitzen konservierte Cysteinreste, können hochaffine, nicht kovalente Bindungen mit den carboxylterminalen Domänen von pro-MMPs eingehen (z. B. TIMP-1 mit pro-MMP-9, TIMP-2 mit pro-MMP-2) und benötigen für ihre Aktivierung keine vorhergehende proteolytische Spaltung.

TIMPs weisen ein unterschiedliches Verhalten in Zellen, Geweben und Flüssigkeiten auf, wobei sie als multifunktionelle Moleküle agieren: TIMP-1 und TIMP-2 liegen in flüssiger Form vor, wobei TIMP-1 auf eine Vielzahl externer Stimuli reagiert, während die Expression von TIMP-2 konstitutiv zu sein scheint. TIMP-3 ist unlöslich und an die extrazelluläre Matrix gebunden; TIMP-4 schließlich weist eine gewebsspezifische Aktivität auf.

Molmasse $28 \mathrm{kDa}$.

Funktion - Pathophysiologie Matrix-Metalloproteinasen (MMPs), insbesondere MMP-2 und MMP-9, werden bei verschiedenen Karzinomen überexprimiert und spielen eine wichtige Rolle bei der Degradation der extrazellulären Matrix im Rahmen der Tumorzellinvasion und Metastasierung. Die „tissue inhibitors of metalloproteinases“ sind endogene Regulatoren der Matrix-Metalloproteinasen; TIMP-1 und -2 inhibieren allerdings nicht nur das Wachstum, die Invasivität sowie die Metastasierung von Tumoren, sondern haben auch proliferative und antiangiogenetische Wirkung.

Bei aktiviertem Tumorwachstum können MMPs und die gegenregulierenden TIMPs gleichzeitig erhöht sein. Deshalb bieten sich TIMPs als Marker der Früherkennung und als Prognosemarker bei malignen Tumoren an.

Untersuchungsmaterial - Entnahmebedingungen Plasma, Serum.

\footnotetext{
Analytik - Enzymimmunoassay (EIA), D Enzyme-linked Immunosorbent Assay (ELISA).
}

Referenzbereich - Erwachsene Median 72 ng/mL (methoden- und materialabhängig).
Indikation Evtl. Prognosemarker bei verschiedenen soliden Tumoren.

Interpretation Generell wurden bei Patienten mit malignen Erkrankungen höhere Plasmakonzentrationen von TIMP-1 beobachtet als bei gesunden Personen und z. T. auch als bei Patienten mit benignen Erkrankungen. Aufgrund der Freisetzung bei Nichttumorpatienten ist die Aussagekraft von TIMP-1 für die Früherkennung des kolorektalen Karzinoms allerdings limitiert, weshalb zuletzt eine Kombination mit CEA vorgeschlagen wurde. Hierbei ist zu jedoch berücksichtigen, dass TIMP-1 sehr empfindlich gegenüber präanalytischen Einflussfaktoren wie Lagerungszeit, -temperatur, Schütteln, wiederholtes Einfrieren etc. ist.

Bei verschiedenen soliden Tumorerkrankungen wurde eine Assoziation einer hohen TIMP-1-Konzentration im Plasma mit einer ungünstigen Prognose gefunden, so bei kolorektalem, Mamma-, Nierenzell-, Ovarial- und Lungenkarzinom.

Diagnostische Wertigkeit Evtl. Prognosemarker bei verschiedenen soliden Tumoren.

\section{Literatur}

Dresse M et al (2008) Dependence of TIMP-1 plasma levels on preanalytical specimen handling. Tumour Biol 29:35-40

Nielsen HJ et al (2011) Plasma TIMP-1 and CEA in detection of primary colorectal cancer: a prospective, population based study of 4509 high-risk individuals. Scand J Gastroenterol 46:60-69

Schrohl AS et al (2004) Tumor tissue levels of tissue inhibitor of metalloproteinase-1 as a prognostic marker in primary breast cancer. Clin Cancer Res 10:2289-2298

\section{Tissue Polypeptide Antigen}

S. Holdenrieder und P. Stieber

Synonym(e) TPA

Englischer Begriff tissue polypeptide antigen

Definition Das „tissue polypeptide antigen“ (TPA) stellt einen Komplex der Zytokeratinfragmente 8, 18 und 19 dar.

Struktur Das TPA umfasst 3 Mitglieder der $>$ ZytokeratinFamilie, 2 aus der Gruppe der sauren Typ-I-Keratine (Zytokeratine 9-20) und eines aus der Gruppe der basischen TypII-Keratine (Zytokeratine 1-8).

Synthese - Verteilung - Abbau - Elimination Physiologisch kommen die Zytokeratine 8, 18 und 19 ubiquitär im 
menschlichen Körper vor, insbesondere in epithelialen Geweben. Die Ausscheidung erfolgt wie bei allen Zytokeratinen überwiegend renal. Niereninsuffizienzen verzögern die Elimination der Zytokeratine und können zu erhöhten Konzentrationen führen. Auch sind erhöhte TPA-Werte bei benignen Lebererkrankungen beschrieben, was auf eine zumindest teilweise hepatische Metabolisierung hinweist.

Funktion - Pathophysiologie Die klinische Bedeutung der TPA-Bestimmung liegt im Therapiemonitoring, der frühzeitigen Rezidiverkennung und Prognose des Bronchialkarzinoms. Bei anderen malignen Tumorerkrankungen wie z. B. dem Blasen-, Ovarial-, Pankreas- und hepatozellulären Karzinom kann TPA allenfalls komplementär zu den Standardmarkern eingesetzt werden.

Gegenüber dem Zytokeratin 19 (syn. CYFRA 21-1, - Zytokeratin-19-Fragment) weist das TPA ein weniger restriktives Verteilungsmuster im menschlichen Körper aus, was sich in einer niedrigeren Spezifität für epitheliale Karzinome niederschlägt.

Untersuchungsmaterial - Entnahmebedingungen Serum, Plasma, Körperflüssigkeiten.

Analytik $>$ Enzymimmunoassay (EIA), $>$ Radioimmunoassay (RIA), > Immunradiometrischer Assay (IRMA).

Konventionelle Einheit $\mathrm{ng} / \mathrm{mL}(\mu \mathrm{g} / \mathrm{L})$.

\section{Indikation}

- Therapiekontrolle und Nachsorge beim Bronchialkarzinom als Zweitmarker, Prognose

- Evtl. Therapiekontrolle und Nachsorge beim Blasen-, Ovarial-, Pankreas- und hepatozellulären Karzinom

Interpretation Die meisten TPA-Assays sind für die Anwendung im Serum und Plasma ausgetestet und können auch für die Bestimmung von TPA in anderen Körperflüssigkeiten eingesetzt werden.

Da TPA keine Organspezifität aufweist, ist bei allen soliden Tumorerkrankungen mit positiven Testergebnissen zu rechnen. Hohe Wertlagen wurden u. a. beim Bronchialkarzinom, beim Blasenkarzinom, beim Ovarialkarzinom, beim Pankreaskarzinom und beim hepatozellulären Karzinom beobachtet. Ebenso können benigne Erkrankungen des pulmonalen, gastrointestinalen, urologischen und gynäkologischen Organsystems zu erhöhten Werten führen. Insbesondere können Einschränkungen der Nieren- und der Leberfunktion (Korrelation mit den Transaminasen; Aspartat-Aminotransferase, Alanin-Aminotransferase) erhöhte TPA-Werte hervorrufen.

Trotz der diagnostischen und differenzialdiagnostischen Limitierung kann die Bestimmung von TPA für die Verlaufs- untersuchung während und nach Therapie beim Bronchialkarzinom und eingeschränkt auch bei den anderen oben genannten Karzinomen sowie für die Prognose beim Bronchialkarzinom als Zweitmarker sinnvoll sein.

Allerdings ist kein eindeutiger Vorteil von TPA gegenüber den standardisiert eingesetzten Kenngrößen CYFRA 21-1 ( $\triangleright$ Zytokeratin-19-Fragment) (Bronchial-, Blasenkarzinom), > Carbohydrate antigen 125 (Ovarialkarzinom), > Carbohydrate antigen 19-9 (Pankreaskarzinom) und $\triangleright \alpha_{1}$-Fetoprotein (AFP; hepatozelluläres Karzinom) gegeben.

\section{Diagnostische Wertigkeit}

- Bronchialkarzinom: Therapiekontrolle und Nachsorge als Zweitmarker, Prognose

- Evtl. Blasen-, Ovarial-, Pankreas- und hepatozelluläres Karzinom: Therapiekontrolle und Nachsorge

\section{Literatur}

Barak V, Goike H, Panaretakis KW, Einarsson R (2004) Clinical utility of cytokeratins as tumor markers. Clin Biochem 37:529-540

Stieber P, Heinemann V (2008) Sinnvoller Einsatz von Tumormarkern. J Lab Med 32:339-360

\section{Tissue Polypeptide Specific Antigen}

S. Holdenrieder und P. Stieber

Synonym(e) TPS

Englischer Begriff tissue polypeptide specific antigen

Definition Das „tissue polypeptide specific antigen“ (TPS) ist die M3-spezifische Komponente des \ tissue polypeptide antigen (TPA) und weist das Zytokeratin 18 nach.

Struktur TPS gehört der Gruppe der sauren Typ-I-Keratine (Zytokeratine 9-20) an, die mit basischen Typ-II-Keratinen (Zytokeratine 1-8) Dimere bilden. Während die Zytokeratine ( $\triangleright$ Zytokeratin) selbst serumunlöslich sind, sind die Fragmente nach proteolytischem Abbau der hydrophoben Amino-Kopfsequenz und Carboxy-Schwanzsequenz löslich und können im Serum nachgewiesen werden.

Synthese - Verteilung - Abbau - Elimination Physiologisch kommen die Zytokeratine 18 ubiquitär im menschlichen Körper vor, insbesondere in epithelialen Geweben. Zytokeratin 18 wird während der späten S- und G2-Phasen produziert und unmittelbar nach der Mitose freigesetzt. Somit gilt TPS als 
Proliferationsmarker vor allem bei Tumorerkrankungen. Die Ausscheidung erfolgt wie bei allen Zytokeratinen überwiegend renal. Niereninsuffizienzen verzögern die Elimination der Zytokeratine und können zu erhöhten Konzentrationen führen.

Funktion - Pathophysiologie Die klinische Bedeutung der TPS-Bestimmung liegt möglicherweise im Therapiemonitoring, der frühzeitigen Rezidiverkennung und Prognose des Bronchial- und des Mammakarzinoms. Bei anderen malignen Tumorerkrankungen wie z. B. dem Blasen-, Ovarial-, Pankreas- und kolorektalen Karzinom ist TPS ebenfalls erhöht, erreicht jedoch nicht die diagnostische Aussagekraft der standardmäßig eingesetzten Marker.

Untersuchungsmaterial- Entnahmebedingungen Serum, Plasma, Körperflüssigkeiten.

Analytik > Enzymimmunoassay (EIA), \ Radioimmunoassay (RIA), > Immunradiometrischer Assay (IRMA).

Konventionelle Einheit $\mathrm{ng} / \mathrm{mL}(\mu \mathrm{g} / \mathrm{L})$.

Referenzbereich - Erwachsene $<80 \mathrm{ng} / \mathrm{mL}$ (methodenabhängig).

\section{Indikation}

- Therapiekontrolle und Nachsorge beim Bronchialkarzinom als Zweitmarker, Prognose

- Evtl. Therapiekontrolle und Nachsorge beim Mammakarzinom

Interpretation Die meisten TPS-Assays sind für die Anwendung im Serum und Plasma ausgetestet und können auch für die Bestimmung von TPS in anderen Körperflüssigkeiten eingesetzt werden.

Da TPS keine Organspezifität aufweist, ist bei allen soliden Tumorerkrankungen mit positiven Testergebnissen zu rechnen. Hohe Wertlagen wurden u. a. beim Bronchial-, Mamma-, Blasen-, Ovarial-, Pankreas- und beim kolorektalen Karzinom beobachtet. Ebenso können benigne Erkrankungen des pulmonalen, gastrointestinalen, urologischen und gynäkologischen Organsystems zu erhöhten Werten führen. Insbesondere können Einschränkungen der Nieren erhöhte TPSWerte hervorrufen.

Trotz der diagnostischen und differenzialdiagnostischen Limitierung kann die Bestimmung von TPS für die Verlaufsuntersuchung während und nach Therapie beim Bronchialkarzinom und beim Mammakarzinom sowie für die Prognose beim Bronchialkarzinom sinnvoll sein.

Allerdings ist kein eindeutiger Vorteil von TPS gegenüber den standardisiert eingesetzten Markern CYFRA 21-1
( $\triangleright$ Zytokeratin-19-Fragment) (Bronchialkarzinom) und CEA ( $\triangleright$ Carcinoembryonales Antigen) bzw. $\triangleright$ Carbohydrate antigen 15-3 (Mammakarzinom) gegeben.

\section{Diagnostische Wertigkeit}

- Bronchialkarzinom: Therapiekontrolle und Nachsorge als Zweitmarker, Prognose

- Evtl. Mammakarzinom: Therapiekontrolle und Nachsorge

\section{Literatur}

Barak V, Goike H, Panaretakis KW, Einarsson R (2004) Clinical utility of cytokeratins as tumor markers. Clin Biochem 37:529-540

Stieber P, Heinemann V (2008) Sinnvoller Einsatz von Tumormarkern. J Lab Med 32:339-360

\section{Tissue-Plasminogenaktivator}

T. Stief

Synonym(e) EC 3.4.21.68; t-PA

Englischer Begriff tissue-type plasminogen activator (t-PA)

Definition t-PA ist eine Serinprotease, die insbesondere an - Fibrin gebundenes > Plasminogen zu Plasmin aktiviert, das Fibringerinnsel auflöst.

Synthese - Verteilung - Abbau - Elimination t-PA wird von unterschiedlichen Zellen gebildet, so von Endothelzellen, Monozyten, Megakaryozyten, neuronalen Zellen. Besonders t-PA-reiche Organe sind Lunge, Prostata und Uterus. Freies und mit seinem primären Inhibitor PAI-1 ( $\triangleright$ PlasminogenAktivator-Inhibitor 1) komplexiertes t-PA wird durch Hepatozyten binnen Minuten aus der Zirkulation genommen (Halbwertszeit bei Patienten mit Leberzirrhose deutlich verlängert). Das Gen, das für t-PA kodiert, ist auf dem kurzen Arm des Chromosoms 8 lokalisiert und umspannt ca. $32 \mathrm{~kb}$. t-PA wird als ein $68 \mathrm{kDa}$ schweres einkettiges Glykoprotein sekretiert (sct-PA), das aus 527 Aminosäureresten besteht. sct-PA kann durch Spaltung an der Position Arg257 durch Plasmin in eine zweikettige Form (tct-PA) überführt werden (limitierte Proteolyse). Beide Formen sind katalytisch aktiv. Die N-terminale Region (A-Kette) enthält die Fingerkonformation, die EGF-ähnliche Domäne und zwei Kringel-Domänen. Die katalytische Domäne von t-PA (B-Kette) besteht aus 230 Aminosäuren und zeigt Sequenzhomologien zu anderen Serinproteasen. t-PA ist wie Urokinase eine hoch spezifische Protease. Einziges Substrat ist Plasminogen, in dem die 
Plasminogenaktivatoren eine einzige Peptidbindung Arg561Val562 spalten (limitierte Proteolyse). Fibrin stimuliert die katalytische Aktivität von t-PA und bietet eine Oberfläche für die Interaktion mit Plasminogen.

Funktion - Pathophysiologie Ein kongenitaler Mangel an t-PA wurde nicht berichtet.

Analytik Im Gegensatz zu Single-Chain-Urokinase (ca. $6 \mathrm{ng} /$ $\mathrm{mL}$ ) findet sich im Plasma nahezu kein freies Single-Chain-tPA, es zirkuliert im inaktiven Komplex mit PAI-1. Die Aktivität von > Plasminogen-Aktivator-Inhibitor 1 ist klinisch wesentlich wichtiger als t-PA-Antigen.

\section{Literatur}

Bachmann F (2001) Plasminogen-Plasmin Enzym System. In: Colman RW, Hirsh J, Marder VJ et al (Hrsg) Hemostasis and thrombosis. Lippincott Williams \& Wilkins, Philadelphia, S 275-320

\section{Titin-Antikörper}

- Autoantikörper gegen Titin

\section{Titrans}

> Titration

\section{Titrant}

> Titration

\section{Titration}

T. Arndt

Synonym(e) Analyse, titrimetrische; Analyse, volumetrische; Maßanalyse; Titrimetrie

Englischer Begriff titration
Definition Quantitative Analysenmethode, bei der die Masse (oder Konzentration) eines Analyten über eine Volumenmessung (Maßanalyse, volumetrische Analyse) bestimmt wird.

Beschreibung Bei der Maßanalyse wird jenes Volumen eines geeigneten Titrators (Reaktionspartner des Analyten, auch Titrant bezeichnet) gemessen, das bis zur vollständigen Gleichgewichtseinstellung einer genau definierten Reaktion verbraucht wird.

Der Vorgang heißt Titration, die Handlung titrieren. Der Ablauf einer Titration lässt sich allgemein wie folgt zusammenfassen: Zur Probe mit dem Analyten wird der Titrator, d. h. eine Titrationslösung mit einem geeigneten Reaktionspartner für den Analyten, in kleinen Volumenanteilen zugegeben. Das Ende der Titration wird am sog. Äquivalenzpunkt (stöchiometrischer Punkt, theoretischer Endpunkt) erreicht. Er bezeichnet jenen Moment, an dem sich entsprechend der Reaktionsgleichung äquivalente Mengen an Analyt (Titrans) und Titrator umgesetzt haben. Er muss entweder direkt sichtbar sein oder auf irgendeine Weise indiziert werden können. Oft gibt man anstelle des Äquivalenzpunktes den sog. Endpunkt der Titration an. Er soll möglichst mit dem Äquivalenzpunkt zusammenfallen. Der Endpunkt bezeichnet jenen Moment, an dem sich die Eigenschaft der Lösung im Probengefäß messbar (z. B. visuell oder elektrochemisch) ändert. Aus dem Verbrauch an Titrator $(\mathrm{mL})$ bis zum Erreichen des Endpunktes lässt sich über geeignete Kalibrationsfunktionen die Masse des Analyten ableiten.

In Abhängigkeit vom Reaktionstyp zwischen Titrans und Titrant sowie den Methoden zur Detektion des Endpunkts lässt sich eine Vielzahl von verschiedenen Titrationsmethoden unterscheiden. Als wichtigste seien die Säure-Basen-, Redox-, Fällungs- und komplexometrischen Titrationen sowie die Titration mit Endpunkterkennung mit Indikatorlösungen oder elektrochemischen Methoden genannt.

Vorteile der Maßanalyse sind der geringe apparative Aufwand und die Unabhängigkeit von kommerziellen Assays. Dennoch kommt die Methode im klinisch-chemischen Labor kaum noch zum Einsatz (bei ungebrochener Popularität für spezielle Anwendungen wie Umwelt- und Wasseranalytik). Gründe hierfür sind der geringe Probendurchsatz bei hoher Personalbindung, die erforderlichen relativ großen Probenvolumina und die zumeist fehlende Mechanisierung. Letztere ist z. B. für die Stickstoffbestimmung nach Kjeldahl ( $\triangleright$ Kjeldahl-Methode) realisiert.

\section{Literatur}

Latscha HP, Linti GW, Klein HA (2004) Analytische Chemie. Chemie - Basiswissen III. Springer-Verlag, Berlin/Heidelberg/New York 


\section{Titration, komplexometrische}

Komplexometrie

\section{Titration, voltametrische}

- Voltametrie

\section{Titrimetrie}

> Titration

TK

- Thymidinkinase

\section{T-Lymphozyt}

H. Baum

Synonym(e) T-Zelle

\section{Englischer Begriff $\mathrm{T}$ cell}

Definition Effektorzelle der T-Zell-Lymphopoese.

Beschreibung Der T-Lymphozyt ist die reife Zellform der T-Zell-Differenzierung. Er kann morphologisch nicht von anderen Lymphozyten ( $\triangleright$ B-Lymphozyt, $\triangleright$ Natural-KillerLymphozyt) unterschieden werden. Nach Aktivierung durch spezifische immunologische Reize erfolgt eine Transformation (lymphozytäre Reizformen). Die Unterscheidung erfolgt durch den spezifischen Nachweis von T-Zellspezifischen Oberflächenmarkern $(\mathrm{CD} 2, \mathrm{CD} 3, \mathrm{CD} 5, \mathrm{CD} 7)$ in der Immunphänotypisierung. Antikörper, die gegen CD3 gerichtet sind, erkennen den T-Zellrezeptor und sind somit linienspezifisch für T-Lymphozyten. Eine weitere Differenzierung ist durch die Erkennung der Oberflächenantigene CD4 (T-Helferzellen) und CD8 (T-Suppressorzellen und zytotoxische T-Lymphozyten) neben CD3 möglich.

\section{Literatur}

Broere F, Apasov SG, Sitkovsky MV, van Eden W (2011) T cell subsets and T cell-mediated immunity. In: Nijkamp FP, Parnham MJ (Hrsg) Principles of immunopharmacology. http://www.springer.com/9783-0346-0135-1. Zugegriffen im 2018

Mondelli MU, Parks DE, Chisari FV (1991) Cellular kinetics of lymphocytes and plasma cells. In: Williams WJ, Beutler E, Erslev AJ et al (Hrsg) Hematology, 4. Aufl. (International edition.) McGraw-Hill, New York, S 945-949

\section{T3-Lymphozyt}

$\vee \mathrm{CD} 3$

\section{T4-Lymphozyt}

\section{$\checkmark \mathrm{CD} 3$ \\ $\checkmark \mathrm{CD} 4$}

\section{T8-Lymphozyt}

$$
\checkmark \mathrm{CD} 8
$$

\section{T-Lymphozyten, autoreaktive}

\section{W. Stöcker}

Synonym(e) Autoimmunantwort, zelluläre; Autoimmunreaktion, T-Zell-vermittelte; Autoreaktive T-Zellen

\section{Englischer Begriff autoreactive T-lymphocytes}

Definition Autoreaktive T-Lymphozyten sind gegen das körpereigene Gewebe gerichtete T-Zellen, sie gehören zum normalen Immunrepertoire eines Organismus. Bei einer Reihe von Autoimmunkrankheiten sind sie aktiviert und proliferieren.

Beschreibung Der Organismus gesunder Individuen verfügt über eine große Anzahl autoreaktiver T- und B-Lymphozyten (T- und B-Zellen). Es kommt aber nur selten zu einer massiven Proliferation autoreaktiver T-Zellen und zur Ausprägung hoher Autoantikörperkonzentrationen, wie man es bei Autoimmunkrankheiten findet. Der Selbstschutz wird vor allem dadurch erreicht, dass autoreaktive T- oder B-Zellen während 
der Entwicklung eliminiert bzw. später inaktiviert werden. Das Immunsystem ist tolerant gegen körpereigene Substanzen. Unter bestimmten Umständen können autoreaktive Lymphozyten jedoch aktiviert und zur Proliferation angeregt werden. Es kommt zu Autoimmunerkrankungen, an deren Pathogenese sowohl autoreaktive T-Lymphozyten als auch Autoantikörper beteiligt sein können.

Ausschlaggebend für die Unterdrückung einer Autoimmunreaktion sind die T-Suppressor-Zellen. Sie kontrollieren nicht nur die Reaktivität der T-Helfer-Zellen, sondern auch die Funktion der B-Zellen. Eine Abnahme der T-Suppressor-ZellAktivität wird als entscheidender Faktor in der Entwicklung von Autoimmunerkrankungen angenommen. Einmal entstanden, kann sich ein autoreaktiver T-Helfer-Zell-Klon vermehren, mit B-Zellen interagieren oder zytotoxische T-Zellen induzieren und Autoimmunreaktionen auslösen. T-Zellvermittelte Autoimmunreaktionen lassen sich beispielsweise bei Insulin-abhängigem Diabetes mellitus (IDDM), rheumatoider Arthritis oder multipler Sklerose nachweisen.

Im Gegensatz zu Autoantikörpern sind autoreaktive T-Zellen schwieriger nachzuweisen, da sie ein Antigen nicht in seiner natürlichen Konformation, sondern lediglich kürzere Antigenfragmente erkennen. Und dies auch nur, wenn sie in körpereigene Oberflächenproteine (HLA-Moleküle) eingebettet präsentiert werden.

Eine T-Zell-vermittelte Immunantwort gegen Autoantigene lässt sich durch Immunsuppressiva wie zum Beispiel $\checkmark$ Ciclosporin A unterdrücken.

\section{TM}

> Thrombomodulin

\section{TMA}

> Trimethylamin

\section{TMAO}

- Trimethylamin-N-Oxid

\section{Tn-Antigen}

K. Kleesiek, C. Götting, J. Diekmann, J. Dreier und M. Schmidt

Synonym(e) Kryptantigen Tn

Englischer Begriff Tn antigen

Definition Durch einen erworbenen Synthesedefekt generiertes erythrozytäres Antigen, das zur $\triangleright$ Tn-Polyagglutinabilität mit AB0-Blutgruppen-kompatiblen ( $>$ AB0-Blutgruppensystem) Seren führt.

Beschreibung Das Tn-Antigen gehört zu den erythrozytären Kryptantigenen ( $>$ Kryptantigen), die erst durch eine Veränderung der Erythrozytenoberfläche freigesetzt und somit dem Immunsystem zugänglich gemacht werden. Das immunodominante Epitop des Tn-Antigens ist ein O-glykosidisch proteingebundener $\alpha$-N-Acetylgalaktosaminrest, der durch eine unvollständige oder fehlende Galaktosylierung des Thomsen-Friedenreich-Antigens, das die Struktur Galaktose-

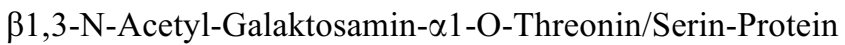
aufweist, entsteht. Für die fehlende oder unvollständige Addition des Galaktosemoleküls wird eine Inaktivierung der Genexpression einer Galaktosyltransferase angenommen, die einen Transfer von Galaktose ausgehend von UDP-Galaktose auf den N-Acetyl-Galaktosaminrest des partiellen ThomsenFriedenreich-Antigens katalysiert. Die Inaktivierung der Genexpression resultiert wahrscheinlich aus der somatischen Mutation einer hämatopoetischen Stammzelle, die zu klonalen Veränderungen führt. Zellpopulationen mit und ohne Mutation im Galaktosyltransferase-kodierenden Gen können koexistieren, sodass Tn-Antigen-positive und Tn-Antigennegative Zellen in der Blutzirkulation vorhanden sind. Dies kann bei Zusatz von Anti-Tn-Antikörpern zur $>$ Mischfeldagglutination von Tn-Antigen-tragenden und Tn-Antigenfreien Erythrozyten führen.

\section{Literatur}

Mueller-Eckhardt C, Kiefel V (Hrsg) (2004) Transfusionsmedizin: Grundlagen - Therapie - Methodik, 3. Aufl. Springer, Berlin/Heidelberg/New York

Strobel E (2000) Erworbene Veränderungen der erythrozytären Merkmale. Infus Ther Transfus Med 27:80-89

\section{TNF- $\alpha$}

- Tumornekrosefaktor- $\alpha$ 


\section{Tn-Polyagglutinabilität}

\author{
K. Kleesiek, C. Götting, J. Diekmann, J. Dreier und \\ M. Schmidt
}

Synonym(e) Permanente Mischfeld-Polyagglutinabilität

Englischer Begriff Tn polyagglutination

Definition Erworbene und zumeist persistierende Eigenschaft von Erythrozyten, die nach Aktivierung des Tn-Kryptantigens auf der Erythrozytenoberfläche, von der Majorität der AB0-kompatiblen Seren agglutiniert werden.

Beschreibung Die Tn-Polyagglutinabilität ist eine durch veränderte Glykostrukturen auf der Erythrozytenoberfläche entstehende Eigenschaft von Erythrozyten, die zu einer Agglutination der Erythrozyten mit den meisten AB0Blutgruppen-kompatiblen Seren führt. Verantwortlich für diese Polyagglutinabilität ist ein Antikörper der Spezifität Anti-T, der sich im Blut fast aller Erwachsenen, nicht aber in Nabelschnurvenenblut findet. Im Gegensatz zur T-Polyagglutinabilität, die temporär bei Infektion mit Neuraminidase-bildenden Bakterien auftreten kann, ist die Tn-Polyagglutinabilität, von wenigen Ausnahmen abgesehen, persistierend und durch das Fehlen einer bakteriellen Infektion gekennzeichnet. Sie kann mit hämolytischer Anämie, Leuko- und Thrombozytopenie einhergehen und scheint mit malignen hämatologischen Systemerkrankungen assoziiert zu sein, tritt aber auch bei gesunden Menschen auf.

Die Erstbeschreibung der Tn-Polyagglutinabilität erfolgte im Jahr 1957 durch Moreau und Jean Dausset (1916-2009), die eine Polyagglutinabilität von Patientenerythrozyten mit fast allen AB0-Blutgruppen-kompatiblen Erwachsenenseren ( $\vee$ AB0-Blutgruppensystem), nicht aber mit Nabelschnurvenenblut zeigten. Als Antikörper konnte ein kältereaktiver IgM-Antikörper der Spezifität Anti-Tn identifiziert werden, der gegen das $>$ Tn-Antigen gerichtet ist. Dieses Antigen gehört zu der Gruppe der erythrozytären Kryptantigene (s. \ Kryptantigen), die erst durch Modifikation der Erythrozytenoberfläche freigesetzt und dem Immunsystem präsentiert werden.

Das immunodominante Epitop des Tn-Antigens ist ein O-glykosidisch proteingebundener $\alpha$-N-Acetylgalaktosaminrest, der durch eine mangelnde Galaktosylierung des Thomsen-Friedenreich-Antigens Galaktose- $\beta 1,3-\mathrm{N}-$ Acetyl-

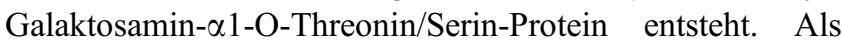
ursächlich für die fehlende Addition des Galaktose-Moleküls wird eine Inaktivierung der Genexpression der Galaktosyltransferase angenommen, die die Übertragung der Galaktose von UDP-Galaktose auf den N-Acetyl-Galaktosaminrest katalysiert. Diese entsteht wahrscheinlich durch eine somatische Mutation in einer hämatopoetischen Stammzelle, die zu klonalen Veränderungen führt.

Tn-Antigen-positive und Tn-Antigen-negative Zellpopulationen können koexistieren, was die bei Versetzen der Erythrozyten mit Anti-Tn-Antikörpern frequent zu beobachtende - Mischfeldagglutination erklärt. Antikörper der Spezifität Anti-Tn finden sich im Blut annähernd aller Erwachsenen, während sie in Nabelschnurvenenblut nicht nachgewiesen werden können. Im Gegensatz zur temporären T-Polyagglutinabilität sind bei Trägern des Tn-Antigens keine Anti-TnAntikörper nachweisbar.

Die Diagnose der Tn-Polyagglutinabilität erfolgt über Nachweis des erythrozytären Tn-Antigens durch Lektine aus Salvia sclarea, Salvia hormium und Glycine soja, die zu der für die Tn-Polyagglutinabilität typische Mischfeldagglutination führen. Eine Methode, das Tn-Antigen in vitro zu aktivieren, ist bislang nicht bekannt. Eine Inkubation der Erythrozyten mit Proteasen wie Papain oder Bromelin zerstört das Tn-Antigen, in deren Folge die Polyagglutinabilität verschwindet. Im Gegensatz zur $\triangleright$ T-Polyagglutinabilität, bei der es bei transfundierten Spendererythrozyten durch die bakteriellen Neuraminidasen zu einer Aktivierung des T-Antigens kommen kann, werden Tn-Antigen-negative Spendererythrozyten nie Tn-Antigen positiv und zeigen eine normale Lebensdauer.

\section{Literatur}

Berger EG (1999) Tn syndrome. Biochim Biophys Acta 1455:255-268 Eckstein R (2005) Immunhämatologie und Transfusionsmedizin. Urban $\&$ Fischer, München

\section{Tobramycin}

C. Vidal und W.-R. Külpmann

Englischer Begriff tobramycin

Definition Aminoglykosid-Antibiotikum.

Strukturformel:

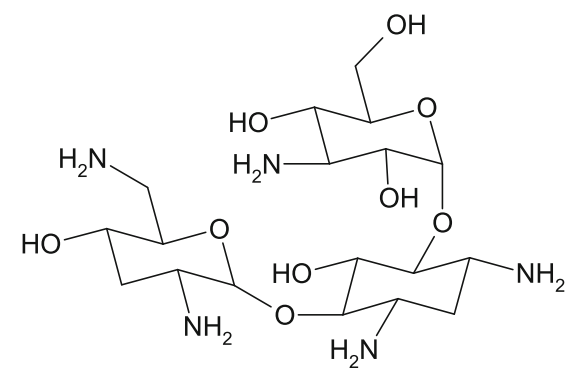

Molmasse 467,52 g. 
Synthese - Verteilung - Abbau - Elimination Tobramycin wird parenteral appliziert und weitgehend vollständig unverändert renal eliminiert.

\section{Halbwertszeit 2-3 Stunden (Plasma).}

Funktion - Pathophysiologie Zahlreiche Bakterien nehmen sauerstoffabhängig Tobramycin auf. In den Bakterien wird es an Ribosomen gebunden und stört die Proteinsynthese. Als unerwünschte Wirkungen treten auf: Ototoxizität, Nephrotoxizität, neuromuskuläre Blockaden, allergische Reaktionen (Blutbildkontrolle erforderlich). Bei Niereninsuffizienz sind die Dosen zu reduzieren zur Vermeidung von Überdosierung durch Kumulation.

Untersuchungsmaterial - Entnahmebedingungen Serum (S), Plasma (P).

Probenstabilität 2 Stunden bei Raumtemperatur, 3 Stunden bei $4{ }^{\circ} \mathrm{C}$.

Analytik \ Immunoassay, \ GC-MS, LC-MS/MS.

Indikation. Therapeutisches Drug Monitoring.

Interpretation Therapeutischer Bereich (S, P): 4-10 mg/L; toxisch: $>12-15 \mathrm{mg} / \mathrm{L}$; Talkonzentration $>2 \mathrm{mg} / \mathrm{L}$; komatösletal: unbekannt.

\section{Literatur}

Schulz M, Schmoldt A (2003) Therapeutic and toxic blood concentrations of more than 800 drugs and other xenobiotics. Pharmazie 58:447-474

Taylor WJ, Diers Caviness MH (1986) A textbook for the clinical application of therapeutic drug monitoring. Abbott, Irving

\section{Tochtergefäß}

- Verteilung von Proben

\section{Tochterprobe}

- Verteilung von Proben

\section{Tocopherol}

- Vitamin E

\section{TOF}

- Massenspektrometrie

$\checkmark$ SELDI-TOF

\section{Tolbutamid-Test}

A. M. Gressner und O. A. Gressner

Synonym(e) Insulinom-Funktionstest

Englischer Begriff tolbutamide test

Definition Funktionstest zur Diagnostik eines Insulinoms (autonome Insulinsekretion), bei dem nach intravenöser Injektion des Sulfonylharnstoffderivates Tolbutamid das aus einem Inselzelltumor (Insulinom) überschießend freigesetzte Insulin oder C-Peptid wie auch der Abfall der Glukosekonzentration im Serum gemessen werden.

Funktion - Pathophysiologie Tolbutamid hemmt den Kaliumausstrom aus der B-Zelle und führt somit über eine Depolarisation der B-Zellen zur Insulinfreisetzung aus pankreatischen und extrapankreatischen, solitären oder multiplen Insulinomen, z. B. im Rahmen einer MEN (multiplen endokrinen Neoplasie) Typ 1.

Untersuchungsmaterial - Entnahmebedingungen Serum.

Präanalytik > Glukose, > Insulin, > C-Peptid.

Analytik $\triangleright$ Glukose, $\triangleright$ Insulin, $\triangleright$ C-Peptid.

Durchführung Die Ausgangskonzentration von Glukose im Serum soll vor Testbeginn $>60 \mathrm{mg} / \mathrm{dL}$ betragen. Der Patient erhält eine Dosis von $1 \mathrm{~g}$ Tolbutamid als wässrige Lösung innerhalb von 3 Minuten intravenös. Vor Testbeginn und nach der Injektion wird im Serum des Patienten bis zu 3 Stunden Blut entnommen, um im Serum die Konzentrationen von Glukose, Insulin und C-Peptid zu bestimmen. Anfänglich werden kurze Zeitintervalle gewählt, nach 30 bis 60 Minuten halbstündige Intervalle.

Referenzbereich - Erwachsene Glukosekonzentration fällt zwischen der 30. und 45. Minute auf ein Minimum ab und liegt nach 3 Stunden nicht mehr als $30 \%$ unter dem Ausgangswert.

Insulin erreicht nach 5-10 Minuten den Maximalwert und fällt innerhalb von 1 Stunde wieder auf den Ausgangswert ab. 
C-Peptid zeigt eine dem Insulin ähnliche, jedoch etwas zeitverzögerte Kinetik mit Erreichen des Ausgangswertes nach 90-120 Minuten.

Referenzbereich - Kinder s. Erwachsene.

Indikation Verdacht auf solitäres oder multiples Insulinom.

Interpretation Bei Insulinompatienten liegt die Blutglukosekonzentration auch 3 Stunden nach Tolbutamidgabe noch mehr als $30 \%$ unter dem Ausgangswert, die Insulinkonzentration steigt (etwas verzögert) nach 5-10 Minuten auf hochpathologische Werte an, die erst zwischen der 30. und 60 . Minute langsam abfallen. C-Peptid zeigt eine dem Insulin ähnliche Kinetik.

Diagnostische Wertigkeit Der Einsatz des TolbutamidTestes in der Insulinomdiagnostik ist aufgrund der Möglichkeit schwerer hypoglykämischer Zwischenfälle, die einen sofortigen Testabbruch und Glukoseinjektionen erforderlich machen, eingeschränkt. Ständige Kontrolle des Patienten während der Testdurchführung ist zwingend. Der $>$ Hungerversuch bietet sich als überlegene Alternative an, obwohl für den Tolbutamid-Test diagnostische Sensitivität ( $\triangleright$ Sensitivität, diagnostische) von $95 \%$ und diagnostische Spezifität ( $\triangleright$ Spezifität, diagnostische) $>95 \%$ angegeben werden.

Hinweisend auf Insulinom ist ferner ein insulinogener Index $>0,5$ ( $\triangleright$ Index, insulinogener).

\section{Literatur}

Service FJ (1991) Hypoglycemias. West J Med 154:442-454

Service FJ (1995) Hypoglycemic disorders. N Engl J Med $332: 1144-1152$

Thomas L (Hrsg) (2005) Labor und Diagnose, 6. Aufl. TH-BooksVerlagsgesellschaft mbH, Frankfurt am Main

\section{Toleranz}

C. Vidal und W.-R. Külpmann

\section{Synonym(e) Gewöhnung}

\section{Englischer Begriff tolerance}

Definition Toleranz liegt vor, wenn bei regelmäßiger Wirkstoffzufuhr steigende Dosen benötigt werden, um eine bestimmte Wirkung in gleichbleibender Stärke zu erhalten oder wenn bei regelmäßiger Zufuhr gleichbleibender Dosen eine bestimmte Wirkung an Stärke abnimmt.
Beschreibung Ursachen der Toleranz sind beschleunigte Inaktivierung des Wirkstoffs durch Enzyminduktion, Inaktivierung durch Antikörper (z. B. Insulin), Abnahme der Transmitterfreisetzung (z. B. regelmäßige Applikation von indirekten Sympathomimetika).

\section{Literatur}

Wellhöner HH (1997) Pharmakologie und Toxikologie, 6. Aufl. Springer, Berlin/Heidelberg/New York

\section{Tolidin-Probe}

Tolidin-Test

\section{Tolidin-Test}

A. M. Gressner und O. A. Gressner

Synonym(e) Ortho-Tolidin-Test; Tolidin-Probe

Englischer Begriff $o$-tolidin-test

Definition Semiquantitatives Nachweisverfahren von Hämoglobin oder Myoglobin im Urin oder Stuhl.

Beschreibung Nach Zugabe von Wasserstoffperoxid $\left(\mathrm{H}_{2} \mathrm{O}_{2}\right)$ und o-Tolidin (3,3'-Dimethyl-Benzidin) kommt es bei Anwesenheit von $\triangleright$ Hämoglobin oder Myoglobin $(\triangleright$ Myoglobin im Urin, \ Myoglobin im Blut) zur Oxidation von $o$-Tolidin mit sofort sichtbarer Grünblauverfärbung. Nachweisreaktion beruht auf der Pseudoperoxidaseaktivität von Hämoglobin bzw. Myoglobin.

\section{Literatur}

Hallmann L (1980) Klinische Chemie und Mikroskopie, 11. Aufl. Georg Thieme Verlag, Stuttgart/New York

\section{Tollens-Probe}

Tollens-Test 


\section{Tollens-Test}

A. M. Gressner und O. A. Gressner

Synonym(e) Phlorogluzin-Probe nach Tollens; Tollens-Probe

Englischer Begriff Tollens test

Definition Nach dem deutschen Chemiker Bernhard Tollens (1841-1918) benannter, heute obsoleter, da unspezifischer, semiquantitativer Nachweis von Galaktose und Pentosen im Urin.

Beschreibung Galaktose, aber auch $>$ Pentosen und Glukuronsäure ergeben mit Phlorogluzin (1,3,5-Trihydroxybenzol) und Salzsäure bei Erhitzen in siedendem Wasserbad innerhalb einiger Minuten eine Rotfärbung, deren Intensität semiquantitativ ausgewertet werden kann. Heute nicht mehr in Gebrauch.

\section{Literatur}

Hallmann L (1980) Klinische Chemie und Mikroskopie, 11. Aufl. Georg Thieme Verlag, Stuttgart/New York

\section{Toluidinblau}

H. Baum

Englischer Begriff Toluidine blue

Definition Farbstoff zur spezifischen Anfärbung der Granula der basophilen Granulozyten und Mastzellen.

Beschreibung Der Farbstoff Toluidinblau bindet spezifisch an die Granula der basophilen Granulozyten ( $>$ Granulozyten, basophile) und Mastzellen. Diese erscheinen im mit Toluidinblau gefärbten Ausstrichpräparat dann als dunkelrote bis purpurne Granula. Die Kerne der Zellen werden blau angefärbt, wie auch die im Zytoplasma vorhandene RNA der Zellen durch einen bläulichen Schimmer in Erscheinung tritt. Die Granula anderer Zellpopulationen werden mit Toluidinblau nicht angefärbt.

\section{Literatur}

Swirsky D, Bain BJ (2001) Erythrocyte and leukocyte cytochemistry - leukaemia classification. In: Lewis SM, Bain BJ, Bates I (Hrsg) Dacie and Lewis practical haematology, 9. Aufl. Churchill Livingstone, London, S 288-289

\section{Toluidinblau-Färbung im Blut}

H. Baum

Englischer Begriff toluidine blue stain

Definition Färbung zur selektiven Darstellung der Granula in basophilen Granulozyten und Mastzellen.

Physikalisch-chemisches Prinzip Das luftgetrocknete Ausstrichpräparat wird 5 Minuten in einer $1 \%$ igen ToluidinblauLösung gefärbt und anschließend mit Wasser gründlich gespült. Dabei bindet $>$ Toluidinblau selektiv an die Granula basophiler Granulozyten und Mastzellen.

Einsatzgebiet Differenzierung basophiler Granulozyten und Mastzellen in Fällen, in denen die Standardfärbung keine eindeutigen Ergebnisse erzielt. So können bei Patienten mit myeloproliferativen Erkrankungen dysplastische Basophile auftreten, die in der $>$ Pappenheim-Färbung nicht oder nur schlecht differenzierbar, jedoch in der Toluidinblau-Färbung eindeutig als basophile Granulozyten identifizierbar sind.

Untersuchungsmaterial Ausstrichpräparat des Knochenmarks oder peripheren Blutes.

Instrumentierung Handmethode.

Praktikabilität - Automatisierung - Kosten Einfach durchzuführende Handmethode.

Bewertung - Methodenhierarchie (allg.) Die Methode wird nur verwendet, wenn in den Standardfärbemethoden keine Differenzierung der dysplastischen Basophilen oder Mastzellen möglich ist.

\section{Literatur}

Swirsky D, Bain BJ (2001) Erythrocyte and leukocyte cytochemistry - leukaemia classification. In: Lewis SM, Bain BJ, Bates I (Hrsg) Dacie and Lewis practical haematology, 9. Aufl. Churchill Livingstone, London, S 288-289

\section{Toluol}

- Hippursäure 


\section{Tolursäuren}

> Hippursäure

- Methylhippursäuren

TOM

- Masse, molare

\section{Toningblue}

- Berlinerblau-Reaktion

\section{Tonometrie}

> Partialdruck

\section{Totale Clearance}

$\checkmark$ Clearance, totale

\section{Totales Qualitätsmanagement}

\section{U. Zimmermann und A. Steinhorst}

$\operatorname{Synonym(e)~TQM~}$

Englischer Begriff total quality management

Definition Auf der Mitwirkung aller ihrer Mitglieder (jegliches Personal in allen Stellen und allen Hierarchieebenen) beruhende Führungsmethode einer Organisation, die Qualität in den Mittelpunkt stellt und durch Zufriedenstellung der Kunden auf langfristigen Geschäftserfolg sowie auf Nutzen für die Mitglieder der Organisation und für die Gesellschaft zielt.

\section{Literatur}

DIN EN ISO 8402:1995 „Qualitätsmanagement und Qualitätssicherung - Begriffe"

\section{Totalionenstrom}

T. Arndt

Synonym(e) TIC

Englischer Begriff total ion current

Definition Die Aufsummierung aller Ionenintensitäten eines Scans, d. h. aller m/z-Signale inkl. jener des Untergrunds, wird in der Massenspektrometrie als Totalionenstrom (TIC) bezeichnet, die resultierende Zeit-Intensitäts-Kurve als Totalionenstrom-Chromatogramm.

Beschreibung Das Totalionenstrom-Chromatogramm hängt vom eingestellten $\mathrm{m} / \mathrm{z}$-Scanbereich $\mathrm{ab}$, er sollte deshalb für den Vergleich von Totalionen-Chromatogrammen (Patientenprobe vs. Spektrenbibliothek) identisch sein.

\section{Literatur}

Hübschmann H-J (1996) Handbuch der GC-MS. Grundlagen und Anwendung, 1. Aufl. VCH, Weinheim, S 214-215

\section{Totalkontrolle}

R.-D. Hilgers, N. Heussen und S. Stanzel

Englischer Begriff total inspection

Definition Unter einer Totalkontrolle versteht man die Kontrolle jedes gewonnenen Analysenergebnisses durch eine zweite, unabhängige Methode.

Beschreibung In der Praxis ist eine Totalkontrolle aus Kostengründen oder aufgrund fehlender materieller Ressourcen nur selten realisierbar. In diesen Situationen wird zur $\triangleright$ Stichprobenkontrolle übergegangen.

\section{Literatur}

Büttner H (1967) Statistische Qualitätskontrolle in der Klinischen Chemie. Z Klin Chem Klin Biochem 5:41-48 


\section{Totvolumen}

T. Arndt

Synonym(e) Extrasäulenvolumen

Englischer Begriff dead volume

Definition Eine allgemeingültige Definition wird durch die Vielfalt der zu betrachtenden Systeme (biologische und nichtbiologische, ein einzelnes Bauteil oder komplexe Anlagen) erschwert. In starker Vereinfachung kann man alle Volumenanteile eines Systems, die nicht unmittelbar mit dessen Funktionalität verbunden sind, als Totvolumen bezeichnen.

Beschreibung Im klinisch-chemischen Labor wird der Begriff Totvolumen u. a. zur Beschreibung des Volumens der Verbindungen zwischen Reagenzien- oder Probenreservoir und Pipettiernadel von Analysegeräten verwandt. Zur Minimierung von Reagenzienverlusten bei Gerätewartungen und Reagenzienwechsel sowie der erforderlichen Probenvolumina wird hier ein möglichst geringes Totvolumen angestrebt.

Der Begriff ist u. a. in der $>$ Chromatographie wichtig. Hier ist das Totvolumen als jenes Volumen definiert, das durch alle Volumina zwischen Probenaufgabe und Trennsäule sowie zwischen Trennsäule und Detektor, also durch Probenaufgabeventil, Schaltventile, Kapillaren und deren Verschraubungen, gebildet wird. Generell gilt, je geringer das Totvolumen, desto geringer ausgeprägt sind Diffusions- und Rückvermischungseffekte und die durch sie bedingten Signal- oder Bandenverbreiterungen und desto besser ist die Trennleistung der chromatographischen Apparatur.

Gelegentlich wird das in der analytischen Trennsäule nicht durch die Partikel der stationären Phase besetzte Volumen dem Totvolumen zugerechnet. Es handelt sich hierbei jedoch um das Zwischenkornvolumen, das nach o. g. Definition nicht Bestandteil des Totvolumens ist. Da der Begriff Totvolumen missverständlich ist, sollte er vermieden und nach IUPAC durch Extrasäulenvolumen ersetzt werden.

\section{Literatur}

Ettre LS (1993) Nomenclature for chromatography. Pure Appl Chem 65:819-872

\section{Totzeit}

Retentionszeit

\section{Tourtelotte IgG Formel}

> Immunglobulinbestimmung, intrathekal empirisch

\section{Toxikokinetik}

C. Vidal und W.-R. Külpmann

\section{Englischer Begriff toxicokinetics}

Definition Quantitative Beschreibung der Konzentrationsänderungen von Giftstoffen ( $\triangleright$ Gift, \Giftung) und/oder ihren Metaboliten im Organismus bei Vergiftungen.

Beschreibung Toxikokinetik beschäftigt sich mit Giftstoffen im engeren Sinne und mit Pharmaka in toxischen Konzentrationen. Für in toxischer Menge aufgenommene Substanzen finden sich häufig Abweichungen gegenüber ihrer Kinetik bei Aufnahme geringer oder therapeutischer Mengen.

\section{Literatur}

Geldmacher-von Mallinckrodt M (1995) Toxikokinetik. In: Greiling H, Gressner AM (Hrsg) Lehrbuch der Klinischen Chemie und Pathobiochemie, 3. Aufl. Schattauer Verlag, Stuttgart, S 1391-1397

\section{Toxin}

A. M. Gressner und O. A. Gressner

Synonym(e) Toxinologie

Englischer Begriff toxin; poison

Definition Im Allgemeinen eine natürlich produzierte Substanz, die auf einen lebenden Organismus schädigend bis letal einwirkt.

Beschreibung Toxine sind chemisch sehr unterschiedliche, natürlich produzierte Substanzen (oft Peptide), die nach Kontakt oder Resorption auf einen Organismus in oft geringen Konzentrationen schädigend bis letal einwirken. Es kann sich dabei um Produkte (z. B. Enzyme, Inhibitoren) von Mikroorganismen (z. B. - Tetanus-, Diphtherie-, Botulinustoxin, En- 
dotoxin, \ Hämolysin), Pflanzen (z. B. \ Amanitine des Knollenblätterpilzes) und Tieren (z. B. Schlangen, Bienen) handeln.

Toxizität wird dabei im Allgemeinen durch die mittlere Letalitätsdosis (LD50) angegeben, die diejenige Menge des Toxins darstellt, die notwendig ist, um $50 \%$ eines Kollektivs von Zielorganismen (z. B. Versuchstiere) im Test zu töten.

Die Lehre von den Toxinen bezeichnet man als Toxinologie, Experten für Toxine als Toxinologen. Fachgesellschaft der Toxinologen ist die im Jahr 1962 gegründete International Society of Toxinology (IST). Die Toxinologie ist ein Teilgebiet der Toxikologie.

\section{Literatur}

www.toxinology.org

\section{Toxinologie}

- Toxin

\section{Toxische Dosis}

C. Vidal und W.-R. Külpmann

$\operatorname{Synonym}(e) \mathrm{TD}_{50}$

Englischer Begriff toxic dose

Definition Dosis, bei der $50 \%$ einer toxischen Wirkung auftreten oder im Kollektiv $50 \%$ der Individuen eine toxische Wirkung zeigen.

\section{Literatur}

Forth W, Henschler D, Rummel W (1987) Allgemeine und spezielle Pharmakologie und Toxikologie. BI Wissenschaftsverlag, Mannheim

\section{Toxische Granulation}

- Granulation, toxische

\section{Toxoplasma gondii}

\section{W. Stöcker}

\section{Englischer Begriff Toxoplasma gondii}

Beschreibung des Erregers Protozoon, Klasse Sporozoa, Stamm Apicomplexa.

Toxoplasma gondii wurde erstmalig im Jahr 1908 in Tunesien als Parasit im Gundi entdeckt. Aufgrund der Halbmondform wurde es von den Entdeckern Nicolle und Manceaux als Toxoplasma bezeichnet (griech. toxon $=$ Bogen).

Erkrankungen T. gondii kommt weltweit vor und infiziert zahlreiche Haus- und Wildtiere. Der Parasit vermehrt sich dort vegetativ und bildet Zysten. Nur in Feliden, z. B. Hauskatzen, findet zusätzlich ein generativer Zyklus im Darm statt, der zur Ausscheidung von Oozysten mit dem Kot führen kann.

Menschen können sich durch orale Aufnahme von Oozysten oder durch den Genuss zystenhaltigen, unzureichend erhitzten Fleisches infizieren. Laborinfektionen beim Umgang mit infektiösem Material sind möglich, theoretisch auch eine Übertragung durch Bluttransfusion zum Zeitpunkt der Parasitämie.

Postnatale Infektionen immunologisch gesunder Personen verlaufen nur in $10 \%$ der Fälle symptomatisch. Am häufigsten sind lokale Lymphadenopathien. Bei immunsupprimierten Patienten können durch Dissemination des Erregers einzelne oder mehrere Organe schwer geschädigt werden, im Falle einer latenten Toxoplasma-Infektion müssen sie gegebenenfalls lebenslang Antibiotika erhalten, um einer Reaktivierung vorzubeugen.

Bei Erstinfektion in der Schwangerschaft kann eine diaplazentare Übertragung auf den Fetus stattfinden, bei Reaktivierung einer latenten Infektion dagegen nur selten.

Die Übertragungswahrscheinlichkeit während der Schwangerschaft hängt vom Zeitpunkt der Erstinfektion ab: Im ersten Trimester liegt sie bei $15 \%$, im zweiten bei $30 \%$, im dritten Trimester bei $60 \%$. Infektionen im ersten Trimester führen zu schwereren Schädigungen des Kindes als Ansteckungen zu einem späteren Zeitpunkt in der Schwangerschaft. Die manifeste konnatale Toxoplasmose präsentiert sich mit geringem Geburtsgewicht, Hepatomegalie, Trinkschwäche, zerebralen Anfällen, Entwicklungsretardierung oder Schielen. In etwa $5 \%$ der Fälle zeigt sich die klassische Trias Hydrozephalus, zerebrale Kalzifikation und Retinochorioiditis. Die Retinochorioiditis kann sich ohne antibiotische Therapie im Laufe der Zeit fortsetzen, mit Visusverschlechterung bis hin zum Erblinden. In günstigeren Fällen erscheinen die infizierten 
Neugeborenen erst einmal unauffällig, aber nach einem zeitlichen Intervall von mehreren Jahren können noch Symptome auftreten.

Analytik Direktnachweis: Befallene Lymphknoten werden histologisch untersucht. Die Erreger können heute in Kultur angezüchtet werden, aber es kommt weitgehend die PCRTechnik ( $\triangleright$ PCR (Polymerase-Kettenreaktion)) zum Einsatz, besonders bei Verdacht auf eine Infektion in der Schwangerschaft. Die Sensitivität beträgt bis zu $65 \%$.

Serologie: Im Sabin-Feldmann-Test wird die neutralisierende Eigenschaft des Serums gegenüber kultivierten Toxoplasmen untersucht. Der Immuno-Sorbent-Agglutinations-Assay (ISAGA) erfasst sehr sensitiv und spezifisch Antikörper der Klasse IgA und IgM: Mittels $\mu$-capture-Technik wird bei diesem Verfahren der Antikörper isoliert, der dann im positiven Fall die intakten Toxoplasmen agglutiniert. Beide Techniken erfordern den Umgang mit Toxoplasma-Kulturen. Größere Verbreitung finden heute verschiedene Enzymimmunoassays (s. - Enzymimmunoassay), mit denen Antikörper der Klassen IgA, IgG oder IgM gegen Toxoplasmen getrennt untersucht werden können (u. a. > Enzyme-linked Immunosorbent Assay, Chemilumineszenz-Immunoassays). Zusätzlich kann man niedrig avides spezifisches IgG bestimmen, um frische Infektionen zu identifizieren (s. Abbildung).

Indirekte Immunfluoreszenz: Antikörper gegen Toxoplasma gondii:

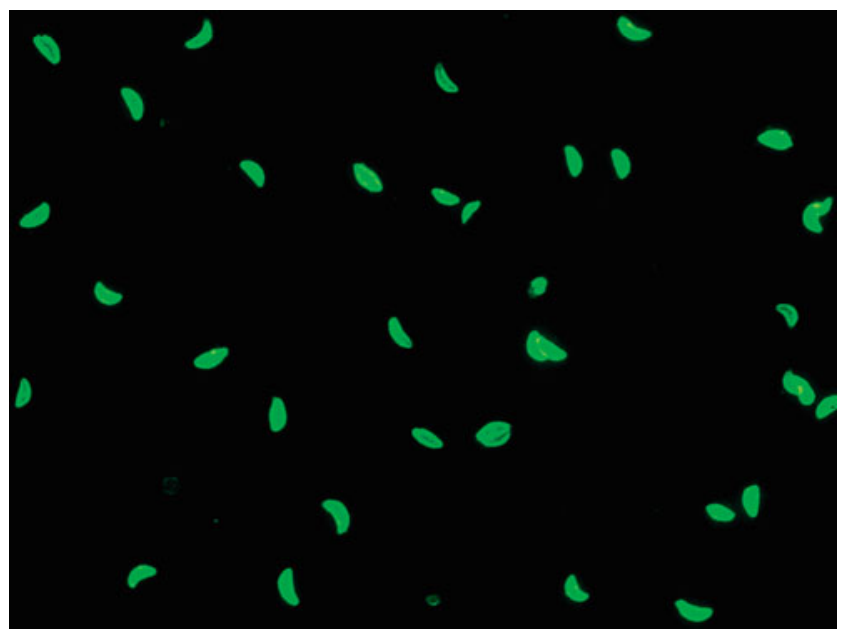

Untersuchungsmaterial - Probenstabilität Direktnachweis und Kultur: Untersucht werden Fruchtwasser, Biopsate von Chorionzotten, Hirngewebe oder Herzmuskel, EDTABlut, bronchoalveoläre Lavageflüssigkeit, Augenkammerwasser, Liquor cerebrospinalis. Das Material sollte bis zur Weiterverarbeitung bei +4 bis $+8{ }^{\circ} \mathrm{C}$ aufbewahrt werden. Bei längerer Transportzeit ist das Material einzufrieren.

Serologie: Serum oder Plasma für den Nachweis der Antikörper sind bei $+4{ }^{\circ} \mathrm{C}$ bis zu 2 Wochen lang beständig, bei $-20{ }^{\circ} \mathrm{C}$ über Monate und Jahre hinweg. Zur Tiefkühlkonser- vierung des IgM kann man den Proben 80 \% gepuffertes Glyzerin beifügen.

Diagnostische Wertigkeit Bei den wenigen symptomatischen Toxoplasma-Infektionen Erwachsener mit voller Immunkompetenz dient die Diagnose in erster Linie zur Abgrenzung gegenüber anderen Infektionen. Bei Reaktivierungen, wie sie bei immunsupprimierten Patienten auftreten können, stehen Medikamente (u. a. Spiramycin, Pyrimethamin, Sulfadiazin) zur Verfügung, die nach entsprechender Diagnosestellung verabreicht werden können. Die Wirkung erstreckt sich jedoch lediglich auf vegetative Formen, nicht auf Zysten.

Durch die Antikörperbestimmung in der frühen Schwangerschaft oder bereits vor Beginn kann man die seronegativen Frauen identifizieren und ggf. eine Serokonversion sofort erkennen. Die rechtzeitige Diagnose einer Neuinfektion während der Schwangerschaft kann das Schicksal des Kindes maßgeblich bestimmen, da es möglich ist, noch während der Schwangerschaft wirksame Antibiotika $\mathrm{zu}$ verabreichen. Seronegative Schwangere werden zur Expositionsprophylaxe angehalten.

\section{Literatur}

Enders G (2006) Mütterliche Infektionen mit dem Risiko der kongenitalen Übertragung. Labormedizinische Aspekte bei Cytomegalie und Toxoplasmose. Gynäkol Geburtshilfe 1:24-28

Gross U, Roos T, Friese K (2001) Toxoplasmose in der Schwangerschaft. Deutsches Ärzteblatt 98:A3293-A3300

Liesenfeld O, Janitschke K (2004) Toxoplasma. In: Hahn H, Falke D, SHE K, Ullmann U (Hrsg) Medizinische Mikrobiologie, 5. Auff. Springer, Berlin/Heidelberg/New York, S 750-753

Scholz H, Belohradsky BH, Bialek R, Heininger U, Kreth HW, Roos R (2009) Toxoplasmose. In: DGPI-Handbuch, 5. Aufl. ThiemeVerlag, Stuttgart, S 514-520

TPA

- Tissue Polypeptide Antigen

t-PA

- Tissue-Plasminogenaktivator

\section{TPO}

> Thrombopoetin

- Thyreoperoxidase 


\section{TPO-Antikörper}

- Autoantikörper gegen Thyreoperoxidase

\section{T-Polyagglutinabilität}

K. Kleesiek, C. Götting, J. Diekmann, J. Dreier und M. Schmidt

Synonym(e) Hübner-Thomsen-Friedenreich-Phänomen

Englischer Begriff $T$ polyagglutination

Definition Erworbene Eigenschaft von Erythrozyten, die, nach einer Neuraminidase-vermittelten Freisetzung des T-Kryptantigens auf der Erythrozytenoberfläche, von der Majorität der AB0-kompatiblen Seren agglutiniert werden.

Beschreibung Die T-Polyagglutinabilität ist eine durch Modifikation von Glykoproteinen auf der Zelloberfläche entstehende Eigenschaft von Erythrozyten, die zu einer Agglutination der Erythrozyten mit den meisten AB0-Blutgruppen-kompatiblen ( $\triangleright$ AB0-Blutgruppensystem) Seren führt. Ursächlich für die Polyagglutinabilität ist ein hochfrequenter Antikörper der Spezifität Anti-T, der sich im Blut fast aller Erwachsenen, nicht aber in Nabelschnurvenenblut findet.

Entdeckt und charakterisiert wurde dieses Phänomen zwischen 1925 und 1930 durch Hübener, Thomsen und Friedenreich. Polyagglutinabilität tritt als Folge von Infektionen mit Neuraminidase-bildenden Bakterien, wie z. B. Corynebakterien, Pneumokokken, Vibrio cholerae, Clostridium perfringens, Bacteroides fragilis oder Klebsiella aeruginosa auf. Durch die Freisetzung des Enzyms Neuraminidase während der Infektion wird Neuraminsäure aus Glykoproteinen der Erythrozytenmembran abgespalten, wodurch ein ansonsten maskiertes und verstecktes T-Kryptantigen auf der Erythrozytenoberfläche freigesetzt und als immunogene Determinante präsentiert wird.

Das T-Kryptantigen weist eine hohe Immunogenität auf und führt zur Bildung von Anti-T-Antikörpern, die sich aufgrund der Häufigkeit von Infektionen mit Neuraminidaseproduzierenden Bakterien ab ca. dem 6. Lebensmonat in annähernd allen Blutproben finden. Anti-T-Antikörper sind komplementaktivierende Antikörper vom IgM-Typ und können im Falle einer Infektion mit Neuraminidase-produzierenden Bakterien zu schweren Hämolysen führen. Die Freilegung des T-Kryptantigens durch bakterielle Neuraminidasen ist ein transientes Phänomen, das jedoch gelegentlich zu Unsicherheiten bei der Blutgruppenbestimmung führen kann. Weiterhin tritt das $>$ T-Antigen auch bei verschiedenen anaplastischen Karzinomen auf.

Eine T-Antigenaktivierung sollte differenzialdiagnostisch abgeklärt werden, sobald bei der Blutgruppenbestimmung die AB0-Blutgruppe der Patientenerythrozyten nicht mit den Isoagglutininen der Serumgegenprobe übereinstimmt, bei positivem direkten Coombs-Test mit Komplementaktivierung und beim Vorliegen einer autoimmunhämolytischen Anämie.

Zum Nachweis einer erythrozytären T-Antigenaktivierung wird die Agglutination der Erythrozyten mit spezifischen Anti-T-Agglutininen angewendet. Diese Anti-T-Lektine stammen aus Erdnussextrakten und reagieren sehr stark und spezifisch mit dem T-Kryptantigen, wie George William Gregory Bird im Jahr 1964 zeigen konnte. In vitro wird die Freisetzung des T-Kryptantigens durch Inkubation von Erythrozyten mit Neuraminidasen induziert. Diese Neuraminidase-behandelten Erythrozyten können zum Nachweis von Antikörpern der Spezifität Anti-T verwendet werden. Weiterhin weisen T-Kryptantigen-aktivierte Erythrozyten aufgrund des Neuraminsäuremangels abgeschwächte Mund N-Antigene auf, sodass die Bestimmung dieser Antigene erschwert sein kann. Bei Vorliegen einer Polyagglutinabilität sollte differenzialdiagnostisch auch die seltenere - Tn-Polyagglutinabilität berücksichtigt werden.

\section{Literatur}

Berger EG (1999) Tn syndrome. Biochim Biophys Acta 1455:255-268 Eckstein R (2005) Immunhämatologie und Transfusionsmedizin. Urban \& Fischer, München

Metaxas-Bühler M (1993) Blutgruppen und Transfusionsmedizin. Verlag Hans Huber, Bern/Göttingen/Toronto/Seatle

Mueller-Eckhardt C, Kiefel V (Hrsg) (2004) Transfusionsmedizin: Grundlagen - Therapie - Methodik, 3. Aufl. Springer, Berlin/Heidelberg/New York

\section{TPR}

> Phosphat-Clearance

TPS

- Tissue Polypeptide Specific Antigen

TPZ

- Thromboplastinzeit 


\section{TQM}

> Totales Qualitätsmanagement

\section{$\gamma$-Trace}

- Liquor-Cystatin C

\section{Tracer}

Immunoassay, heterogener

Immunoassay, homogener

- Radioimmunoassay

\section{Trägergas}

> Mobile Phase

\section{Trägergebundene Reagenzien}

- Analyse mit trägergebundenen Reagenzien

> Trockenchemie

\section{Trait-Marker}

\section{T. Arndt}

Definition Sammelbegriff für zustands- und zeitunabhängige Kenngrößen einer Prädisposition für einen bestimmten physiologischen oder pathologischen Prozess.

Beschreibung Der Begriff kann allgemein auf alle physiologischen oder pathologischen Zustände angewendet werden, findet innerhalb der Klinischen Chemie aber vor allem im Rahmen der Alkoholmissbrauchsdiagnostik ( $\vee$ Alkoholmissbrauchskenngrößen) Anwendung. Er umfasst, in Abgrenzung $\mathrm{zu}$ den in der Routinediagnostik etablierten sog. StateMarkern ( $\triangleright$ State-Marker), all jene Kenngrößen, die eine genetisch determinierte und damit lebenslange Prädisposition zum Alkoholmissbrauch anzeigen (sollen), z. B. die Thrombozyten-Monoaminoxidase-Aktivität, das A1-Allel in
Nähe des Dopamin-2-Rezeptors oder das visuell und akustisch evozierbare Potenzial P300 im EEG. Trait-Marker des Alkoholmissbrauchs haben wegen mangelnder diagnostischer Aussagekraft keine Routinetauglichkeit erreicht und finden außerhalb von Forschungsprojekten keine Anwendung. Die Bestimmung von genetischen Prädispositionen für bestimmte Erkrankungen im Gebiet der Humangenetik, wie z. B. einer familiären Thrombophilie durch $>$ Gerinnungsfaktor V-Genmutation, ist dagegen ein wichtiges Einsatzgebiet von Trait-Markern.

\section{Literatur}

Arndt T (2011) Biomarker des Alkoholkonsums - eine Übersicht. Toxichem Krimtech 78:419-430

Arndt T, Gressner AM, Kropf J (1994) Labordiagnostik und Kontrolle des Alkoholabusus - Ein Plädoyer für Carbohydrate-Deficient Transferrin (CDT). Med Welt 45:247-257

\section{TRAk}

- Autoantikörper gegen TSH-Rezeptoren

\section{Tramadol}

T. Arndt

\section{Englischer Begriff tramadol}

Definition Opioidanalgetikum mit einer zum Codein vergleichbaren und zum Morphin deutlich geringeren analgetischen Potenz.

Tramadol und sein analgetisch wirksamer Metabolit O-Desmethyltramadol:<smiles>COc1cccc(C2(O)CCCCC2CN(C)C)c1</smiles>

Tramadol<smiles>CN(C)CC1CCCCC1(O)c1cccc(O)c1</smiles>

O-Desmethyl-Tramadol 
Molmasse 263,381 g.

Synthese - Verteilung - Abbau - Elimination Bioverfügbarkeit ca. $68 \%$ bei einmaliger Gabe, höher bei wiederholter Gabe. Plasmaproteinbindung $20 \%$. Plasmaspitzenkonzentrationen nach 1,5-2 Stunden, Metabolisierung in der Leber zum analgetisch wirksamen O-Desmethyltramadol und zu weiteren, pharmakologisch inaktiven Metaboliten und deren Glukuroniden. Ausscheidung einer Einzeldosis innerhalb von 3 Tagen zu $90 \%$ über die Niere und $10 \%$ über den Stuhl. Im 3-Tage-Urin lagen $u$. a. vor (frei+glukuronidiert): $29 \%$ Tramadol, $20 \%$ O-Desmethyltramadol, $17 \%$ N-Desmethyltramadol, $20 \%$ O-Desmethyl-N-Desmethyltramadol.

Halbwertszeit Eliminationshalbwertszeit nach Einzeldosis ca. 5-6 Stunden (Blaschek et al. 2007), 5-10 Stunden (Schulz et al. 2012).

Funktion - Pathophysiologie Die analgetische Wirkung von Tramadol ist stärker als die Affinität zu den Opioidrezeptoren erwarten lässt. Dies wird als Hinweis gesehen, dass neben der opioiden Wirkkomponente eine nicht opioide existiert, die sich in einer Verstärkung des adrenergen Systems mit Hemmung der präsynaptischen Wiederaufnahme von Noradrenalin (und Serotinin) im Zentralnervensystem und mit einer verstärkten Noradrenalinausschüttung äußert. Tatsächlich sind insbesondere für eine $\alpha_{2}$-adrenerge Stimulation eine analgetische Wirkung und ein Synergismus mit Opioidwirkungen bekannt. O-Desmethyltramadol soll nach Baselt (2014) eine 2- bis 4-fach stärkere analgetische Wirkung als Tramadol besitzen.

Intoxikationen zeigen sich mit Erbrechen, Schläfrigkeit, Benommenheit, Kopfschmerzen, Atemdepression (auf Naloxon ansprechend). Letztere wurde auch unter analgetischer Dosis intra- und postoperativ beobachtet.

Untersuchungsmaterial - Entnahmebedingungen Serum (S), Plasma (P), Urin.

Analytik HPLC ( $>$ Hochleistungs-Flüssigkeitschromatographie), > GC-MS. LC-MS/MS; Opiat-Immunassays ( $>$ Immunoassay) erfassen Tramadol und O-Desmethyltramadol nicht.

Indikation Therapeutisches Drug Monitoring, Verdacht auf Intoxikation, Drogenscreening.

Interpretation Therapeutischer Bereich (S, P): 0,1-1,0 mg/L; toxisch: $>1,0 \mathrm{mg} / \mathrm{L}$; komatös-letal: $\geq 2,0 \mathrm{mg} / \mathrm{L}$ (Schulz et al. 2012).
Tramadol hat ein geringes Abhängigkeitspotenzial. Es ist derzeit nicht dem Betäubungsmittelgesetz unterstellt. Vor diesem Hintergrund ist die Verwendung von O-Desmethyltramadol als synthetischer Zusatz zu einer laut Produktbeschreibung harmlosen, zum Räuchern empfohlenen Kräutermischung mehrfach interessant. Es belegt nicht nur eine genaue Kenntnis des jeweils aktuellen Betäubungsmittelgesetzes, sondern auch eine pharmakologische und analytische Expertise der „Drogenmischer", indem ein hochwirksamer Metabolit eines nicht sanktionierten Opioids zugesetzt wurde, der im Routinedrogenscreening gewöhnlich nicht erfasst wird (Arndt et al. 2011). Siehe hierzu auch $>$ Neue Psychoaktive Substanzen (NPS).

Carbamazepin induziert den hepatischen Tramadolabbau.

\section{Literatur}

Arndt T, Claussen U, Güssregen B, Schröfel S, Stürzer B, Werle A, Wolf G (2011) Kratom alkaloids and O-desmethyltramadol in urine of a „Krypton“ herbal mixture consumer. Forensic Sci Int 208:47-52

Baselt RC (2014) Disposition of toxic drugs and chemicals in man, 10. Aufl. Biomedical Publications, Seal Beach, S 2021-2024

Blaschek W, Ebel S, Hackenthal E, Holzgrabe U, Keller K, Reichling J, Schulz V (Hrsg) (2007) Hagers Enzyklopädie der Arzneistoffe und Drogen, Bd 15 Sul-Tre, 6. Aufl. Wiss Verlagsges Springer, Stuttgart/ Heidelberg, S 986-991

Schulz M, Iwersen-Bergmann S, Andresen H, Schmoldt A (2012) Therapeutic and toxic concentrations of nearly 1000 drugs and other xenobiotics. Crit Care 16:R136

\section{Tränentropfen-Erythrozyten}

\section{H. Baum}

\section{Synonym(e) Dakryozyten}

\section{Englischer Begriff tear drops}

Definition Erythrozyten mit tropfenförmiger Morphologie im Ausstrichpräparat.

Beschreibung In der morphologischen Begutachtung können $>$ Erythrozyten mit einer kurzen, relativ spitz zulaufenden Ausziehung differenziert werden, die an die Form eines Tropfens erinnern. Diese Erythrozyten werden als Tränentropfen-Erythrozyten oder Dakryozyten bezeichnet.

Die Abbildung zeigt Tränentropfen-Erythrozyten (Pfeile); ein wichtiges Unterscheidungskriterium gegenüber Ausstrichartefakten, die ähnliche Erythrozytenformen hervorrufen können, ist die unterschiedliche Richtung der Ausziehungen im Ausstrichpräparat $(1000 \times$, May-Giemsa-Grünwald-Färbung): 


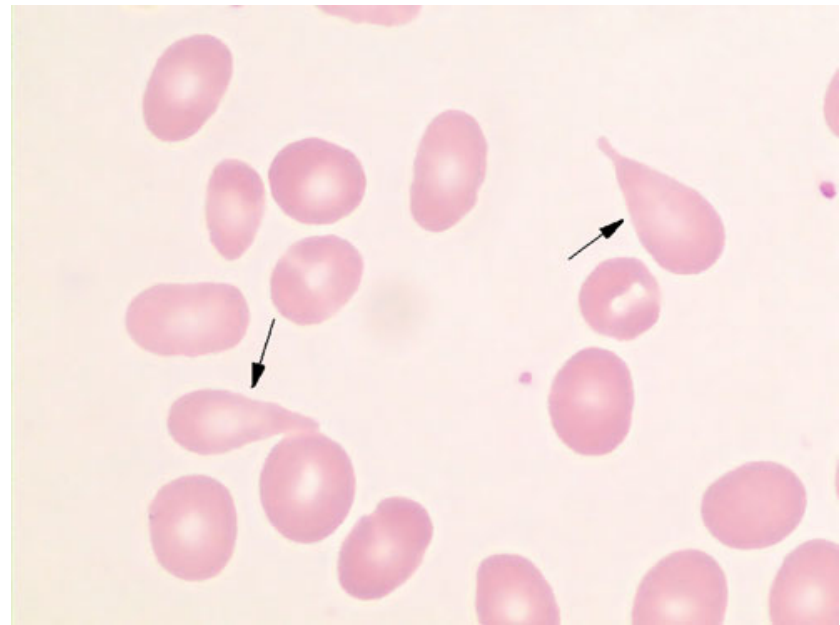

Sie gehören, wie andere Erythrozyten mit veränderter Morphologie, zu den Fragmentozyten ( $\triangleright$ Fragmentozyt). Differenzialdiagnostisch muss beim Nachweis von Dakryozyten in erster Linie an eine Myelofibrose, aber auch an megaloblastäre Anämie, Thalassämie und Knochenmarkkarzinose gedacht werden.

\section{Literatur}

Koeppen KM, Heller S (1991) Differentialblutbild (panoptische Färbung). In: Boll I, Heller S (Hrsg) Praktische Blutzelldiagnostik. Springer, Berlin/Heidelberg/New York, S 171-172

\section{Transaminasen-GLDH-Quotient}

\section{A. M. Gressner und O. A. Gressner}

Synonym(e) Aminotransferasen-GLDH-Quotient; SchmidtQuotient

\section{Englischer Begriff transaminases-GLDH-ratio}

Definition Ein zur Differenzialdiagnostik akuter und chronischer Lebererkrankungen eingesetzter Enzymaktivitätsquotient aus der Summe von $>$ Aspartat-Aminotransaminase und $>$ Alanin-Aminotransaminase (AST, ALT) zu $>$ GlutamatDehydrogenase (GLDH).

Beschreibung Der dimensionslose Quotient wird nach der Formel berechnet:

$$
\frac{\mathrm{AST}+\mathrm{ALT}}{\mathrm{GLDH}}
$$

Aufgrund unterschiedlicher subzellulärer Kompartimentierung (AST überwiegend und GLDH ausschließlich in
Mitochondrien, ALT im Zytosol) und metabolischer Zonierung der Enzyme im Leberläppchen (GLDH in der perizentralen Zone 3, ALT in der periportalen Zone 1, AST gleichmäßig in den Zonen 1-3) ist die Freisetzungskinetik aus den Hepatozyten bei akuten und chronischen Lebererkrankungen unterschiedlich. Empirisch wurden folgende, in der Tabelle dargestellte Quotienten zur Differenzialdiagnostik akuter und chronischer Lebererkrankungen ermittelt.

Klinische Bewertung des Transaminasen-GLDH-Quotienten:

\begin{tabular}{|c|c|c|}
\hline \multicolumn{3}{|c|}{ Transaminasen-GLDH-Quotient } \\
\hline$>50$ & $20-50$ & $<20$ \\
\hline $\begin{array}{l}\text { Akute } \\
\text { Virushepatitis } \\
\text { Akute } \\
\text { alkoholtoxische } \\
\text { Hepatitis }\end{array}$ & $\begin{array}{l}\text { Akute Schübe bei } \\
\text { chronischer Hepatitis } \\
\text { Cholestase }\end{array}$ & $\begin{array}{l}\text { Verschlussikterus } \\
\text { Metastasenleber } \\
\text { Biliäre Zirrhose } \\
\text { Schwerer toxischer } \\
\text { Leberschaden }\end{array}$ \\
\hline
\end{tabular}

$\mathrm{Zu}$ berücksichtigen ist, dass sich die Quotienten aufgrund der unterschiedlichen Eliminationsgeschwindigkeiten der Enzyme (AST- und GLDH-Enzymhalbwertszeiten [ $\triangleright$ Enzymhalbwertszeiten im Blutkreislauf] ca. 18 Stunden, ALT ca. 47 Stunden) im Verlauf ändern.

\section{Literatur}

Schmidt E, Schmidt FW (1978) Normwerte und Befundmuster bei Lebererkrankungen. Therapiewoche 28:1788-1799

\section{Transaminierung}

\section{A. C. Sewell}

Englischer Begriff transamination

Definition Transaminierung ist die Verschiebung der $\alpha$-Aminogruppe einer Aminosäure auf eine $\alpha$-Ketosäure. Dadurch werden eine neue Aminosäure und eine neue $\alpha$-Ketosäure gebildet.

Beschreibung Enzyme der Transaminierung sind Transaminasen oder Aminotransferasen (siehe z. B. \& Alanin-Aminotransaminase, $\triangleright$ Aspartat-Aminotransaminase). Transaminierung ist der häufigste Syntheseprozess von 10 nicht essenziellen Aminosäuren, wobei Pyridoxalphosphat $\left(\triangleright\right.$ Vitamin $\left.\mathrm{B}_{6}\right)$ als Kofaktor benötigt wird. $\triangleright$ Alanin, $\triangleright$ Asparaginsäure oder $\triangleright$ Glutaminsäure sind die Produkte.

\section{Literatur}

Nelson D, Cox M (2001) Lehninger Biochemie, 3. Aufl. Springer, Berlin/Heidelberg/New York, S 680-681 


\section{Transcobalamin}

- Vitamin $\mathrm{B}_{12}$

\section{Transcortin}

- Transkortin

\section{Transferrin}

\section{G. Töpfer}

Synonym(e) Metallseromucoid- $\beta$-1; Siderophilin

\section{Englischer Begriff transferrin}

Definition Transferrin ist ein Glykoprotein (s. \ Glykoproteine), das pro Molekül $2 \mathrm{Fe}^{3+}$-Ionen binden kann, wobei die Sättigung des Moleküls mit Eisen ein Maß für die Verfügbarkeit von > Eisen für die > Hämoglobin-Synthese darstellt, aber auch für die Möglichkeit von übermäßigen Eisenablagerungen.

Struktur Transferrin wird mit 2 Kohlenhydratseitenketten, die bis zu 8 endständige Sialinsäure-(Neuraminsäure-)Reste enthalten, synthetisiert. Die Penta-, Tetra- und Trisialoform machen im Serum normalerweise ca. $99 \%$ aus, die Disialoform zumeist weniger als 1,5\%. Bei starkem Alkoholkonsum sind im Serum erhöhte Konzentrationen sog. Kohlenhydratdefizienter Transferrin-Isoformen zu beobachten ( $\triangleright$ Carbohydrate-deficient transferrin). Diese Isoformen treten auch beim „Carbohydrate-deficient-glycoprotein“-Syndrom (,congenital disorder of glycosylation") auf. Bei den betroffenen Kindern werden Störungen des Nervensystems, Wachstumsretardierung und Lebersynthesestörungen beobachtet. Ein Glykosylierungsdefekt wird dabei auch bei anderen Glykoproteinen (u. a. AT) gesehen.

Im Liquorraum wird $\beta_{2}$-Transferrin ( $\tau$-Fraktion der Elektrophorese) synthetisiert. Es handelt sich dabei um die Asialoform des Transferrins (Konzentration etwa $6 \mathrm{mg} / \mathrm{L}$ ). $(\triangleright$ Liquor-Transferrin (Tf)).

\section{Molmasse $79,6 \mathrm{kDa}$.}

Synthese - Verteilung - Abbau - Elimination Synthese (stimuliert durch niedrige Eisenkonzentrationen im Blutplasma, Östrogene und Kortikosteroide) und Speicherung (an $>$ Ferritin gebunden) erfolgen hauptsächlich in der Leber. Synthesehemmend wirkt Tumornekrosefaktor- $\beta$ bei einer - Akute-Phase-Reaktion. Die Synthese ist vermindert bei Aminosäuremangel (s. > Aminosäuren) und Leberparenchymschäden. Transferrin ist ein negativer Reaktant der akuten Phase.

Halbwertszeit 7-10 Tage für das intakte Molekül und 14 Tage für die Disialo- und Asialoform.

Funktion - Pathophysiologie Das Protein transportiert - Eisen (Transferrin-gebunden an Funktionseisen $=$ Holotransferrin) zu Zellen mit Transferrinrezeptor (PlasmaeisenTurnover). $0,15 \mathrm{~g} / \mathrm{L}$ (weniger als $10 \%$ der normalen Transferrinkonzentration) sind für eine normale Erythropoese ausreichend. An Transferrin ist 1 \%o (ca. $4 \mathrm{mg}$ ) des Gesamtkörpereisenbestandes gebunden. Transferrin verhindert durch diese Bindung die toxischen Wirkungen des freien ionisierten Eisens, $2 \mathrm{Fe}^{3+}$-Ionen werden maximal von 1 Transferrinmolekül gebunden. Normalerweise ist nur ein Drittel der Transferrin-Eisenbindungskapazität mit $\mathrm{Fe}^{3+}$ besetzt. Besonders das eisenfreie Apotransferrin wirkt bakteriostatisch, indem es Bakterien lebenswichtiges - Eisen entzieht. Intravenös hoch dosiertes Transferrin reduzierte im Mausmodell die Konzentration intravasaler Bakterien und Pilze und erhöhte die Lebensdauer der Versuchstiere. Die Eisenbindung färbt das Transferrin lachsrot, was zu einer rosa Einfärbung des Serums bei hohen Eisenwerten führt.

Untersuchungsmaterial-Entnahmebedingungen Serum, Heparinplasma, EDTA-Plasma.

Probenstabilität Serum: $20-25^{\circ} \mathrm{C} 1 \mathrm{Tag}, 4-8^{\circ} \mathrm{C} \leq 3$ Tage, $-20{ }^{\circ} \mathrm{C} 6$ Monate.

Im Liquor sank $\beta_{2}$-Transferrin bei Kontamination durch Streptococcus pneumoniae im Blot unter die Nachweisgrenze.

Präanalytik Der Patient sollte nüchtern sein.

Analytik Internationaler Standard: ERM - DA 470 k/IFCC.

- Im Serum, Plasma, Urin, in der Tränenflüssigkeit: $>$ Immunturbidimetrie, $>$ Immunnephelometrie, radiale Immundiffusion ( $\triangleright$ Immundiffusion, radiale nach Mancini, Carbonara und Heremans)

- Im Liquor (Nasensekret) Liquor-Asialotransferrin $=\beta_{2^{-}}$ Transferrin: Immunofixation, Immunblot

- Carbohydrate-deficient transferrin (CDT)

Konventionelle Einheit $\mathrm{mg} / \mathrm{dL}$. 
Internationale Einheit g/L.

Referenzbereich - Erwachsene und Kinder 2,0-3,6 g/L.

\section{Indikation}

- Verdacht auf Funktionseisenmangel

- Verdacht auf Eisenüberladung

\section{Interpretation Serum}

\section{Erhöhte Transferrinkonzentrationen}

Transferrinerhöhungen treten schon bei (latentem) Eisenmangel auf. Transferrin ersetzt infolge seiner einfacheren analytischen Bestimmbarkeit zunehmend die totale Eisenbindungskapazität (TEBK). Nährungsweise errechnet sich die TEBK aus dem Transferrin zu:

TEBK $\mu \mathrm{mol} / \mathrm{L}=$ Transferrin $\mathrm{g} / \mathrm{L} \times 25,12(\mathrm{SI})$

TEBK $\mu \mathrm{g} / \mathrm{dL}=$ Transferrin $\mathrm{mg} / \mathrm{dL} \times 1,40$ (konventionell) (relative Atommasse von Eisen: 55,847)

Für die Feststellung eines latenten Eisenmangels ist die > Transferrinsättigung (\%) (Koreaner haben eine höhere Transferrinsättigung als die kaukasische Rasse) empfindlicher als die TEBK und die Eisenkonzentration:

$\%$ Transferrinsättigung $=$ Serumeisen $\mu \mathrm{mol} / \mathrm{L}$ : TEBK $\mu \mathrm{mol} / \mathrm{L} \times 100(\mathrm{SI})$

$\%$ Transferrinsättigung $=$ Serumeisen $\mu \mathrm{mol} / \mathrm{L}$ : Transferrin $\mathrm{g} / \mathrm{L} \times 3,98(\mathrm{SI})$

$\%$ Transferrinsättigung $=$ Serumeisen $\mu \mathrm{g} / \mathrm{dL}$ : Transferrin $\mathrm{mg} / \mathrm{dL} \times 71,2$ (konventionell)

Werte für die Transferrinsättigung von $<15 \%$ bei Erwachsenen, $<10 \%$ bei Kindern und $<8 \%$ bei alten Menschen (in Verbindung mit $>$ Ferritin-Werten $<45 \mu \mathrm{g} / \mathrm{L}$ ) zeigen empfindlich einen „latenten“ oder bei zusätzlichem Abfall von > Hämoglobin einen manifesten Eisenmangel an (Eisenmangelanämie).

Besteht dabei eine chronische Entzündung oder eine maligne Erkrankung, so scheint der lösliche Transferrinrezeptor(sTfR-)Anstieg ( $\triangleright$ Transferrinrezeptor, löslicher) den vorhandenen Eisenmangel noch empfindlicher anzuzeigen.

Es gibt Störfaktoren bei der Bewertung von Eisen- und Transferrinkonzentrationen für die Fragestellung „Eisenmangelanämie“: Wichtig ist, dass der Patient 12 Stunden keine Nahrung aufgenommen hat und dass der zirkadiane Rhythmus für $>$ Eisen im Blut beachtet wird (Maximum variabel, überwiegend in den Morgenstunden). Die Blutabnahme für Transferrin und Eisen sollte deshalb zwischen 7 und $10 \mathrm{Uhr}$ erfolgen. Bei der Fragestellung „Eisenüberladung“ sollten 2 Blutabnahmen an 2 verschiedenen Tagen bezüglich der Transferrinsättigung und des Ferritins bewertet werden.

Weiterhin können hohe Estrogenkonzentrationen ( $\triangleright$ Estrogene; Schwangerschaft), Kontrazeptiva und Kortikosteroidkonzentrationen zu erhöhten Transferrinkonzentrationen führen.

\section{Erniedrigte Transferrinkonzentrationen}

- Akute-Phase-Reaktionen (Infekte, chronische Entzündungen, Neoplasien)

- Hämoglobinsynthesestörungen (Porphyrie, Thalassämie)

- Hämochromatose - auch infolge vermehrter enteraler Eisenabsorption steigt die Transferrinsättigung

- Proteinverlust (exsudative Enteropathie, nephrotisches Syndrom), dabei kann auch Eisenmangel auftreten

- Proteinsynthesestörungen, z. B. fortgeschrittene Leberzirrhose

Wegen dieser Einflussfaktoren empfiehlt es sich, bei der Fragestellung „Eisenmangelanämie“ und/oder „Anämie bei chronischer Entzündung“" neben Transferrin immer auch > Ferritin, und auch sTfR bzw. den Ferritinindex (sTfR/log Ferritin) mit zubestimmen sowie außerdem $>$ Akute-PhaseProteine (z. B. $\alpha_{1}$-saures Glykoprotein, unbeeinflusst durch Östrogene und Lebersynthesestörungen und kaum durch Proteinverlust - und CRP). Außerdem ist eine Kontrolle auf Urinproteine (Verlust des Transferrins) erforderlich. Bei alten Menschen (>65 Jahre) mit einer höheren Transferrinsättigung werden mehr Krankenhaustage und eine höhere Mortalität beobachtet.

Eine erniedrigte Transferrinkonzentration im Blutserum führt zur Drosselung der Hepcidinexpression und damit zu erhöhtem Eisenexport aus Darm und Makrophagen.

Transferrin ist ein empfindlicher Parameter zur Beurteilung eines latenten Proteinmangels/Mangelernährung. Bei Urämikern und Dialysepatienten ist Transferrin als Überwachungsparameter für den Proteinhaushalt (Proteinmangel im Serum) besser geeignet als Retinol-bindendes Protein (RBP) und $>$ Präalbumin, es versagt aber hier zur Einschätzung des Eisenmangels. Bei Dialysepatienten, die mit Erythropoese stimulierenden Agenzien behandelt werden, ist Voraussetzung für den Hämoglobinanstieg eine Transferrinsättigung von $>20 \%$.

\section{Tränenflüssigkeit}

Transferrin hat in der Tränenflüssigkeit einen Referenzbereich von $0,2-14 \mathrm{mg} / \mathrm{L}$. Patienten mit Conjunctivitis vernalis haben Werte von 10-270 mg/L. Der Quotient Tf Tränenflüssigkeit/Tf Serum beträgt bei Gesunden 0,002 und bei Konjunktivitis visceralis 0,046.

\section{Nasensekret/Liquor}

Feststellung von $\beta_{2}$-Transferrin $(\tau$-Fraktion $=$ LiquorAsialotransferrin im Nasensekret beweist Liquorbeimengungen im Nasensekret (Verbindung zwischen Liquor- und Nasenraum) ( $\triangleright$ Liquor-Fistel). Einige Stämme von Staphylococcus aureus entwickeln im Liquor Neuraminidaseaktivität - in der Immunofixation verschwindet $\beta_{1}$-Transferrin. Bei multipler Sklerose ist die Transferrinkonzentration nur im Liquor niedrig, und diese Reduktion ist auch assoziiert mit dem Fortschreiten physischer Ausfälle. 
Diagnostische Wertigkeit Bei Verdacht auf ein Eisenüberladung und zu deren Differenzialdiagnostik sollte neben der Transferrinsättigung das Ferritin bestimmt werden (Empfehlungen klinischer Guidelines). Ein $>$ Eisen-Mangel (Funktionseisenmangel) wird anhand der Transferrinsättigung von $<15 \%$ empfindlich erkannt. Zur Differenzialdiagnose von Entzündungs-/Tumoranämie (Anämie bei chronischer Entzündung), bei der die Transferrinsättigung ebenfalls reduziert ist (Transferrinsynthese sinkt - Eisenaufnahme im Darm und Abgabe aus dem Speicherpool sinken noch stärker), sollten immer Ferritin und $>$ Akute-Phase-Proteine (z. B. C-reaktives Protein und $\alpha_{1}$-saures Glykoprotein) mit bestimmt werden. Die Differenzialdiagnostik wird vereinfacht und verbessert durch zusätzliche Bestimmung des löslichen Transferrinrezeptors ( $\triangleright$ Transferrinrezeptor, löslicher). Besonders bei Ferritinwerten $>12 \mu \mathrm{g} / \mathrm{L}$ und $<100 \mu \mathrm{g} / \mathrm{L}$ zeigt ein normaler sTfR eine Anämie bei chronischer Entzündung und eine Erhöhung des sTfR eine Eisenmangelanämie oder eine Mischform (Klinik, Akute-Phase-Proteine) an. Zur Verbesserung der Trennschärfe kann hier der Quotient sTfR/log Ferritin (Ferritinindex) geeignet sein (die Hepcidinkonzentration wird bei größerer Verbreitung einen weiteren Zuwachs an Trennschärfe bringen).

Auch zur Überwachung des Eisenstoffwechsels in der Schwangerschaft ist der Ferritinindex geeignet. Ferritin ist in der normalen Schwangerschaft teilweise erhöht, sTfR jedoch zuverlässig nur bei Eisenmangel. Zur Verlaufskontrolle ist Ferritin meist ausreichend. Hypochrome mikrozytäre Anämien können auch durch einen Kupfermangel ( $\triangleright$ Kupfer und $\triangleright$ Coeruloplasmin erniedrigt) bedingt sein.

Einige Messgrößen zur Differenzialdiagnostik von Eisenmangel-, Entzündungsanämie und Eisenüberladung sind bei der Kenngröße Ferritin tabellarisch erfasst (Transferrinsättigung, sTfR, Ferritin, Eisen).

\section{Literatur}

Greiling H, Gressner AM (1994) Lehrbuch der Klinischen Chemie und Pathobiochemie, 3. Aufl. Schattauer Verlag, Stuttgart/New York, S 228-229

Laurell CB (1951) What is the function of transferrin in plasma? Blood 6(2):183-187

Sherwood RA, Pippard MJ, Peters TJ (1998) Iron homeostasis and the assessment of iron status. Ann Clin Biochem 35:693-708

Zegers I, Keller T, Schreiber W et al (2010) Characterization of the new serum protein reference material ERM-DA $470 \mathrm{k} / \mathrm{IFCC}$ : value assignment by immunoassay. Clin Chem 56(12):1880-1888

\section{Transferrin im Liquor cerebrospinalis} (CSF)

Liquor-Transferrin $(\mathrm{Tf})$

\section{2-Transferrin im Liquor}

- Liquor-Asialotransferrin

\section{Transferrinrezeptor}

CD71

\section{Transferrinrezeptor, löslicher}

\author{
G. Töpfer
}

Synonym(e) Löslicher Serum-Transferrinrezeptor; sTfR

Englischer Begriff soluble transferrin receptor; serum transferrin receptor

Struktur Der zelluläre Transferrinrezeptor (CD-71) stellt ein Aktivierungsprotein auf der Oberfläche von proliferierenden Zellen dar, die $>$ Eisen zum Zellwachstum benötigen. Der Transferrinrezeptor ist ein transmembranöses, dimeres Glykoprotein (s. - Glykoproteine). Beide Ketten sind identisch und in der Plasmamembran durch eine Disulfidbrücke zusammengehalten. Das jeweils kleinere phosphorylierte N-terminale Stück ist intrazellulär und das C-terminale Stück extrazellulär. Das C-terminale Stück jeder 95-kDa-Kette hat 3 Oligosaccharide gebunden und besitzt eine Bindungsstelle für $>$ Transferrin. Dabei wird Transferrin mit $2 \times \mathrm{Fe}^{3+}$ bevorzugt gebunden. Besonders viel Transferrinrezeptor enthält das - Erythron (etwa $80 \%$ des Körpers), wobei polychromatische - Erythroblasten den stärksten Besatz aufweisen. Auch die Syncytiotrophoblasten sind TfR-reich. Auf der Oberfläche proliferierender Zellen können sich 10.000-100.000 TfR-Moleküle befinden. Neuronen besitzen ebenfalls den Transferrinrezeptor. Im Jahr 1983 wurde entdeckt, dass Retikulozyten (s. > Retikulozyt) bei der Reifung zu $>$ Erythrozyten ihren Transferrinrezeptor an das Blut abgeben (,shedding“). Dieser lösliche (Serum-)Transferrinrezeptor entsteht durch Spaltung einer Kette zwischen Aminosäure 100 ( $\triangleright$ Arginin) und 101 ( $\triangleright$ Leucin) noch in der Zelle. Nach Ausschleusung der Proteinkette mit $85 \mathrm{kDa}(74 \mathrm{kDa})$ bildet sich meist ein Komplex aus 2 dieser Proteinketten mit einem Transferrinmolekül (250 kDa). Im Serum kommen aber auch geringe Mengen eines $2 \times 85 \mathrm{kDa}$-Dimers und eines sTfR-Monomers vor.

Die Spaltung des Transferrinrezeptors wird von einer membranständigen Serin-Proteinase bewirkt, eine weitere Fraktion wird intrazellulär in den Exosomen gespalten und 
durch Exozytose freigesetzt. Die Menge des löslichen Transferrinrezeptors im Serum ist proportional der Menge des zellulären Transferrinrezeptors, wobei der größte Anteil von - Erythroblasten und etwas weniger von Retikulozyten stammt. Im Jahr 1999 wurde ein zweiter Transferrinrezeptor beschrieben (TfR2), der hauptsächlich in der Leber gebildet wird. Die extrazelluläre Domäne ist zu $45 \%$ identisch und zu $55 \%$ dem TfR ähnlich. Seine Bildung ist aber trotz Regulation der zellulären Eisenaufnahme nicht vom Eisengehalt der Zelle selbst abhängig. Eine Mutation am TfR2-Gen führt zur Hämochromatose des Typs 3.

Molmasse $95 \mathrm{kDa}$ als Monomer des zellulären TfR.

$85 \mathrm{kDa}$ als Monomer des löslichen TfR (nach proteolytischer Abspaltung von ca. 100 Aminosäuren am N-Terminus).

$250 \mathrm{kDa}$ als sTfR-Tf-sTfR-Komplex.

Synthese - Verteilung - Abbau - Elimination Die Bildung von Transferrinrezeptor oder $>$ Ferritin unterliegt in den Zellen einer vom Eisenbedarf der Zelle diktierten Steuerung. Bei hohem Eisengehalt wird die Synthese des Transferrinrezeptors gebremst, bei niedrigem Eisengehalt reduziert sich dagegen die Bildung von $>$ Ferritin. Steuerungsinstrument ist das Fe-S-Cluster-enthaltende (bei guter Versorgung mit Funktionseisen) oder freie ( $\triangleright$ Apoprotein), ,iron responsive element binding protein" (IRE-BP).

Bei Zellen des Erythrons spielt für die Expression des Transferrin-Rezeptors auch die verminderte Transkription während der Zellreifung eine Rolle.

Die Konzentration des löslichen Transferrinrezeptors im Blut korreliert eng mit der Menge des zellulären Rezeptors. Die Menge des zellulären Rezeptors wiederum ist proportional

- der Menge des roten Knochenmarks und dem

- Eisendefizit dieser Zellen.

Bei chronischen Entzündungen unterbleibt die verstärkte Bildung von Transferrinrezeptor bzw. wird durch IL-1Wirkung sogar etwas gedrosselt, allerdings erhöht IL-1 die - Erythropoetin-Konzentration, der kompensatorisch das Erythron wachsen lässt, sodass die TfR-Masse nahezu unverändert bleibt.

\section{Halbwertszeit Etwa 10 Tage.}

Funktion - Pathophysiologie Nach der Bindung an den Transferrinrezeptor-1 wird der $\left(\mathrm{Fe}^{3+}\right)_{2}$-Transferrin-Komplex durch Endozytose in die Zelle eingeschleust. Die Endosomen senken mittels einer ATP-abhängigen Protonenpumpe ihren $\mathrm{pH}-$ Wert auf $\mathrm{pH}=5,5$, wodurch $\mathrm{Fe}^{3+}$ vom Transferrin abkoppelt (Reduktion zu Fe ${ }^{2+}$ folgt und Einbau in Häm bzw. Ablagerung in $>$ Ferritin). Das eisenfreie Transferrin bleibt am Transferrinrezeptor und bewegt sich innerhalb von Minuten wieder zur Zelloberfläche, wo das Transferrin wegen des nunmehr physiologischen $\mathrm{pH}$-Wertes freigesetzt wird. Eine normale Konzentration des löslichen Transferrinrezeptors ist ein Indikator für eine gute Eisenversorgung bei normaler Zahl und Menge der blutbildenden Zellen. Desgleichen tritt eine normale Konzentration des sTfR auch bei chronischen Entzündungen auf trotz Eisenmangels in den blutbildenden Zellen. Eine Erhöhung des löslichen Transferrinrezeptors zeigt sich bei allen Zuständen mit verstärkter Bildung von > Erythrozyten (ineffektive Erythropoese, \ Hämolyse, in vivo und in vitro). Eine Verminderung des löslichen Transferrinrezeptors beobachtet man bei verminderter Bildung der roten Blutkörperchen (aplastische Anämie, Thalassämie). Diese Erhöhungen und Verminderungen sind diagnostisch ohne wesentlichen Nutzen. Anders beim Eisenmangel: Hier tritt auch bei chronischen Entzündungen durch den stärkeren Besatz der $\triangleright$ Erythroblasten mit TfR eine Erhöhung des löslichen Transferrinrezeptors auf, wobei das $>$ Ferritin als Akute-Phase-Protein (s. $>$ Akute-Phase-Proteine) trotz des Eisenmangels häufig Erhöhungen zeigt und damit nur der lösliche Transferrinrezeptor den Eisenmangel anzeigt. Eine hohe Transferrinsättigung führt zur Holotransferrinbindung an TfR-1 an Hepatozyten. Nachdem sich HFE Protein aus der TfR-1-Bindung gelöst hat, bindet es an Membran-TfR-2, das ebenfalls Holotransferrin gebunden hat. Damit wird ein Signal zur Hepcidinexpression ausgelöst. Es folgt die Hemmung des Eisenexports aus den Enterozyten und den Makrophagen (Eisensensing).

Untersuchungsmaterial - Entnahmebedingungen Serum, Heparinplasma.

Probenstabilität Vollblut: $20-25{ }^{\circ} \mathrm{C} 2$ Stunden; Serum: $20-25{ }^{\circ} \mathrm{C} 3$ Tage, $4-8{ }^{\circ} \mathrm{C} 7$ Tage, $-20{ }^{\circ} \mathrm{C} 2$ Wochen.

Nur einmal einfrieren!

Stabilität (im Serum) bei $20{ }^{\circ} \mathrm{C}$ und bei $4{ }^{\circ} \mathrm{C} 7$ Tage (Thomas 2012).

Präanalytik Serum und Citratplasma zeigen vergleichbare Konzentrationen, sind aber sofort zu zentrifugieren. EDTAPlasma weist drei- bis viermal so hohe Werte auf wie Serum und Citratplasma.

\section{Analytik \\ - $>$ Enzymimmunoassay \\ - $>$ Radioimmunoassay \\ - Latexverstärkte $>$ Immunnephelometrie \\ - Latexverstärkte $\triangleright$ Immunturbidimetrie}

Die Immunturbidimetrie zeigt vergleichbare Ergebnisse wie die Immunnephelometrie. 
Verwendete Antikörper:

- Monoklonal gegen Transferrinrezeptor, zellgebunden

- Monoklonal gegen Plazentarezeptor

- Polyklonal gegen Transferrin-Rezeptor-Komplex

Standards:

- Gereinigter Plazentarezeptor

- Transferrin - Transferrin-Rezeptor-Komplex

- Gereinigter löslicher Transferrinrezeptor (sTfR)

Die > Unpräzision beträgt sowohl in Serie als auch von Tag zu Tag VK $<5 \%$ (bei $>$ Immunnephelometrie wurde VK $<2,1 \%$ erreicht). Es fehlt noch ein international akzeptierter Standard.

\section{Konventionelle Einheit $\mathrm{mg} / \mathrm{L}$.}

Referenzbereich - Frauen $2,1-4,6 \mathrm{mg} / \mathrm{L}$.

Referenzbereich - Männer 1,9-4,7 mg/L.

In einer größeren Untersuchung wurde im Jahr 1999 festgestellt, dass die höchsten Konzentrationen in den ersten 2 Lebensjahren auftreten. Vom 3.-16. Lebensjahr sind die Referenzbereiche um ein Drittel niedriger und ab dem 17. Lebensjahr etwa halb so hoch wie in den ersten 2 Lebensjahren. Es liegt keine Geschlechtsabhängigkeit der Referenzbereiche vor. Schwarze haben etwa $9 \%$ höhere Werte als Weiße (bei 3-4 \% niedrigerem Hämoglobin). Menschen, die in größeren Höhen leben (1600 m über N.N.), haben um etwa $10 \%$ höhere Konzentrationen des sTfR als bei 0 m über N.N. Das Hämoglobin ist in dieser Höhe um 3 \% höher als in Meeresspiegelhöhe.

\section{Referenzbereich - Kinder Nicht verfügbar.}

\section{Indikation Differenzialdiagnose zwischen}

- Eisenmangelanämie

- Anämie bei chronischer Erkrankung (ACD)

- Eisenmangelanämie bei chronischer Erkrankung

- Eisenmangel in der Schwangerschaft

Interpretation Eine Erhöhung der Konzentration gegenüber dem Referenzbereich wird bei allen Erkrankungen mit gesteigerter Erythrozytenbildung beobachtet bei

- ineffektiver Erythropoese (myelodysplastisches Syndrom, megaloblastäre Anämie),
- verstärkter Hämolyse (hereditäre Sphärozytose, Sichelzellanämie),

- ineffektiver Erythropoese und verstärkter Hämolyse (Vitamin-B ${ }_{12}$-Folsäuremangel, Thalassämie),

- gesteigerter Bildung (Polyzythämie, Polyglobulie).

Bei all diesen Erkrankungen bietet der lösliche Transferrinrezeptor keine wesentlichen diagnostischen Informationen. Entscheidende Bedeutung hat der lösliche Transferrinrezeptor bei der Frage, ob ein echter Eisenmangel vorliegt oder eine Anämie bei chronischen Erkrankungen (ACD) mit einem Mangel an Funktionseisen (das Eisen befindet sich dabei fixiert im Monozyten-Makrophagen-System und wird nicht für die blutbildenden $>$ Erythroblasten des Knochenmarks verfügbar). Trotz Fehlens des Funktionseisens kommt es hier nicht zur verstärkten Synthese des Transferrinrezeptors. Bei Ferritinwerten $<20 \mu \mathrm{g} / \mathrm{L}$ (Eisenmangel) und $>100 \mu \mathrm{g} / \mathrm{L}$ bei ACD ist eine Entscheidung zu Eisenmangel oder Anämie bei chronischen Erkrankungen meist allein über das $>$ Ferritin möglich. Allerdings kann auch bei Ferritinwerten $>100 \mu \mathrm{g} / \mathrm{L}$ bei Tumoren und chronischen Entzündungen ein Eisenmangel mit dabei sein. Zwischen 20 und $100 \mu \mathrm{g} / \mathrm{L}$ und/oder bei chronischen Erkrankungen (besonders chronischen Entzündungen und Tumoren) mit sehr hohen Ferritinwerten leistet die zusätzliche Bestimmung des löslichen Transferrinrezeptors eine bessere Zuordnung besonders dann, wenn bei chronischer Entzündung ein Eisenmangel hinzukommt (Eisenmangel führt zur Synthesesteigerung des Transferrinrezeptors und damit zu erhöhtem sTfR). Einen zusätzlichen diagnostischen Gewinn zur Information von sTfR und Ferritin kann bei Verwendung des Quotienten sTfR/log Ferritin (Ferritinindex) erreicht werden. Bei Messmöglichkeit für das Retikulozytenhämoglobin bietet der Thomas-Plot (Cutoff-Werte methodenabhängig - der Hepcidin-Plot eher mit geringerer Trennschärfe) verbesserte Möglichkeiten einer Therapieüberwachung (anwendbar auch für Kleinkinder). Dabei weisen der sTfR und die vom löslichen Transferrirezeptor ableitbaren Indices bei malignen Erkrankungen eine geringere Effizienz zur Einschätzung des Eisenstatus auf als bei chronischen Entzündungen. Hervorragend ist der lösliche Transferrinrezeptor auch zum Nachweis eines Eisenmangels in der Schwangerschaft (2. und 3. Trimester) geeignet, da die Ferritinkonzentration bei Eisenmangel erhöht sein kann. Ein erhöhter sTfR zeigt hier zuverlässig einen Eisenmangel an. Außerdem lässt sich die Eisensubstitution dabei mit dem sTfR überwachen. Die Steuerung einer Therapie mit $>$ Erythropoetin (EPO) mithilfe des löslichen Transferrinrezeptors scheint ebenfalls erfolgversprechend zu sein. Die Konzentration des löslichen Transferrinrezeptors hängt nicht vom Ernährungszustand ab. Deshalb ist der sTfR einsetzbar zur Diagnostik des Eisenmangels bei unterernährten Personen. Säuglinge mit angeborener Hypothyreose ohne Eisenmangel zeigten erhöhte sTfR- Konzentrationen. 
Diagnostische Wertigkeit Die Feststellung eines Eisenmangels bei chronischen Entzündungen (wobei der Ferritinindex die Trennschärfe erhöht) und in der Schwangerschaft. Kenngröße für die Größe des Erythrons und seiner Aktivität.

Bei Verdacht auf einen latenten Eisenmangel besonders bei Sportlern, Blutspendern mit hoher Spendefrequenz, Kleinkindern und Frauen mit hohem Menstruationsblutverlust. Der sTfR zeigt den Eisenmangel des Erythron eher an als die Transferrinsättigung oder der MCV-Wert. Therapieüberwachung bei Therapie mit Erythropoese-stimulierenden Agenzien (z. B. Erythropoietin), Bei Eisensubstitution mit intravenös verabreichten Eisenpräparaten und nach Knochenmarktransplantation.

\section{Literatur}

Beguin Y (2003) Soluble transferrin receptor for the evaluation of erythropoiesis and iron status. Clin Chim Acta 329:9-22

Feelders RA, Kuiper-Kramer EPA, van Eijk HG (1999) Structure, function and clinical significance of transferrin receptors. Clin Chem Lab Med 37:1-10

Thomas L (Hrsg) (2012) Labor und Diagnose, 8. Aufl. TH-Books, Frankfurt am Main, S. 469

\section{Transferrinsättigung}

\section{A. M. Gressner und O. A. Gressner}

Synonym(e) Eisensättigung, prozentuale

Englischer Begriff transferrin saturation; iron saturation; percent transferrin saturation

Definition Als Kenngröße des Eisenhaushalts benutzter Quotient aus der Serum/Plasma-Eisenkonzentration und der Serum/Plasma-Transferrinkonzentration (korrigiert um einen Faktor).

Beschreibung $>$ Transferrin als das zentrale Eisentransportprotein bindet pro Molekül zwei $\mathrm{Fe}^{3+}$-Ionen und ist normalerweise nur zu etwa einem Drittel mit Eisen gesättigt. Der Gesamtbestand von dem an Transferrin gebundenem Transporteisen im Blutplasma eines gesunden Erwachsenen beträgt nur etwa $4 \mathrm{mg}$, was etwa $1 \%$ o des Gesamtkörpereisenbestandes entspricht. Die Bestimmung der Transferrinsättigung als dimensionsloser Quotient aus der Serum/Plasma-Eisenkonzentration und der Serum/Plasma-Transferrinkonzentration bietet als Kenngröße des Eisenhaushaltes gegenüber der alleinigen Eisenbestimmung die Vorteile, dass diese Kenngröße unabhängig vom Hydratationszustand des Patienten, von den Einflüssen unterschiedlicher Blutentnahmetechniken sowie von unterschiedlichen Transferrinkonzentrationen ist. Gegenüber der Bestimmung der $\triangleright$ Eisenbindungskapazität sind bei der Angabe der Transferrinsättigung unspezifische Eisenbindungen durch andere Proteine unbedeutend.

Nach Bestimmung der Serum/Plasma-Eisen- und Transferrinkonzentration erfolgt die Berechnung der Transferrinsättigung (\%) nach einer der folgenden Formeln (s. a. > Transferrin):

- $\%$ Transferrinsättigung $=$ Serumeisen $(\mu \mathrm{mol} / \mathrm{L}) /$ Transferrin $(\mathrm{g} / \mathrm{L}) \times 3,98(\mathrm{SI})$

- \% Transferrinsättigung $=$ Serumeisen $(\mu \mathrm{g} / \mathrm{dL}) /$ Transferrin $(\mathrm{mg} / \mathrm{dL}) \times 71,2$ (konventionell)

Relative Atommasse von Eisen: 55,847; Molmasse ApoTransferrin: 79,570 kDa.

Der Referenzbereich liegt für Männer und Frauen zwischen 15 und $45 \%$. Bei Neugeborenen und Kleinkindern bis ca. 6 Monate sind Sättigungen bis zu $95 \%$ normal.

Erhöhte Transferrinsättigungen finden sich bei allen Zuständen mit Eisenüberladung wie Hämochromatose, exzessive Eisenaufnahme, Thalassämie, Vitamin B6-Mangel und aplastische Anämien.

Erniedrigte Transferrinsättigungen sind bei allen Zuständen von Eisenmangel oder Eisenverteilungsstörungen feststellbar wie hypochrome Anämien, gastrointestinale Karzinome, akute Infektionen, Entzündungen, Myokardinfarkt und Menstruation.

\section{Literatur}

Wick M, Pinggera W, Lehmann P (2000) Eisenstoffwechsel, AnämienDiagnostik und -Therapie, 5. Aufl. Springer-Verlag, Wien/New York

\section{Transformation}

R.-D. Hilgers, N. Heussen und S. Stanzel

\section{Englischer Begriff transformation}

Definition Unter einer Transformation versteht man die Umformung beobachteter Daten aufgrund einer Rechenvorschrift, wobei jedem ursprünglichen Wert ein ihm entsprechender, sog. transformierter Wert zugeordnet wird.

Beschreibung Viele statistisch Verfahren stellen an die Verteilung ( $\triangleright$ Verteilung, statistische) der Werte, aus der die Stichprobendaten stammen, gewisse Anforderungen, wie 
z. B. Normalität ( $\triangleright$ Normalverteilung) oder Linearität. In manchen Fällen sind diese Anforderungen nur zum Teil erfüllt, jedoch lassen sich durch geeignete Transformationen der Messwerte die gewünschten Eigenschaften zumindest näherungsweise erreichen. Gebräuchliche Transformationen sind die inverse Transformation ( $\triangleright$ Transformation, inverse), die Wurzeltransformation und die logarithmische Transformation ( $\triangleright$ Transformation, Log-).

\section{Literatur}

Hartung J, Elpelt B, Klösener KH (1995) Statistik, Lehr- und Handbuch der angewandten Statistik. Oldenbourg Verlag, München

\section{Transformation, Arcus-Sinus-}

\section{R.-D. Hilgers, N. Heussen und S. Stanzel}

Synonym(e) Arcus-Sinus-Transformation

Englischer Begriff arcus-sinus-transformation

Definition Die Arcus-Sinus-Transformation ordnet jedem ursprünglichen Wert $\mathrm{x}$ als transformierten Wert

$$
\sqrt{\mathrm{n}+\mathrm{w}_{1}} \times \arcsin \sqrt{\frac{\mathrm{x}+\mathrm{w}_{2}}{\mathrm{n}+\mathrm{w}_{3}}}
$$

zu, wobei $n$ den Stichprobenumfang bezeichnet sowie $w_{1}$, $w_{2}$ und $w_{3} \mathrm{zu}$ wählende Größen sind.

Beschreibung Die Arcus-Sinus-Transformation wird vor allem zur $\triangleright$ Transformation von Daten aus einer $>$ Binomialverteilung in solche aus einer $>$ Normalverteilung verwandt.

\section{Literatur}

Hartung J, Elpelt B, Klösener KH (1995) Statistik, Lehr- und Handbuch der angewandten Statistik. Oldenbourg Verlag, München

\section{Transformation, inverse}

R.-D. Hilgers, N. Heussen und S. Stanzel

Englischer Begriff inverse transformation
Definition Die inverse Transformation ordnet jedem ursprünglichen Wert als transformierten Wert den jeweiligen Kehrwert zu.

Beschreibung Entstammen die beobachteten Werte der - Stichprobe einer stark schiefen Verteilung ( $\vee$ Verteilung, statistische), erreicht man durch die Anwendung der inversen Transformation oftmals eine recht gute Anpassung an die - Normalverteilung. Man arbeitet nicht mit den beobachteten, sondern mit den Kehrwerten. Diese Transformation sollte nur dann angewendet werden, wenn die beobachteten Daten den Wert Null nicht annehmen.

\section{Literatur}

Hartung J, Elpelt B, Klösener KH (1995) Statistik, Lehr- und Handbuch der angewandten Statistik. Oldenbourg Verlag, München

\section{Transformation, Log-}

R.-D. Hilgers, N. Heussen und S. Stanzel

Synonym(e) Logarithmische Transformation

Englischer Begriff log transformation; logarithmic transformation

Definition Die Log-Transformation ordnet jedem ursprünglichen Wert als transformierten Wert den entsprechenden natürlichen Logarithmus dieses Werts zu.

Beschreibung Die Log-Transformation wird vor allem zur - Transformation von Daten aus einer $>$ Log-Normalverteilung in solche aus einer $>$ Normalverteilung verwandt. Diese Transformation sollte nur dann angewendet werden, wenn die beobachteten Daten Werte größer als Null annehmen.

\section{Literatur}

Hartung J, Elpelt B, Klösener KH (1995) Statistik - Lehr- und Handbuch der angewandten Statistik. Oldenbourg Verlag, München

\section{Transformation, logistische}

R.-D. Hilgers, N. Heussen und S. Stanzel

Synonym(e) Logit-Transformation 
Englischer Begriff logistic transformation; logit transformation

Definition Die Funktion $y=\ln (\mathrm{p} /(1-\mathrm{p}))$ wird logistische Transformation einer binären Variablen genannt, wobei $p$ die Wahrscheinlichkeit für einen „Erfolg“ kennzeichnet. Die Variable y wird auch kurz als ,logit“ bezeichnet.

Beschreibung Die logistische Transformation bildet die Grundlage der logistischen Regression ( $\triangleright$ Regression, logistische).

\section{Literatur}

Day S (1999) Dictionary for clincal trials. Wiley, New York

\section{Transformation, Wurzel-}

R.-D. Hilgers, N. Heussen und S. Stanzel

Englischer Begriff square root transformation

Definition Die Wurzeltransformation ordnet jedem ursprünglichen Wert als transformierten Wert die Wurzel des ursprünglichen Werts bzw. eine Funktion des ursprünglichen Wertes zu.

Beschreibung Entstammen die beobachteten Werte der - Stichprobe einer Poisson-Verteilung, wird die Wurzeltransformation zur $>$ Transformation der Daten verwendet. Diese Transformation sollte nur dann angewendet werden, wenn die beobachteten Daten Werte größer als Null annehmen.

\section{Literatur}

Hartung J, Elpelt B, Klösener KH (1995) Statistik - Lehr- und Handbuch der angewandten Statistik. Oldenbourg Verlag, München

\section{Transformationslösungen zur Hämoglobinbestimmung}

A. M. Gressner und O. A. Gressner

Synonym(e) Drabkin-Lösung; Umwandlungslösungen für Hämoglobinbestimmung; Van-Kampen-Zijlstra-Lösung
Englischer Begriff transforming solution/reagent for hemoglobin measurement

Definition Chemische Umwandlung (Transformation) von Hämoglobin in die oxidierte (3-wertiges Eisen) Form des Hämiglobins mit nachfolgender Überführung in stabiles, photometrierbares Hämiglobincyanid (s. a. DrabkinLösung).

Beschreibung Hämoglobin wird in einer zweistufigen chemischen „Transformation“ zunächst (I) durch Kaliumhexacyanoferrat zum dreiwertigen $\left(\mathrm{Fe}^{3+}\right)$ Hämiglobin ( $>$ Methämoglobin) oxidiert, um anschließend (II) durch Kaliumcyanid in stabiles Hämiglobincyanid (Cyanhämiglobin) überführt zu werden. Die Intensität der sich entwickelnden, stabilen, bräunlichen Farbe wird nach Abschluss der Farbentwicklung bei 546 nm photometriert gemessen ( $>$ Hämoglobin). Dabei kann die Quantifizierung des Hämiglobins grundsätzlich über einen Standard oder über den molaren Extinktionskoeffizienten des Hämiglobincyanids erfolgen. Hämoglobin, Oxyhämoglobin, Kohlenmonoxidhämoglobin (Carboxyhämoglobin), Methämoglobin (Hämiglobin) werden quantitativ in Hämiglobincyanid überführt, nicht jedoch $>$ Sulfhämoglobin.

Im Wesentlichen sind zwei leicht verschiedene, in Farbentwicklungszeit und Farbstabilität unterschiedliche Transformationslösungen in Gebrauch:

- Drabkin-Lösung (Kaliumhexacyanoferrat, Kaliumcyanid, Natriumbicarbonat, pH 8,6): Farbentwicklung 10-20 min, Stabilität mehrere Tage.

- Van-Kampen- und Zijlstra-Lösung (Kaliumhexacyanoferrat, Kaliumcyanid, Kaliumhydrogenphosphat, pH 7,2): Farbentwicklung 4 Minuten, Stabilität 24 Stunden. Wegen der Schnelligkeit der Farbentwicklung ist diese Methode (oder ggf. weitere Modifikationen) für mechanisierte Analysensysteme von Vorteil.

\section{Literatur}

Greiling H, Gressner AM (1995) Lehrbuch der Klinischen Chemie und Pathobiochemie, 3. Aufl. F K Schattauer Verlag, Stuttgart

Hallmann L (1980) Klinische Chemie und Mikroskopie, 11. Aufl. Georg Thieme Verlag, Stuttgart

Transforming growth factor beta receptor III

- Betaglykan 


\section{Transforming Growth Factor $\beta$}

A. M. Gressner und O. A. Gressner

$\operatorname{Synonym(e)~TGF-~} \beta 1$; TGF- $\beta 2$; TGF- $\beta 3$

Englischer Begriff transforming growth factor $\beta$

Definition Weitgehend ubiquitär verbreitetes, niedermolekulares $(25 \mathrm{kDa})$, dimeres Zytokin ( $\triangleright$ Zytokine) mit multiplen (patho-)physiologischen Funktionen, dessen Bestimmung in Körperflüssigkeiten zurzeit noch keine klinisch-diagnostische Bedeutung besitzt.

Beschreibung TGF- $\beta$ gehört zu einer Superfamilie von etwa 30 ähnlichen Proteinen, die 3 Isoformen von TGF- $\beta(1,2,3)$, 3 Isotypen von Aktivinen und etwa 20 Isoformen von ,bone morphogenetic proteins" (BMPs) umfassen. Von nahezu allen kernhaltigen Zellen wird TGF- $\beta$ als dimerer „precursor“ (Molmasse $100 \mathrm{kDa}$ ) synthetisiert, intrazellulär durch die Endopeptidase Furin proteolytisch prozessiert, in kovalenter Verbindung mit dem "large latent TGF- $\beta$-binding protein“ (LTBP) in latenter Form sezerniert und in extrazellulärer Matrix deponiert. Proteolytische Aktivierung führt zum aktiven TGF- $\beta$-Homodimer (Molmasse $25 \mathrm{kDa}$ ), das über 3 Serin-Threonin-Kinase-Rezeptoren den intrazellulären Smad-Signalweg aktiviert und zur Regulation TGF- $\beta$-abhängiger Gene führt.

\section{Wichtige Funktionen:}

- Expressionssteigerung extrazellulärer Matrixproteine (z. B. Kollagen, Proteoglykane, Glykoproteine)

- Reduktion des Matrixabbaus durch Expressionsminderung von Matrix-Metalloproteinasen (MMPs) und Hochregulation von spezifischen Inhibitoren (,tissue inhibitors of metalloproteinases", TIMPs)

- Proliferationshemmung

- Zelldifferenzierung, Onkogenese, Fibrogenese, Atherogenese

- Apoptoseinduktion (bei spezifischen Zelltypen)

- Immunsuppression u. a.

Pathophysiologisch ist TGF- $\beta$ von entscheidender Bedeutung für Wundheilung, Organfibrosierungen (Leber, Lunge, Niere, Pankreas, Atherosklerose u. a.), Onkogenese, Autoimmunität, Asthma bronchiale u. a. Im Plasma ist nahezu ausschließlich latentes TGF- $\beta$ komplexiert mit $>\alpha_{2}$-Makroglobulin vorhanden, Halbwertszeit des aktiven TGF- $\beta$ ca. 2 Minuten mit Elimination über Leber und Nieren. Bindung auch an den vaskulären Endothelzellrezeptor Endoglin
(CD 105). Hohe Konzentration in $>$ Thrombozyten. Trotz großer pathophysiologischer Relevanz bei entzündlichen, fibrogenen und malignen Erkrankungen ist die enzymimmunologische Bestimmung (auch der Isoformen) bisher ohne klinische Bedeutung.

\section{Literatur}

Oskarsson T, Massagué J (2011) Extracellular matrix players in metastatic niches. EMBO J 31:254-256

Prud'homme GJ (2007) Pathobiology of transforming growth factor beta in cancer, fibrosis and immunologic disease, and therapeutic considerations. Lab Investig 87:1077-1091

\section{Transfusionen als Störgrößen}

$>$ Störgrößen

\section{Transfusionsgesetz}

\author{
K. Kleesiek, C. Götting, J. Diekmann, J. Dreier und \\ M. Schmidt
}

Synonym(e) Gesetz zur Regelung des Transfusionswesens

Englischer Begriff transfusion law

Definition Gesetz, das das Transfusionswesen in Deutschland regelt.

Beschreibung Das Gesetz zur Regelung des Transfusionswesens (Transfusionsgesetz, TFG) wurde 1998 verabschiedet und in den Folgejahren umfassend überarbeitet. Es entstand als Reaktion auf die Entdeckung vieler HIV-Infektionen nach Erhalt von Blut oder Blutbestandteilen (sog. Blutskandal 1993) und dient daher dem Zweck, ,[... ] für eine gesicherte und sichere Versorgung der Bevölkerung mit Blutprodukten zu sorgen $[\ldots]$. $(\S 1 \mathrm{TFG})$.

Im Gesetz finden sich verschiedene Abschnitte, unter anderem werden im Abschnitt „Gewinnung von Blut und Blutbestandteilen" die Anforderungen an Spendeeinrichtungen und Blutspender festgelegt, in den weiteren Kapiteln werden qualitätssichernden Maßnahmen für die „Anwendung von Blutprodukten“ geregelt, das Verfahren der „Rückverfolgung“ definiert sowie das „Meldewesen“ koordiniert. Darüber hinaus werden „Sachverständige“ als Expertenkommission bestimmt (Arbeitskreis Blut), und die „Pflichten der Behörden“ und „Sondervorschriften“ festgelegt. Abschließend 
werden die „zuständigen Bundesoberbehörden“ definiert (PaulEhrlich-Institut, Robert Koch-Institut für epidemiologische Fragestellungen, Bundeszentrale für gesundheitliche Aufklärung und das Deutsche Institut für medizinische Dokumentation und Information) sowie „Straf- und Bußgeldvorschriften“ festgelegt.

\section{Transfusionsmedizin, Fachärztin/ Facharzt für}

\section{O. A. Gressner und A. M. Gressner}

Synonym(e) Arzt/Ärztin für Transfusionsmedizin

Englischer Begriff specialist of transfusion medicine

Definition Nach Abschluss des Studiums der Humanmedizin und Erlangung der Approbation führt die Ableistung der in der Weiterbildungsordnung der Landesärztekammer vorgeschriebenen Weiterbildungszeiten und -inhalte über 5 Jahre zur Facharztkompetenz, die durch eine erfolgreich abgelegte Prüfung vor der zuständigen Landesärztekammer zu bestätigen ist.

Beschreibung Das klinische Fachgebiet der Transfusionsmedizin beinhaltet die medizinische Auswahl und Betreuung von Blutspendern, die Prüfung und Weiterentwicklung allogener und autologer zellulärer und plasmatischer Blutpräparate und die mit hämotherapeutischen Aufgaben verbundenen Maßnahmen. Die Weiterbildungszeit von 60 Monaten verlangt mindestens 24 Monate in der stationären Patientenversorgung (z. B. Chirurgie, Innere Medizin, Allgemeinmedizin, Anästhesiologie) wovon Teilzeiten in der $>$ Laboratoriumsmedizin (bis zu 12 Monate) und Mikrobiologie, Virologie und Infektionsepidemiologie (davon 6 Monate) abgeleistet werden können. 36 Monate sind in Transfusionsdiensten oder transfusionsmedizinischen Instituten/Zentren unter der Leitung eines für dieses Fachgebiet Weiterbildungsbefugten abzuleisten. Die zu erwerbenden Weiterbildungsinhalte, Untersuchungs- und Behandlungsverfahren sind in den Richtlinien der Landesärztekammern im Einzelnen festgelegt und dort in der jeweils aktuellen Form nachzulesen. Diese umfassen $u$. a. neben allen relevanten fachgebietsbezogenen diagnostischen und hämotherapeutischen Untersuchungen bzw. Verfahren die dokumentierten Qualitätssicherungsmaßnahmen der Blutbestandteilgewinnung und -konservierung. Schließlich sind Patienten über mögliche Nebenwirkungen aufzuklären. Am Ende der dokumentierten Weiterbildung erfolgt eine Prüfung der erworbenen Kenntnisse bei der zuständi- gen Landesärztekammer. Es praktizieren in Deutschland ca. 500 Transfusionsmediziner/innen, überwiegend im stationären Bereich.

\section{Literatur}

Informatiosmaterial über die zuständigen Landesärztekammern

\section{Transglutaminase}

> Gerinnungsfaktor XIII

\section{Transiente Elastographie}

- Elastographie, transiente

\section{Transkortin}

W. Hubl

$\operatorname{Synonym(e)~CBG;~Transcortin~}$

Englischer Begriff transcortin; corticosteroid-binding globulin

Definition Transkortin ist in der Lage, Kortikosteroide im Blutplasma mit hoher Affinität und begrenzter Kapazität zu binden. Es dient damit als wichtiges Transportprotein der Kortikosteroide.

Beschreibung Transkortin ist ein Kortikosteroid-bindendes $\alpha 1$-Globulin mit einer Molmasse von $56 \mathrm{kDa}$. Es ist in der Lage, folgende $>$ Kortikosteroide und Vorläufer der Biosynthese im Blutplasma zu binden und damit zu transportieren: - Kortisol, Kortikosteron, > 11-Desoxykortisol, - Progesteron, 17-Hydroxyprogesteron, jedoch nicht $>$ Aldosteron. Transkortin denaturiert bei $60^{\circ} \mathrm{C}$. Es gehört zur Gruppe der Serin-Proteinase-Inhibitoren (SERPIN A6).

Pathophysiologie: Die Konzentration des Transkortins im Plasma reguliert in entscheidender Weise die KortikosteroidKonzentrationen, wobei die physiologische Wirkung der Kortikosteroide von der Konzentration der freien, nicht proteingebundenen Fraktion abhängt.

Von besonderer Relevanz sind die Erhöhungen der Transkortinkonzentrationen im Verlauf der Schwangerschaft, bei 
Hyperthyreose, Diabetes mellitus sowie bei Einnahme von Östrogenen bzw. hormonellen Kontrazeptiva. Diese erhöhten Transkortinkonzentrationen ziehen eine Erhöhung der Gesamt-Kortikosteroid-Konzentrationen nach sich, wobei der Anteil der ungebundenen Hormonfraktion jedoch im Normbereich verbleibt. Aus diesem Grund besitzen die Methoden zur Erfassung der freien, ungebundenen Hormone eine deutlich höhere klinische Relevanz als die Bestimmung der Gesamthormone.

Erniedrigte Transkortinkonzentrationen treten auf bei Hypothyreose, Proteinmangelzuständen, Leberzirrhose sowie beim nephrotischen Syndrom. Hierbei werden erniedrigte Gesamt-Kortisol-Konzentrationen gemessen, wobei der freie Kortisolanteil im Referenzbereich liegt.

In der Praxis wird zur Abschätzung des freien, ungebundenen Kortisols die Bestimmung im 24-Stunden-Sammelurin verwendet, weil hierbei eine gute Korrelation zur freien Kortisolfraktion im Plasma nachgewiesen werden konnte.

Kürzlich wurde ein angeborener Transkortindefekt (Mutation Asp367Asn, CBG Lyon) in 4 Familien beschrieben, dieser scheint jedoch extrem selten aufzutreten. Bei diesen Patienten wurde neben erniedrigten Transkortinkonzentrationen sowohl eine erniedrigte Affinität als auch eine erniedrigte Kapazität für Kortisol - als Gegenregulation nachgewiesen.

Methoden: Zur Abschätzung des freien Anteils der Kortikosteroide wurden Transkortinmethoden entwickelt, die gemeinsam mit der Bestimmung der Kortikosteroidkonzentration zur Berechnung eines freien Hormonindex dienen sollten. In der Praxis sind diese Verfahren wegen der begrenzten klinischen Relevanz jedoch wenig verbreitet.

$\checkmark$ Immunoassay, $>$ Radioimmunoassay, $>$ Enzymimmunoassay.

\section{Literatur}

Lei JH, Yang X, Peng S et al (2015) Impact of corticosteroid-binding globulin deficiency on pregnancy and neonatal sex. J Clin Endocrinol Metab 100:1819-1827

Lewis JG, Elder PA (2013) Intact or „active“ corticosteroid-binding globulin $(\mathrm{CBG})$ and total $\mathrm{CBG}$ in plasma: determination by parallel ELISAs using monoclonal antibodies. Clin Chim Acta 416:26-30

Meyer EJ, Nenke MA, Rankin W et al (2016) Corticosteroid-binding globulin: a review of basic and clinical advances. Horm Metab Res 48:359-371

\section{Transkription}

J. Arnemann

Synonym(e) RNA-Synthese
Englischer Begriff transcription

Definition Die Transkription bildet den ersten Schritt der Genexpression und umfasst die Übertragung der in der DNA kodierten genetischen Information mittels des Enzyms RNA-Polymerase in RNA, hauptsächlich mRNA.

Beschreibung Der komplexe Prozess der Transkription lässt sich in mehrere Abschnitte einteilen:

1. Im Promotorbereich des zu transkribierenden Gens bilden im initialen Schritt Transkriptionsfaktoren und eine RNAPolymerase, meist RNA-Polymerase II, einen Komplex und dirigieren die RNA-Polymerase an den korrekten Transkriptionsstartpunkt.

2. Innerhalb dieses Komplexes werden die Wasserstoffbrückenbindungen zwischen den komplementären Nukleotiden beider Stränge gelöst und die DNA-Helix so in ihre Einzelstränge überführt.

3. Die RNA-Polymerase bindet an den Matrizenstrang, dem Antisense-Strand der DNA.

4. Die RNA-Polymerase startet die Kettensynthese der RNA mit einem Nukleosidtriphosphat, an das bei der nachfolgenden Kettenverlängerung Nukleosidmonophosphatreste am freien 3'-OH-Ende eingebaut werden. Die RNA-Synthese läuft solange, bis am $3^{\prime}$-Ende ein entsprechendes Signal, z. B. ein Polyadenylierungssignal, das Ende des Transkriptionsvorgangs signalisiert. Die Triphosphatgruppe am 5'-Ende der RNA wird am Ende des Transkriptionsvorgangs durch Capping vor einem Abbau geschützt.

Die RNA-Sequenz ist dem Sinn-(Sense-)Strang der DNA weitestgehend identisch bis auf die Ausnahme, dass $\mathrm{T}$ (Thymin) durch $\mathrm{U}$ (Uracil) ersetzt wird.

Es werden grundsätzlich 3 verschiedene Arten von RNA kodiert, die jeweils ihre eigenen RNA-Polymerasen (Klasse I-III) einsetzen. So werden die ribosomalen RNAs (28S-rRNA, 18S-rRNA, 5,8S-rRNA) durch die RNAPolymerase I, die proteinkodierenden Gene durch die RNA-Polymerase II und die „kleinen“ RNAs (tRNAs, siRNAs, U6-snRNA etc.) durch die RNA-Polymerase III transkribiert.

\section{Literatur}

Strachan T, Read AP (2005) Molekulare Humangenetik. Elsevier $\mathrm{GmbH}$, München 


\section{Transkriptionsregulator}

Promotor

\section{Translation}

J. Arnemann

Synonym(e) Aminosäure-Übersetzung

Englischer Begriff translation

Definition Die Translation ist neben $>$ Transkription ein weiterer Schritt der Genexpression und beschreibt die Synthese eines Polypeptids anhand einer mRNA.

Beschreibung Gemäß des Dogmas der Molekularbiologie von Francis Crick geht der Informationsfluss von der DNA über die RNA zum Polypeptid, wobei die „Übersetzungen“ mittels Transkription bzw. Translation erreicht werden. Während die Transkription im Zellkern abläuft, erfolgt die Translation im Zytoplasma in den folgenden postulierten Schritten:

1. Die ribosomale Untereinheit 40S erkennt die CAPStruktur des mRNA-Molküls und lagert sich an das Startcodon AUG an.

2. Anschließend bindet das Startcodon das entsprechende Anticodon eines tRNA-Moleküls mit der gekoppelten Aminosäure Methionin sowie die ribosomale 60S-Untereinheit für ein nun funktionsfähiges Ribosom.

3. Das Ribosom bewegt sich ein Triplett weiter (auch als Translokation bezeichnet) und entsprechend der Codonabfolge in der mRNA lagern sich weitere tRNAs mit der entsprechenden Aminosäure an die mRNA. Im Ribosom erfolgt die Verknüpfung der angelagerten Aminosäuren zu einem Peptid. Dieser Prozess, auch als Elongation bezeichnet, wiederholt sich mehrfach, bis das Stoppcodon der mRNA erreicht ist und die Translation abbricht.

4. Die Aminosäuren, die durch eine Peptidyltransferase zu einem Polypeptid verknüpft wurden, werden als Protein freigesetzt und das Ribosom zerfällt wieder in seine beiden Untereinheiten.

Die Transfer-RNAs werden im Zytoplasma durch die Aminoacyl-tRNA-Synthetase zunächst mit der jeweils spezifischen Aminosäure beladen. Die mit Aminosäuren beladenen tRNAs binden als Anticodon die Triplettsequenzen der mRNA und geben die Aminosäure zur Peptidbindung frei. Aufgrund des degenerierten genetischen Codes stehen statt theoretisch 64 nur ca. 30 verschiedene tRNAs zur Verfügung. So muss gemäß der Wobble-Hypothese eine exakte Paarung nur bei den ersten beiden Basen erfolgen, während an der dritten Position eine gewisse Ungenauigkeit erlaubt ist.

\section{Literatur}

Strachan T, Read AP (2005) Molekulare Humangenetik. Elsevier $\mathrm{GmbH}$, München

\section{Translationale Forschung}

> Translationale (Laboratoriums-) Medizin

\section{Translationale (Laboratoriums-) Medizin}

A. M. Gressner und O. A. Gressner

Synonym(e) Translationale Forschung

Englischer Begriff translational (laboratory-) medicine; translational research

Definition Translationale Medizin (TM) überführt neue (Grundlagen-) wissenschaftliche Erkenntnisse in einem geordneten Verfahren (z. B. klinische Studien) zur klinischen Anwendung in Diagnose, Therapie und Prävention spezifischer Erkrankungen. TM entwickelt integrative Konzepte, denen zufolge eine strategisch geplante, rasche und konsequente Umsetzung der Grundlagenforschung in die klinische Realität ermöglicht wird.

Beschreibung Zielsetzung der translationalen (Labor-) Medizin ist es, neue Ergebnisse der biomedizinischen Grundlagen- oder Patienten-orientierten Forschung (z. B. Stammzell- und Genomforschung) sowie technologische Innovationen (z. B. Nanotechnologie, \ Micro-RNA) für eine Verbesserung der medizinischen Patientenversorgung konsequent und zielgerichtet nutzbar zu machen. Dazu gehören auf labordiagnostischem Sektor beispielsweise Früherkennungsparameter von Tumoren, Infektionen, Entzündungen und ihrer Komplikationen, Krankheitsprädiktoren (z. B. neurodegenerativer und kardiovaskulärer Erkrankungen), innovative Prognoseparameter und Methoden des kontinuierlichen In-situ-Monitorings von Laborparametern bei Intensivpatienten. TM betreibt konsequent und rasch die Bench-to-bedside-Forschung und 
-Entwicklung in einem geordneten, strategischen Evaluationsverfahren (z. B. experimentelle und humane diagnostische oder therapeutische Studien) an der Nahtstelle zwischen wissenschaftlicher Entdeckung und ärztlichem Erfordernis. TM ist für forschungsaktive Universitäten, die innovative Industrie und außeruniversitäre Forschungseinrichtungen weltweit zu einem zentralen Kooperationsschwerpunkt geworden.

\section{Literatur}

Hörig H, Marincola E, Marincola MF (2005) Obstacles and opportunities in translational research. Nat Med 11:705-708

Sonntag K-C (2005) Implementations of translational medicine. J Transl Med 3:33-35

\section{Translokation}

> Chromosomentranslokation

\section{Transmission}

> Lambert-Beer-Gesetz

\section{Transmission Control Protocol/ Internet Protocol}

> TCP/IP

\section{Transparenz}

> Lambert-Beer-Gesetz

\section{Transponder}

O. Colhoun

\section{Englischer Begriff transponder}

Definition Miniaturisierte Funkeinheit zur Signalaufnahme und -abgabe.

Beschreibung Der Begriff Transponder ist eine Wortschöpfung aus Transmitter und Responder. Es handelt sich um eine miniaturisierte Funkeinheit, die in der Lage ist, Signale aufzunehmen und zu beantworten. Aktive Transponder verfügen über eine eigene Energieversorgung, was eine hohe Reichweite und größere Datenspeicher ermöglicht (z. B. Identifikation von Flugzeugen). Passive Transponder bestehen nur aus einem Prozessorchip, Antenne und dauerhaften Speicher. Sie beziehen ihre Betriebsenergie aus den Funkwellen, die durch die zugehörigen Lesegeräte (z. B. RFID-Reader) ausgestrahlt werden. Passive Transponder kommen in vielen Bereichen der Medizin zum Einsatz, etwa zur Identifikation von Blutprodukten, Reagenzien ( $\triangleright$ Warenwirtschaftsystem), Laborspezimen oder zum raschen und unkomplizierten Einloggen eines Benutzers im Laborinformationssystem.

\section{Transport, aktiver}

C. Vidal und W.-R. Külpmann

Englischer Begriff active transport

Definition Transport gegen ein Konzentrationsgefälle.

Beschreibung Beim primär aktiven Transport ist die ATPSpaltung direkt mit dem Transportprozess gekoppelt. Beim sekundär aktiven Transport gehört der ATP verbrauchende Schritt des Transports zu einer anderen Reaktion (z. B. Glukosetransport in die Enterozyten des Dünndarms).

\section{Literatur}

Löffler G, Hasilik A (2003) Zelluläre Organellen und Strukturen. In: Löffler G, Petrides P (Hrsg) Biochemie und Pathobiochemie. Springer, Berlin/Heidelberg/New York, S 169-205

\section{Transportsysteme für Aminosäuren}
A. C. Sewell

Synonym(e) Aminosäuren-Transportsysteme

Englischer Begriff aminoacid transport system (activity)

Definition Genetisch bedingte Aminosäuren-Transportsysteme mit unterschiedlicher Funktion.

Beschreibung Aminosäuren-Transportsysteme befördern keine einzelnen Aminosäuren, sondern Aminosäurengrup- 
pen. Solche Systeme wurden in einigen Zelltypen nachgewiesen und molekulargenetisch charakterisiert. Störungen im biochemischen Ablauf dieser Systeme sind die Basis für verschiedene Stoffwechselstörungen wie Cystinurie, Morbus Hartnup, lysinurische Proteinintoleranz. Nachfolgende Tabelle fasst die molekulargenetische Charakterisierung von Transportsystemen für Aminosäuren zusammen.

\begin{tabular}{|c|c|c|}
\hline System & Gen & Aminosäure \\
\hline A & SLC38A2 & Ala, Ser, Pro, Gly, Cys, Gln \\
\hline ASC & SLC1A4 & Ala, Ser, Cys \\
\hline $\mathrm{B}^{0}$ & SLC6A19 & Neutrale Aminosäuren \\
\hline $\mathrm{b}$ & SLC6A6 & Tau \\
\hline Gly & SLC6A18 & Gly \\
\hline IMINO & SLC6A20 & Pro, Hypro \\
\hline $\mathrm{L}$ & SLC3A2/SLC7A5 & His, Met, Leu, Ile, Val, Phe, Tyr, Trp \\
\hline $\mathrm{N}$ & SLC38A3 & Gln, Asn, His \\
\hline PAT & SLC36A1 & Pro, Gly, Ala, GABA, b-Ala \\
\hline $\mathrm{T}$ & SLC16A10 & Phe, Tyr, Trp \\
\hline $\mathrm{X}^{-} \mathrm{AG}^{-}$ & SLC1A2 & Glu, Asp \\
\hline $\mathrm{x}_{\mathrm{c}}^{-}$ & $\begin{array}{l}\text { SLC3A2/ } \\
\text { SLC7A11 }\end{array}$ & Glu, Cys \\
\hline $\mathrm{y}^{+}$ & SLC7A1 & Arg, Lys, Orn, His \\
\hline $\mathrm{y}^{+} \mathrm{L}$ & SLC3A2/SLC7A7 & Lys, Arg, Gln, His, Met, Leu \\
\hline
\end{tabular}

\section{Literatur}

Bröer S (2008) Amino acid transport across mammalian intestinal and renal epithelia. Physiol Rev 88:249-286

\section{Transportzeiten von diagnostischen Proben}

W. G. Guder

Synonym(e) Präanalytische Zeit außerhalb des Labors

\section{Englischer Begriff transport time}

Definition Als Transportzeit (s. a. D Turnaround-Time, TAT) wird die Zeit definiert, die eine diagnostische Probe vom Verlassen des Ortes der Probengewinnung bis zur Registrierung im Labor benötigt.

Beschreibung Im Zusammenhang mit der Erfassung der einzelnen Zeiten des diagnostischen Prozesses wurde die präanalytische Zeit außerhalb des Labors mit 15-20\% als die größte innerhalb des gesamten Prozesses der Diagnostik erkannt. Dieser prozentuelle Anteil setzt optimale Organisation und Labornähe voraus, da sonst wesentlich größere
Transportzeiten zu erwarten sind. Die Transportzeit beeinflusst das zu erwartende $>$ Messergebnis, wenn sie die Zeit der Stabilität des Analyten in der Matrix übersteigt, wenn während des Transports mechanische oder physikalisch-chemische Vorgänge die Zusammensetzung der Matrix verändern (z. B. mechanische Hämolyse durch zu heftige Schüttelvorgänge in Rohrpostanlagen, Einfrieren der Blutprobe mit Erzeugung einer Hämolyse bei Durchmessen kalter Zonen während des Transports, Überhitzung der Probe durch unsachgemäße Aufbewahrung während des Transports) oder metabolische Vorgänge in der Probe den zu messenden Analyten vermehren (z. B. D Laktat, Ammoniak) oder vermindern (z. B. Glukose oder $p \mathrm{CO}_{2}$ ). Daher ist es anzustreben, dass für jeden Analyten die Form der Probe (z. B. Plasma oder Vollblut) und die Temperatur und Zeit während des Transports dem Absender bekannt ist, um entsprechende Maßnahmen zur Vermeidung falscher Ergebnisse zu ergreifen. Es wurden internationale Empfehlungen zur Definition der maximalen Stabilität jedes Analyten veröffentlicht und Maßnahmen zur Dokumentation der präanalytischen Zeiten empfohlen.

\section{Literatur}

Guder WG, Fiedler GM, da Fonsecca-Wollheim F, Schmitt Y, Töpfer G, Wisser H, Zawta B (2015) Quality of diagnostic samples. BD-Diagnostics, Oxford

World Health Organization (WHO) (1977) Guidance on regulation for transport of infectious substances. WHO, Geneva

\section{Transsudat}

\section{A. M. Gressner und O. A. Gressner}

\section{Englischer Begriff transudate}

Definition Extravasales Auftreten eines protein-und zellarmen Ultrafiltrats des Bluts in präformierten Körperhöhlen überwiegend auf der Basis eines nicht -entzündlichen Prozesses

Beschreibung Hämozirkulationsstörungen (Stauungen) können zur Extravasation und Ansammlung (Transsudation) einer relativ proteinarmen (Gesamtprotein $<30 \mathrm{~g} / \mathrm{L})$, serösen, transparenten, gelblichen, zellfreien oder -armen Flüssigkeit (Transsudat) in präformierten Körperhohlräumen führen (z. B. portaler Aszites, Perikard-, Pleuraerguss). Das Transsudat stellt ein Ultrafiltrat des Plasmas dar, das im nicht entzündlichen Gewebe entsteht, wenn im Blutgefäß der onkotische (kolloidosmotische) Druck ( $\triangleright$ Kolloidosmotischer Druck) geringer als der hydrostatische Druck ist und somit 
ein Mißverhältnis der Starling-Kräfte vorliegt, die den transkapillären Flüssigkeitsaustausch regulieren. Im Gegensatz zum entzündlich bedingten $\vee$ Exsudat beträgt die Aktivität der $>$ Laktatdehydrogenase (LDH) im Transsudat weniger als $200 \mathrm{U} / \mathrm{L}$ und die $>$ Albumin-Konzentrationsdifferenz zwischen Serum und Aszites ist $<11 \mathrm{~g} / \mathrm{L}$. Da die Proteinkonzentrationen von Transsudat und Exsudat jedoch fließende Übergänge zeigen, ist die Unterscheidung beider Körperflüssigkeiten nur noch von eingeschränkter diagnostischer Bedeutung.

\section{Literatur}

Greiling H, Gressner AM (Hrsg) (1995) Lehrbuch der Klinischen Chemie und Pathobiochemie, 3., neubearb. Aufl. Schattauer Verlag, Stuttgart, New York

\section{Transthyretin}

> Präalbumin

- Protein-Fehlfaltungs-Erkrankungen (tau, alpha-Synuclein, Polyglutamin, Huntingtin, Transthyretin)

\section{Transversalbeurteilung}

\section{A. M. Gressner und O. A. Gressner}

Synonym(e) Querschnittsbeurteilung

Englischer Begriff cross-sectional; transverse judgement

Definition Sie erfolgt durch Vergleich des ermittelten Analysenergebnisses mit Beurteilungskriterien, die durch Untersuchung einer $\triangleright$ Stichprobe aus einer geeigneten $\triangleright$ Referenzpopulation gewonnen wurden.

Beschreibung Es gibt 2 Arten der medizinischen $>$ Beurteilung von Analysenergebnissen:

- $>$ Longitudinalbeurteilung

- Transversalbeurteilung

Die Transversalbeurteilung wird bei verschiedenen Fragestellungen angewandt:

- Vergleich des Analysenergebnisses mit dem altersund geschlechtsentsprechenden $>$ Referenzintervall ( $\triangleright$ Referenzbereich, biologischer). Sie ist die häufigste und typische Vorgehensweise bei der Erstellung einer medizinischen Diagnose. Beispiel: Beurteilung der Glukosekonzentration im Nüchternserum zur Diagnose eines Diabetes mellitus.

- Vergleich des Analysenergebnisses mit einer $>$ Entscheidungsgrenze, die durch andere Kriterien, z. B. atherosklerotische Risikokonstellationen, definiert ist. Beispiel: Beurteilung der Gesamtcholesterin- und/oder HDL- und/ oder LDL-Cholesterinkonzentration.

- Vergleich des Analysenergebnisses mit therapeutischen Bereichen oder Intoxikationsgrenzen. Beispiel: Beurteilung von Medikamenten- bzw. Ethanolkonzentrationen.

- Vergleich mit Entscheidungsgrenzen, die der Therapieoptimierung dienen. Beispiel: Beurteilung der Glykohämoglobinkonzentration (HbAlc, > Hämoglobin, glykiertes) im Vollblut und der Mikroalbuminausscheidung im Urin ( $\triangleright$ Albumin im Urin) zur Beurteilung der Einstellungsqualität eines Diabetes mellitus.

\section{Literatur}

Stamm D, Büttner J (1995) Beurteilung Klinisch-Chemischer Analysenergebnisse. In: Greiling H, Gressner AM (Hrsg) Lehrbuch der Klinischen Chemie und Pathobiochemie, 3. Aufl. Schattauer Verlag, Stuttgart

\section{Tr-Antikörper}

- Autoantikörper gegen neuronale Antigene

\section{Tr-Autoantikörper}

- Autoantikörper gegen Tr/DNER

\section{TRED}

Trinukleotidrepeat-Amplifikation

\section{Trendkontrolle}

- Delta-Check

\section{Trennflüssigkeit}

- Stationäre Phase 


\section{Trenngel}

W. G. Guder

Synonym(e) Serum-/Plasmatrenngel

Englischer Begriff serum or plasma separator gel

Definition Kunststoffgel, das bei der Zentrifugation von Blut aufgrund seines spezifischen Gewichts zwischen Blutzellen und dem darüber stehenden Plasma/Serum eine für Zellen und wässrige Lösungen dichte Barriere bildet und so erlaubt, - Plasma oder $\triangleright$ Serum im Primärröhrchen zu belassen, ohne dass sich ihre Zusammensetzung wesentlich verändert.

Beschreibung Kunststoffgele wurden neben mechanischen Trennhilfen seit den 1960er-Jahren verwendet, um Serum oder Plasma während der Zentrifugation vom Blutkuchen zu trennen und eine Verwendung des überstehenden Untersuchungsmaterials ohne die Verwendung eines Sekundärröhrchens zu ermöglichen und die Probe nach der Analyse im Primärröhrchen für längere Zeit ohne Änderungen aufbewahren zu können. Diese Kriterien sind für die derzeit im Handel befindlichen Trenngele für die meisten Analyte erfüllt, wenn die Probe nicht ein zweites Mal zentrifugiert wird, nicht eingefroren und nicht über $25^{\circ} \mathrm{C}$ erhitzt wird. Einige Trenngele erwiesen sich als Bindungsort für im Blut enthaltene lipophile Medikamente. Daher muss vor Verwendung von Trenngelen für $\triangleright$ therapeutisches Drug Monitoring die Unschädlichkeit des verwendeten Gels für den zu messenden Stoff nachgewiesen werden. Auch zur Trennung von definierten Zelltypen z. B. für die DNA- oder RNA-Analyse wurden Trenngele entwickelt. Umfangreiche Studien haben die Vorteile der Verwendung von Gelen, aber auch die Grenzen ihrer Anwendung dokumentiert.

\section{Literatur}

Bowen RAR, Adcock-Funk DM (2015) Interferences from blood sampling device materials on clinical assays: I. Blood collection devices and their constituents and additives. In: Guder WG, Narayanan $\mathrm{S}$ (Hrsg) Pre-examination procedures in laboratory diagnostics. Walter de Gruyter, Berlin/Boston, S 170-204

Steimer W (2004) Besondere Bedeutung der Präanalytik und Interpretation bei der Bestimmung von Arzneimittelkonzentrationen. Der Bay Int 24:147-157

\section{Trennhilfen}

W. G. Guder

Synonym(e) Kunststoffgranulat, gerinnungsförderndes; Ventil-Filter
Englischer Begriff separator gel; separator filter; separating plastic granules

Definition Überbegriff für alle Materialien und Methoden, während oder nach der Zentrifugation die Trennung von Plasma/Serum und Blutkuchen zu sichern, zu beschleunigen oder zu unterstützen.

Beschreibung Mit steigender Verwendung von Primärröhrchen für die Analyse von > Serum- und > Plasma-Bestandteilen sowie für die Aufbewahrung des Untersuchungsmaterials wurde es notwendig, die Trennung von Plasma/Serum vom Blutkuchen zu sichern, um spätere Vermischungen von Zellbestandteilen mit der abgetrennten analytischen Probe $\mathrm{zu}$ verhindern. Dies wurde durch die Einführung von Plastikgefäßen mit verminderter Gerinnungszeit noch beschleunigt. Folgendes Verfahren ist derzeit noch in weltweiter Verwendung: Trenngele, die sich im Röhrchenboden befinden und beim Zentrifugieren zwischen Blutkuchen und Plasma/Serum eine bei Raumtemperatur dichte Barriere bilden ( $\triangleright$ Trenngel).

\section{Literatur}

Aktuelle Produktkataloge der Firmen BD., Greiner-Bio-One, und Sarstedt

\section{Trennleistung}

> Trennvermögen

\section{Trennschärfe}

- Auflösung
- Auflösungsvermögen
- Trennvermögen

\section{Trennstrecke}

• Dünnschichtchromatographie

\section{Trennvermögen}

T. Arndt

Synonym(e) Trennleistung; Trennschärfe 
Englischer Begriff separation efficiency

Definition Im klinisch-chemischen Labor zumeist im Zusammenhang mit der Leistungsfähigkeit einer chromatographischen Trennung von Substanzgemischen benutzter Begriff. Beschreibt die Trennleistung einer chromatographischen Säule und entspricht der Zahl ihrer sog. theoretischen Böden (Ebenen der Gleichgewichtseinstellung der Analytkonzentration in stationärer und mobiler Phase).

Beschreibung Zur Berechnung der Zahl der theoretischen Böden (Bodenzahl N) werden verschiedene Formeln verwendet. Bei gegebener Säulenlänge L lässt sich die Höhe eines theoretischen Bodens (Bodenhöhe $\mathrm{H}$ ) über $\mathrm{H}=\mathrm{L} / \mathrm{N}$ ermitteln. Je kleiner $\mathrm{H}$, desto schärfer die Signale ( $\triangleright$ Peak) im - Chromatogramm und desto besser die Signaltrennung, d. h. desto größer die Trennleistung der Säule.

Von großer Bedeutung für das Trennvermögen einer chromatographischen Säule ist die Gleichförmigkeit des die \ stationäre Phase bildenden Packungsmaterials und dessen (konstante) Packungsdichte. Sie beeinflussen die Wanderung der Analyte durch Poren und Kanäle der stationären Phase, die Molekulardiffusion bei kleinen Elutionsgeschwindigkeiten und den Massentransfer bei hohen Durchflussgeschwindigkeiten mit unvollständiger Gleichgewichtseinstellung zwischen mobiler und stationärer Phase und damit auch die Bodenhöhe H. Diese Einflussgrößen werden in der VanDeemter-Gleichung berücksichtigt (s. Lehrbücher der Chromatographie).

Weitere Begriffe, die das Trennvermögen (,separation efficiency") eines chromatographischen Systems beschreiben sind ,peak resolution“ ( $\triangleright$ Auflösungsvermögen), ,separation number" (Trennzahl), Bodenzahl und Bodenhöhe, effektive Bodenzahl und -höhe und die reduzierte Bodenhöhe (s. Ettre 1993).

\section{Literatur}

Ettre LS (1993) Nomenclature for chromatography. Pure Appl Chem $65: 819-872$

\section{Trennzone-Antikörper}

- Autoantikörper gegen Midbody

Treponema pallidum

W. Stöcker

Englischer Begriff Treponema pallidum
Definition Der Name Treponema (griech.: gedrehter Faden) beschreibt die charakteristische Beweglichkeit des dünnen Schraubenbakteriums, das angesichts seiner geringen Färbbarkeit von seinen Entdeckern Fritz Schaudinn und Erich Hoffmann (1905) mit dem Attribut „pallidum“ (lat.: blass) versehen wurde.

Beschreibung des Erregers Zum Genus Treponema gehören gramnegative, spiralig gewundene Bakterien (6-14 Windungen) aus der Familie der Spirochaetaceae. Endoflagellen ermöglichen die besondere Motilität (Rotation um die Längsachse) der Spirochäten.

Erkrankungen Als gesichert humanpathogen gelten T. pallidum subspec. pallidum (Syphilis) sowie die Erreger der nicht venerischen Treponematosen T. pallidum subspec. endemicum (endemische Syphilis, Bejel), T. pallidum subspec. pertenue (Frambösie) und T. carateum (Pinta).

Die Syphilis bzw. Lues (lat. für Seuche) ist eine weltweit verbreitete Allgemeininfektion und wird überwiegend durch sexuellen Kontakt übertragen. Es folgen Inkubation, Primäraffekt, Generalisation und Organmanifestation. Der Kliniker unterteilt die Erkrankung in unterschiedliche Stadien. Den Frühstadien primäre Syphilis (Lues I) und sekundäre Syphilis (Lues II) kann eine längere, bis zu mehreren Jahren schlummernde latente Syphilis (Lues latens) folgen. Die unbehandelte Infektion geht in die Spätstadien tertiäre Syphilis (Lues III) und Neurosyphilis (quartäres Stadium, Lues IV) über. Eine diaplazentare Übertragung der Erreger in der Schwangerschaft führt zur Lues connata mit der Unterteilung in die Phasen präcox (Neugeborene und Säuglinge) und tarda (Kinder $>3$ Jahre).

Therapeutikum der Wahl für alle Krankheitsstadien ist Penicillin. Eine Erregerresistenz ist bisher nicht bekannt, gelegentlich werden Therapieversager beobachtet.

Analytik Direktnachweis und Kultur: Direktnachweis von Treponema pallidum kann aus dem Primäraffekt (sog. harter Schanker: derb, indolent, Befall regionaler Lymphknoten) mit der wenig sensitiven, aber spezifischen Dunkelfeldmikroskopie versucht werden. Ein alternativer, sensitiverer Erregernachweis ist die direkte Immunfluoreszenz unter Verwendung - Fluoreszenz-markierter, monoklonaler Antikörper. Die Diagnostik mittels $>$ PCR (Polymerase-Kettenreaktion) bleibt speziellen Fragestellungen vorbehalten. Der kulturelle Nachweis von Treponema pallidum auf künstlichen Nährmedien war bisher nicht erfolgreich.

Serologie: Nachweis erregerspezifischer Antikörper in Serum oder Liquor durch indirekte Immunfluoreszenz ( $\triangleright$ Immunfluoreszenz, indirekte), \ Enzymimmunoassay, ` Immunblot-Techniken und Hämagglutinationstest.

Untersuchungsmaterial - Probenstabilität Direktnachweis: Reizsekret aus Läsionen (Primäraffekt). Das Material 
sollte möglichst frisch untersucht (Dunkelfeldmikroskopie) oder bis zur Weiterverarbeitung bei +4 bis $+8^{\circ} \mathrm{C}$ aufbewahrt werden, es ist innerhalb von 4 Stunden zu analysieren.

Serologie: Serum, Plasma oder Liquor für den Nachweis der Antikörper sind bei $+4{ }^{\circ} \mathrm{C}$ bis zu 2 Wochen lang beständig, bei $-20{ }^{\circ} \mathrm{C}$ über Monate und Jahre hinweg. Zur Tiefkühlkonservierung des $\operatorname{IgM}$ kann man den Proben $80 \%$ gepuffertes Glyzerin beifügen.

Diagnostische Wertigkeit Der Schwerpunkt der Labordiagnostik liegt im Antikörpernachweis. Man folgt einer Stufendiagnostik mit den Schritten Screening (Suchtest), Bestätigung und - bei positivem Ergebnis - Beurteilung der Aktivität. Als Screeningtests kommen der Treponema-pallidum-spezifische Partikelimmuntest (TPPA) oder der Hämagglutinationstest (TPHA) zum Einsatz. Prinzip: Mit Treponema-Antigenen beladene Latexpartikel oder Erythrozyten agglutinieren bei Zugabe positiver Patientenseren. Sie werden jedoch zunehmend vom $>$ Enzymimmunoassay (u. a. \ Enzyme-linked Immunosorbent Assay, Chemilumineszenz-Immunoassays) abgelöst, die zusätzlich Auskunft über die Immunglobulinklassen der spezifischen Antikörper geben.

Für die Bestätigung reaktiver Ergebnisse im Suchtest stehen Immunblots (s. - Immunblot) zur Verfügung, auf denen die spezifischen Antigene von Treponema pallidum, getrennt voneinander, dargestellt werden. Ebenfalls als Betätigungstest gilt die indirekte Immunfluoreszenz ( $\triangleright$ Immunfluoreszenz, indirekte), bei der das Patientenserum vor dem ersten Inkubationsschritt mit lysiertem Treponema phagedenis-Extrakt versetzt wird, wodurch unspezifische Reaktanden neutralisiert werden (,FTA-Abs“). Vor der Bestimmung der spezifischen IgM-Antikörper muss das möglicherweise vorhandene spezifische IgG eliminiert werden, um durch $>$ Rheumafaktoren bedingten falsch positiven Reaktionen zu entgehen oder durch konkurrierendes IgG falsch negative IgM-Reaktionen zu vermeiden. Die Abtrennung erfolgt durch Ultrazentrifugation (19S-IgMFTA-Abs-Test) oder durch Absorption mittels eines IgG-präzipitierenden „RF-Absorbens“. Alternativ kann man die $\mu$-Capture-Technik einsetzen, bei der das IgM der Probe vor der Reaktion mit dem spezifischen Testantigen selektiv an eine Oberfläche gebunden wird.

Bei einem positiven Bestätigungstest ist die Krankheitsaktivität $\mathrm{zu}$ beurteilen. Labordiagnostisch kann dies über eine quantitative Lipoid-(Cardiolipin-)Antikörper-Flockungsreaktion erfolgen (vormals „Wassermann-Reaktion“, heute u. a. VDRL [,,veneral disease research laboratory"]-Test). Lipoid-Antikörper sind nicht spezifisch für eine Treponema-pallidum-Infektion, dienen aber als Aktivitätsmarker und sind hilfreich für die Verlaufsbeurteilung. Eine Reduktion um den Faktor 10 oder mehr unter Therapie spricht für eine Sanierung der Infektion.

Bei Verdacht auf eine Beteiligung des zentralen Nervensystems werden die spezifischen und die Gesamtantikörper parallel in Liquor und Serum bestimmt und der spezifische Liquor/Serum-
Quotient ( $>$ Liquor/Serum-IgA-Quotient; > Liquor/Serum-IgGQuotient; - Liquor/Serum-IgM-Quotient) errechnet. Ein Wert deutlich $>1$ spricht für eine intrathekale Antikörpersynthese und damit für eine Neurosyphilis.

\section{Literatur}

Hagedorn HJ (2001) Qualitätsstandards in der mikrobiologischinfektiologischen Diagnostik: Syphilis. Urban \& Fischer Verlag, München/Jena

Robert-Koch-Institut Berlin. RKI-Ratgeber für Ärzte, 11. Dezember 2007. Syphilis. https://www.rki.de/DE/Content/Infekt/EpidBull/Merkblaetter/ Ratgeber_Syphilis.html

\section{TRF}

- Thyreotropin-Releasing-Hormon

\section{TrFIA}

- Fluoreszenz, zeitaufgelöste

\section{TR-FIA}

- Time-resolved Fluorescence Immunoassay

\section{TRH}

- Thyreotropin-Releasing-Hormon

\section{TRH-Test}

W. Hubl

Synonym(e) Thyreotropin-Releasing-Hormon-Test; TSH-Stimulation; Tyreoliberin-Test

Englischer Begriff thyreotropin-releasing hormone test

Definition Der TRH-Test überprüft die Reaktion von - Thyreotropin (TSH) auf das im Hypothalamus gebildete - Thyreotropin-Releasing-Hormon (TRH). 


\section{Durchführung}

- Erste Blutentnahme zur basalen TSH-Bestimmung

- Intravenöse Verabreichung von $200 \mu \mathrm{g}$ TRH (für Kinder $7 \mu \mathrm{g} / \mathrm{kg} \mathrm{KG})$

- Oder: nasale Applikation von je einem Sprühstoß zu $1 \mathrm{mg}$ TRH in jedes Nasenloch mit einem speziellen Applikator

- Nach 30 Minuten zweite Blutentnahme zur TSH-Bestimmung

Untersuchungsmaterial - Entnahmebedingungen Serum, Plasma.

Probenstabilität $>$ Thyreotropin.

Präanalytik $>$ Thyreotropin.

- Applikation von Kortikosteroiden ( $\triangleright$ Kortikosteroide), Estrogenen ( $\triangleright$ Estrogene), L-Dopa, Salicylaten ( $\vee$ Salicylate) und Bromocriptin können zu negativen Testergebnissen führen.

- Während einer Thyroxin-Substitutionstherapie ist der TRHTest nicht auswertbar.

Analytik $>$ Thyreotropin.

Referenzbereich - Erwachsene TSH-Anstieg um 2,5-20 $\mathrm{mIE} / \mathrm{L}$. Interpretation des TSH-Anstiegs nach TRH-Gabe:

\begin{tabular}{|c|c|}
\hline $\begin{array}{l}\text { TSH-Anstieg nach TRH-Gabe } \\
(\mathrm{mIU} / \mathrm{L})\end{array}$ & Interpretation \\
\hline Um 2,5-20 & Euthyreose \\
\hline$<2,5$ & $\begin{array}{l}\text { Subklinische Hyperthyreose } \\
\text { bzw. sekundäre, hypophysäre } \\
\text { Hypothyreose }\end{array}$ \\
\hline$>20$ & $\begin{array}{l}\text { Primäre Hypothyreose } \\
\text { Schilddrüsenhormonresistenz } \\
\text { (überhöhte Stimulierbarkeit) }\end{array}$ \\
\hline $\begin{array}{l}\text { Kein TSH-Anstieg }(<2,5) \text { bei } \\
\text { intakter Schilddrüsenfunktion, } \\
\text { bedingt durch andere Erkrankungen } \\
\text { und Störeinflüsse }\end{array}$ & $\begin{array}{l}\text { Akromegalie, Cushing- } \\
\text { Syndrom } \\
\text { Leber- und } \\
\text { Nierenfunktionsstörungen } \\
\text { Medikamenteneinflüsse: } \\
\text { Glukokortikoide }\end{array}$ \\
\hline
\end{tabular}

Referenzbereich - Kinder TSH-Anstieg um 2,5-20 mIE/L.

\section{Indikation}

- Verdacht auf Hypophysenvorderlappeninsuffizienz verbunden mit einer Störung der TSH-Sekretion, häufig gemeinsam mit weiteren Störungen anderer Proteohormone
- Verdacht auf subklinische Hyper- oder Hypothyreose

- Differenzierung zwischen sekundärer und tertiärer Hypothyreose

- Differenzierung zwischen Schilddrüsenhormonresistenz und autonomer TSH-Sekretion (Tumor)

Kontraindikation(en) Myokardinfarkt, instabile Angina pectoris, Epilepsie, zerebrales Krampfleiden, schwere obstruktive Atemwegserkrankungen, Schwangerschaft.

Nebenwirkung(en) Selten auftretend:

- Flush-Symptome

- Krampfanfälle und Bewusstlosigkeit bei Patienten mit großen Hypophysentumoren

- Allergische Reaktionen

Interpretation S. Tabelle unter, Referenzbereich - Erwachsene".

Diagnostische Wertigkeit Mit der Einführung hochsensitiver TSH-Bestimmungen wurde die Anwendung des TRHTestes in den letzten Jahren stark zurückgedrängt. Er hat heute nur noch bei seltenen Problemfällen eine Berechtigung. Hierzu gehören die isolierte TSH-Insuffizienz, Thyrotropinome sowie die Schilddrüsenhormonresistenz.

\section{Literatur}

Hartoft-Nielsen ML, Lange M, Rasmussen AK et al (2004) Thyrotropinreleasing hormone stimulation test in patients with pituitary pathology. Horm Res 61:53-57

Mönig H, Harbeck B, Domm C et al (2014) Dynamische Funktionstests in der Endokrinolgie und Diabetologie. TRH-Test. In: Lehnert H (Hrsg) Rationelle Diagnostik und Therapie in Endokrinologie, Diabetologie und Stoffwechsel. Thieme-Verlag, Stuttgart, S 645-666

Thomas L (Hrsg) (2012) Schilddrüsenfunktion. In Labor und Diagnose. Indikation und Bewertung von Laborbefunden für die medizinische Diagnostik, Frankfurt am Main 8. Aufl. TH-Books, S. 1718-1752, TRH-Test S. 1732

\section{Triacylglyzerin}

- Triglyzeride

\section{Tricarboxyporhyrin}

Porphyrine 


\section{Triglyzeride}

\section{K. J. Lackner und D. Peetz}

$\operatorname{Synonym(e)~Triacylglyzerin~}$

\section{Englischer Begriff triglyceride}

Definition Ester aus Glyzerin und 3 meist mittel- bis langkettigen $>$ Fettsäuren.

Grundstruktur:<smiles>[R]C(=O)OCC(COC([R])=O)OC(=O)O</smiles>

Molmasse Hängt von der Fettsäurezusammensetzung ab; Triolein $885,43 \mathrm{~g}$, Tripalmitin $807,35 \mathrm{~g}$.

Synthese - Verteilung - Abbau - Elimination Die Hauptquelle von Triglyzeriden sind Nahrungsfette. Da sie praktisch wasserunlöslich sind, werden sie im Blut an $>$ Lipoproteine gebunden transportiert. Im Darm resorbierte Triglyzeride werden nach Hydrolyse und erneuter Veresterung des Glyzerins ( $\triangleright$ Glyzerin, freies) mit $\triangleright$ Fettsäuren an $\triangleright$ Chylomikronen gebunden transportiert. Im Plasma werden sie durch die endothelständige $>$ Lipoproteinlipase in Monoglyzeride und freie Fettsäuren gespalten. Diese können entweder als Substrate zur Energiegewinnung genutzt und hier vollständig zu $\mathrm{CO}_{2}$ und Wasser abgebaut werden oder im Fettgewebe wiederum als Triglyzeride gespeichert werden. Neben den Chylomikronen transportieren auch die VLDL $(\triangleright$ Very low density lipoprotein) relevante Mengen Triglyzeride. VLDL werden in der Leber synthetisiert und dienen in erster Linie dem Transport endogener Lipide.

Halbwertszeit Die Halbwertszeit von Triglyzeriden, die an Chylomikronen gebunden sind, ist kurz. Postprandial wird ein Maximum der Triglyzeridkonzentration nach ca. 3-5 Stunden erreicht. Nach ca. 6-8 Stunden sind keine Chylomi- kronen mehr im Plasma nachweisbar. Unter pathologischen Bedingungen kann sich die Clearance von triglyzeridreichen Lipoproteinen stark verlängern. - Insulin beschleunigt den Abbau von Triglyzeriden und hemmt die Freisetzung von freien Fettsäuren aus dem Fettgewebe.

Funktion - Pathophysiologie Triglyzeride sind mit ca. 9 $\mathrm{kcal} / \mathrm{g}$ das energiedichteste physiologisch relevante Substrat. Ihre Fettsäuren dienen den meisten Geweben als Energiequelle. Daneben sind sie der wichtigste längerfristige Energiespeicher. Die Adipositas als Folge einer längerfristig den Bedarf übersteigenden Nahrungsaufnahme ist einer der wichtigsten Risikofaktoren der Insulinresistenz und des metabolischen Syndroms. Hypertriglyzeridämien, also erhöhte Triglyzeridserumkonzentration, entstehen sowohl alimentär als auch genetisch bedingt.

Untersuchungsmaterial - Entnahmebedingungen Triglyzeride werden üblicherweise aus Serum oder Plasma, das nach 12 Stunden Nahrungskarenz abgenommen wurde, bestimmt. Es existieren aber auch Methoden zur Bestimmung aus Vollblut. Triglyzeride sind nach Abtrennung der zellulären Bestandteile aus der Probe ähnlich stabil wie \ Cholesterin.

Analytik Für die Triglyzeridbestimmung existieren derzeit keine allgemein akzeptierten definitiven Methoden oder Referenzmethoden. Protokolle für auf Isotopenverdünnung basierende massenspektrometrische Verfahren wurden publiziert. Eine von den Centers for Disease Control verwendete Referenzmethode hat sich international nicht durchsetzen können. In der klinischen Routine werden Triglyzeride enzymatisch bestimmt. Grundprinzip aller Methoden ist die vollständige Hydrolyse zu Glyzerin und 3 freien Fettsäuren mit nachfolgender enzymatischer Bestimmung des Glyzerins (s. Reaktionsschema in Abb. 1).

Kritische Faktoren sind hier die vollständige Hydrolyse der Triglyzeride auch bei sehr unterschiedlichem Fettsäuregehalt. Es hat sich gezeigt, dass nicht alle verwendeten Lipasen dazu in der Lage sind und meist ein mehr oder weniger geringer Anteil von Mono- und Diglyzeriden zurückbleibt. Ein weiteres Problem stellen im Plasma vorhandenes endogenes freies Glyzerin sowie Mono- und Diglyzeride dar.
Triglyzeride, Abb. 1 Schematische Darstellung des Prinzips der Triglyzeridbestimmung
I

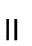

III

(1)

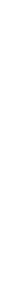

Triglyzerid $\stackrel{\text { Lipase/Esterase }}{\longrightarrow}$ Glyzerin + 3 Fettsäuren

Glyzerin + ATP $\longrightarrow$ Glyzerokinase $\longrightarrow \alpha$-Glyzerophosphat + ADP

Glyzerophosphat-

$$
\text { Glyzerophosphat }+\mathrm{O}_{2} \longrightarrow \text { oxidase } \longrightarrow \text { Dihydroxyacetonphosphat }+\mathrm{H}_{2} \mathrm{O}_{2}
$$

Peroxidase $\longrightarrow$ Chinonimin-Farbstoff 
Dabei sind letztere für klinische Zwecke vernachlässigbar. Freies Glyzerin kann auf 2 Wegen berücksichtigt werden:

- Durch separate Bestimmung der Probe ohne Lipasezusatz kann das freie Glyzerin bestimmt und von dem mit Lipase erhaltenen Resultat abgezogen werden.

- Alternativ kann zunächst in Abwesenheit der Lipase freies Glyzerin umgesetzt und die entstehende Extinktion als Probenleerwert verwendet und anschließend die Extinktionsänderung in Anwesenheit der Lipase bestimmt werden.

Der erste Ansatz hat den Nachteil, dass grundsätzlich 2 Analysen durchgeführt werden müssen. Dafür steht theoretisch ein Messwert für das freie Glyzerin zur Verfügung. Der zweite Ansatz stellt höhere Anforderungen an das Analysensystem, die aber die meisten modernen Analysatoren erfüllen.

Konventionelle Einheit $\mathrm{mg} / \mathrm{dL}$.

Internationale Einheit $\mathrm{mmol} / \mathrm{L}$.

Umrechnungsfaktor zw. konv. u. int. Einheit In Abhängigkeit der angenommenen Fettsäurezusammensetzung ergeben sich Faktoren von 0,01123 (Veresterung mit 3 Molekülen Stearinsäure, C18:0), 0,01129 (3 Molekülen Ölsäure, C18:1) bis 0,0124 (3 Moleküle Palmitinsäure, C16:0). Da die enzymatischen Methoden im Prinzip äquimolar messen, ist die Angabe in SI-Einheiten theoretisch die einzig korrekte. Bereits die Unsicherheit bezüglich der Fettsäurezusammensetzung führt zu Abweichungen bis zu $10 \%$ bei Angabe der Werte in konventionellen Einheiten.

Referenzbereich - Erwachsene $<200 \quad \mathrm{mg} / \mathrm{dL} \quad$ bzw. $<2,3 \mathrm{mmol} / \mathrm{L}$.

\section{Referenzbereich - Kinder S. Erwachsene.}

Indikation Basisuntersuchung des Fettstoffwechsels $(\triangleright$ Cholesterin). Der Triglyzeridwert wird zur Berechnung von LDLCholesterin mit der $>$ Friedewald-Formel neben Gesamt- und $>$ HDL-Cholesterin benötigt.

Interpretation Nüchternwerte $>200 \mathrm{mg} / \mathrm{dL}$ weisen auf eine Fettstoffwechselstörung hin. Bei Nüchternwerten $>400 \mathrm{mg} / \mathrm{dL}$ sollte zumindest einmal eine vollständige Analyse aller Lipoproteine am besten mit Ultrazentrifugation zur Diagnosestellung erfolgen.

\section{Literatur}

Chen Y, Liu Q, Yong S et al (2014) An improved reference measurement procedure for triglycerides and total glycerides in human serum by isotopedilution gas chromatography-mass spectrometry. Clin Chim Acta 428:20-25

\section{Triglyzeridlipase}

K. J. Lackner und D. Peetz

Synonym(e) Lipase

Englischer Begriff triglyceride lipase

Definition Intra- und extrazelluläre Enzyme, die freie Fettsäuren aus Triglyzeriden hydrolytisch abspalten können.

Beschreibung Verschiedene Triglyzeridlipasen sind physiologisch bedeutsam. Dazu gehören die $>$ Lipoproteinlipase, die hepatische Lipase ( $\triangleright$ Lipase, hepatische), die pankreatische Lipase ( $\triangleright$ Lipase, pankreatische) sowie die hormonsensitive Lipase in Adipozyten.

\section{Triglyzerid-Transferprotein, mikrosomales}

K. J. Lackner und D. Peetz

Synonym(e) Mikrosomales Triglyzerid-Transferprotein; MTP

Englischer Begriff microsomal triglyceride transfer protein

Definition Transferprotein, das neutrale Lipide zwischen Membranen und Lipoproteinpartikeln, vor allem neu synthetisierte VLDL ( $\triangleright$ Very low density lipoprotein) (Leber) bzw. > Chylomikronen (Darm), transferiert.

Beschreibung MTP ist ein mikrosomal lokalisiertes heterodimeres Protein, das neutrale Lipide transportiert. Es besteht aus einer großen 97-kDa-Untereinheit, die für die Aktivität entscheidend ist und einer 55-kDa-Einheit, die identisch mit der Proteindisulfidisomerase ist. Die Lipidtransferaktivität ist unverzichtbar für die normale Synthese triglyzeridreicher - Lipoproteine. Genetische Defekte der 97-kDa-Untereinheit führen zur A- $\beta$-Lipoproteinämie, einer autosomal rezessiven Erkrankung, bei der die ApoB-haltigen $>$ Lipoproteine fehlen mit der Folge eines gestörten Transportes von Neutralfetten und fettlöslichen Vitaminen. Der MTP-Inhibitor Lomitapid ist in einigen Ländern zur Therapie der homozygoten familiären Hypercholesterinämie trotz signifikanter Nebenwirkungen (u. a. Transaminasenanstieg) zugelassen. 


\section{Literatur}

Barter PJ, Rye KA (2016) New era of lipid-lowering drugs. Pharmacol Rev 68:458-475

Hussain MM, Shi J, Dreizen P (2003) Microsomal triglyceride transfer protein and its role in apoB-lipoprotein assembly. J Lipid Res $44: 22-32$

\section{1,2,4-Trihydroxybenzol}

$>$ Benzol

\section{Triiodthyronin, freies}

W. Hubl

Synonym(e) FT3; Liothyronin; T3, freies

Englischer Begriff triiodothyronine; liothyronine

Definition Das freie Triiodthyronin wird in der Schilddrüse gebildet und gehört zu den lebenswichtigen Hormonen, da es gemeinsam mit dem freien Thyroxin den Stoffwechsel nahezu sämtlicher Körperorgane reguliert. Auf zellulärer Ebene steigern sie den Sauerstoffverbrauch und die Wärmeproduktion. Sie zeichnen für die geistige und körperliche Entwicklung und das Wachstum des gesamten Organismus verantwortlich.

Struktur 0-(4-Hydroxy-3-Iodophenyl)-3,5-Diiodo-L-tyro$\sin , \mathrm{C}_{15} \mathrm{H}_{12} \mathrm{I}_{3} \mathrm{NO}_{4}$.

Molmasse $651,0 \mathrm{~g}$.

Synthese-Verteilung-Abbau-Elimination Biosynthese: Das mit der Nahrung aufgenommene $\triangleright$ Iod wird im Dünndarm als Iodid resorbiert. Über die Blutbahn gelangt das Iodid in die Schilddrüse. Dieser Iodidtransport in die Schilddrüse kann durch hochdosierte Iodapplikationen gehemmt werden (Wolff-Chaikoff-Effekt). Zum anderen kann dieser Iodidtransport auch kompetitiv im Rahmen der Therapie durch Perchlorat gehemmt werden.

In der Schilddrüse wird das Iodid mithilfe der Schilddrüsenperoxidase (TPO) und $\mathrm{H}_{2} \mathrm{O}_{2}$ oxidiert und in Tyrosylreste des Thyreoglobulins ( $\triangleright$ Thyreoglobulin) eingebaut.

Es entstehen inaktive Hormonvorläufer, das 3-Monoiodtyrosin und das 3,5-Diiodtyrosin. Durch Kopplung dieser beiden Substanzen über eine oxidative Kondensation entste- hen die Schilddrüsenhormone Thyroxin (Tertaiodthyronin, T4) und das Triiodthyronin (T3). Während das T4 komplett in der Schilddrüse synthetisiert wird, kommt das T3 nur zu $20 \%$ aus der Schilddrüse und ca. $80 \%$ werden in extraglanduären Geweben durch enzymatische Abspaltung eines Iodatoms gebildet.

Die Schilddrüse ist in der Lage, Schilddrüsenhormone als Anpassung an eine unregelmäßige Iodaufnahme bis zu 2 Monate zu speichern.

Transport: Die Schilddrüsenhormone werden in das Blut abgegeben und unmittelbar an folgende Transportproteine mit abfallender Affinität gebunden: $>$ Thyroxin-bindendes Globulin (TBG), $>$ Albumin und in geringem Maße das - High Density Lipoprotein. Nur 0,3\% des T3 liegt in freier, ungebundener Form vor. Dieser freie Anteil ist biologisch aktiv und korreliert deshalb deutlich besser mit der aktuellen Stoffwechsellage als die Gesamtkonzentrationen.

Durch die Proteinbindung der Schilddrüsenhormone wird eine rasche Ausscheidung verhindert.

Metabolismus: Im Rahmen des Stoffwechsels in den Zellen wird von $30 \%$ des T4-Anteils ein Iodatom abgespalten (Monodeiodierung), und es entsteht daraus T3. Daneben wird durch eine spezielle Monodeiodierung an der Position 5 des inneren T4-Ringes ein Iodatom abgespalten, wodurch das sogenannte reverse T3 (rT3) entsteht, das biologisch inaktiv ist. Durch weitere Abspaltungen von Iodatomen entstehen schließlich iodfreie Thyroninkerne.

Die einzelnen Monodeiodierungen benötigen verschiedene Deiodinasen. Das Isoenzym I aus der Leber und der Niere bewirkt die Konversion des T4 zum T3. Diese Deiodase wird durch die Schilddrüsenhornmone, durch Selen und TSH stimuliert, und gehemmt durch Fasten, schwere Erkrankungen sowie Zytokine.

Die Typ-II-Deiodase bildet T3 in der Hypophyse, im Zentralnervensystem, der Plazenta und im Fettgewebe, Typ III kommt im ZNS vor.

Ein anderer Stoffwechselweg (20 \% der Schilddrüsenhormone) ist die Konjugation von T4 und T3 mit Glukuronat und Sulfat in der Leber. Diese Konjugate werden über die Galle ausgeschieden oder weiter deiodiert.

Halbwertszeit Das T3 ist im Blut an Transportproteine gebunden. Hierdurch beträgt die Halbwertszeit 19 Stunden. Für das freie T3 liegen keine verlässlichen Angaben vor.

Funktion - Pathophysiologie Die Schilddrüsenhormone besitzen aufgrund ihrer zahlreichen Wirkungen auf zentrale Stoffwechselvorgänge eine herausragende Bedeutung:

- Die Schilddrüsenhormone zeichnen für ein normales Wachstum verantwortlich. Bereits in der Fetalzeit kann eine Unterfunktion der Schilddrüse zu einer verminderten Gehirnreifung führen, die bei unbehandeltem Schilddrü- 
senhormonmangel in der Neugeborenenphase einen irreversiblen Kretinismus entwickeln kann.

- Umgekehrt führt ein Überangebot an Schilddrüsenhormonen in der Neugeborenenphase zu einem verstärktem Wachstum mit einem verspäteten Schluss der Epiphysenfugen.

- Innerhalb des Kohlenhydratstoffwechsels bewirken Schilddrüsenhormone sowohl eine Steigerung der Glukoneogenese als auch einen gesteigerten Kohlenhydratabbau. Zum anderen ziehen Schilddrüsenhormone einen ansteigenden Insulinbedarf nach sich.

- Im Fettstoffwechsel führen erhöhte Schilddrüsenhormone zu einem beschleunigten Abbau von Speicherfetten und einem Cholesterinabfall.

- Erhöhte Schilddrüsenhormonwerte bewirken im Proteinstoffwechsel einen verstärkten Proteinabbau.

- Im Knochenstoffwechsel spielen Schilddrüsenhormone für eine normale Skelettreifung eine primäre Rolle. Eine Unterfunktion der Schilddrüse bewirkt eine verzögerte Skelettreifung.

- Am Herzmuskel bewirken die Schilddrüsenhormone eine Steigerung der Kontraktilität des Myokards, ein erhöhtes Schlagvolumen mit einer erhöhten Schlagfrequenz. Im Rahmen der Schilddrüsenüberfunktion können sich Extrasystolen, Vorhofflimmern und Angina pectoris entwickeln.

- Abnorme Schilddrüsenhormonkonzentrationen können zu Gonadenfunktionsstörungen führen.

- Im zentralen Nervensystem können abnormale Schilddrüsenhormonwerte zu Veränderungen der Sehnenreflexe führen.

- Die Angriffspunkte für die Wirkungen der Schilddrüsenhormone liegen: im Zellkern mit 2 funktionellen T3-Rezeptoren, hTR- $\alpha$ und hTR- $\beta$, an den Mitochondrien und an der Zellmembran.

Untersuchungsmaterial - Entnahmebedingungen Serum, Plasma.

Probenstabilität Blut, Serum, Plasma: $20-25{ }^{\circ} \mathrm{C} 1 \mathrm{Tag}$; Serum, Plasma: $4-8{ }^{\circ} \mathrm{C} 14$ Tage, $-20{ }^{\circ} \mathrm{C} 3$ Monate.

Präanalytik Triiodthyronin, freies ggf. erhöht unter: Schilddrüsenhormonen, Salicylaten, Phenylbutazon, Diclofenac, Furosemid, erhöhten Konzentrationen an Transportproteinen; erniedrigt unter: Thyreostatika, Glukokortikoide, Amiodaron, Propranolol.

Analytik $>$ Immunoassay.

Konventionelle Einheit $\mathrm{ng} / \mathrm{L}$.

Internationale Einheit $\mathrm{pmol} / \mathrm{L}$.
Umrechnungsfaktor zw. konv. u. int. Einheit ng/L $\times 1,536=\mathrm{pmol} / \mathrm{L}$.

Referenzbereich - Erwachsene 2,5-5,2 pmol/L FT3.

Referenzbereich - Kinder Referenzbereich Säuglinge und Kleinkinder:

\begin{tabular}{|l|l|}
\hline $\begin{array}{l}\text { Alter } \\
\text { Neugeboren } \\
\text { (Nabelschnurblut) }\end{array}$ & Triiodthyronin, freies $(\mathrm{FT} 3)(\mathrm{pmol} / \mathrm{L})$ \\
\hline $\begin{array}{l}\text { 1. }+ \text { 2. Tag } \\
\text { 3.-30. Tag }\end{array}$ & $1,6-3,2$ \\
\hline 1.-12. Monat & $5,2-14,3$ \\
\hline
\end{tabular}

\section{Referenzbereich Kinder (KIGGS-Studie):}

\begin{tabular}{|l|l|l|}
\hline & \multicolumn{2}{|l|}{ Triiodthyronin, freies (FT3) } \\
\cline { 2 - 3 } Alter & Jungen & Mädchen \\
\hline 4 Jahre & $4,9-7,5$ & $5,1-7,7$ \\
\hline 5 Jahre & $4,9-7,5$ & $5,1-7,7$ \\
\hline 6 Jahre & $4,9-7,5$ & $5,1-7,7$ \\
\hline 7 Jahre & $4,9-7,7$ & $5,1-7,7$ \\
\hline 8 Jahre & $4,9-7,5$ & $4,9-7,7$ \\
\hline 9 Jahre & $4,9-7,5$ & $4,9-7,7$ \\
\hline 10 Jahre & $4,9-7,5$ & $4,9-7,7$ \\
\hline 11 Jahre & $4,9-7,5$ & $4,9-7,7$ \\
\hline 12 Jahre & $5,0-7,7$ & $4,8-7,5$ \\
\hline 13 Jahre & $5,1-7,8$ & $4,6-7,2$ \\
\hline 14 Jahre & $5,1-7,8$ & $4,3-6,9$ \\
\hline 15 Jahre & $5,1-7,8$ & $4,1-6,6$ \\
\hline 16 Jahre & $4,9-7,5$ & $4,0-6,5$ \\
\hline 17 Jahre & $4,8-7,4$ & $4,0-6,5$ \\
\hline
\end{tabular}

\section{Indikation}

- Nachweis einer manifesten, primären Hyperthyreose

- Nachweis einer isolierten T3-Hyperthyreose

- Verdacht auf Low-T3-Syndrom

- Nachweis einer Hyperthyreose unter Amiodarontherapie

Interpretation Befundinterpretation:

\begin{tabular}{|c|c|c|c|}
\hline $\mathrm{TSH}$ & FT4 & FT3 & \\
\hline $\mathrm{n}$ & & & $\begin{array}{l}\text { Ausschluss einer } \\
\text { Schilddrüsenfunktionsstörung }\end{array}$ \\
\hline- & + & + & Manifeste primäre Hyperthyreose \\
\hline+ & - & $\begin{array}{l}- \\
\mathrm{n},+\end{array}$ & Manifeste primäre Hypothyreose \\
\hline+ & & & $\begin{array}{l}\text { Neugeborenen-Screening auf angeborene } \\
\text { Hypothyreose }(\mathrm{TSH}<50 \mathrm{mIU} / \mathrm{L})\end{array}$ \\
\hline
\end{tabular}

Weitere Befundkonstellationen s. Tab. 1. 
Triiodthyronin, freies, Tab. 1 Weitere Befundkonstellationen

\begin{tabular}{|c|c|c|c|c|}
\hline TSH & FT4 & FT3 & Mögliche Ursache & Aktivitäten \\
\hline+ & $\mathrm{n}$ & $\mathrm{n}$ & $\begin{array}{l}\text { 1. Subklinische Hypothyreose } \\
\text { 2. Thyroxintherapie: Dosis zu niedrig oder mangelnde Compliance } \\
\text { 3. Persistierende TSH-Erhöhung in den ersten } 6-8 \text { Wochen der } \\
\text { Thyroxintherapie bei Hypothyreose } \\
\text { 4. HAMA-Störung }\end{array}$ & $\begin{array}{l}\text { 1. Schilddrüsenantikörper: }+ \text { ? } \\
\text { 2. T4-Dosis erhöhen bzw. Compliance } \\
\text { verbessern } \\
\text { 3. TSH-Wiederholungsmessung nach 2-4 } \\
\text { Wochen } \\
\text { 4. Anderen TSH-Testkit wählen (ohne HAMA- } \\
\text { Störung) }\end{array}$ \\
\hline+ & + & + & TSH-produzierendes Hypophysenadenom & $\begin{array}{l}\text { Hypophysenuntersuchung mit bildgebenden } \\
\text { Verfahren, TRH-Test }\end{array}$ \\
\hline $\mathrm{n}$ & + & + & $\begin{array}{l}\text { 1. Thyroxintherapie } \\
\text { 2. Antikörperinterferenzen: T4- bzw. T3-Antikörper, Rheumafaktor }\end{array}$ & $\begin{array}{l}\text { 1. Therapiekontrolle mit TSH } \\
\text { 2. T4- bzw. T3-AK-Bestimmung }\end{array}$ \\
\hline $\mathrm{n}$ & - & - & $\begin{array}{l}\text { 1. Zentrale Hypothyreose (Hypophyseninsuffizienz) } \\
\text { 2. Verringerte Bioaktivität des TSH } \\
\text { 3. Schwangerschaft: } 2 \text {. und 3. Trimester }\end{array}$ & $\begin{array}{l}\text { 1. Bildgebende Untersuchung } \\
\text { 2. TRH-Test (TSH-Anstieg }<200 \% \text { ) } \\
\text { 3. Verwendung schwangerschaftsspezifischer } \\
\text { Referenzwerte }\end{array}$ \\
\hline- & $\mathrm{n}$ & $\mathrm{n}$ & $\begin{array}{l}\text { 1. Subklinische Hyperthyreose } \\
\text { 2. In den ersten } 2-3 \text { Monaten nach Therapiebeginn der Hyperthyreose } \\
\text { 3. Medikamentenstörung: Glukokortikoide, Dopamin }\end{array}$ & $\begin{array}{l}\text { 1. Bildgebende Verfahren: Autonomie? } \\
\text { 2. Verwendung von FT4 und FT3 zur } \\
\text { Therapiekontrolle } \\
\text { 3. Absetzen der Medikamente, wenn möglich }\end{array}$ \\
\hline- & - & + & Überdosierung mit T3-haltigen Medikamenten (T3-Thyreotoxikose) & Dosisanpassung mit TSH-Kontrolle \\
\hline
\end{tabular}

$\mathrm{n}=$ normal; + erhöht $;$ - erniedrigt

\section{Diagnostische Wertigkeit}

- FT3 besitzt eine hohe klinische Relevanz zum Nachweis einer isolierten T3-Hyperthyreose mit FT4-Werten im Referenzbereich.

- Im Vergleich zur Gesamt-T3-Bestimmung liefern FT3-Befunde bei Patienten mit pathologisch veränderten Konzentrationen der Transportproteine (TBG etc.) deutlich höhere diagnostische Sensitivitäten.

- Durch die frühere Konzentrationsveränderung im Vergleich zum FT4 dient die FT3-Bestimmung zur Frühdiagnostik der Hyperthyreose (gemeinsam mit TSH) einerseits sowie des Low-T3-Syndroms andererseits.

\section{Literatur}

Demers LM, Spencer CA (2002) National Academy of Clinical Biochemistry, Washington (NACB) - Laboratory Medicine Practice Guidelines (LMPG) - Laboratory Support for the Diagnosis and Monitoring of Thyroid Disease. AACC Press, Washington, DC. http://www. nacb.org/

Lehnert H (Hrsg) (2003) Deutsche Gesellschaft für Endokrinologie: Rationelle Diagnostik und Therapie in Endokrinologie, Diabetologie und Stoffwechsel, 2. Aufl. Georg Thieme Verlag, Stuttgart/New York

\section{Triiodthyronin, gesamt}

W. Hubl

\section{$\operatorname{Synonym(e)~T3~}$}

Englischer Begriff triiodothyronine

Definition Triiodthyronin wird in der Schilddrüse gebildet und gehört zu den lebenswichtigen Hormonen, da es gemeinsam mit dem Thyroxin ( $>$ Thyroxin, freies; $>$ Thyroxin, gesamt) den Stoffwechsel nahezu sämtlicher Körperorgane reguliert. Auf zellulärer Ebene steigern sie den Sauerstoffverbrauch und die Wärmeproduktion. Sie zeichnen für die geistige und körperliche Entwicklung und das Wachstum des gesamten Organismus verantwortlich.

Schilddrüsenfunktionsstörungen werden vom freien Triiodthyronin ( $\triangleright$ Triiodthyronin, freies; FT3) mit einer höheren diagnostischen Sensitivität angezeigt, sodass Bestimmungen des Gesamt-T3 zunehmend seltener durchgeführt werden.

Struktur 0-(4-Hydroxy-3-iodophenyl)-3,5-diiodo-L-tyrosin, $\mathrm{C}_{15} \mathrm{H}_{12} \mathrm{I}_{3} \mathrm{NO}_{4}$.

Molmasse $651,0 \mathrm{~g}$.

Synthese - Verteilung - Abbau - Elimination $>$ Triiodthyronin, freies.

Triiodthyronin ist im Blut zu 99,7 \% an Transportproteine gebunden, nur etwa $0,3 \%$ sind frei (FT3). Für den Transport im Blut kommen primär $>$ Thyroxin-bindendes Globulin (TBG), Thyroxin-bindendes Präalbumin (TTR, Transthyretin) und Albumin in Betracht. Der größte Anteil T3 wird aufgrund der höchsten Affinität durch TBG transportiert, obwohl Albumin die größte Transportkapazität besitzt. Das Thyroxin-bindende Präalbumin folgt hinsichtlich der Affini- 
tät auf das TBG, während Albumin die geringste Affinität zu T3 besitzt.

Das Triiodthyronin besitzt jedoch im Vergleich zum Thyroxin eine 10 - bis 20 -fach geringere Affinität zu TBG, woraus eine kürzere Halbwertszeit von 19 Stunden resultiert.

Halbwertszeit 19 Stunden.

Funktion - Pathophysiologie $>$ Triiodthyronin, freies.

Untersuchungsmaterial-Entnahmebedingungen Serum, Plasma.

Probenstabilität Blut, Serum, Plasma: $20-25{ }^{\circ} \mathrm{C} 1 \mathrm{Tag}$; Serum, Plasma: $4-8{ }^{\circ} \mathrm{C} 14$ Tage, $-20{ }^{\circ} \mathrm{C} 3$ Monate.

Präanalytik Triiodthyronin, gesamt ist ggf. erhöht unter: Schilddrüsenhormonen, Salicylaten, Phenylbutazon, Diclofenac, Furosemid, erhöhten Konzentrationen an Transportproteinen (Schwangerschaft, orale Kontrazeptiva); erniedrigt unter: Thyreostatika, Glukokortikoiden, Amiodaron, Propranolol, schweren extrathyreoidalen Erkrankungen, iodhaltigen Röntgenkontrastmitteln, hoch dosierten Iodgaben (Verminderung der Konversion von T4 zu T3), erniedrigten Konzentrationen an Transportproteinen.

Analytik Immunoassay.

\section{Konventionelle Einheit $\mu \mathrm{g} / \mathrm{L}$.}

Internationale Einheit $\mathrm{nmol} / \mathrm{L}$.

Umrechnungsfaktor zw. konv. u. int. Einheit $\mu \mathrm{g} / \mathrm{L} \times 1,54$ $=\mathrm{nmol} / \mathrm{L}$.

\section{Referenzbereich - Erwachsene 1,4-2,8 nmol/L. \\ Referenzbereich - Kinder}

\begin{tabular}{|l|l|}
\hline Alter & Triiodthyronin (T3) (nmol/L) \\
\hline Neugeboren (Nabelschnurblut) & $0,6-2,0$ \\
\hline 1. + 2. Tag & $1,2-4,0$ \\
\hline 3.-30. Tag & $1,1-3,1$ \\
\hline 1.-12. Monat & $1,7-3,5$ \\
\hline 1.-7. Jahr & $1,8-3,1$ \\
\hline 7.-13. Jahr & $1,7-3,1$ \\
\hline 13.-18. Jahr & $1,5-2,8$
\end{tabular}

\section{Indikation}

- Bestätigung einer Hyperthyreose bei erniedrigtem TSH

- Verlaufskontrolle der Schilddrüsenhormon-Substitutionstherapie

- Low-T3-Syndrom
Interpretation Normalbefund:

- Euthyreose, Iodmangelstruma

- Latente Hyperthyreose

- Hypothyreose, verstärkte Umwandlung von T4 in T3

Triodthyronin, gesamt erhöht:

- Hyperthyreose

- Isolierte T3-Hyperthyreose (5-10\%)

- Einnahme von T3-haltigen Medikamenten

Triiodthyronin, gesamt erniedrigt:

- Ausgeprägte Hypothyreose, bei latenter Hypothyreose sogar T3-Erhöhung

- Chronisch Schwerkranke, ältere Menschen

- Low-T3-Syndrom mit verminderter Umwandlung von T4 zu T3 und Anstieg des reverse-T3

Diagnostische Wertigkeit Die T3-Werte sind von der Konzentration der Bindungsproteine abhängig, die Werte des freien T3 nicht. Aus diesem Grund wird die Bestimmung des Gesamt-T3 in zunehmenden Ausmaß durch die Bestimmung des FT3 (freies T3) ersetzt.

\section{Literatur}

Brabant G, Luster M, Schmid KW et al (2015) Diagnostik von Schilddrüsenerkrankungen. In: Lehnert H (Hrsg) Rationelle Diagnostik und Therapie in Endokrinologie, Diabetologie und Stoffwechsel. Thieme-Verlag, Stuttgart, S 98-105

Thomas L (Hrsg) (2012) Schilddrüsenfunktion. In: Labor und Diagnose. Indikation und Bewertung von Laborbefunden für die medizinische Diagnostik, 8. Aufl. TH-Books, S 1718-1752, T3 S 1738-1740

\section{Triiodthyronin, reverses}

W. Hubl
Englischer Begriff reverse T3; reverse triiodothyronine

Definition Reverse Triiodthyronin (rT3) ist im Gegensatz zum Triiodthyronin (T3; $>$ Triiodthyronin, freies) ein biologisch inaktiver Metabolit, der durch Monodeiodierung des Schilddrüsenhormons Thyroxin ( $\vee$ Thyroxin, freies) gebildet wird. Es wird bei einem geringen Bedarf an biologisch aktivem T3 als physiologischer Schutzmechanismus in erhöhtem 
Ausmaß produziert. Bei Schwerkranken wird durch die Absenkung des biologisch aktiven T3 der Energiekonsum der Peripherie gedrosselt.

Die rT3-Bestimmung dient zur Abklärung der Ursache niedriger FT3-Konzentrationen beim Low-T3-Syndrom.

Beschreibung Reverse T3 (rT3) wird vorwiegend extrathyreoidal durch Abspaltung eines Iodatoms aus Thyroxyin (T4) mithilfe der 5-Deiodase gebildet. Das Reverse T3 stellt eine zu Triiodthyronin(3,4,3'-T3) strukturisomere Verbindung (3,3'5'-T3) dar. Es werden ca. $35 \mu \mathrm{g}$ rT3 pro Tag gebildet. Die Halbwertszeit beträgt 4 Stunden. rT3 besitzt keine biologische Aktivität.

Indikationen: Bei schweren extrathyreoidalen Allgemeinerkrankungen, wie z. B. bei der terminalen Niereninsuffizienz, Tumorerkrankungen, Leberzirrhose, hepatozellulärem Karzinom und dem septischen Schock sinkt die biologisch aktive T3-Konzentration als physiologischer Schutzmechanismus ab, wobei die Umwandlung des Thyroxins vorwiegend zum inaktiven rT3 umgelenkt wird. Dieses Low-T3-Syndrom mit erhöhten rT3-Werten wird neben schweren Erkrankungen auch beim Fasten mit Kohlenhydratentzug, bei Operationen sowie im Zusammenhang mit Medikamenteneinnahmen (Kortikosteroiden, Amiodaron, $\beta$-Rezeptorenblocker) beobachtet.

Während des akuten Myokardinfarktes kommt es zur Down-Regulation der Schilddrüsenhormone mit einem Abfall des T3 um ca. $20 \%$, des TSH um ca. $50 \%$ und einem kompensatorischen Anstieg des biologisch inaktiven rT3 um ca. $22 \%$. Des Weiteren waren stark erhöhte rT3-Werte über $410 \mathrm{pmol} / \mathrm{L}$ mit einem Anstieg des Mortalitätsrisikos innerhalb eines Jahres nach dem Herzinfarkt assoziiert und könnten zur Risikoeinschätzung verwendet werden. Diese Ergebnisse bedürfen noch der Bestätigung mit größeren Patientenkollektiven.

In der Routinediagnostik besitzt die rT3-Bestimmung eine geringe diagnostische Relevanz. Es wird in der biomedizinischen Forschung bei speziellen Fragestellungen eingesetzt, z. B. als Messgröße für den Metabolismus der Schilddrüsenhormone.

Analytik: $\vee$ Radioimmunoassay.

Referenzbereich im Serum: 139-300 pmol/L.

\section{Literatur}

Mebis L, Van den Berghe G (2011) Thyroid axis function and dysfunction in critical illness. Best Pract Res Clin Endocrinol Metab 25:745-757

Sorvillo F, Mazziotti G, Carbone A et al (2003) Increased serum reverse triiodothyronine levels at diagnosis of hepatocellular carcinoma in patients with compensated HCV-related liver cirrhosis. Clin Endocrinol 58:207-212

Thomas L (Hrsg) (2012) Schilddrüsenfunktion. In Labor und Diagnose. Indikation und Bewertung von Laborbefunden für die medizinische Diagnostik, 8. Aufl. TH-Books, Frankfurt am Main, 1718-1752, rT3 S 1740

\section{3,4,5-Trimethoxyphenethylamin}

$>$ Mescalin

\section{Trimethylamin}

G. F. Hoffmann, C.-D. Langhans und A. Schulze

Synonym(e) N,N-Dimethylmethanamin; TMA

Englischer Begriff trimethylamine

Definition Trimethylamin ist bei Raumtemperatur ein farbloses, unangenehm stechend riechendes Gas, das in wässriger Lösung basisch reagiert. Trimethylamin ist schleimhautreizend und schwach giftig. Im Urin liegt es als Trimethylammoniumsalz vor.

Struktur $\mathrm{C}_{3} \mathrm{H}_{9} \mathrm{~N}$; Strukturformel:<smiles>CN(C)C</smiles>

Molmasse 59,11 g.

Synthese - Verteilung - Abbau - Elimination Trimethylamin wird durch Enterobakterien im Verdauungstrakt gebildet. Ausgangsprodukte für die bakterielle Zersetzung sind dabei Nahrungsmittelkomponenten wie Trimethylamin-N-Oxid (aus dem Muskelfleisch von Meerwasserfischen) sowie Cholin, Carnitin und andere Betaine, die besonders in Eiern, Innereien und Hülsenfrüchten vorkommen.

Trimethylamin wird in der Leber durch Enzyme aus der Familie der Flavin-abhängigen Monooxygenasen in das geruchlose $>$ Trimethylamin-N-Oxid (TMAO) umgewandelt und in dieser Form effizient über den Urin ausgeschieden.

Funktion - Pathophysiologie Trimethylamin hat im menschlichen Organismus keine bekannte Funktion.

Eine Störung der N-Oxidation, verursacht durch einen Defekt der Flavin-Monooxygenase 3 (FMO3), führt dazu, dass Trimethylamin nicht mehr effizient in TMAO überführt werden kann. Das sich anstauende Trimethylamin wird in großen Mengen über Urin, Schweiß und Atem ausgeschieden. Die Trimethylaminurie, auch "fish odour syndrome“ genannt, ist eine autosomal rezessiv vererbte Stoffwechselstörung. 
Untersuchungsmaterial - Entnahmebedingungen 5-10$\mathrm{mL}$ Urin mit 4N HCl angesäuert. Eine längere Lagerung sollte bei $-20{ }^{\circ} \mathrm{C}$ erfolgen.

Präanalytik Um eine reduzierte N-Oxidationskapazität $\mathrm{zu}$ erkennen, empfiehlt sich die Bestimmung vor und nach einer Belastung mit Cholin oder vor und nach einer Seefischmahlzeit.

Analytik Für die Bestimmung von Trimethylamin wird die Dampfraumanalyse (,headspace“) eingesetzt. Dabei wird gasförmiges Trimethylamin durch Alkalisieren aus dem im Urin vorliegenden Trimethylammoniumsalz freigesetzt und direkt oder nach Adsorption/Desorption an einer SolidPhase-Microextraction-(SPME-)Faser gaschromatographisch getrennt.

Die Detektion erfolgt mittels Flammenionisationsdetektor (FID). Eine massenspektrometrische Stabilisotopen-Verdünnungsanalyse ist ebenfalls möglich.

Direkte Messmethoden für Trimethylamin sind die > NMR-Spektrometrie oder die Elektrospray-Tandemmassenspektrometrie (ESI-MSMS; > Massenspektrometrie) nach Derivatisierung mit Ethylbromoacetat.

Referenzbereich Bei gesunden Probanden liegt der Trimethylamingehalt im Urin $<1 \mathrm{mmol} / \mathrm{mol} \mathrm{Kreatinin.} \mathrm{Der} \mathrm{Gehalt}$ unterliegt ernährungsbedingten Schwankungen.

Im pathologischen Fall ist der Gehalt im Urin deutlich erhöht.

Valide Normwerte und Cut-off-Werte sind nicht veröffentlicht.

Indikation Unangenehm fischartiger Körpergeruch aufgrund vermehrter Trimethylaminausscheidung über Urin, Schweiß und Atem.

Interpretation Eine erhöhte Trimethylaminkonzentration bei gleichzeitig erniedrigter N-Oxidationsaktivität ist hinweisend auf das Vorliegen einer Trimethylaminurie.

Die primäre Trimethylaminurie kann auf einen durch Mutationen im FMO3-Gen verursachten Defekt der FlavinMonooxygenase 3 (FMO3) zurückgeführt werden.

Polymorphe Variationen im FMO3-Gen sind dagegen eher die Ursache einer intermittierenden (sekundären) Trimethylaminurie, bei der ein nahrungsbedingtes Überangebot an Trimethylamin nicht effizient abgebaut werden kann. Bakterielle Überwucherung des Darms oder andere Darmerkrankungen sind häufig die Ursache für eine übermäßig hohe Trimethylaminbildung aus Nahrungskomponenten.

Diagnostische Wertigkeit Die alleinige Bestimmung der Trimethylaminkonzentration im Urin ist ohne diagnostische Relevanz.
Eine pathologisch erniedrigte Aktivität der FlavinMonooxygenase kann nur durch die gleichzeitige Betrachtung von freiem und oxidiertem Trimethylamin ( $>$ TrimethylaminN-Oxid) in Form der TMA/TMAO-Ratio erkannt werden.

Die Ergebnisse einer biochemischen Urinanalytik muss durch eine molekulargenetische Untersuchung bestätigt werden.

\section{Literatur}

Blau N, Duran M, Gibson KM, Dionisi-Vici C (Hrsg) (2014) Physician's guide to the diagnosis, treatment, and follow-up of inherited metabolic diseases. Springer, Berlin/Heidelberg

Chalmers RA, Bain MD, Michelakakis H et al (2006) Diagnosis and management of trimethylaminuria (FMO3 deficiency) in children. J Inherit Metab Dis 29:162-172

\section{Trimethylamin-N-Oxid}

G. F. Hoffmann, C.-D. Langhans und A. Schulze

Synonym(e) N,N-Dimethylmethanamin-N-Oxid; TMAO

Englischer Begriff trimethylamine-N-oxide

Definition Oxidationsprodukt von Trimethylamin (TMA).

Struktur $\mathrm{C}_{3} \mathrm{H}_{9} \mathrm{NO}$; Strukturformel:<smiles>C[N+](C)(C)[O-]</smiles>

Molmasse $75,11 \mathrm{~g}$.

Synthese - Verteilung - Abbau - Elimination Trimethylamin-N-Oxid wird in der Leber durch Enzyme aus der Familie der Flavin-abhängigen Monoxygenasen aus - Trimethylamin gebildet. Es wird effizient über den Urin ausgeschieden.

Funktion - Pathophysiologie Trimethylamin-N-Oxid kommt in hohen Konzentrationen im Fleisch von Meeresfischen vor und dient bei diesen Tieren zur Regulation des osmotischen Druckes.

Geruchlose wasserlösliche Ausscheidungsform von Trimethylamin.

Eine gestörte Bildung von Trimethylamin-N-Oxid aus Trimethylamin ist die Ursache für das Auftreten der Trimethyl- 
aminurie, auch „fish odour syndrome“ genannt, einer autosomal rezessiv vererbten Stoffwechselstörung.

Untersuchungsmaterial - Entnahmebedingungen 5-10$\mathrm{mL}$ Urin mit $4 \mathrm{~N} \mathrm{HCl}$ angesäuert. Eine längere Lagerung sollte bei $-20{ }^{\circ} \mathrm{C}$ erfolgen

Präanalytik Um eine reduzierte N-Oxidationskapazität zu erkennen, empfiehlt sich die Bestimmung vor und nach einer Belastung mit Cholin oder vor und nach einer Seefischmahlzeit.

Analytik Eine direkte Bestimmung von Trimethylamin-NOxid ist mit der $>$ NMR-Spektrometrie und der ElektrosprayTandemmassenspektrometrie ( $\triangleright$ Massenspektrometrie) möglich.

Bei der Bestimmung mittels Headspace-Analytik in Kombination mit der Gaschromatographie kann TrimethylaminN-Oxid nicht direkt, sondern nur über eine Differenzbestimmung nach Reduktion zu Trimethylamin gemessen werden.

Referenzbereich Normwerte TMAO: $50-1000 \mathrm{mmol} / \mathrm{mol}$ Kreatinin.

Die Gehalte an TMAO im Urin können ernährungsbedingt stark schwanken.

Indikation Unangenehm fischartiger Körpergeruch aufgrund vermehrter Trimethylaminausscheidung über Urin, Schweiß und Atem.

Interpretation Eine verminderte oder fehlende Fähigkeit zur Bildung von Trimethylamin-N-Oxid aus Trimethylamin ist die biochemische Ursache für das Auftreten einer Trimethylaminurie, bei der das sich anreichernde Trimethylamin vermehrt ausgeschieden wird.

Diagnostische Wertigkeit Die alleinige Bestimmung der Trimethylaminkonzentration im Urin ist ohne diagnostische Relevanz.

Eine pathologisch erniedrigte Aktivität der Flavin-Monooxygenase kann nur durch die gleichzeitige Betrachtung von freiem und oxidiertem $>$ Trimethylamin (Trimethylamin-NOxid) in Form der TMA/TMAO-Ratio erkannt werden.

Die Ergebnisse einer biochemischen Urinanalytik muss durch eine molekulargenetische Untersuchung bestätigt werden.

\section{Literatur}

Blau N, Duran M, Gibson KM, Dionisi-Vici C (Hrsg) (2014) Physician's guide to the diagnosis, treatment, and follow-up of inherited metabolic diseases. Springer, Berlin/Heidelberg

Chalmers RA, Bain MD, Michelakakis H et al (2006) Diagnosis and management of trimethylaminuria (FMO3 deficiency) in children. J Inherit Metab Dis 29:162-172

\section{Trinder-Reaktion}

T. Arndt

Synonym(e) Salicylate, Schnellnachweis mit TrinderReagenz

Englischer Begriff Trinder reaction; Trinder reagent; Trinder method

Definition Bezeichnung für den von P. Trinder im Jahr 1954 beschriebenen schnellen Nachweis von Salicylaten in biologischen Flüssigkeiten mithilfe von $\mathrm{Fe}^{3+}$-Ionen sowie Oberbegriff für quantitative Analysen von Substraten und Stoffwechselendprodukten auf der Basis einer Peroxidase-katalysierten oxidativen Kopplung von Phenol und 4-Aminophenazon (Trinder-Methode).

\section{Beschreibung}

Nachweis der Salicylate:

$40 \mathrm{~g} \mathrm{HgCl}_{2}$ und $40 \mathrm{~g} \mathrm{Fe}\left(\mathrm{NO}_{3}\right)_{3} \times 9 \mathrm{H}_{2} \mathrm{O}$ werden in $1000 \mathrm{~mL}$ Wasser (mit $10 \mathrm{~mL}$ konzentrierter HCL) gelöst (Trinder-Reagenz). Zum Salicylatnachweis werden $2 \mathrm{~mL}$ Trinder-Reagenz und 0,2 mL Probe gemischt und zentrifugiert. In Gegenwart von Salicylsäure färbt sich der Überstand violett. Obwohl eine Vielzahl von Verbindungen mit $\mathrm{Fe}^{3+}$ Ionen farbige Reaktionsprodukte bildet, ist der Salicylatnachweis ( $\triangleright$ Salicylate) im Plasma für eine erste Übersichtsanalyse recht spezifisch. Bei Einsatz von Urin ist die Spezifität herabgesetzt, u. a. in Gegenwart von Phenothiazinen (die im Urin höhere und damit für die Interferenz relevante Konzentrationen im Vergleich zu Plasma erreichen).

Substratbestimmung mit der Trinder-Methode:

In einem ersten Reaktionsschritt wird durch enzymatische Umsetzung des Analyten (z. B. Oxidation von \ Glukose mit Glukoseoxidase) u. a. Wasserstoffperoxid gebildet, der unter der Wirkung von Peroxidase mit Phenol und 4-Aminophenazon zu einem Farbkomplex und Wasser weiterreagiert. Die Farbintensität des Reaktionsansatzes wird spektrometrisch gemessen und über geeignete Kalibrationsfunktionen der Analytkonzentration zugeordnet. Es sind Modifikationen u. a. für die Bestimmung von $>$ Harnsäure und $>$ Kreatinin bekannt. Ein weiteres Beispiel für die Anwendung der Trinder-Reaktion ist die enzymatische Bestimmung von Cholesterin (s. Reaktion III in der Abbildung bei $\triangleright$ Cholesterin).

\section{Literatur}

Sonnenwirth AC, Jarett L (Hrsg) (1980) Gradwohl's clinical laboratory methods and diagnosis. CV Mosby, St. Louis

Trinder P (1954) Rapid determination of salicylate in biological fluids. Biochem J 57:301-303 


\section{Trinukleotidrepeat-Amplifikation}

J. Arnemann

Synonym(e) TRED; Trinukleotidrepeat-Erkrankungen

Englischer Begriff triplet repeat expansion diseases; TRED

Definition Trinukleotidrepeat-Erkrankungen sind gekennzeichnet durch den pathogenen Effekt einer illegitimen Vermehrung, d. h. Amplifikation, einer vorgegebenen Abfolge von sich wiederholenden, definierten 3 Basenpaaren (sog. Trinukleotidrepeats) in der kodierenden oder regulatorischen Region eines Gens.

Beschreibung Es sind im Wesentlichen 6 verschiedene, zueinander reziproke Tripletts, die krankheitsverursachend sind, nämlich d(CAG.CTG), d(CGG.CCG) oder d(GAA. TTC). Die molekulare Basis einer illegitimen Amplifikation ist noch nicht vollständig aufgeklärt, aber es wird postuliert, dass die Trinukleotidrepeats flexible Haarnadel-(,,hairpin“-) Strukturen ausbilden können, die mittels DNA-Replikation und einem Zusammenspiel verschiedener Enzyme, wie z. B. DNA-Helikase, instabile Vorstufen ausbilden können, die in der Meiose und über verschiedene Generationen zu einer pathogenen Vermehrung dieser Repeats führen.

Besonders gut untersucht ist dies am Beispiel des fraX-bzw. FMR1-Syndroms. Hier findet sich das CGG-Trinukleotidrepeat in der 5'-UTR-Region des FMR1-Gens, das bei Normalpersonen $<45$ Repeats beträgt (durchschnittlich 29-30 Repeats). Zwischen 45-54 Repeats liegt ein Intermediär- oder Graubereich vor. Der Bereich von 55-200 Repeats wird als Prämutationsbereich definiert, zumal ab dieser Größenordnung eine Keimbahninstabilität in der DNA-Sequenz einsetzt, die den Übergang zu einer Vollmutation begünstigt. Eine pathogene Vollmutation und damit das Vollbild der Erkrankung liegt bei mehr als 200 Repeats (z. T. bis über 1000 Repeats) vor. Die Amplifikation der CGG-Repeats, zusätzlich verbunden mit einer Hypermethylierung, führt zu einer Dysregulation und einem Funktionsausfall des FMR1-Gens.

Träger einer Amplifikation im Graubereich sind gänzlich unauffällig, wie auch die Mehrzahl der Träger einer Prämutation. Frauen mit einer Prämutation haben jedoch häufiger eine vorzeitige Menopause (vorzeitige Ovarialinsuffizienz, POF), während die Männer im fortgeschrittenen Alter häufiger eine progressive neurodegenerative Erkrankung (FXTAS) mit Intensionstremor, Parkinson-ähnlichen Symptomen, autonomer Dysfunktion und z. T. vorzeitiger Demenz entwickeln. Die schrittweise Zunahme der Trinukleotidrepeats über mehrere Generationen wird als Antizipation bezeichnet.
Bei den Trinukleotidrepeat-Amplifikationen im kodierenden Bereich des Gens steht vor allem die Ausbildung von Polyglutamin-, aber auch von Polyalaninsträngen im Vordergrund. Bekannte Beispiele für Polyglutaminerkrankungen mit einer Zunahme der für Glutamin kodierenden CAGTripletts sind u. a. Chorea Huntington, spinobulbäre Muskelathrophie Typ Kennedy (SBMA) oder verschiedene Formen von spinozerebellären Ataxien (SCAs). Die Zunahme von 6-34 Glutaminmolekülen im Normalfall hin zu 36-121 im pathogenen Zustand bei Chorea Huntington führt zu einer Störung der Sekundär- und Tertiärstruktur des Proteins und einem Funktionsausfall. Auch bei diesen Erkrankungen gilt, dass es erst bei Überschreitung einer definierten, kritischen Anzahl an Trinukleotidrepeats zu einer Erkrankung kommt.

Für den praktischen Nachweis der TrinukleotidrepeatErkrankungen stehen verschiedene Methoden zur Verfügung, wie z. B. die klassische $>$ Southern-Blot-Analyse oder aktuell die $\triangleright$ Fragmentlängenanalyse eines PCR-Produktes (s. \& PCR (Polymerase-Kettenreaktion)) mittels $\triangleright$ Kapillarelektrophorese und Genescan-Auswertung.

\section{Literatur}

Mitas M (1997) Trinucleotide repeats associated with human disease. Nucleic Acids Res 25:2245-2253

\section{Trinukleotidrepeat-Erkrankungen}

> Trinukleotidrepeat-Amplifikation

\section{Tripelphosphat-Kristalle}

W. G. Guder

Synonym(e) Magnesium-Ammonium-Phosphat-Hexahydrat; Sargdeckelkristalle

Englischer Begriff triple phosphate cristals; coffin-lid crystals; struvit

Definition Magnesium-Ammonium-Phosphat-Hexahydrat $\left(\mathrm{MgNH}_{4} \mathrm{PO}_{4} \times 6 \mathrm{H}_{2} \mathrm{O}\right)$.

Beschreibung Im alkalischen Urin ( $\mathrm{pH} 7,2-8,8)$, der meist durch bakteriellen (ureasehaltige gramnegative Bakterien) Abbau von Harnstoff zu Ammonium entsteht, fallen Phosphate zu einem trüben Niederschlag beim Abkühlen aus, die 
im Mikroskop als trapezoide Kristalle sichtbar sind. Diese „sargdeckelförmigen“ Kristalle wurden bereits im Jahr 1798 von Pearson als ein Mischsalz von Magnesium, Ammonium und Phosphat identifiziert und erhielten den Namen Tripelphosphat, kristallographisch Struvit nach dem Mineralogen HCG Struve. Obwohl diese Form bei ca. 6 \% Gegenstand der Harnsteinbildung ist, hat der Nachweis von Tripelphosphaten im Harnsediment nahezu keine diagnostische Bedeutung. Dies ist durch die Tatsache bedingt, dass spontan gewonnener Urin häufig und rasch durch Kontamination mit ureasehaltigen Bakterien zersetzt. Lediglich die Kombination des trüben Urins mit alkalischem $\mathrm{pH}$ beim Wasserlassen lässt sich als Voraussetzung zur Phosphatsteinbildung in vivo deuten.

\section{Literatur}

Guder WG (Übersetzer) (2003) Atlas des Harnsediments. CD-Rom. Chronolab, Zug

Hesse A, Jahnen A, Klocke K et al (1994) Nachsorge bei HarnsteinPatienten. Gustav Fischer Verlag, Jena/Stuttgart

\section{Triple-Quadrupole- Massenspektrometrie}

$>$ LC-MS

\section{Triple-Test}

M. Bidlingmaier

Englischer Begriff triple test; in Großbritannien auch: Bart's test

Definition Test aus dem Bereich der $>$ Pränataldiagnostik, der eine Wahrscheinlichkeit für das Vorliegen einer Trisomie 21 (Down-Syndrom) oder einer Neuralrohrfehlbildung beim Feten errechnet.

Beschreibung Für den Triple-Test werden typischerweise zwischen der 15. und 18., seltener bis zur 20. Schwangerschaftswoche im maternalen Serum die Konzentrationen von $>\alpha 1$-Fetoprotein (AFP), freiem $>$ Estriol (unkonjugiertes Estriol) und der freien $\beta$-Kette des Choriongonadotropins ( $\beta$-hCG; > Choriongonadotropin, humanes) bestimmt. Die mittels eines Algorithmus aus den Messergebnissen errechnete Wahrscheinlichkeit ist das eigentliche Testergebnis. Damit kann keine Diagnose einer Trisomie oder einer Neuralrohrfehlbildung gestellt werden - diese erfordert weitere, nichtinvasive (z. B. Ultraschall) oder invasive Diagnostik ( $\triangleright$ Chorionzotten-Biopsie, $\triangleright$ Amniocentese; $\triangleright$ Chordozentese).

Nachdem es sich nicht um einen diagnostischen Test handelt, übernehmen die Krankenversicherungen die Kosten nicht. Aufgrund der potenziell weitreichenden Konsequenzen besteht für den Arzt vor, während und nach der Untersuchung Beratungspflicht.

Der Triple-Test ist im Vergleich zur reinen Altersindikation besser geeignet, Schwangerschaften zu erkennen, bei denen weitere Diagnostik sinnvoll sein kann. Er steht jedoch aufgrund einer geringen Sensitivität und vor allem schlechter Spezifität in der Kritik. Eine Vielzahl von Einflussfaktoren müssen berücksichtigt werden, so u. a. Alter und Körpergewicht der Mutter, vorangegangene Schwangerschaften und das - oft nicht präzise erfasste - Gestationsalter. Auch können die Konzentrationen der genannten Hormone aus einer Reihe anderer Gründe verändert sein, sodass sich insgesamt eine Vielzahl falsch positiver Befunde ergibt. Der Test wird heute nur noch selten angewandt, teilweise wird er ersetzt durch den Double- oder den Quadruple-Test mit Hinzunahme anderer Laborparameter (z. B. \ Inhibin A, \& Pregnancy-AssociatedPlasma-Protein A [PAPP-A]). Insbesondere aber die Verfügbarkeit verbesserter bildgebender Verfahren (Ultraschall) sowie gendiagnostischer Methoden (freie fetale DNA) verändern die Strategien in der pränatalen Diagnostik derzeit stark.

\section{Literatur}

Wald NJ, Cuckle HS, Densem JW, Nanchahal K, Royston P, Chard $T$ et al (1988) Maternal serum screening for Down's syndrome in early pregnancy. BMJ 297:883-887

Yao Y, Liao Y, Han M, Li SL, Luo J, Zhang B (2016) Two kinds of common prenatal screening tests for Down's syndrome: a systematic review and meta-analysis. Sci Rep 6:18866. https://doi.org/10.1038/ srep 18866

\section{Triplett-Zustand}

Lumineszenz

\section{Trisomie-21-Risikoanalyse}

$>$ Triple-Test

\section{tRNA-Synthetase-Antikörper}

- Autoantikörper gegen Aminoacyl-t-RNS-Synthetase 


\section{Trockenblut}

T. Arndt

Synonym(e) Blutkärtchen; DBS

Englischer Begriff dried blood spot

Definition Auf Filterpapier getrocknete Blutprobe.

Beschreibung Es handelt sich um ein derzeit vor allem im Neugeborenenscreening ( $\triangleright$ Neugeborenenscreening auf Stoffwechselerkrankungen und Endokrinopathien) eingesetztes Probenmaterial, das durch Punktion der Ferse des Neugeborenen oder der Fingerbeere des erwachsenen Patienten und Aufbringen einiger Bluttropfen auf eine geeignete Filterpapierkarte gewonnen wird.

Im Vergleich zur „normalen“ Blutprobe hat Trockenblut folgende Vorteile:

- Geringeres Probenvolumen von 200-300 $\mu \mathrm{L}$ im Vergleich zu 2,5-10 mL bei Venenpunktion

- Höhere Stabilität der meisten Analyte durch Entzug des Lösungsmittels (Wasser)

- Einfacher Versand im normalen Briefumschlag ohne Kühlung, Umverpackung und Auslauf- und Infektionsrisiko z. B. bei Beschädigung oder unbeabsichtigtem Öffnen der Sendung

- Einfache Lagerung mit erheblich reduziertem Raumbedarf und ohne Kühlung

Um ein möglichst reproduzierbares Blutvolumen zu analysieren wird mithilfe einer Stanze eine definierte Fläche des mit der Blutprobe beladenen Filterpapiers ausgestanzt. Anschließend werden die Analyte in ein geeignetes Lösungsmittel (z. B. physiologische NaCl-Lösung) extrahiert. Alternativ können die Analyte durch geeignete Desorptionsverfahren (z. B. Laser) aus dem Trockenblut direkt in das Analysengerät überführt werden.

Trockenblutproben werden derzeit vor allem für qualitative Analysen oder Multianalytanalysen, in denen die relativen Anteile einzelner Analyte zueinander beobachtet werden, eingesetzt. Damit schließt man z. T. noch nicht hinreichend gelöste Probleme der Standardisierung quantitativer Analysen aus.

Als Nachteile der (quantitativen) DBS-Technik gelten:

- Ungenügende Reproduzierbarkeit wegen differierendem Blutvolumen, evtl. nicht homogener Blutverteilung im Filterpapier, unbekanntem Einfluss des Hämatokrits auf die Rheologie des Blutes im Filterpapier sowie auf das für die Analyse wichtige resultierende Plasmavolumen

- Ungenügende Kontrolle der Extraktionseffizienz wegen fehlenden internen Standards im Trockenblut

- Unzureichende Infrastruktur in den Krankenhäusern und Praxen, die auf Blutröhrchen abgestellt ist

- Unzureichende Infrastruktur in den Laboratorien, die, zumindest im Bereich der Hochdurchsatzanalytik, für Analysenautomaten und Blutröhrchen entwickelt ist

- Unzureichendes Angebot an Qualitätskontroll- und Ringversuchsmaterial auf der Basis von Trockenblutproben

Hieraus wird deutlich, dass wesentliche Nachteile der DBS-Analytik eher im Umfeld als in der Technologie selbst liegen. Damit ergeben sich Chancen für einen breiteren Einsatz von Trockenblutproben, nämlich in jenen Bereichen und Speziallaboratorien, die aufgrund ihrer Technologie nicht auf Blutröhrchen abgestellt und gleichzeitig in der Lage sind, die mit der DBS-Analytik einhergehenden spezifischen Anforderungen an die Methodenvalidierung zu bewältigen. Mögliche Einsatzgebiete sind z. B. Massenspektrometrie, Stoffwechselscreening, therapeutisches Drug Monitoring, Toxikologie.

\section{Literatur}

Chace DH, de Jesús VR, Spitzer AR (2014) Clinical Chemistry and dried blood spots: increasing laboratory utilization by improved understanding of quantitative challenges. Bioanalysis 6(21):2791-2794

Lehmann S, Delaby C, Vialaret J, Ducos J, Hirtz C (2013) Current and future use of ,dried blood spot“ analyses in clinical chemistry. Clin Chem Lab Med 51:1897-1909

\section{Trockenchemie}

T. Arndt

Synonym(e) Trägergebundene Reagenzien

Englischer Begriff dry chemistry

Definition Umgangssprachlicher Begriff für die Analytik mit trägergebundenen Reagenzien

Beschreibung Es handelt sich um Analyseverfahren für eine qualitative oder quantitative Analyse mit (zumeist) geringem apparativen Aufwand und unter Verwendung von in getrockneter Form auf sog. Slides (kleinen Testfeldern) oder $>$ Teststreifen fixierten Reagenzien.

Die Bezeichnung Trockenchemie ist nicht korrekt. Tatsächlich laufen, ebenso wie bei der konventionellen 
(nasschemischen) Analytik, die chemischen Reaktionen in wässriger Phase ab. Im Unterschied zur Nasschemie liefert bei der Trockenchemie jedoch ausschließlich die zu untersuchende Probe (Blut bzw. Plasma oder Serum, Urin etc.) das Lösungsmittel (Wasser) für die chemischen Reaktionen. Exakter ist die Verwendung des Begriffs Analytik mit trägergebundenen Reagenzien ( $\triangleright$ Analyse mit trägergebundenen Reagenzien). Ein wichtiges Einsatzgebiet sind Point-of-CareTests (POCT; $>$ Patientennahe Sofortdiagnostik).

\section{Literatur}

Greiling H, Gressner AM (Hrsg) (1995) Lehrbuch der Klinischen Chemie und Pathobiochemie. Schattauer Verlag, Stuttgart/New York

\section{Trockenrückstand}

- Abdampfrückstand

\section{Trolox-Äquivalent}

$>$ Antioxidative Kapazität

\section{Trommer-Probe}

$>$ Trommer-Test

\section{Trommer-Test}

W. G. Guder

Synonym(e) Trommer-Probe; Zuckertest nach Trommer

\section{Englischer Begriff trommer reaction}

Definition Reduktionsprobe für den (nicht spezifischen) Nachweis von Glukose mit Kupfersulfat in alkalischer Lösung.

Beschreibung Im Jahr 1841 beschrieb Carl August Trommer (1806-1879) die Farbreaktion von Glukose bei Zusatz von Kupfersulfatlösung zu alkalisiertem Urin. Die dadurch entstehende Orange- bis Rotfärbung beim Erhitzen deutete auf das Vorhandensein von Kohlenhydraten mit einer freien Acetylhydroxylgruppe hin ( $\triangleright$ Fruktose, $\triangleright$ Glukose, $\triangleright$ Galaktose, $>$ Pentosen, Ascorbinsäure u. a.). Der Test wurde abgelöst durch andere Farbtests ( $\triangleright$ Fehling-Probe, einer Modifikation mit Tartrat, Nylander-Test) und ist seit Einführung der enzymatischen Teststreifenmethode nicht mehr im Gebrauch.

\section{Literatur}

Büttner J (1991) Urina ut signum: Zur historischen Entwicklung der Urin-Untersuchung. In: Guder WG, Lang H (Hrsg) Pathobiochemie und Funktionsdiagnostik der Niere. Springer, Berlin/Heidelberg/ New York, S 1-20

Leybold K, Grabener E (1976) Praxis-Laboratorium, 7. Aufl. Georg Thieme Verlag, Stuttgart

\section{Tropan}

$>$ Alkaloide

\section{Tropenmedizin-Institut}

A. M. Gressner und O. A. Gressner

Synonym(e) Bernhard-Nocht-Institut für Tropenmedizin Hamburg; BNITM

Definition Das Bernhard-Nocht-Institut für Tropenmedizin widmet sich der Erforschung von Tropenkrankheiten, der Betreuung betroffener Patienten, der Fortbildung von Ärzten auf dem Gebiete der Tropenmedizin sowie der Reiseberatung und tropenmedizinischen Information von Laien.

Beschreibung Das im Jahr 1900 von dem Marine- und späteren Hafenarzt Bernhard Nocht (Nocht, Bernhard) (1857-1945) gegründete und 30 Jahre geleitete Hamburger Tropeninstitut widmet sich unverändert der Lehre, dem Studium und der Behandlung tropischer Krankheiten. Als größte, zur Leibniz-Gemeinschaft gehörende tropenmedizinische Forschungseinrichtung in Deutschland dient es als Nationales Referenzzentrum für tropische Infektionserreger und nimmt Aufgaben wahr in der

- Behandlung und Diagnostik von Tropenkrankheiten,

- tropenmedizinischen Ausbildung von medizinischen Fachkräften.

- anwendungsorientierten Grundlagenforschung sowie

- tropenmedizinischen Beratung und Information von Ärzten und Laien. 
Träger des Bernhard-Nocht-Institutes sind das Bundesministerium für Gesundheit (BMG) und die Behörde für Wissenschaft und Gesundheit (BWG) der Freien und Hansestadt Hamburg.

\section{Adresse}

Bernhard-Nocht-Institut für Tropenmedizin

Bernhard-Nocht-Str. 74

D-20359 Hamburg

Tel.: 04042818.

Fax.: 040 42818-400

E-Mail: bni@bnitm.de; labordiagnostik@bnitm.de Internet: www.bni.uni-hamburg.de

\section{Trophozoiten}

H. Baum

Englischer Begriff trophozoite

Definition Ungeschlechtliche, einkernige Wachstumsform der Protozoen.

Beschreibung Die ungeschlechtliche, einkernige Wachstumsform der Protozoen (Urtierchen) wird als Trophozoit bezeichnet. Die Diagnostik der Malaria beruht in der Regel auf dem Nachweis der Trophozoiten in den Erythrozyten.

Die Abbildung zeigt 3 Trophozoiten bei Malaria tropica in einem Erythrozyten $(1000 \times$, May-Giemsa-Grünwald-Färbung):

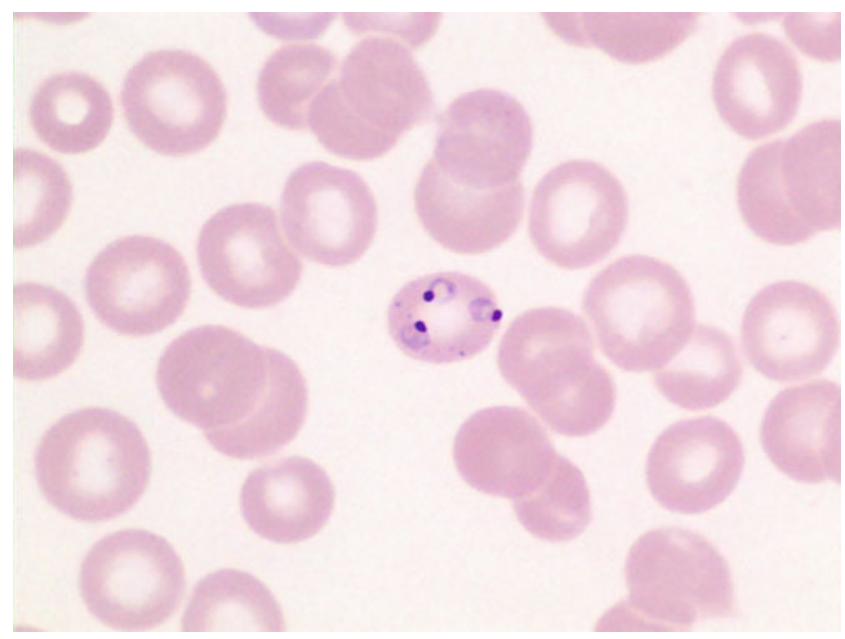

\section{Literatur}

Seitz HM, Maier W (1994) Parasitologie - Plasmodien, Erreger der Malaria. In: Brandis H, Köhler W, Eggers HJ et al (Hrsg) Lehrbuch der Medizinischen Mikrobiologie. Gustav Fischer Verlag, Stuttgart, S 658-665

\section{Troponin}

K. J. Lackner und D. Peetz

Englischer Begriff troponin

Definition Troponine sind regulatorische Proteine des kontraktilen Apparates der quer gestreiften Muskulatur.

Struktur Der über Tropomyosin an Aktin gebundene Troponinkomplex setzt sich aus den 3 Troponinen Troponin C (TnC), Troponin I (TnI) und Troponin T (TnT) zusammen. Troponin $\mathrm{T}$ vermittelt dabei die Bindung des Komplexes an Tropomyosin, indem die C-terminale Kopfregion an TnC und die N-terminale Schaftregion an Tropomyosin bindet. Troponin I ist reversibel in eine Ausstülpung des Troponin $\mathrm{C}$ gebunden. Troponin I und T kommen jeweils im menschlichen Körper postnatal in 3 Isoformen vor. Diese befinden sich in der Herzmuskulatur, in den schnellen und den langsamen Muskelfasern. Von TnC existiert nur eine Isoform, die in allen Muskelzellen exprimiert wird. Die kardialen Isoformen von Troponin I und T (cTnI und cTnT; $>$ Troponin I, kardiales, $>$ Troponin T, kardiales) weisen an ihrem N-terminalen Ende spezifische zusätzliche Aminosäureresiduen auf. Das cTnI-Molekül setzt sich aus 209 Aminosäuren (30 mehr als die Skelettmuskelisoformen) zusammen. Die Funktion des Troponin I wird durch Phosphorylierung an verschiedenen Stellen des Moleküls moduliert. Von besonderer Bedeutung sind 2 Serinresiduen an den Positionen 22 und 23, die durch Proteinkinase A phosphorylisiert werden können, da hierdurch 4 verschiedene phosphorylierte cTnI-Formen entstehen, die relevante Auswirkung auf die Antikörperspezifität haben können. Zusätzlich kann an den Cysteinresten an Position 80 und 97 eine Oxidation des Proteins stattfinden, die die Interaktion mit den anderen Troponinen beeinflusst. Kardiales Troponin T weist dagegen an seinem N-terminalen Ende nur wenige zusätzliche Aminosäuren auf. Zusätzlich werden im Föten 3 weitere Isoformen gefunden, die auch im Skelettmuskelgewebe gebildet werden.

Molmasse TnC: 18 kDa; cTnI: 22 kDa; cTnT: 37 kDa.

Synthese - Verteilung - Abbau - Elimination Jede Troponin-Isoform wird von einem individuellen Gen kodiert. Die Gene der kardialen Isoformen befinden sich auf den langen Armen von Chromosom 19 (19q32, TnI) und Chromosom 1 (1q13.3, TnT). Der Großteil der synthetisierten Troponine ist an die Myofibrillen gebunden. In der Herzmuskelzelle kommen 3-4\% des cTnI und 6-8 \% des cTnT als freier zytoplasmatischer Pool vor. Im Plasma kommt cTnI vor allem als cTnI-TnC-Komplex vor. Daneben werden auch 
cTnI-cTnT-TnC-Komplexe und in sehr geringer Menge freies cTnI gefunden. cTnT kommt im Plasma hauptsächlich in freier Form vor, in geringen Mengen auch in den cTnI-cTnTTnC- und cTnT-TnC-Komplexen sowie als freie cTnTFragmente. Insbesondere TnI wird im Blut proteolytisch abgebaut.

Halbwertszeit cTnT: ca. 2 Stunden; cTnI: ca. 24 Stunden.

Pathophysiologie Kardiale Troponine sind im Blut Gesunder praktisch nicht nachweisbar. Nach kardialer Schädigung kommt es innerhalb von wenigen Stunden zu einer Troponinfreisetzung. In Abhängigkeit von der unteren Nachweisgrenze der verwendeten Testsysteme (s. Analytik) zeigen 50 bis $>95 \%$ der Myokardinfarktpatienten nach 1-3 Stunden nachweisbare Troponinkonzentrationen im Blut, 6-10 Stunden nach Symptombeginn weisen alle Patienten erhöhte Troponinkonzentrationen auf (100\% Sensitivität). Troponin T zeigt dabei eine zweiphasige Freisetzung, die nach 12 Stunden ihr erstes Maximum erreicht, dem eine etwa 48-stündige Plateauphase und ein Abfall der Konzentration unterhalb das Detektionslimit innerhalb von etwa 10 Tagen folgt. In Abhängigkeit von der Infarktgröße sind erhöhte cTnT-Werte zwischen 7 Tagen (kleiner Infarkt) und 21 Tagen (großer, transmuraler Infarkt) nachweisbar. Die Freisetzungskinetik von Troponin I ist monophasisch, die wie cTnT nach 10-12 Stunden ihr Maximum erreicht, jedoch etwas schneller, innerhalb von 5-10 Tagen, wieder in den Referenzbereich zurückkehrt.

Untersuchungsmaterial Serum, Plasma, Vollblut.

Analytik Für die Bestimmung von Troponin I existieren mehr als 20 kommerzielle, voll automatisierte Immunoassays (s. Immunoassay) und Point-of-Care-Testsysteme. Diese unterscheiden sich unter anderem hinsichtlich unterer Nachweisgrenze, verwendeten Antikörperpaaren, Probenmaterial, Kalibration und Stabilität, äquimolarem Nachweis verschiedener oxidierter und phopshorylierter cTnI-Komplexe. Die Testantikörper sollten gegen den stabilen zentralen Teil des Moleküls zwischen den Aminosäureresiduen 30 und 110 gerichtet sein, der nur gering proteolytisch degradiert wird. Insbesondere Teste der ersten Generation wiesen Messwertunterschiede bis zu einem Faktor von 20 auf. Die aktuell verfügbaren modernen cTnI-Teste messen mittlerweile ähnlichere Ergebnisse. Als erster Schritt zur Standardisierung steht ein primäres Referenzmaterial (SRM\#2921) des National Institute of Standards and Technology (NIST) zur Verfügung.

Für die cTnT-Bestimmung hält Roche Diagnostics den Patentschutz, sodass ein voll automatisierter ECLIA-Test ( $\triangleright$ Elektrochemilumineszenz-Immunoassay) und ein POCTSystem ( $\triangleright$ Patientennahe Sofortdiagnostik) des Herstellers sowie in Lizenz hergestellte Teste anderer Hersteller auf dem Markt sind.
Nach Empfehlungen der IFCC wird die Messqualität von Testsystemen nach 2 Kriterien bewertet. Bei einem Variationskoeffizienten von $<10 \%$ am 99. Perzentil (s. Referenzbereich) wird ein Test als leitliniengerecht, bei 10 bis $\leq 20 \%$ als klinisch geeignet und bei $>20 \%$ als ungeeignet eingestuft. Die Sensitivität eines Testsystems wird anhand des Anteils messbarer Werte im gesunden Kollektiv $(<99$. Perzentil) bewertet. Tests mit $<50 \%$ messbarer Werte werden als zeitgemäß, mit 50 bis $<75 \%$ als hochsensitiv der ersten Generation, mit 75 bis $<95 \%$ als hochsensitiv der zweiten Generation und mit $>95 \%$ messbarer Werte als hochsensitiv der dritten Generation klassifiziert.

Referenzbereich Nach der Konsensusempfehlung der amerikanischen und europäischen Gesellschaft für Kardiologie sowie der aktuellen WHO-Definition des akuten Myokardinfarktes wird als Entscheidungskriterium das 99. Perzentile der oberen Referenzbereichsgrenze eines gesunden Kontrollkollektivs definiert (,cut-off"). Voraussetzung ist, dass bei diesem Messwert ein Variationskoeffizient (VK) von $<10 \%$ erreicht wird. Sowohl für Troponin I als auch für Troponin $\mathrm{T}$ sind mittlerweile sog. „hoch sensitive“ und leitliniengerechte Tests verfügbar (s. Analytik), die dieses Kriterium erfüllen. Der Cut-off-Wert für cTnI ist herstellerabhängig, für den cTnT-Test (vierte Generation) liegt er bei $0,03 \mu \mathrm{g} / \mathrm{L}$, für den hoch sensitiven TnT-Test bei $14 \mathrm{ng} / \mathrm{L}$ (99. Perzentil, VK $<10 \%$ ) (Übersicht unter www.ifcc.org, ,search“: „Troponin Assay Analytical Characteristics").

Bewertung Troponine sind die wichtigsten Laborparameter für die Diagnose einer kardialen Schädigung. Ihr Einsatzgebiet umfasst $u$. a. die Diagnose und Verlaufsbeobachtung des akuten Koronarsyndroms, die Prognoseeinschätzung und Therapiesteuerung (s. a. $>$ Troponin I, kardiales und $>$ Troponin $\mathrm{T}$, kardiales).

\section{Literatur}

Apple FS, Jesse RL, Newby LK, Wu AH, Christenson RH, Cannon CP, Francis G, Morrow DA, Ravkilde J, Storrow AB, Tang W, IFCC Comittee on Standardization of Markers of Cardiac Damage, Jaffe AS, Mair J, Ordonez-Llanos J, Pagani F, Panteghini M, Tate J, National Academy of Clinical Biochemistry (2007) National Academy of Clinical Biochemistry and IFCC Committee for Standardization of Markers of Cardiac Damage Laboratory Medicine Practice Guidelines: analytical issues for biochemical markers of acute coronary syndromes. Clin Chem 53:547-551

Roffi M, Patrono C, Collet JP et al (2016) 2015 ESC Guidelines for the management of acute coronary syndromes in patients presenting without persistent ST-segment elevation: task force for the Management of Acute Coronary Syndromes in Patients Presenting without Persistent ST-Segment Elevation of the European Society of Cardiology (ESC). Eur Heart J 37:267-315

Thygesen K, Alpert JS, Jaffe AS et al (2012) Third universal definition of myocardial infarction. Circulation 126:2020 


\section{Troponin I, kardiales}

K. J. Lackner und D. Peetz

Englischer Begriff cardiac troponin I

Definition Kardiales Troponin I (cTnI) ist die herzspezifische Isoform eines zum Troponin-Komplex gehörenden regulatorischen Proteins.

Struktur $>$ Troponin.

Molmasse $22 \mathrm{kDa}$.

Synthese-Verteilung-Abbau-Elimination $>$ Troponin

Halbwertszeit 25 Stunden (bei Creatinin-Clearance $>60 \mathrm{~mL} / \mathrm{min}$ ), 38 Stunden (bei Creatinin-Clearance $\leq 60 \mathrm{~mL} / \mathrm{min})$.

Funktion - Pathophysiologie $>$ Troponin.

Untersuchungsmaterial - Entnahmebedingungen Serum, Plasma, Vollblut.

Probenstabilität Abhängig von Probenmaterial und Testsystem (insbesondere der verwendeten Antikörperpaare, > Troponin).

Analytik Für die Bestimmung von Troponin I existieren mehr als 20 kommerzielle, voll automatisierte Immunoassays und Point-of-Care-Testsysteme ( $\triangleright$ Troponin).

Konventionelle Einheit $\mu \mathrm{g} / \mathrm{L}$ bzw. ng/L (vor allem für neue hoch sensitive Tests verwendet).

Referenzbereich - Erwachsene $<99 \%$-Perzentil eines gesunden Kontrollkollektivs und Variationskoeffizient $<10 \%$ (herstellerabhängig).

\section{Indikation}

- Nachweis myokardialer Nekrose jeglicher Genese

- Diagnose, Verlaufskontrolle und Prognose des akuten Koronarsyndroms/Myokardinfarkts

- Erfolgskontrolle einer thrombolytischen Therapie bei akutem Myokardinfarkt

- Diagnose perioperativer Infarkte bei herzchirurgischen Eingriffen

- Prognose bei chronischer Niereninsuffizienz

- Abstoßungsreaktion nach Herztransplantation
- Risikostratifizierung bei Lungenembolie

- Nachweis myokardialer Schäden bei Patienten mit Myopathien

Interpretation Für die Diagnose eines akuten Myokardinfarkts mit ST-Hebung im EKG (STEMI) haben kardiale Biomarker, bevorzugt Troponine, nur eine sekundäre Bedeutung und finden in diagnostisch nicht eindeutigen Fällen Anwendung. Für die Diagnose eines akuten Myokardinfarkts ohne ST-Hebung (NSTEMI) ist die Messung von Troponinen dagegen für die Diagnosestellung unerlässlich. Nach den Konsensusempfehlungen der amerikanischen und europäischen Gesellschaft für Kardiologie sollen hoch sensitive Troponin-Tests ( $\triangleright$ Troponin) angewendet werden. Nach einem akuten Myokardinfarkt kommt es innerhalb von 3-4 Stunden nach Schmerzbeginn zu einem Anstieg von Troponin im Blut. Wird bei Aufnahme und mehr als 6 Stunden bestehender Schmerzsymptomatik ein negatives Resultat $(<99$. Perzentil eines gesunden Kontrollkollektivs) mit einem hochsensitiven Test gemessen, kann ein Infarkt mit hoher Wahrscheinlichkeit ausgeschlossen werden. Bei $<6$ Stunden bestehender Symptomatik oder einem positivem Messwert bei Aufnahme soll eine Folgemessung nach 3 Stunden durchgeführt werden. Ist diese weiterhin negativ bzw. ohne signifikante Dynamik, ist ein akuter Infarkt ebenfalls unwahrscheinlich. Bei Patienten mit initial sehr hohen Troponin-Messwerten kann bei passender klinischer Präsentation auf eine Folgemessung verzichtet und direkt therapeutische Maßnahmen eingeleitet werden. Einige hochsensitive Tests sind für einen sog. ,RapidRule-Out"-Algorithmus evaluiert, bei dem durch spezifische Cut-off-Werte eine Diagnose innerhalb 1 Stunde durch Messung bei Aufnahme und nach 1 Stunde gestellt werden kann. Aufgrund der Sensitivität der hoch sensitiven Tests werden auch bei vielen Patienten mit stabiler Angina pectoris und bei anderen Erkrankungen Troponin-Werte über dem Cut-off-Wert gefunden. Bei diesen Patienten ist die Dynamik der Messergebnisse (Anstieg/Abfall) daher von besonderer diagnostischer Bedeutung.

Beim Nicht-ST-Hebungsinfarkt weisen erhöhte TroponinWerte auf eine schlechtere Kurz- und Langzeitprognose hin (Reinfarkt oder Tod innerhalb der nächsten 30 Tage bzw. 6-12 Monate) als bei Troponin-negativen Patienten.

Der Nachweis eines Reinfarktes nach perkutaner Koronarintervention wird bei negativem Ausgangswert (kleiner Cut-off-Wert) durch einen Troponin-Anstieg auf $>5$-fach des Cut-off-Werts innerhalb von 48 Stunden gestellt, bei positivem Ausgangswert bei Anstieg $>20 \%$. Nach Bypasschirurgie wird die Diagnose eines perioperativen Infarkts (PMI) gestellt, wenn bei negativem Ausgangswert ein Troponin-Anstieg $>10$-fach des Cut-off-Wertes innerhalb 48 Stunden beobachtet wird.

Bei Patienten mit chronischer Niereninsuffizienz sind erhöhte Troponin-Werte mit einer schlechteren Prognose 
(Myokardinfarkt und Tod) innerhalb der folgenden 6-24 Monate verbunden.

Bei Patienten mit Myopathien ohne nachweisbare myokardiale Schädigung werden aus bisher nicht bekannter Ursache regelmäßig erhöhte Troponin-T-, jedoch normwertige Troponin-I-Konzentrationen im Blut gefunden.

Diagnostische Wertigkeit $>$ Troponin.

\section{Literatur}

Apple FS, Jesse RL, Newby LK, Wu AH, Christenson RH, Cannon CP, Francis G, Morrow DA, Ravkilde J, Storrow AB, Tang W, IFCC Comittee on Standardization of Markers of Cardiac Damage, Jaffe AS, Mair J, Ordonez-Llanos J, Pagani F, Panteghini M, Tate J, National Academy of Clinical Biochemistry (2007) National Academy of Clinical Biochemistry and IFCC Committee for Standardization of Markers of Cardiac Damage Laboratory Medicine Practice Guidelines: analytical issues for biochemical markers of acute coronary syndromes. Clin Chem 53:547-551

Roffi M, Patrono C, Collet JP et al (2016) 2015 ESC guidelines for the management of acute coronary syndromes in patients presenting without persistent ST-segment elevation: task force for the management of acute coronary syndromes in patients presenting without persistent ST-segment elevation of the European Society of Cardiology (ESC). Eur Heart J 37:267-315

Thygesen K, Alpert JS, Jaffe AS et al (2012) Third universal definition of myocardial infarction. Circulation 126:2020

\section{Troponin T, kardiales}

\section{K. J. Lackner und D. Peetz}

\section{Englischer Begriff cardiac troponin T}

Definition Kardiales Troponin T (cTnT) ist die herzspezifische Isoform eines zum Troponin-Komplex gehörenden regulatorischen Proteins.

Struktur $>$ Troponin.

Molmasse $37 \mathrm{kDa}$.

Synthese-Verteilung-Abbau-Elimination $\downarrow$ Troponin.

Halbwertszeit 120 Minuten.

Funktion - Pathophysiologie $>$ Troponin.

Untersuchungsmaterial- Entnahmebedingungen Serum, Plasma, Vollblut.

Probenstabilität Vollblut: $20-25{ }^{\circ} \mathrm{C} 8$ Stunden; Serum, Plasma: $20-25{ }^{\circ} \mathrm{C} 1 \mathrm{Tag}, 2-8{ }^{\circ} \mathrm{C} 1 \mathrm{Tag},-20^{\circ} \mathrm{C} 12$ Monate.
Analytik Die Bestimmung von cTnT kann aus Serum oder Plasma voll automatisiert als $>$ ElektrochemilumineszenzImmunoassay (ECLIA) oder aus Vollblut als Point-of-CareTest (POCT, \& Patientennahe Sofortdiagnostik) durchgeführt werden. Eine hoch sensitive Testversion (s. $>$ Troponin) ist verfügbar (hsTnT).

Der hoch sensitive (hs) Test ECLIA hat eine Messzeit von 9 oder 18 Minuten, der POCT von 14 Minuten. Der Messbereich des hoch sensitiven TnT-Tests beträgt 3-25.000 ng/L, der des POCT 4-2000 ng/L.

\section{Konventionelle Einheit ng/L.}

Referenzbereich - Erwachsene hsTnT: 14 ng/L $(<99$. Perzentil eines gesunden Kontrollkollektivs und Variationskoeffizient $<10 \%$ ).

cTnT (4. Generation): $0,01 \mu \mathrm{g} / \mathrm{L}$.

POCT: $<50 \mathrm{ng} / \mathrm{L}$.

\section{Indikation}

- Nachweis myokardialer Nekrose jeglicher Genese

- Diagnose, Verlaufskontrolle und Prognose des akuten Koronarsyndroms/Myokardinfarkts

- Erfolgskontrolle einer thrombolytischen Therapie bei akutem Myokardinfarkt

- Diagnose perioperativer Infarkte bei herzchirurgischen Eingriffen

- Risikostratifizierung bei Lungenembolie

- Prognose bei chronischer Niereninsuffizienz

Interpretation $>$ Troponin I, kardiales.

Diagnostische Wertigkeit $>$ Troponin.

\section{Literatur}

Apple FS, Jesse RL, Newby LK, Wu AH, Christenson RH, Cannon CP, Francis G, Morrow DA, Ravkilde J, Storrow AB, Tang W, IFCC Comittee on Standardization of Markers of Cardiac Damage, Jaffe AS, Mair J, Ordonez-Llanos J, Pagani F, Panteghini M, Tate J, National Academy of Clinical Biochemistry (2007) National Academy of Clinical Biochemistry and IFCC Committee for Standardization of Markers of Cardiac Damage Laboratory Medicine Practice Guidelines: analytical issues for biochemical markers of acute coronary syndromes. Clin Chem 53:547-551

Roffi M, Patrono C, Collet JP et al (2016) 2015 ESC guidelines for the management of acute coronary syndromes in patients presenting without persistent ST-segment elevation: task force for the management of acute coronary syndromes in patients presenting without persistent ST-segment elevation of the European Society of Cardiology (ESC). Eur Heart J 37:267-315

Thygesen K, Alpert JS, Jaffe AS et al (2012) Third universal definition of myocardial infarction. Circulation 126:2020 


\section{Troubleshooting}

J. Arnemann

Synonym(e) Fehlerbehebung; Troubleshooting-Guides (Genetik)

Englischer Begriff troubleshooting

Definition Fehler und Störungen in routinemäßig durchgeführten diagnostischen Tests verlangen eine umgehende Fehlerbehebung und Dokumentation der durchgeführten Maßnahmen.

Beschreibung Als Qualitätssicherungsmaßnahme für eine korrekte Durchführung der analytischen Diagnostik wird unmittelbar nach Auftreten eines Fehlers eine allgemeine Fehleranalyse und Dokumentation verlangt. Der Fehler muss durch dokumentierte Maßnahmen behoben werden.

Häufig werden von den Kit-Herstellern, aber auch in allgemeinen Anleitungen zu oftmals anspruchsvollen Methoden, wie z. B. PCR-Varianten, Pyrosequenzierung oder Next-GenerationSequencing sog. Troubleshooting-Guides veröffentlicht, die auf mögliche Fehlerursachen ausführlich eingehen und damit für den Experimentator auch eine Prüfliste zur Abarbeitung und Fehlersuche geben.

\section{Literatur}

Good laboratory practice compliance. European Commission Directive 2004/09/EC and Directive 2004/10/EC

\section{Troubleshooting-Guides (Genetik)}

> Troubleshooting

\section{$\operatorname{Trp}$}

- Tryptophan

\section{Trübung}

T. Arndt

Englischer Begriff dispersion
Definition Die Trübung einer Lösung oder Dispersion ist ein optisches Phänomen, das durch $\triangleright$ Reflexion und Streuung von Licht an kolloidalen Teilchen auftritt, wenn diese einen anderen Brechungsindex als das Lösungs- oder Dispersionsmittel haben.

Beschreibung Durch Lipide, Kristalle oder Mikroorganismen ausgelöste Trübungen in Untersuchungsmaterialien wie Plasma, Punktat, Serum, Urin sind eine häufige Fehlerquelle in der (spektrometrischen) Analytik. Sie können durch geeignete präanalytische Maßnahmen wie Nahrungskarenz vor Blutentnahme, korrekte Aufbewahrung des Untersuchungsgutes oder adäquate Probenvorbereitung vermieden oder beseitigt werden.

Trübungen werden in bestimmten Analysemethoden gezielt erzeugt. Dabei muss das Ausmaß der Trübung in einem Zusammenhang mit der Analytkonzentration der Probe stehen. Wichtigste Beispiele für das klinisch-chemische Labor sind die zur Tyndallometrie ( $\vee$ Tyndall-Phänomen) gehörenden $\triangleright$ Immunnephelometrie und $\triangleright$ Immunturbidimetrie.

\section{Trübung des Urins}

W. G. Guder

Synonym(e) Harntrübung

Englischer Begriff urine turbidity

Definition Sichtbare Trübung des frisch gelassenen Urins im Sammelbehälter unabhängig von der Entstehung vor, während oder nach der Miktion.

Beschreibung Eine Trübung des Harns war schon in der antiken und mittelalterlichen Uroskopie (Harnschau) Gegenstand mehr oder weniger spekulativer Interpretationen. Unterschied der Uroskopiker die Trübung noch nach Wolken (nephele), Suspension (enaiorema) und Niederschlag (hypostasis), wurden im 18.-19. Jahrhundert die chemischen Eigenschaften und mit Erfindung des Mikroskops die kristallinen Formen der $>$ Trübung unterschieden und in Beziehung zu Erkrankungen des Patienten gebracht. Von diagnostischer Bedeutung blieben Trübungen, die auf definierte Erkrankungen hindeuteten und gemeinsam mit der Farbe der Trübung, teilweise namengebend für die Substanzen oder die Erkrankung wurden (Alkaptonurie, Zystinurie oder Phosphaturie). Weitgehend ersetzt durch die spezifischen Teststreifen und chemischen Untersuchungen ist die Deutung einer Harntrübung kompliziert geworden durch artefizielle Ursachen (z. B. Kontrastmittel, Medikamente oder Nahrungszusätze). 
Dennoch sollte die Deutung einer Trübung des Urins jedem Arzt geläufig sein:

- Trübung des Harns im alkalischen pH-Bereich: Phosphate, Carbonate, Oxalate, Bakterien durch Verunreinigung, Schleim

- Trübung im sauren $\mathrm{pH}-$ Bereich: Urate

- Trübungen unabhängig vom $\mathrm{pH}$ des Urins: Schleim, Leukozyten, Epithelien, Erythrozyten (rot), Kontrastmittel, Fett (Chylurie), Medikamente ( $\triangleright$ Harnsediment)

\section{Trübungsmessung}

$\checkmark$ Immunturbidimetrie

\section{Trülbungstest nach Rivalta}

- Rivalta-Test

\section{Trübungsteste}

> Serumprotein-Labilitätsreaktionen

\section{Trypanosoma cruzi}

W. Stöcker

\section{Englischer Begriff Trypanosoma cruzi}

Beschreibung des Erregers Gattung: Trypanosoma; Art: Trypanosoma cruzi; einzelliger Flagellat.

Der einzellige Parasit Trypanosoma (T.) cruzi ist der Erreger der Chagas-Krankheit (Amerikanische/Südamerikanische Trypanosomiasis, Morbus Chagas). Auf Säugetiere und Menschen übertragen wird der Erreger, der einen Wirtswechsel durchmacht, von 3-4 cm großen blutsaugenden Raubwanzen (Reduviidae).

\section{Erkrankungen Chagas-Krankheit.}

Verbreitung: insbesondere Mittel- und Südamerika, vor allem ländliche Gebiete.

Übertragung: Kontamination kleiner Hautverletzungen oder Schleimhäute (besonders im Auge) mit erregerhaltigem
Kot der blutsaugenden Raubwanzen; Wild- und Haustiere dienen als Erregerreservoir; Mensch-zu-Mensch-Übertragungen durch Bluttransfusionen und Organtransplantationen sowie transplazentar sind möglich.

Klinik: akute Symptome bei 30-40 \% der infizierten Personen, häufig bei Kindern; die Chagas-Krankheit durchläuft mehrere Stadien:

1. Lokale Schwellung nach Wanzenstich an der Eintrittsstelle des Erregers, oft in Augennähe (Romana-Zeichen).

2. Akute Phase nach wenigen Tagen mit Fieber, Luftnot, Ödemen, Durchfall, Bauchschmerzen, Lymphknotenschwellungen, Krampfanfällen (bei Hirnbeteiligung) und Herzvergrößerung. Die Letalitätsrate bei kardialen oder zerebralen Komplikationen in dieser Phase liegt bei $5-10 \%$.

3. Weitestgehend symptomfreie Latenzphase, diese kann mehrere Jahre andauern.

4. Bei chronischer Erkrankung (10-30\% der Infizierten) kommt es zu Manifestationen insbesondere am Herzen (Herzvergrößerung, Herzinsuffizienz, Reizleitungsstörungen) und am Verdauungstrakt (Untergang von Nervenzellen, Megaösophagus, Megakolon). Selten treten zentralnervöse Symptome auf.

Schätzungsweise 7 Millionen Menschen sind weltweit mit T. cruzi infiziert, jährlich sterben über 10.000 Menschen an der Chagas-Krankheit.

Analytik Direktnachweis: mikroskopischer Nachweis des Erregers im Blut (gefärbter Blutausstrich); Nachweis der Erreger-DNA durch $>$ PCR (Polymerase-Kettenreaktion); Xenodiagnostik (laborgezüchtete erregerfreie Raubwanzen erhalten auf der Haut des Patienten eine Blutmahlzeit; nach 2-4 Wochen wird der Kot der Raubwanzen auf Erregerbefall untersucht).

Serologie: Nachweis spezifischer Antikörper (IgG) im Serum durch Enzymimmunoassays ( $\triangleright$ Enzyme-linked Immunosorbent Assay, Chemilumineszenz-Immunoassay), indirekte Immunfluoreszenz (IIFT; \ Immunfluoreszenz, indirekte).

Probenmaterial Direktnachweis: Blut oder Blutbestandteile. Das Material sollte bis zur Weiterverarbeitung bei +4 bis $+8{ }^{\circ} \mathrm{C}$ aufbewahrt werden.

Serologie: Serum oder Plasma für den Nachweis der Antikörper sind bei $+4{ }^{\circ} \mathrm{C}$ bis zu 2 Wochen lang beständig, bei $-20^{\circ} \mathrm{C}$ über Monate und Jahre hinweg. Zur Tiefkühlkonservierung des IgM kann man den Proben $80 \%$ gepuffertes Glyzerin beifügen.

Diagnostische Wertigkeit In der akuten Phase kann der Parasit mikroskopisch oder mittels PCR nachgewiesen wer- 
den. In der latenten und insbesondere in der chronischen Phase der Chagas-Krankheit ist der Nachweis des IgG gegen T. cruzi im Serum von Bedeutung für die Diagnose, hierfür werden vor allem Enzymimmunoassays oder IIFT verwendet. Bei rechtzeitiger Diagnose und Behandlung ist die ChagasKrankheit heilbar.

Differenzialdiagnose: Typhus abdominalis, Influenza, viszerale Leishmaniose, Malaria, Brucellose.

\section{Literatur}

Robert-Koch-Institut, Berlin (2011) Steckbriefe seltener und importierter Infektionskrankheiten. Robert-Koch-Institut, Berlin

World Health Organization (2017) Media centre. Chagas disease (American trypanosomiasis) Fact sheet. http://www.who.int/mediacentre/ factsheets/fs340/en/. Zugegriffen am 11.04.2017

\section{Trypsin}

A. M. Gressner und O. A. Gressner

Synonym(e) EC 3.4.21.4

\section{Englischer Begriff trypsin}

Definition Pankreatogene Serinproteinase mit wichtiger Funktion bei der intestinalen Proteinverdauung und Zymogenaktivierung, deren Serumkonzentration zur Diagnostik akuter Pankreaserkrankungen immunologisch bestimmt werden kann.

Synthese - Verteilung - Abbau - Elimination Es existieren 2 Isoenzyme:

- Trypsin- $1=$ kationisches Trypsin: Molmasse 25,8 kDa, pI 4,6-6,5, pH-Optimum 8,0-9,0

- Trypsin-2 = anionisches Trypsin: Molmasse 22,9 kDa, pI >6,5, pH-Optimum 8,0-10,0; Aktivatoren: Kalzium, Magnesium; Inhibitoren: Citrat, Fluorid, Schwermetalle

Von den Azinuszellen des Pankreas synthetisierte, als inaktives Trypsinogen-1 (kationisch) und Trypsinogen-2 (anionisch) durch Vagusreiz und die intestinalen Hormone - Cholecystokinin-Pankreozymin freigesetzte Serinproteinasen, die etwa $19 \%$ des Gesamtproteingehaltes des Pankreassaftes (täglich 2,5-3,0 L) ausmachen. Trypsinogen-1 stellt die 2- bis 4-fache Menge des Trypsinogen-2 dar. Aktivierung der Proenyzme durch Enterokinase (Enteropeptidase: Glykoprotein, $45 \%$ Kohlenhydrate, Molmasse
$316 \mathrm{kDa}, \mathrm{pH}-$ Optimum 6,0-9,0) der Enterozyten des proximalen Dünndarms durch Abspaltung eines Tetrapeptids ( $\triangleright$ Trypsinogen-Aktivierungspeptid, TAP), dessen Konzentration in Serum und Urin gemessen werden kann. Natürliche Trypsininhibitoren sind $\alpha_{1}$-Proteinaseinhibitor ( $\triangleright \alpha_{1}$-Antitrypsin) und $\triangleright \alpha_{2}$-Makroglobulin, die zu einer irreversiblen Inaktivierung des aktiven Zentrums führen. Damit werden Proteine (z. B. Gerinnungskaskade) und Gewebestrukturen (z. B. Lungenalveoli) vor ungezieltem proteolytischen Abbau geschützt.

Funktion - Pathophysiologie Freisetzung von Trypsinogen bzw. Trypsin in die Zirkulation als freies Trypsinogen oder als Komplex mit Antiproteinasen bei nekrotischen Pankreasprozessen, z. B. akuter Pankreatitis. In äquimolaren Mengen Freisetzung von $>$ Trypsinogen-Aktivierungspeptid (TAP). Verminderung von Trypsin(ogen) in der aspirierten, nach Pankreozyminstimulation gewonnenen Duodenalflüssigkeit dient als Kenngröße der exokrinen Pankreasinsuffizienz ( $\triangleright$ Sekretin-Pankreozymin-Test).

Untersuchungsmaterial - Entnahmebedingungen Serum, EDTA-, Heparin-Plasma, Duodenalsaft, Fäzes, Urin, Trockenblut auf Filterpapier.

Probenstabilität Enzym ist 8 Tage bei $4{ }^{\circ} \mathrm{C}$ und dauerhaft bei $-20{ }^{\circ} \mathrm{C}$ stabil.

\section{Analytik}

- Immunreaktive Konzentrationsbestimmung von Trypsin (ogen)-1 und -2: Wegen geringer immunologischer Kreuzreaktivität sind spezifische Immunoassays ( $\triangleright$ Immunoassay) für beide Trypsinformen möglich. Erfasst werden Trypsinogen, Trypsin und (mit Einschränkung) Trypsin$\alpha_{1}$-Proteinaseinhibitorkomplex (nicht Trypsin- $\alpha_{2}$-Makroglobulinkomplex). Freies Trypsin ist im Serum im Wesentlichen nicht nachweisbar.

- Katalytische Aktivitätsbestimmung: Erfolgt mit verschiedenen synthetischen Peptidsubstraten wie Benzoyl-LArgininethylester (BAEE), Benzoyl-L-Lysinamid (BLA), Benzoyl-L-Arginin-4-Nitroanilid (BAPNA) und 2-Toluensulphonyl-L-Arginin-Methylester (TAME). Je nach Substrat wird die Messung spektrometrisch bei $253 \mathrm{~nm}$ (BAEE), bei $405 \mathrm{~nm}$ (BAPNA) oder durch Titration der durch tryptische Aktivität freigesetzten Carboxylwasserstoffionen (TAME) durchgeführt.

Referenzbereich - Erwachsene Immunreaktive Konzentrationen methodenabhängig verschieden. Serum: Richtwert: $135-400 \mu \mathrm{g} / \mathrm{L}$ für Männer, $50 \%$ höhere Konzentrationen für Frauen, Anstieg mit Alter; Fäzes: 40-760 $\mu \mathrm{g} / \mathrm{g}$ Stuhl. 


\section{Indikation}

- Diagnostik und Schweregradbeurteilung der akuten und chronisch rezidivierenden Pankreatitis

- Diagnostik der zystischen Pankreasfibrose

- Diagnostik und Verlaufskontrolle von Pankreastumoren

Interpretation 2- bis 400-facher Anstieg der immunreaktiven Trypsinkonzentration im Serum bei akuter Pankreatitis, wobei milde Formen zu über 80 \% freies Trypsinogen, schwere Verläufe mit ungünstiger Prognose nur noch zu $30 \%$ freies, ansonsten komplexiertes Trypsinogen aufweisen. Hohe Konzentrationen bei Neugeborenen mit zystischer Pankreasfibrose, die mit fortschreitender Erkrankung abnehmen. Anionisches Trypsin-2 erhöht bei Pankreaskarzinom. Konzentrationserhöhungen auch bei chronischer Niereninsuffizienz. Verminderungen der Serumkonzentration bei ausgeprägter Pankreasinsuffizienz mit Steatorrhoe. In diesen Fällen auch Verminderung der Trypsinkonzentration im Duodenalsaft und im Fäzes.

Diagnostische Wertigkeit Sensitiver Nachweis aktueller Pankreasnekrosen im Rahmen akuter und chronisch rezidivierender Pankreatitiden. Wichtige Kenngröße bei der Frühdiagnose der zystischen Pankreasfibrose im Trockenbluttest. Trypsinogen-2-Erhöhung reflektiert den Schweregrad der Pankreatitis. Bei einem Cut-off von 1000 mg/L kann zwischen einer milden und komplizierten Erkrankung mit einer Sensitivität ( Sensitivität, diagnostische) von $91 \%$ und Spezifität ( $\triangleright$ Spezifität, diagnostische) von $71 \%$ differenziert werden. Der negative Vorhersagewert für akute Pankreatitis beträgt $99 \%$. Die Trypsinbestimmung im Stuhl hat keine klinische Bedeutung, da das Enzym nicht stabil ist. Hier sind $\checkmark$ Elastase, pankreasspezifische, PE oder $>$ Chymotrypsin im Stuhl zum Nachweis einer exkretorischen Pankreasinsuffizienz zu bestimmen.

\section{Literatur}

Tietz NW (1997) Support of the diagnosis of pancreatitis by enzyme tests - old problems, new techniques. Clin Chim Acta 257:85-98

\section{Trypsinogen-Aktivierungspeptid}

A. M. Gressner und O. A. Gressner

$\operatorname{Synonym(e)~TAP~}$

Englischer Begriff trypsinogen activation peptide
Definition Niedermolekulares, bei der proteolytischen Aktivierung von Trypsinogen zu Trypsin entstehendes Peptidfragment, dessen Konzentrationserhöhung in Plasma und Urin zur frühen Diagnose, Schweregradbeurteilung und Prognose der akuten Pankreatitis bestimmt wird.

Synthese - Verteilung - Abbau - Elimination Die Aktivierung des Trypsinogens, des Zymogens ( $\triangleright$ Zymogene) von - Trypsin, erfolgt nach dessen Übertritt vom Pankreas in das Duodenum durch eine Serinproteinase ( $>$ Enteropeptidase), deren Sekretion von der Duodenalmukosa unter hormoneller Kontrolle erfolgt. Anschließend setzt die autokatalytische Aktivierung des Trypsins ein. Dabei wird ein N-terminales Pentapeptid (Trypsinogen-Aktivierungspeptid, TAP) in Blut und Urin freigesetzt und ist in diesen Körperflüssigkeiten als Kenngröße der Trypsinogenaktivierung messbar (s. Abbildung). Die Halbwertszeit in der Zirkulation beträgt ca. 8 Minuten.

Funktion - Pathophysiologie Exzesstrypsinaktivierung mit erhöhter Freisetzung von TAP in Blut und Urin sind eine frühe Kenngröße der akuten Pankreatitis, wobei das Ausmaß des Konzentrationsanstieges mit dem Schweregrad korreliert. Intrapankreatische Trypsinogenaktivierung ist von großer pathogenetischer Bedeutung für die Autolyse des Pankreas im Rahmen der akuten Pankreatitis.

Abbildung 1 zeigt die Symptomschwere in Korrelation zur Plasmakonzentration von Trypsinogen-Aktivierungspeptid.

Untersuchungsmaterial- Entnahmebedingungen EDTAPlasma, Urin, Aszites.

Analytik. Enzymimmunoassay (ELISA) mit polyklonalem Antikörper gegen das Pentapeptid TAP.

Referenzbereich - Erwachsene Plasma $\leq 2,8 \mathrm{nmol} / \mathrm{L}$, Urin $\leq 15 \mathrm{nmol} / \mathrm{L}$.

Indikation Frühdiagnostik, Schweregradstratifizierung und Prognosebeurteilung der akuten Pankreatitis.

Interpretation Aufgrund der sehr kurzen Halbwertszeit in der Zirkulation ist die TAP-Erhöhung im Plasma flüchtiger als im Urin, andererseits haben $30 \%$ aller Patienten mit akuter Pankreatitis eine normale TAP-Konzentration im Urin bei Aufnahme. Die TAP-Konzentrationen in Urin und Plasma korrelieren eng mit dem Schweregrad der Erkrankung, wenn die Bestimmung innerhalb der ersten 48 Stunden (spätestens 72 Stunden) erfolgt (s. Abbildung).

Diagnostische Wertigkeit Bei einem Cut-off von 2,8 nmol/L besitzt Plasma-TAP eine Sensitivität von $70 \%$, Spezifität von $78 \%$, positiven Vorhersagewert von $61 \%$ und einen negativen 


\section{Trypsinogen-}

Aktivierungspeptid, Abb. 1

Symptomschwere in Korrelation zur Plasmakonzentration von

Trypsinogen-Aktivierungspeptid (TAP); CAPAP =

Pro-Carboxypeptidase-

Aktivierungspeptid

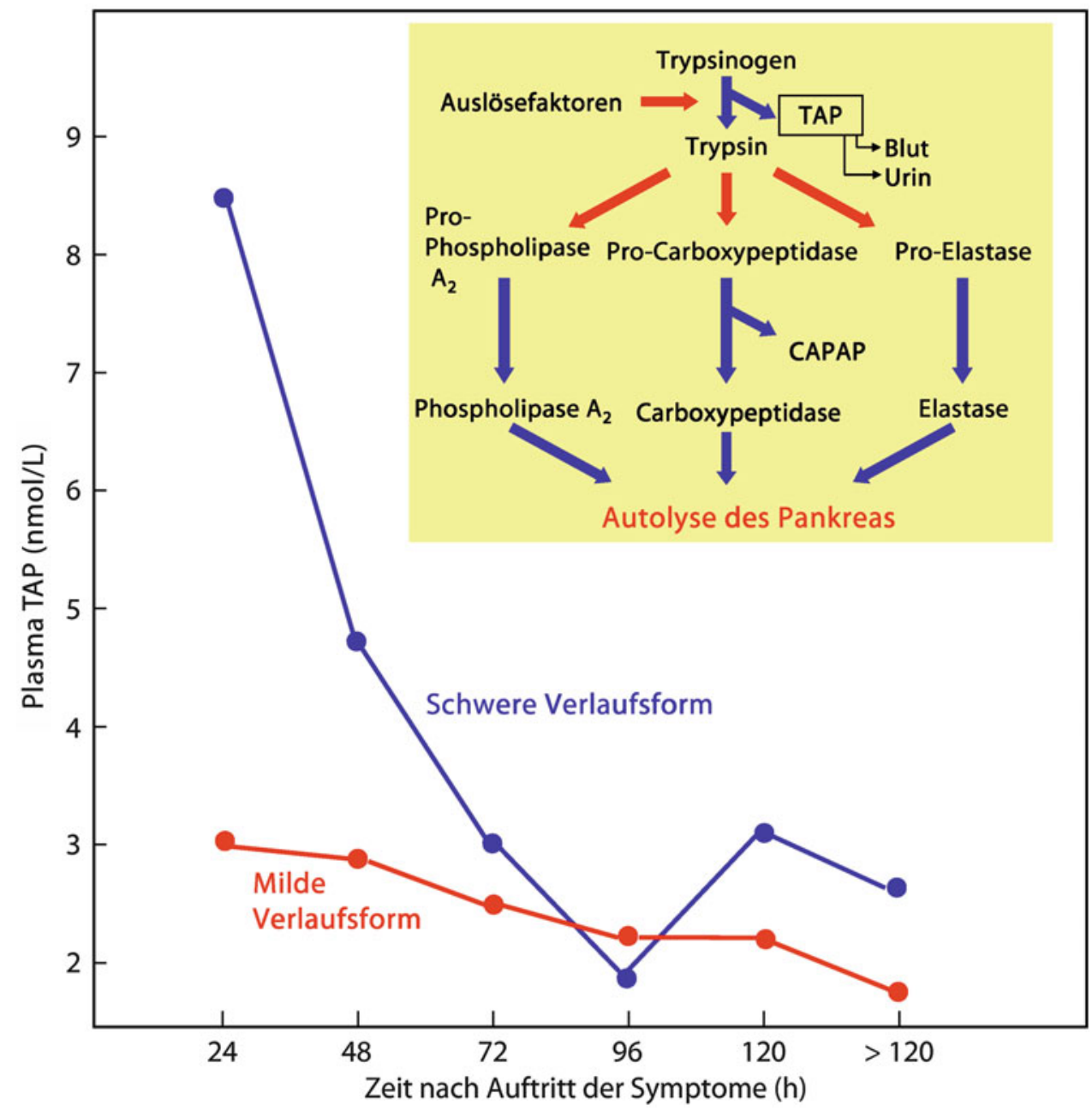

Vorhersagewert von $84 \%$ als Prognoseindex (innerhalb der ersten 24 Stunden bestimmt) (Abb. 1).

Im Urin liegen die diagnostischen Kriterien bei einem Cutoff von $35 \mathrm{nmol} / \mathrm{L}$ und einem Bestimmungszeitpunkt von 24 Stunden nach Krankheitsbeginn für die Differenzierung der milden von der schweren akuten Pankreatitis wie folgt: Sensitivität $58 \%$, Spezifität $73 \%$, positiver Vorhersagewert $39 \%$, negativer Vorhersagewert $86 \%$. Die TAP-Konzentration im Urin erlaubt somit eine akkurate Schweregradbeurteilung innerhalb der ersten 24 Stunden nach Beginn der Symptome.

\section{Literatur}

Huang W, Altaf K, Jin T et al (2013) Prediction of the severity of acute pancreatitis on admission by urinary trypsinogen activation peptide: a meta-analysis. Workd J Gastroenterol 19(28):4607-4615

Neoptolemos JP, Kemppainen EA, Mayer JM et al (2000) Early prediction of severity in acute pancreatitis by urinary trypsinogen activation peptide: a multicentre study. Lancet 355:1955-1960

\section{Tryptase}

\section{H. Renz und B. Gierten}

\section{Englischer Begriff tryptase}

Definition Serinproteinase, die beim Menschen nahezu ausschließlich in den Granula von Mastzellen und in wesentlich geringeren Konzentrationen in basophilen Granulozyten ( $\triangleright$ Granulozyten, basophile) vorkommt.

Struktur Tetramere Serinproteinase, 4 Isoformen (eine $\alpha$ und $3 \beta$-Tryptasen), EC 3.4.21.59.

\section{Molmasse $134 \mathrm{kDa}$}

Synthese - Verteilung - Abbau - Elimination $\alpha$-Tryptase wird kontinuierlich im Zytoplasma der basophilen Granulozyten synthetisiert und sezerniert. 
$\beta$-Tryptase befindet sich zu $>90 \%$ in enzymatisch aktiver Form in Komplexen mit Heparin ( $\triangleright$ Heparin und Heparinoide) und anderen $\triangleright$ Proteoglykanen in den sekretorischen Granula der Mastzellen. Zusammen mit anderen Serinproteasen wie Chymase, Kathepsin G und Carboxypeptidase A wird sie beispielsweise durch Aktivierung von hochaffinen IgERezeptoren auf der Zelloberfläche oder kontinuierlich (,piecemeal degranulation") freigesetzt.

Die extrazelluläre Inaktivierung erfolgt wahrscheinlich durch den Zerfall des sezernierten Tryptase-Heparin- oder Tryptase-Proteoglykan-Komplexes.

Funktion - Pathophysiologie $\alpha$-Tryptase wird in geringen Mengen kontinuierlich von Mastzellen freigesetzt. Sie ist wegen der geringen zirkulierenden Menge pathophysiologisch von geringer Bedeutung.

$\beta$-Tryptase liegt in enzymatisch aktiver Form als Tetramer an Heparin oder andere Proteoglykane gebunden in den Granula der Mastzellen vor. Vernetzung hochaffiner IgERezeptoren an der Zelloberfläche durch Bindung spezifischer IgE-Moleküle führt schlagartig zu Freisetzung des Granulainhaltes.

Die biologische Funktion des Enzyms ist weitgehend unklar. Mangels spezifischer Inhibitoren kann sie in vitro bisher kaum spezifisch beeinflusst werden. Pathophysiologische Bedeutung erhält die Tryptase im Rahmen der frühen allergischen Reaktion durch folgende Wirkungen:

- Förderung des Plasmaeinstroms in den Extrazellularraum durch erhöhte Kapillarpermeabilität und Aktivierung von Kininogenen (z. B. Präkallikrein) zu Kininen, Vasodilatatoren und Entzündungsmediatoren

- Gerinnungshemmung durch indirekte Aktivierung von Plasminogen über Aktivierung der Prourokinase zu Urokinase und dadurch weitere Erleichterung des Plasmaeinstroms

- Expressionsstimulation von ICAM-1 und IL-8.

In neurogenen Entzündungsherden könnte Tryptase aufgrund einer inhibierenden Wirkung auf neurogene Peptide wie VIP (,vasoactive intestinal peptide“) und CGRP (,calcitonin gene-related peptide") inhibierend wirken.

Weitere Effekte der Mastzelltryptase liegen in der Syntheseförderung von Typ-1-Kollagen und Wachstumsförderung von Epithelzellen, glatten Muskelzellen und Fibroblasten. Indirekt greift Tryptase auch in den Abbau extrazellulärer Matrix ein, indem sie durch proteolytische Spaltung Vorstufen von - Matrix-Metalloproteinasen und Prourokinase aktiviert, die ihrerseits am Abbau der Extrazellularmatrix beteiligt sind.

Untersuchungsmaterial-Entnahmebedingungen Serum, Plasma (Heparin, EDTA).
Präanalytik Probenentnahme 15 Minuten - 3 Stunden nach der vermuteten Mastzelldegranulation.

Analytik Enzymimmunoassay.

Konventionelle Einheit $\mu \mathrm{g} / \mathrm{L}$.

Internationale Einheit $\mu \mathrm{g} / \mathrm{L}$.

Referenzbereich - Erwachsene $<13,5 \mu \mathrm{g} / \mathrm{L}$.

Referenzbereich - Kinder. $<13,5 \mu \mathrm{g} / \mathrm{L}$.

Indikation V. a. allergische oder anaphylaktische Reaktion.

Interpretation In Serum/Plasma gemessene Tryptasekonzentrationen stammen zum weit überwiegenden Teil aus der schnellen Degranulation der Mastzellen und spiegeln somit den Anteil an $\beta$-Tryptase und Mastzellaktivierung wider. Die Konzentration der auch beim Gesunden kontinuierlich in geringen Mengen freigesetzten Mengen an $\alpha$-Tryptase ist mit immunologischen Textsystemen messbar und der Anzahl der im Körper vorhandenen aktivierten Mastzellen proportional.

Diagnostische Wertigkeit Als Indikator der Mastzellaktivierung ist Tryptase wegen der längeren Halbwertszeit im Serum/Plasma und der höheren Spezifität aussagekräftiger als Messung von Histamin. Diagnose oder Verlaufsbeobachtung einer Mastzelldegranulation z. B. im Rahmen einer anaphylaktischen Reaktion ist somit mittels Tryptasebestimmung leicht möglich. Ein signifikanter Anstieg der Serumtryptase ist nach bereits 15 Minuten nach dem Ereignis zu verzeichnen. Die Werte steigen bei einem Akutereignis kontinuierlich bis zum Maximalwert nach etwa 2 Stunden an.

Bestimmung von Tryptase ohne anamnestisch bekannte Basophilendegranulation kann bei erhöhten Werten auf eine Mastozytose hindeuten.

Mittels Parallelbestimmung von Histamin und Tryptase kann man die Aktivierung von Mastzellen und Basophilen unterscheiden, da von Basophilen nur geringe Mengen an Tryptase, jedoch große Mengen $\triangleright$ Histamin freigesetzt werden.

\section{Literatur}

Ludolph-Hauser D et al (1999) Tryptase, ein Marker für die Aktivierung und Lokalisation von Mastzellen. Hautarzt 50:556-561 


\section{Tryptophan}

A. C. Sewell

Synonym(e) Trp

Englischer Begriff tryptophan

Definition Trp ist eine proteinogene $\alpha$-Aminosäure mit einem aromatischen Indolring. Gemeinsam mit $>$ Phenylalanin, \ Tyrosin und $>$ Histidin zählt Trp daher zu den aromatischen Aminosäuren.

Struktur $\triangleright$ Aminosäuren.

Molmasse 204,23 g.

Synthese - Verteilung - Abbau - Elimination Trp ist eine essenzielle Aminosäure, muss mit der Nahrung aufgenommen werden und ist in vielen Lebensmitteln enthalten, vor allem in Milch und Milchprodukten. Trp ist auch in Kakaobohnen (Schokolade) enthalten. Beim Abbau von Trp werden beide aromatischen Ringe gespalten, und es entsteht 3Hydroxykynurenin ( $\triangleright$ Kynurenin) als Endprodukt.

Funktion - Pathophysiologie Trp ist wichtig als Vorstufe der $>$ Serotoninsynthese (Schokolade macht glücklich!), gilt daher als ,natürliches Antidepressivum“ ( $\vee$ Antidepressiva, trizyklische) und wird zur Behandlung von leichten Depressionen und Verstimmungen sowie bei Schlafstörungen eingesetzt. Verzögerte gastrointestinale Absorption führt zu einer Erhöhung der Indolausscheidung im Urin (Morbus Hartnup).

Untersuchungsmaterial - Entnahmebedingungen Plasma, Serum, Liquor, Urin.

Analytik $>$ Aminosäuren.

Referenzbereiche $>$ Aminosäuren.

\section{Literatur}

Duran M (2008) Amino acids. In: Blau N, Duran M, Gibson KM (Hrsg) Laboratory guide to the methods in biochemical genetics. Springer, Berlin, S 53-90

Levy H (2001) Hartnup disorder. In: Scriver CR, Beaudet AL, Sly WS, Valle D (Hrsg) The metabolic basis of inherited disease II. McGrawHill, New York, S 2525-2527

\section{Tryptophanreiches Präalbumin}

> Präalbumin

TS

- Tumorsuppressorgen

TSH

- Thyreotropin

- TSH-Bestimmung aus Trockenblut

\section{TSH in Trockenblut}

> TSH-Bestimmung aus Trockenblut

\section{TSH-Bestimmung aus Trockenblut}

G. F. Hoffmann, C.-D. Langhans und A. Schulze

Synonym(e) Hypothyreose-Screening; TSH in Trockenblut

Englischer Begriff thyroid-stimulating hormone in dried blood spots; congenital hypothyroidism $(\mathrm{CH})$ screening

Definition Bestimmung der Konzentration von TSH ( $\vee$ Thyreotropin) im $>$ Trockenblut von Neugeborenen zum Screening auf das Vorliegen einer angeborenen primären Hypothyreose.

Physikalisch-chemisches Prinzip Der AutoDELFIA-Neonatal-humanTSH-(hTSH-)Test ist ein zweiseitiger, fluoroimmunometrischer Festphasentest nach dem direkten Sandwichprinzip, bei dem 2 monoklonale Mausantikörper gegen 2 separate Antigendeterminanten auf dem hTSH-Molekül gerichtet sind. Standards, Kontrollen und Patientenproben, die hTSH enthalten, reagieren gleichzeitig mit den immobilisierten monoklonalen Antikörpern, die gegen eine spezifische Antigenstelle auf der $\beta$-Untereinheit des hTSH gerichtet sind, und mit den Europium-markierten monoklonalen Antikörpern (gerichtet teilweise sowohl auf der $\beta$-Untereinheit als auch auf der $\alpha$-Untereinheit) im Testpuffer. Der Testpuffer löst das hTSH aus den 
TSH-Bestimmung aus Trockenblut, Abb. 1 Prinzip der fluorometrischen

TSH-Bestimmung
hTSH-Molekül

Inkubation

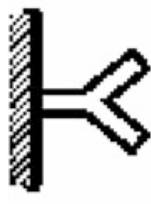

Festphase anti- $\beta$ hTSH IgG
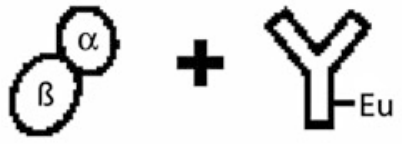

Eu-markiertes anti-hTSH IgG

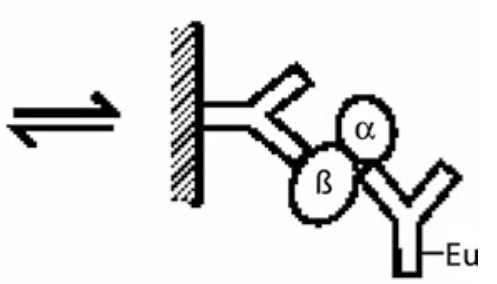

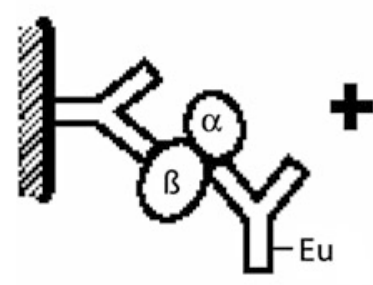

EnhancementLösung

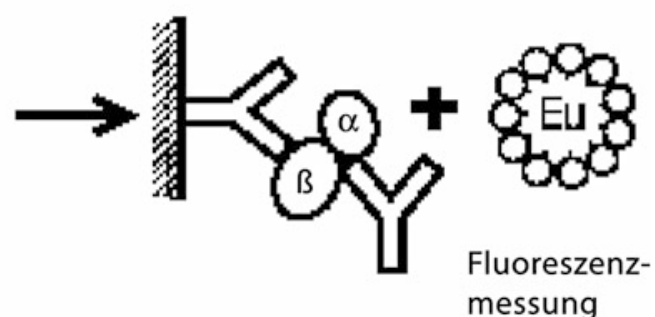

Filterpapierscheibchen heraus. Der Test kommt mit einem Inkubationsschritt aus. Die Enhancement-Lösung spaltet Europiumionen vom markierten Antikörper in die Lösung ab, wo die Europiumionen ihrerseits mit den Komponenten der Enhancement-Lösung hochfluoreszente Chelate bilden. Die resultierende Fluoreszenz ist proportional zur hTSH-Konzentration in der Probe (Abb. 1).

Einsatzgebiet Neugeborenenscreening.

Untersuchungsmaterial Vollblut getrocknet auf Filterpapier (Trockenblut).

Instrumentierung Automatisiertes Immunoassay-System 1235 AutoDELFIA, Multipuncher oder Handstanzen, Mikrotiterfilterplatten, Pipetten.

Spezifität Diagnostische Spezifität im Screening: ca. 99,9 \%.

Sensitivität Diagnostische Sensitivität im Screening: > $99 \%$; die angeborene primäre Hypothyreose wird sicher detektiert, sekundäre und tertiäre Hypothyreose werden nicht erkannt.

Analytische Sensitivität: $4,4 \mu \mathrm{U} / \mathrm{mL}$ Serum $(2 \mu \mathrm{U} / \mathrm{mL}$ Blut $)$.

Fehlermöglichkeit Dopamintherapie, Iodmangel, Iodexzess, Iodkontamination (iodhaltige Antiseptika, Kontrastmittel), Thyreostatika, Frühgeborene $<27$ Schwangerschaftswoche, EDTABlut, Citrat-Blut.

Praktikabilität - Automatisierung - Kosten Praktikabilität: sehr gut. Automatisierung: nahezu vollständig.

Kosten: ca. 1,50 Euro/Test (für Chemikalien und Verbrauchsmaterialien), Gesamtkosten hängen von der Probenzahl ab.
Bewertung - Methodenhierarchie (allg.) Die TSH-Bestimmung mittels AutoDELFIA stellt ein zuverlässiges Verfahren zum Hypothyreose-Neugeborenenscreening dar.

\section{Literatur}

Klett M, Zabransky S (2001) Screening auf Hypothyreose bei Neugeborenen. In: Zabransky S (Hrsg) Screening auf angeborene endokrine und metabole Störungen. Springer, Wien/New York, S 129-157

\section{TSH-Rezeptor-Antikörper}

- Autoantikörper gegen TSH-Rezeptoren

\section{TSH-Stimulation}

TRH-Test

TSP

- Thrombospondine

t-Test

Test, statistischer 


\section{Tubuläre Basalmembran-Antikörper}

- Autoantikörper gegen Nierentubuli

\section{Tumorgene}

> Onkogen

\section{Tumorkenngrößen}

> Tumormarker

\section{Tumormarker}

S. Holdenrieder und P. Stieber

Synonym(e) Tumorkenngrößen

Englischer Begriff tumour markers

Definition Als Tumormarker werden alle charakteristischen zellulären, genetischen, epigenetischen, Transkript-, Peptidund Protein- oder sonstigen Veränderungen bezeichnet, die im Rahmen einer Tumorerkrankung auftreten, im Blut oder anderen Körperflüssigkeiten nachweisbar sind und zur Diagnostik oder zur Verlaufsbeobachtung der Tumorerkrankung benutzt werden können. Allerdings sind nur wenige, heute in der klinischen Anwendung befindlichen Biomarker tatsächlich tumorspezifisch, sodass der Begriff „Tumormarker“ unscharf ist. In vielen Fällen weisen jedoch Quantität oder Häufung solcher Veränderungen auf ein malignes Geschehen hin.

Beschreibung Derzeit in der Routinediagnostik gebräuchliche Tumormarker sind häufig deregulierte $\$ Glykoproteine und -lipide, die von der Oberfläche maligner Zellen abschilfert werden, wie etwa die embryofetalen Marker $>$ Carcinoembryonales Antigen (CEA) und $>\alpha_{1}$-Fetoprotein (AFP) und die Hybridmarker CA 15-3 ( $\triangleright$ Carbohydrate antigen 15-3), CA 19-9 (॰ Carbohydrate antigen 19-9), CA 125 ( $\triangleright$ Carbohydrate antigen 125) und CA 72-4 ( $\triangleright$ Carbohydrate antigen 72-4). Außerdem zählen hierzu intrazelluläre Moleküle wie Bestandteile des Zytoskeletts (Zytokeratinfragmente, z. B. CYFRA 21-1 > Zytokeratin-
19-Fragment), Enzyme ( $\triangleright$ Neuronenspezifische Enolase im Blut und PSA [ $\triangleright$ Prostataspezifisches Antigen]) und Hormone (z. B. \ Calcitonin, \ Katecholamine), die aktiv ins Blut sezerniert oder beim Absterben der Zelle freigesetzt werden. Das Ausmaß, in dem diese Biomarker im Blut nachweisbar sind, hängt ab von

- Durchblutung des Tumors,

- Metabolisierung der Marker in Organismus und Blutkreislauf und

- hepatischer oder renaler Exkretion.

Bei frühen, lokal begrenzten Tumoren finden sich häufig nur geringgradig erhöhte Konzentrationen der Tumormarker im Blut, die noch innerhalb der Referenzbereiche liegen und nur durch serielle Messungen in individuellen Patienten erkannt werden können. Bei ausgedehntem Tumorbefall, aber auch bei einigen nicht malignen Erkrankungen und bei Einschränkung des Markerkatabolismus können die Konzentrationen mitunter mäßig bis stark erhöht sein, wodurch sich erklärt, dass bei den meisten Tumormarkern eine Tumorspezifität erst bei sehr hohen Wertlagen erreicht wird.

Nur wenige Tumormarker wie das PSA ( $\triangleright$ Prostataspezifisches Antigen) oder das $>$ Thyreoglobulin (HTG) weisen eine Organspezifität auf, während andere Marker wie CEA und CYFRA 21-1 von vielen Tumoren freigesetzt werden. Für die Differenzialdiagnostik von Tumorerkrankungen sind deshalb weniger einzelne Biomarker, sondern vielmehr das Expressionsmuster mehrerer Marker hilfreich, wobei sowohl eine starke Über- wie auch Unterexpression von Bedeutung sind. Abbildung 1 fasst für ausgewählte Tumorerkrankungen relevante Tumormarker zusammen.

Die Einsatzmöglichkeiten von Tumormarkern im Rahmen einer Tumorerkrankung sind:

- Unterstützung der Differenzialdiagnose bei Vorliegen von klinischen Symptomen oder verdächtigen bildgebenden Befunden

- Überwachung von Risikogruppen

- Abschätzung der Prognose eines Patienten zum Zeitpunkt des Primärtumors oder eines Rezidivs

- Prädiktion und frühzeitigen Beurteilung des Ansprechens einer zytotoxischen Therapie

- Verlaufsbeobachtung in der Nachsorgesituation zur frühzeitigen Erkennung eines Tumorrezidivs

Für das Screening von asymptomatischen Populationsgruppen zur frühzeitigen Tumorentdeckung sind die meisten Tumormarker derzeit nicht geeignet. Dies kommt auch in diversen Leitlinien zum klinischen Gebrauch von Tumormarkern zum Ausdruck (www.aacc.org; EGTM). Der Nutzen des Einsatzes von PSA zur Frühentdeckung des Prostatakarzinoms wird kontrovers diskutiert. 


\begin{tabular}{|c|c|c|c|c|c|c|c|c|c|c|c|c|c|c|c|c|c|c|c|c|c|c|c|}
\hline $\begin{array}{l}\text { Marker I } \\
\text { Karzinome }\end{array}$ & CEA & AFP & \begin{tabular}{|c|} 
CA \\
$19-9$ \\
\end{tabular} & \begin{tabular}{|c|} 
CA \\
$72-4$ \\
\end{tabular} & \begin{tabular}{|c|} 
CA \\
$15-3$ \\
\end{tabular} & \begin{tabular}{|l|} 
CA \\
125 \\
\end{tabular} & \begin{tabular}{|l|} 
CYF \\
$21-1$
\end{tabular} & SCC & NSE & \begin{tabular}{|l|} 
Pro \\
GRP \\
\end{tabular} & CgA & \begin{tabular}{|l|} 
Her2 \\
-neu
\end{tabular} & HE4 & $\begin{array}{l}\text { RO } \\
\text { MA }\end{array}$ & HCG & PSA & fPSA & HTG & Cal & S100 & TK & \begin{tabular}{|l|} 
IG + \\
fLK
\end{tabular} & LDH \\
\hline \multicolumn{24}{|l|}{ Ösophagus } \\
\hline \multicolumn{24}{|l|}{ Magen } \\
\hline \multicolumn{24}{|l|}{ Colon/Rektum } \\
\hline \multicolumn{24}{|l|}{ Pankreas } \\
\hline \multicolumn{24}{|l|}{ Gallenblase } \\
\hline \multicolumn{24}{|l|}{ Leber } \\
\hline \multicolumn{24}{|l|}{ GEP-NET } \\
\hline \multicolumn{24}{|l|}{ Lunge NSCLC } \\
\hline \multicolumn{24}{|l|}{ Lunge SCLC } \\
\hline \multicolumn{24}{|l|}{ HNO } \\
\hline \multicolumn{24}{|l|}{ Mamma } \\
\hline \multicolumn{24}{|l|}{ Ovar } \\
\hline \multicolumn{24}{|l|}{ Endometrium } \\
\hline \multicolumn{24}{|l|}{ Cervix } \\
\hline \multicolumn{24}{|l|}{ Chorion } \\
\hline \multicolumn{24}{|l|}{ Keimzell } \\
\hline \multicolumn{24}{|l|}{ Niere } \\
\hline \multicolumn{24}{|l|}{ Blase } \\
\hline \multicolumn{24}{|l|}{ Prostata } \\
\hline \multicolumn{24}{|l|}{ Schilddrüse } \\
\hline \multicolumn{24}{|l|}{ C-Zell } \\
\hline \multicolumn{24}{|l|}{ Melanom } \\
\hline \multicolumn{24}{|l|}{ Mult. Myelom } \\
\hline CUP & & & & & & & & & & & & & & & & M & & & & & & & \\
\hline
\end{tabular}

Tumormarker, Abb. 1 Für ausgewählte Tumorerkrankung relevante, z. T. geschlechtsspezifische Biomarker. $A F P, \mathrm{a}_{1}$-Fetoprotein; $C A$, Cancer Antigen; $\mathrm{Cal}$, Calcitonin; $C E A$, carcinoembryonales Antigen; $C g A$, Chromogranin A; CUP, Karzinom mit unbekanntem Primärtumor (,cancer of unknown primary“); CYF 21-1, Zytokeratin-19-Fragmente; $(f)$ $P S A$, (freies) prostataspezifisches Antigen; $H C G$, humanes Choriongonadotropin; HE4, Human Epididymis Protein 4; Her2/neu, Her2/neu shed Antigen; $H T G$, humanes Thyreoglobulin; GEP-NET, gastroentero-

Hauptindikationen für Tumormarker sind aufgrund der geringen Invasivität der Untersuchungen insbesondere serielle Messungen zum Monitoring einer systemischen Therapie und zur Tumornachsorge. Für die korrekte Interpretation der Markerkinetik sind allerdings die Verwendung derselben Messmethode und die Beurteilung von relativen, individuellen Markerveränderungen Voraussetzung. Bei der Wahl der Untersuchungsintervalle ist die Halbwertszeit der Tumormarker zu berücksichtigen, die von wenigen Stunden (CYFRA 21-1) bis zu mehreren Tagen (CEA, AFP) reichen. Abhängig vom Ausgangswert kann es nach der primären Tumortherapie mitunter mehrere Wochen dauern, bis bei einem Patienten die individuellen Basiswerte der jeweiligen Tumormarker erreicht sind.

Im Falle der Tumormarkerdiagnostik ist die Bedeutung der Referenzbereiche ( $\triangleright$ Referenzbereich, biologischer) stets kritisch zu hinterfragen. Häufig sind die Grenzwerte bei der 95 . Perzentile gesunder Personen definiert, woraus sich schon ein pankreatische neuroendokrine Tumoren; $I g$, Immunglobulin; $L D H$, Laktat Dehydrogenase; $L K$, Leichtkette; $\beta 2 M G, \beta 2$-Mikroglobulin; $(N)$ $S C L C$, (nicht) kleinzelliges Lungenkarzinom; NSE, neuronenspezifische Enolase; ProGRP, Pro-Gastrin Releasing Peptide; ROMA, Risk of Ovarian Malignancy Algorithm; $S C C$, Squamous Cell Cancer Antigen; $T K$, Thymidinkinase. Einzelheiten zu den verschiedenen Tumormarkern siehe jeweils dort

Anteil von $5 \%$ falsch positiver Befunde ( $\triangleright$ Testergebnis, falsch-positives) bei Gesunden und in der Regel ein noch höherer Anteil bei Patienten mit benignen, differenzialdiagnostisch relevanten Erkrankungen ergibt. Hingegen weisen Tumorpatienten v. a. in frühen Stadien immer wieder Werte innerhalb des Referenzbereichs auf. Relative individuelle Veränderungen bei seriellen Messungen sind deshalb aussagekräftiger, auch innerhalb des Referenzbereichs. Da sich die absoluten Wertlagen verschiedener Tumormarker-Testverfahren im Einzelfall jedoch deutlich unterscheiden können, müssen hierbei Methode, Assay und Hersteller beibehalten werden. Bei einem Methodenwechsel sind überlappende Messungen mit dem alten und neuen Testsystem durchzuführen.

Hinsichtlich der In-vivo-Einflussfaktoren sind alle physiologischen und pathophysiologischen Situationen zu berücksichtigen, die mit einer vermehrten Synthese, Expression und Freisetzung oder einer verminderten Metabolisierung und 
Elimination der Tumormarker einhergehen. Erhöhte Serumwerte von CA125 finden sich während des Menstruationszyklus, bei einer Endometriose und bei Vorliegen eines Aszites, Pleura- oder Perikardergusses. AFP und HCG sind regelhaft während der Gravidität erhöht; ebenso in geringerem Ausmaß auch andere Biomarker wie CEA, CA15-3, CA125 und CYFRA 21-1. PSA wird durch iatrogene Manipulationen der Prostata wie digital-rektale Palpation, transrektaler Ultraschall, Zystoskopie, Koloskopie und intensives Fahrradfahren sowie bei einer Prostatitis vermehrt sezerniert. Bei aktiven Rauchern werden mit einigen Testverfahren erhöhte CEA-Werte gemessen. Aufgrund der geringeren hepatischen Exkretion sind CA19-9-Werte bei cholestatischen Lebererkrankungen häufig erhöht; außerdem auch bei Pankreatitis und diversen gastrointestinalen Erkrankungen. AFP-Erhöhungen finden sich bei hepatobiliären Erkrankungen. Bei verminderter renaler Exkretion im Rahmen einer Niereninsuffizienz sind außerdem die Serumwerte von $\beta$ HCG $(\triangleright$ Choriongonadotropin, humanes), $\beta 2 \mathrm{MG}$ ( $\beta_{2}$-Mikroglobulin), CYFRA 21-1, ProGRP ( $\triangleright$ Pro-Gastrin Releasing Peptide), SCCA ( $\triangleright$ Squamous cell carcinoma antigen), HE4 (Human Epididymis Protein 4; $>$ Risk of ovarian malignancy algorithm) und z. T. auch von den hochmolekularen CA 15-3 und CA 125 erhöht. Schließlich können benigne Lungenerkrankungen zu erhöhten Konzentrationen von CA 15-3, CA 19-9, CA 125, CEA und CYFRA 21-1 führen, Hauterkrankungen zu erhöhten SCCA-Werten und zerebrale Schädigungen zu erhöhten S100-Werten ( $\$$ S100-Protein).

Zur Vermeidung von In-vitro-Störgrößen ( $\triangleright$ Störgrößen) ist bei einzelnen Tumormarkern auf eine korrekte präanalytische Behandlung der Blutproben, insbesondere auf eine rasche Abtrennung des Serums vom Blutkuchen und kurze Lagerungszeiten zu achten. Dadurch kann falsch hohen NSE-Werten ( $\triangleright$ Neuronenspezifische Enolase im Blut) aufgrund einer artifiziellen Hämolyse sowie falsch niedrigen ProGRP und freies PSA-Werten ( $\vee$ Prostataspezifisches Antigen, freies) durch zu lange Lagerung vorgebeugt werden. In seltenen Fällen treten falsch positive Tumormarkerresultate im Zuge von Immundiagnostik und -therapien aufgrund von heterophilen Antikörpern ( $\triangleright$ Antikörper, heterophile) auf.

Aufgrund aktueller technologischer Entwicklungen wurde zuletzt eine Vielzahl neuer Biomarkerkandidaten auf Protein-, RNA, \mRNA, genetischer und epigenetischer Ebene für die Serum- und Gewebediagnostik beschrieben. Eine Steigerung der diagnostischen Informationsdichte wird insbesondere durch die parallele Bestimmung von multiplen Markern in Mikroarrays und anderen Hochdurchsatzverfahren und die effiziente bioinformatische Aufarbeitung der Daten zu Protein-, Peptid-, RNA und DNA-Signaturen erreicht. Zur Stratifizierung von Patienten für molekulare zielgerichtete Therapien (,targeted therapies") werden spezifische molekulare Veränderungen im Tumorgewebe und z. T. auch auf im Blut zirkulierender zellfreier Tumor-DNA (cfDNA) gemes- sen. Mittels dieses sogenannten Liquid Profilings (oder Liquid Biopsy) kann auch der Therapieerfolg gemonitort und das Auftreten von Rezidiven sensitiv detektiert werden. In ähnlicher Weise werden anhand immunologischer und molekularer Tests Patienten für Immuncheckpoint-Inhibitortherapien stratifiziert. Zirkulierende Tumorzellen (CTCs; > Tumorzellen, zirkulierende) stellen hierzu alternative diagnostische Ansätze dar. Prospektive Studien werden die Eignung dieser diagnostischen Instrumente und ihren potenziellen, additiven Nutzen zu den derzeit etablierten Tumormarkern für die einzelnen Indikationen im Verlauf einer Tumorerkrankung zeigen.

\section{Literatur}

Holdenrieder S (2014) Circulating nucleic acids in therapy monitoring. In: Gahan PB (Hrsg) Circulating nucleic acids in early diagnosis, prognosis and treatment monitoring, Advances in predictive, preventive and personalised medicine, $\mathrm{Bd}$ 5. Springer, Dordrecht, S 309-348

http://www.aacc.org/members/nacb/lmpg/onlineguide/published guideli nes/major/pages/ default.aspx

o. A. (1999) European Group on Tumour Markers (EGTM): consensus recommendations. Anticancer Res 19:2785-2820

Stieber P, Heinemann V (2008) Sinnvoller Einsatz von Tumormarkern. J Lab Med 32:339-360

Trape J et al (2011) Increased plasma concentrations of tumour markers in the absence of neoplasia. Clin Chem Lab Med 49:1605-1620

\section{Tumor-M2-Pyruvatkinase}

\section{S. Holdenrieder und P. Stieber}

\section{Synonym(e) TM2-PK; M2-PK}

\section{Englischer Begriff tumor M2-pyruvate kinase}

Definition Die Tumor-M2-Pyruvatkinase (M2-PK) ist eine Isoform der Pyruvatkinase, eines glykolytischen Enzyms, das die Umwandlung von Phosphoenolpyruvat zu Pyruvat katalysiert.

Struktur Es existieren mehrere gewebsspezifische Isoformen der $>$ Pyruvatkinase, wie die M1-PK in Muskel- und Hirngewebe, L-PK in Leber- und Nierengewebe sowie R-PK in Erythrozyten. Während der Entwicklung von malignen Prozessen wurde die Expression einer tumorspezifischen M2-PK beschrieben.

Die Pyruvatkinase kann in aktiver tetramerer oder weniger aktiver dimerer Form vorkommen. 
Synthese - Verteilung - Abbau - Elimination Die Pyruvatkinase ist ein ubiquitär vorkommendes Enzym der Glykolyse. Die tumorspezifische Form der Tumor-M2-PK wird von Tumorzellen in vermehrtem Ausmaß produziert und liegt vorwiegend in der dimeren Form vor. Bei hohen Konzentrationen von Fruktose-1,6-biphosphat und Serin erfolgt eine verstärkte Assoziation zu tetrameren Formen, wodurch ein kataboler, energieproduzierender Zustand gefördert wird.

Funktion - Pathophysiologie Die Pyruvatkinase katalysiert die Umwandlung von Phosphoenolpyruvat zu Pyruvat, wobei energiereiche Adenosintriphosphate oder Guanosintriphosphate gebildet werden. Dadurch werden die DNA-Synthese und die Zellproliferation stimuliert bzw. gefördert.

Während der Karzinogenese wird das Muster der Pyruvatkinasen-Isoformen charakteristisch verändert: Die gewebsspezifischen Pyruvatkinasen (M1-PK, L-PK, R-PK) werden in geringerem Ausmaß, die Tumor-M2-PK in größerem Ausmaß produziert.

Tumor-M2-PK ist im Serum erhöht bei verschiedenen malignen Karzinomen insbesondere im fortgeschrittenen Stadium, außerdem bei Infekten und Polytraumata.

Untersuchungsmaterial - Entnahmebedingungen Serum, Plasma, Stuhl.

Analytik $>$ Enzymimmunoassay (EIA).

\section{Konventionelle Einheit kU/L.}

Referenzbereich - Erwachsene $\quad<17,5 \mathrm{kU} / \mathrm{L}$ (methodenabhängig).

Indikation Allgemeiner Aktivitätsmarker bei malignen Tumoren.

Interpretation Erhöhte Werte der Pyruvatkinase finden sich im Plasma beim Nierenzellkarzinom, Pankreaskarzinom, Bronchialkarzinom, Mammakarzinom und Kolonkarzinom insbesondere im metastasierten Stadium. Auch werden erhöhte Konzentrationen bei Infektionen und Polytraumata beschrieben. Ebenso wurden erhöhte Werte bei benignen gastrointestinalen, gynäkologischen, pulmonalen und urologischen Erkrankungen insbesondere bei Niereninsuffizienz beobachtet.

Aufgrund der fehlenden Organ- und Tumorspezifität bietet die Tumor-M2-PK gegenüber heute standardisiert eingesetzten Tumormarkern keinen Vorteil für die Diagnostik von Tumorerkrankungen. Ein Einsatz in der Verlaufskontrolle bei Patienten mit malignen Erkrankungen während und nach Therapie wurde beim Bronchial- und Mammakarzinom bereits an kleinen Patientengruppen gezeigt, jedoch noch nicht systematisch untersucht.
Als weitere mögliche Anwendung wurde die Detektion der Tumor-M2-PK im Stuhl als neue Screeningmethode für das Vorliegen eines kolorektalen Karzinoms angegeben. Allerdings zeigten umfangreiche Screening-Studien eine deutliche Unterlegenheit gegenüber dem immunologischen FOBT sowie nur eine unzureichende Sensitivität und Spezifität zur Erkennung von kolorektalen Adenomen. Somit hat die Tumor-M2-PK im Stuhl keinen Stellenwert zur Frühentdeckung von kolorektalen Karzinomen.

Diagnostische Wertigkeit Allgemeiner Aktivitätsmarker bei malignen Tumoren.

\section{Literatur}

Diamandis E, Fritsche HA, Lilja H et al (2002) Tumor markers. Physiology, pathobiology, technology, and clinical applications, 1. Aufl. AACC Press, Washington, DC

Hardt PD, Mazurek S, Toepler M et al (2004) Faecal tumour M2 pyruvate kinase: a new, sensitive screening tool for colorectal cancer. Br J Cancer 91:980-984

Haug U, Hundt S, Brenner H (2008) Sensitivity and specificity of faecal tumour M2 pyruvate kinase for detection of colorectal adenomas in a large screening study. British Journal of Cancer 99 (1):133-135

Yogesh MS, Stefan L, Nicolas H, Nada P, Ernst H, Wolfgang R, Joachim M, Jürgen MS (2008) Comparison of an Established Simple OfficeBased Immunological FOBT With Fecal Tumor Pyruvate Kinase Type M2 (M2-PK) for Colorectal Cancer Screening: Prospective Multicenter Study. The American Journal of Gastroenterology 103 (6):1496-1504

Tumor-Mutationsdatenbank

COSMIC-Datenbank

Tumornekrosefaktor- $\alpha$

A. M. Gressner und O. A. Gressner

Synonym(e) Kachectin; TNF- $\alpha$

Englischer Begriff tumor necrosis factor- $\alpha$; cachectin

Definition Vorwiegend von (stimulierten) Makrophagen, aber auch von anderen Zelltypen gebildetes, als Trimer vorliegendes, unglykosyliertes Zytokin mit pleiotropen inflammatorischen Wirkungen, dessen Serumkonzentration mögliche klinische Bedeutung in der (Ergänzungs-)Diagnostik der Sepsis und weiterer entzündlicher Systemerkrankungen hat. 
Tumornekrosefaktor- $\alpha$, Tab. 1 Synopsis der Eigenschaften von Tumornekrosefaktor $\alpha$ (TNF- $\alpha)$

\begin{tabular}{|c|c|}
\hline Bildungsort & $\begin{array}{l}\text { Makrophagen, Monozyten, T-, } \\
\text { B-Lymphozyten, NK-Zellen, neutrophile } \\
\text { Granulozyten, Astrozyten, glatte Muskelzellen, } \\
\text { Mastzellen, Keratinozyten u. a. }\end{array}$ \\
\hline Syntheseregulation & $\begin{array}{l}\text { Stimuli: Endotoxin, Interferon- } \gamma \text {, Interleukin-2, } \\
\text { GM-CSF, Bradykinin, C5a, } 1,25-(\mathrm{OH})_{2^{-}} \\
\text {Vitamin D3, Uratkristalle } \\
\text { Inhibitoren: Interleukin-6, TGF- } \beta \text {, } \\
\text { Prostaglandin E2, Dexamethason, Thalidomid, } \\
\text { Pentoxifyllin }\end{array}$ \\
\hline Struktur & $\begin{array}{l}\text { Membranverankerte Proform: Molmasse } \\
26 \mathrm{kDa} \text {, funktionell aktiv } \\
\text { Lösliche Form: Molmasse } 17 \mathrm{kDa} \text {, trimerer } \\
\text { Komplex, unglykosyliert } \\
\text { TNF- } \alpha \text {-converting Enzym (TACE) spaltet } \\
\text { Proform in lösliche Form }\end{array}$ \\
\hline Rezeptoren & $\begin{array}{l}\text { TNF-Rezeptor 1: Molmasse } 55 \mathrm{kDa} \text { (p 55) mit } \\
\text { Death-Domäne } \\
\text { TNF-Rezeptor 2: Molmasse } 75 \mathrm{kDa} \text { (p 75), } \\
\text { lösliche Rezeptoren im Blut } \\
\text { Signaltransduktion über Aktivierung von NF- } \chi \\
\text { B und JNK }\end{array}$ \\
\hline Effekte & $\begin{array}{l}\text { Zytolyse verschiedener Tumorzellen } \\
\text { Neutrophilen-Chemotaxis, -Proliferation und } \\
\text {-Apoptose } \\
\text { Neutrophilenadhäsion an Endothelzellen } \\
\text { Phagozytosestimulation } \\
\text { Vermittlung von Kachexie, septischem Schock, } \\
\text { Entzündungs- und Immunreaktionen }\end{array}$ \\
\hline
\end{tabular}

Synthese - Verteilung - Abbau - Elimination Das vorzugsweise in $\triangleright$ Monozyten/ $\triangleright$ Makrophagen, aber auch in - T-Lymphozyt und > B-Lymphozyt, glatten Muskelzellen, polymorphkernigen neutrophilen Granulozyten und Astrozyten produzierte Zytokin ( $\triangleright$ Zytokine) hat äußerst vielseitige lokale und systemische, dosis- und zeitabhängige Wirkungen (Tab. 1).

Die Expression in Makrophagen wird extrem stimuliert durch Lipopolysaccharide (LPS), die die Transkription 3 -fach, die TNF- $\alpha$-Messenger-RNA 50 - bis 100-fach und die Proteinsekretion etwa 10.000-fach erhöhen, wobei Präinkubation mit Interferon- $\gamma$ die TNF- $\alpha$-Produktionsrate weiter steigert. Weitere Stimuli sind Interleukin-2, GranulozytenMakrophagen-Colony-stimulierender Faktor (GM-CSF) und Bradykinin. Inhibitoren sind $\triangleright$ Interleukin-6 (IL-6), $\triangleright$ Transforming Growth Factor $\beta$ (TGF- $\beta$ ), Dexamethason, Thalidomid u. a. TNF- $\alpha$ wird in einer Präkursorform mit der Molmasse $27 \mathrm{kDa}$ gebildet und ist in dieser Form transmembranös gebunden und biologisch aktiv (pro-TNF- $\alpha$ ). Durch eine auf der membranverankerte Metalloproteinase (TNF- $\alpha$ converting enzyme, TACE) wird die membrangebundene Proform in die sezernierte Form mit der Molmasse $17 \mathrm{kDa}$ gespalten, die im Blut zirkuliert und eine trimere Struktur bildet. Über 2 Rezeptoren (TNFR1 [p 55, CD120 a] und TNFR2 [p 75, CD120 b]), die im Wesentlichen auf allen
Zellarten außer Erythrozyten zu finden sind, werden über intrazelluläre, NF- $\chi$-B-involvierende Signalwege Transkriptionsveränderungen ausgelöst.

Die biologischen und metabolischen Effekte sind abhängig von Wirkungsdauer und der Dosis des TNF- $\alpha$ (s. folgende Tabelle).

Synopsis metabolischer Wirkungen von TNF- $\alpha$ :

\begin{tabular}{l|l} 
Akute metabolische & Chronische metabolische \\
Wirkungen (Hochdosiseffekte) & Wirkungen (Niedrigdosiseffekte) \\
\hline Sepsis, SIRS & Gewichtsverlust \\
Schock, Gewebeschädigung & Anorexie \\
$\begin{array}{l}\text { Freisetzung kataboler } \\
\text { Hormone }\end{array}$ & $\begin{array}{l}\text { Proteinkatabolismus } \\
\text { Vipidabbau }\end{array}$ \\
Akutes respiratorisches & Subendokardiale Entzündung \\
Atemnotsyndrom & Insulinresistenz \\
Akute renale Tubulusnekrose & Erhöhte Tumormetastasierung \\
Adrenale Blutungen & Akute-Phase-Protein-Freisetzung \\
Reduzierte & Endothel(zell)aktivierung \\
Muskelmembranpotenziale & \\
Disseminierte intravaskuläre & \\
Koagulation & \\
Fieber &
\end{tabular}

Funktion - Pathophysiologie Aufgrund der potenten proinflammatorischen, proapoptotischen, immunmodulatorischen, prokoagulatorischen, hämodynamischen, endokrinen u. a. Wirkungen ist TNF- $\alpha$ ein wichtiger Mediator systemischer inflammatorischer Reaktionen und deshalb therapeutisches Ziel TNF- $\alpha$-blockierender Maßnahmen. Eine pathogenetische Rolle beim septischen Schock, bei Transplantatabstoßungen, multipler Sklerose, Autoimmunerkrankungen, Diabetes mellitus, rheumatoider Arthritis, Malaria, Lepra, Reperfusionsschäden $u$. a. wird postuliert. Immunneutralisation von TNF- $\alpha$ bei systemischen Entzündungen wird therapeutisch eingesetzt.

Untersuchungsmaterial - Entnahmebedingungen Serum, Heparin-Plasma.

Probenstabilität Analytstabilität bei $2-8{ }^{\circ} \mathrm{C} 2$ Tage, bei $-20{ }^{\circ} \mathrm{C} 6$ Monate.

Präanalytik Lipämie und Hämolyse sollten vermieden werden.

\section{Analytik}

- Immunologische Methoden: $>$ Radioimmunoassay, $>$ Enzymimmunoassay oder Chemolumineszenzimmunoassay ( $\triangleright$ Chemolumineszenz).

- Funktionelle Bestimmung: Zytolyseassay mit Mauszelllinie L929 für klinische Zwecke nicht geeignet. Durch Vorliegen löslicher TNF- $\alpha$-Rezeptoren im Serum, die den Liganden binden, kann die Messbarkeit beeinträchtigt sein. 
Referenzbereich - Erwachsene Nicht allgemein gültig, abhängig von der eingesetzten Methode. Richtwert: $<8 \mathrm{ng} / \mathrm{L}$.

\section{Indikation}

- Diagnose akut entzündlicher Erkrankungen

- Ergänzungsdiagnostik der Sepsis

Interpretation Systemische Konzentrationserhöhungen können bei Sepsis, Autoimmunerkrankungen, diversen Infektionserkrankungen, bei Transplantatabstoßungskrisen $u$. a. auftreten. TNF- $\alpha$ verhält sich als ein in der Zirkulation sehr flüchtiges (schmales Zeitfenster) Akute-Phase-Protein ( $\triangleright$ Akute-PhaseProteine), was krankheitsunspezifische Konzentrationserhöhungen im Serum mit sich bringt.

Diagnostische Wertigkeit Gegenwärtig lässt sich eine eindeutige Indikation und besondere klinische Bedeutung der Konzentrationsbestimmungen im Blut nicht feststellen.

\section{Literatur}

Hehlgans T, Pfeffer K (2005) The intriguing biology of the tumour necrosis factor/tumour necrosis factor receptor superfamily: players, rules and the games. Immunology 115:1-20

Papadakis KA, Targan SR (2000) Tumor necrosis factor: biology and therapeutic inhibitors. Gastroenterology 119:1148-1157

\section{Tumornekrosefaktor- $\alpha$-ex-vivo- Stimulationstest}

\section{A. M. Gressner und O. A. Gressner}

Synonym(e) LPS-Vollblut-Stimulationstest

Englischer Begriff TNF- $\alpha$ ex vivo stimulation

Definition Durch Zugabe von Lipopolysaccharid (LPS) zu einer pyrogenfrei abgenommenen und inkubierten Vollblutprobe werden die im Blut befindlichen Monozyten/Makrophagen zur Zytokinexpression und -sekretion stimuliert, unter der TNF- $\alpha$ nach Abzentrifugation im zellfreien Überstand gemessen wird und als Kenngröße der Immunreaktivität bei Sepsis dient.

Durchführung Erfolgt mit einem $>$ Bioassay. Pyrogenfreie Abnahme einer Heparin-antikoagulierten $50 \mu \mathrm{L}$-Vollblutprobe, die in $500 \mu \mathrm{L}$ Medium mit 50 und $500 \mathrm{ng}$ Lipopolysaccharid (LPS) für 4 Stunden bei $37{ }^{\circ} \mathrm{C}$ inkubiert wird.
Danach Abzentrifugation der zellulären Bestandteile (5 Minuten, $1000 \mathrm{~g}$ ) und Messung von TNF- $\alpha$, ggf. weiterer $>$ Zytokine (IL-1, IL-6, IL-8, IL-10) im Überstand mittels immunologischer Methoden.

Funktion - Pathophysiologie Lipopolysaccharide sind potente Stimulatoren der Transkription von TNF- $\alpha(\triangleright \mathrm{Tu}-$ mornekrosefaktor- $\alpha$ ) in Monozyten/Makrophagen und führen zu einer extremen Erhöhung inflammatorischer Zytokinsekretionen, z. B. TNF- $\alpha$. In der hyperinflammatorischen Phase der Sepsis liegt eine überschießende Immunreaktion mit hohem Ausstoß inflammatorischer Zytokine vor. In der späteren Phase der Immunparalyse besteht eine Immunsuppression mit deutlich reduzierter LPS-induzierter TNF- $\alpha$-Bildung (Abb. 1).

\section{Untersuchungsmaterial - Entnahmebedingungen}

Heparin-Vollblut.

Präanalytik Frisches Untersuchungsmaterial, pyrogenfreie Gewinnung und Inkubation.

Analytik S. Einzelzytokine ( $\triangleright$ Tumornekrosefaktor- $\alpha, \triangleright$ Interleukin-6, u. a.).

Referenzbereich - Erwachsene Stark abhängig von den Durchführungsbedingungen.

Richtwerte für TNF- $\alpha$ : bei $50 \mathrm{ng} / \mathrm{L}$ LPS: $104-516 \mathrm{ng} / \mathrm{L}$, bei $500 \mathrm{ng} / \mathrm{L}$ LPS: 265 bis $>1000 \mathrm{ng} / \mathrm{L}$.

Indikation Differenzialdiagnose der immunreaktiven Phasen des Sepsisverlaufs in Hyperinflammation und Immunparalyse.

Interpretation Die Ergebnisse des Vollblutstimulationstestes sind durch die Abhängigkeit von vielen variablen Einflussgrößen vorsichtig zu interpretieren und zudem durch das Fehlen einer geeigneten internen Qualitätskontrolle ( $\vee$ Qualitätssicherung, interne) im Einzelnen nicht überprüfbar. Eine verminderte TNF- $\alpha$-Bildung unter LPS-Stimulation weist auf ein Immunparalysestadium, eine normale bis hochnormale TNF- $\alpha$-Bildung auf eine hyperinflammatorische Sepsisphase hin (Abb. 1).

Diagnostische Wertigkeit Probleme der Standardisierung und internen Qualitätskontrolle sowie methodischer (zeitlicher) Aufwand schränken die klinische Anwendung erheblich ein. Der Test hat heute nur noch untergeordnete, auf spezialisierte Laboratorien beschränkte Bedeutung und kann z. B. durch flowzytometrische Expressionsanalyse von $\checkmark$ HLA-DR auf CD14(+)-Monozyten ersetzt werden. 


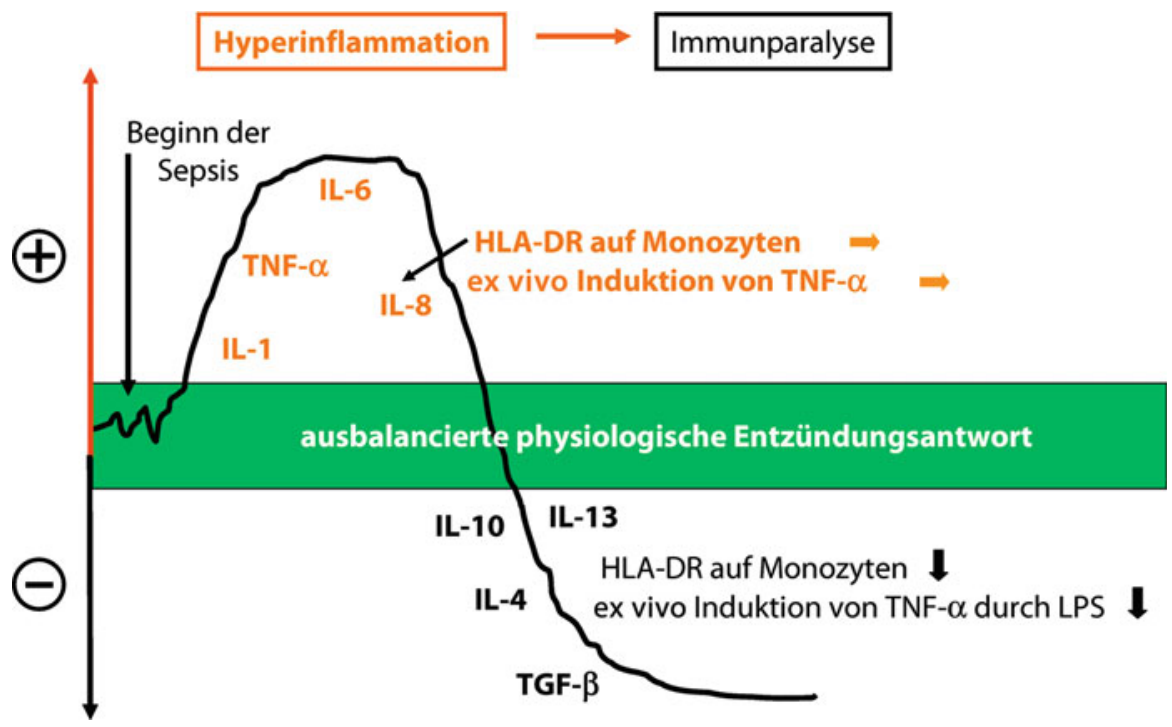

Tumornekrosefaktor- $\alpha$-ex-vivo-Stimulationstest, Abb. 1 Biphasischer Sepsisverlauf. (Modifiziert nach Grimminger et al. 1997)

\section{Literatur}

De Beaux AC, Ross JA, Maingay JP et al (1996) Proinflammatory cytokine release by peripheral blood mononuclear cells from patients with acute pancreatitis. Brit J Surgery 83:1071-1075

Grimminger F, Mayer K, Seeger W (1997) Gibt es eine gesicherte Immuntherapie bei der Sepsis? Internist 38:541-552

\section{Tumorsuppressorgen}

\section{J. Arnemann}

\section{$\operatorname{Synonym(e)~TS~}$}

\section{Englischer Begriff tumor suppressor gene}

Definition Als Tumorsuppressoren werden solche Proteine bezeichnet, die eine ungehemmte Zellproliferation unterdrücken, indem sie Kontrollfunktionen ausüben beim Zellzyklus, beim Übergang zur $>$ Apoptose, bei der DNA-Reparatur und der Segregation der zellulären DNA.

Beschreibung Der Verlust einer dieser Kontrollfunktionen durch Mutationen in einem der Tumorsuppressorgene (TS) ist oftmals ein erster Schritt hin zu einer Destabilisierung der Zelle. Erst ein homozygoter Funktionsausfall des Tumorsuppressors kann eine Tumorentwicklung fördern, indem beispielsweise Zellzyklus und -teilung aktiviert werden, Apoptose verhindert wird, eine Zellproliferation einsetzt und durch Aufhebung einer strikten Zelladhäsion zu den Nachbarzellen Metastasen ausgebildet und gestreut werden.
Tumorsuppressorgene folgen einem autosomal dominanten Erbgang, bei dem eine erste Mutation bereits über die Keimbahn vererbt wird, was dann als Anlageträgerschaft für eine erbliche Tumorerkrankung definiert wird. Eine Mutation kann auch spontan somatisch auftreten und über mehrere Zellzyklen ohne Auswirkung bleiben. In beiden Fällen führt erst das Auftreten einer zweiten, somatischen Mutation (s. - Somatische Mutation) in diesem Gen, sei es als pathogene Punktmutation oder chromosomale Deletion, zu einem Funktionsverlust und damit zu einer ungebremsten Zellproliferation.

\section{Literatur}

Lee EYHP, Muller WJ (2010) Oncogenes and tumor suppressor genes. Cold Spring Harb Perspect Biol 2(10):a003236

Marshall CJ (1991) Tumor suppressor genes. Cell 64:313-326

\section{Tumorzellen, zirkulierende}

\section{S. Holdenrieder}

\section{Synonym(e) Circulating tumour cells; CTC}

Definition Als zirkulierende Tumorzellen (,circulating tumour cells", CTC) werden Tumorzellen im peripheren Blut bezeichnet, während Tumorzellen im Knochenmark als disseminierte Tumorzellen (,disseminate tumour cells“, DTC) benannt werden. Bei soliden epithelialen Tumoren zeichnen sich die Tumorzellen durch Oberflächenmarker ( $\vee$ Oberflä- 
chenmarker-Expression) wie EpCAM oder Zytokeratine ( $\triangleright$ Zytokeratin) aus und sind negativ für den Leukozytenmarker $\triangleright \mathrm{CD} 45$.

Beschreibung Zirkulierende und disseminierte Tumorzellen sind vielversprechende diagnostische Werkzeuge zur Erkennung und zum Monitoring einer minimalen residualen Erkrankung (MRD). Sie weisen eine prognostische Wertigkeit bei epithelialen Tumoren im metastasierten und auch im nicht metastasierten Stadium auf. Der hohe diagnostische Stellenwert der DTCs deutet darauf hin, dass das Knochenmark ein bevorzugter Rückzugsort für Tumorzellen ist. Von diesem Reservoir aus kann dann später eine erneute Aussaat der Tumorzellen erfolgen.

Da zirkulierende Tumorzellen im Blut sehr rar sind, ist bei den meisten Methoden ein Anreicherungsschritt nötig, der sich die physikalischen Eigenschaften der Größe, Dichte oder elektrischen Ladung der Tumorzellen zunutze macht oder mittels Antikörper-beladener Magnetpartikel spezifische Oberflächenmoleküle wie z. B. das Adhäsionsmolekül EpCAM oder den Wachstumsrezeptor Her2-neu auf den Tumorzellen bindet. Zur Steigerung der Spezifität ( $\triangleright$ Spezifität, diagnostische) wird gleichzeitig eine Negativselektion gegenüber Leukozyten durch Verwendung eines CD45-Antikörpers durchgeführt. Anschließend werden die Tumorzellen immunhistochemisch durch den Nachweis von Zytokeratinen (CK) (wie im CellSearch-System und im CTC-chipMicrochip) oder durch die Sekretion von Proteinen in der Kurzzeitkultur (Nachweis lebender Tumorzellen im EPISPOT-Assay) quantifiziert. Eine Reihe alternativer Möglichkeiten, z. B. durch Nachweis tumorspezifischer mRNA oder DNA sowie von Methoden ohne Anreicherungsschritte wie die ultraschnelle automatisierte digitale Mikroskopie mit dem FAST-(,fibreoptic array scanning technology“-)System erweitern das Repertoire.

Positive Studienergebnisse zum Nachweis von CTC bei fortgeschrittenen Mamma-, Prostata- und kolorektalen Karzinomen und deren Korrelation mit Tumorprogress und Überleben der Patienten führten zur FDA-Zulassung des EpCAM/ CK-basierten CellSearch-Systems. Auch bei nicht metastasierten Tumorerkrankungen werden CTC inzwischen zu Therapiemonitoring und Rezidiverkennung eingesetzt, wobei es allerdings für die Interpretation individueller Verläufe noch weitergehender Studien bedarf. Aktuelle Bemühungen zielen auf die Verbesserung der Sensitivität ( $\triangleright$ Sensitivität, diagnostische) der Systeme und der Erfassung von EpCAMnegativen Zellen ab, die bereits die epithelial-mesenchymale Transition (EMT) vollzogen haben. Andererseits werden bei den sensitiveren CTC-Chips und RT-PCR-Verfahren ( $\triangleright$ PCR (Polymerase-Kettenreaktion)) unspezifische falsch positive Ergebnisse ( $\triangleright$ Testergebnis, falsch-positives) bei Kontrollpersonen beobachtet, was die Einführung von Grenzwerten nötig macht und die Interpretation erschwert. Dennoch sind zirkulierende Tumorzellen ein vielversprechendes Diagnostikum, dessen Stellenwert für Routineanwendungen sich in weiteren prospektiven Studien im Vergleich zu etablierten Biomarkern zeigen wird. Als Liquid Biopsy werden molekulare Untersuchungen von zirkulierenden Tumorzellen bezeichnet. Mittels molekularer Einzelzellanalyse kann die Heterogenität der zirkulierenden Tumorzellen dargestellt werden.

\section{Literatur}

Alix-Panabières C, Pantel K (2013) Circulating tumor cells: liquid biopsy of cancer. Clin Chem 59:110-118

Alix-Panabières C, Pantel K (2017) Characterization of single circulating tumor cells. FEBS Lett 591:2241-2250

Pantel K et al (2010) Circulating tumour cells in cancer patients: challenges and perspectives. Trends Mol Med 16:398-406

\section{Tüpfelung, basophile}

- Basophile Tüpfelung

\section{T-Uptake}

- Thyroxinbindungskapazität

\section{Turbidimetrie}

- Immunturbidimetrie

\section{Turbo-flow-Chromatographie}

- Turbulent-flow-Chromatographie

\section{Turbulent-flow-Chromatographie}

T. Arndt

Synonym(e) TFC; Turbo-flow-Chromatographie

Definition Eine Form der $>$ Flüssigkeitschromatographie, die wiederum eine Form der $\triangleright$ Chromatographie ist. 
Beschreibung TFC basiert auf der Injektion einer biologischen Probe ohne vorherige Probenaufbereitung durch $>$ Flüssig-Flüssig-Extraktion oder $>$ Festphasenextraktion.

Die Probenaufbereitung erfolgt bei TFC on-line, das heißt, auf einer kleinen Extraktionssäule (Turbo-flow-Säule), die integraler Bestandteil des Chromatographen ( $\triangleright$ Chromatograph) ist. Diese Extraktionssäule enthält als > stationäre Phase für die jeweilige analytische Fragestellung bzgl. Porendurchmesser und Hydrophobizität geeignete, relativ große Partikel.

Der Analysengang lässt sich wie folgt beschreiben: Nachdem die biologische Probe über den Probengeber injiziert wurde, wird diese mit einer geeigneten mobilen Phase ( $\triangleright$ Mobile Phase) mit hohem Wasseranteil bei vergleichsweise hohen Flussraten $(1,5-5 \mathrm{~mL} / \mathrm{min})$ durch die Extraktionssäule transportiert. Aufgrund der hohen Strömungsgeschwindigkeit vorbei an den relativ großen Partikeln der stationären Phase entstehen Turbulenzen. Diese bewirken, dass kleine Analytmoleküle noch in die Poren der Partikel diffundieren können. Große Moleküle wie Proteine werden dagegen sehr schnell, ohne dass sie in die Poren diffundieren oder ausgeprägte elektrostatische Wechselwirkungen mit der Partikeloberfläche aufnehmen können, aus der Säule herausgewaschen und in einen Abfallbehälter transportiert. Bei diesem Arbeitsschritt ist die Extraktionssäule im Fließschema der mobilen Phase von der analytischen Säule getrennt (s. Abbildung).

Nachfolgende Abbildung stellt den ersten Analysenschritt dar: hoher Fluss der mobilen Phase, Extraktion der Analytmoleküle an der Extraktionssäule (Turbo-flow-Säule), Elution höhermolekularer Matrixbestandteile (z. B. Proteine) in den Abfall:

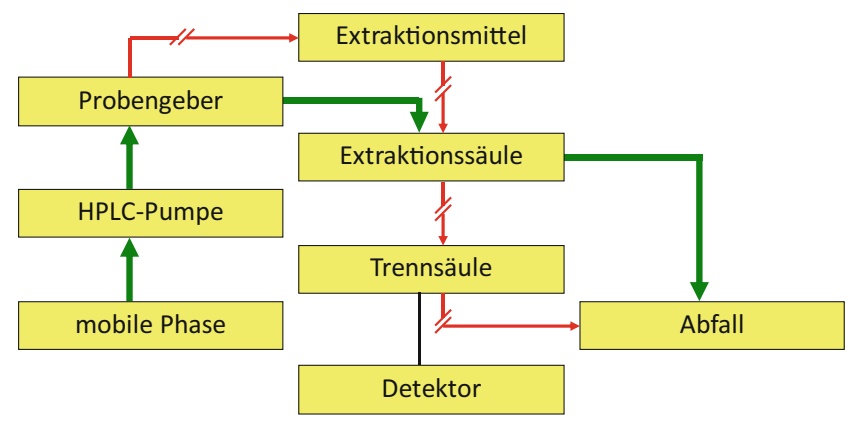

Nachdem Analyt- (aber auch nicht ausgewaschene Probenmatrix-)Moleküle auf der Extraktionssäule extrahiert und angereichert wurden, wird der Weg der mobilen Phase über ein mit einem Extraktionsmittel gefülltes Reservoir (Kapillarschleife mit einem mindestens 10-fach größerem Volumen als jenes der Extraktionssäule) gelenkt. Die mobile Phase schiebt dieses gewöhnlich organische Lösungsmittel enthaltende Extraktionsmittel durch die Extraktionssäule, wodurch die dort retinierten Moleküle extrahiert, aus der Extraktionssäule eluiert und auf die jetzt zugeschaltete analytische Trenn- säule transportiert werden. Dabei wird der Fluss der mobilen Phase auf $0,1-0,8 \mathrm{~mL} / \mathrm{min}$ reduziert, was eine ausreichende Trennung ( $\triangleright$ Auflösung) der Analytmoleküle von den verblieben Probenmatrixbestandteilen auf der analytischen Säule gewährleisten soll. Diese Trennung und die anschließende Detektion der Analytmoleküle erfolgt nach den bekannten, unter Chromatographie bzw. > Hochleistungs-Flüssigkeitschromatographie beschriebenen Prinzipien (s. Abbildung).

Der zweite Analysenschritt - Elution der Analytmoleküle, Trennung auf der Trennsäule/Detektion bei geringem Fluss der mobilen Phase, Aufzeichnung eines Chromatogramms - ist nachfolgend dargestellt:

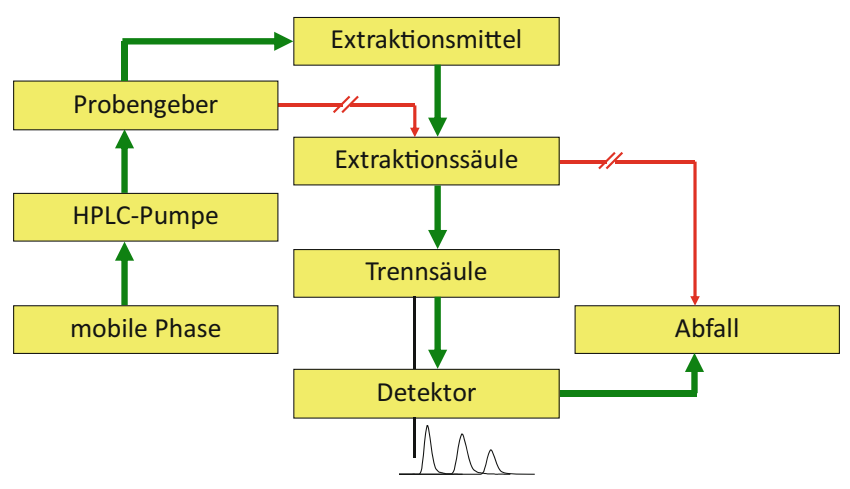

Anschließend werden Extraktionssäule und analytische Säule im Fluss der mobilen Phase wieder getrennt und die Extraktionssäule gewaschen und für die nächste Injektion vorbereitet. Die TFC ist letztlich eine Hochleistungs-Flüssigkeitschromatographie mit On-line-Probenaufbereitung unter besonderen Strömungsbedingungen der mobilen Phase. Vorteile dieser Technik sind der hohe Mechanisierungsgrad auch der Probenvorbereitung und damit die Schnelligkeit und der hohe Probendurchsatz. Bei Verwendung mehrerer parallel geschalteter Extraktionssäulen und damit zeitlich versetzter paralleler Probenvorbereitung und Analyse für mehrere Proben kann der Probendurchsatz weiter erhöht werden. Entwicklung, Betrieb und Wartung von TFC-Systemen erfordern ausgeprägte Kenntnisse und Fähigkeiten in der analytischen Chemie.

\section{Literatur}

Chassaing C, Robinson S (2009) Turbulent flow chromatography: an evolving solution for bioanalysis. Chromatogr Today 20-24

\section{Türk-Lösung}

H. Baum

Englischer Begriff Türk solution 
Definition Lösung zur Leukozytenzählung im Blut.

Beschreibung Zusammensetzung: 3,0 mL Eisessig $+1 \mathrm{~mL}$ $1 \%$ ige Gentianaviolettlösung $+100 \mathrm{~mL}$ destilliertes Wasser.

Türk-Lösung wird zur mikroskopischen $>$ Leukozytenzählung verwendet. Dabei werden die Erythrozyten durch die Essigsäure lysiert und die Leukozytenkerne durch die Gentianaviolettlösung angefärbt. Allerdings werden alle kernhaltigen Zellen (wie z. B. • Erythroblasten) angefärbt, sodass keine Unterscheidung in Leukozyten und andere kernhaltige Zellen möglich ist.

\section{Literatur}

Diagnostica MERCK (Hrsg) (1986) Hämatologische Labormethoden, 4. Aufl. GIT Verlag, Darmstadt, S 21-22

Hallmann L (1980) Klinische Chemie und Mikroskopie, 11. Aufl. Georg Thieme Verlag, Stuttgart/New York

Türk-Reizform

> Türk-Zelle

\section{Türk-Zelle}

A. M. Gressner und O. A. Gressner

Synonym(e) Lymphoidzelle; Türk-Reizform

Englischer Begriff Türk's irritation cell or leukocyte

Definition Stimulierte Lymphozyten („Reizformen“) mit morphologischen Merkmalen von sowohl Lymphozyten als auch Plasmazellen bei Infektionskrankheiten, Intoxikationen und Malignomen.

Beschreibung Die auch als Lymphoidzellen, atypische Lymphozyten, lymphatische Reizformen ( $\triangleright$ Lymphozyten, gereizte) bezeichneten, im Jahr 1898 von dem östereichischen Arzt W. Türk (1871-1916) erstmalig beschriebenen Zellen des peripheren Blutbildes weisen morphologische Merkmale sowohl der Lymphozyten (॰ Lymphozyt) als auch der Plasmazellen ( $\vee$ Plasmazelle; $\triangleright$ Lymphozyt, plasmozytoider) auf (,lymphatische Plasmazellen"), wie eingebuchteter, nierenförmiger Kern und blaues Zytoplasma. Es bestehen deutliche morphologische Ähnlichkeiten mit den 1936 von H. Downey (1877-1959) beschriebenen monozytoiden „Downey-Zellen“ (atypische mononukleäre Zellen) bei Morbus Pfeiffer (Mononukleose). TürkZellen finden sich im peripheren Blut bei lymphotropen Viruserkrankungen (z. B. Röteln, Mononucleosis infectiosa), Listeriose, Allergien, Intoxikationen und Malignomen.

\section{Literatur}

Türk W (1898) Klinische Untersuchungen über das Verhalten des Blutes bei akuten Infektionskrankheiten. Braumüller, Wien

\section{Turnaround-Time}

O. Colhoun

Synonym(e) Antwortzeit, gesamte; TAT; Untersuchungszeit, gesamte

Englischer Begriff turnaround-time

Definition Zeitabschnitt zwischen dem Untersuchungsauftrag an das Labor und der Berichterstattung.

Beschreibung In der Qualitätssicherung des gesamten diagnostischen Prozesses sind alle Abschnitte der Präanalytik ( $\triangleright$ Präanalytische Phase) außerhalb (Patientenvorbereitung, Probentransport) und innerhalb des Labors (Zentrifugation, Probenvorbereitung, Probenlagerung) sowie die Prozesse der Postanalytik bis zur Umwandlung des Ergebnisses in eine ärztliche Handlung in den Begriff eingeschlossen. Die Definition misst üblicherweise die Zeit von der $>$ Probennahme bis zur Ankunft des Befunds (s. \ Befund) beim Auftraggeber. In der Praxis Zeitdauer von der Eingangsbestätigung des Laboratoriums für das Material des Auftrags und die Übermittlung bzw. den Druck des Ergebnisses. Die Messung der TAT erfolgt üblicherweise für die Dauer der Erledigung eines kompletten Auftrags (Notfallanalytik) oder eines Laborbereichs (TAT für Klinische Chemie, für Hämatologie etc.) zur Feststellung der Leistungsfähigkeit eines medizinischen Labors und zu Vergleichszwecken.

\section{Literatur}

Guder WG (2009) Die Qualität labormedizinischer Untersuchungen Voraussetzungen in der präanalytischen und analytischen Phase. In: Guder WG, Nolte J (Hrsg) Das Laborbuch für Klinik und Praxis, 2. Aufl. Elsevier Urban und Fischer, München, S 1-20 


\section{Turnbullsblau}

- Berlinerblau-Reaktion

\section{Turner-Index}

$>$ Index, insulinogener

\section{Tüte}

T. Arndt

Definition Straßenname/Deckname für Haschisch $(\triangleright$ Straßennamen von Drogen: Cannabinoide).

\section{Twisted-Pair-Kabel}

- Shielded twisted pair

\section{TXA2}

> Thromboxan

\section{Tyndall, John}

\section{T. Arndt}

Lebensdaten Britischer Physiker, geboren am 02. August 1820 in Leighlin Bridge (Irland), gestorben am 04. Dezember 1893 in Hind Head (England)

Verdienste Studium in Marburg und Berlin. Physiker und Naturphilosoph. Untersuchungen über lichtempfindliche Gase, Lichtpolarisation, Diamagnetismus, Wärmestrahlung, Schallfortpflanzung und Thermoelektrizität. Genauere Beschreibung des von Faraday im Jahr 1857 entdeckten, später als „Faraday-Tyndall-Effekt“", oft nur noch > Tyndall-Phänomen bezeichneten Effekts der Lichtstreuung in kolloidalen Lösungen, der Grundlage der $>$ Immunnephelometrie und $\checkmark$ Immunturbidimetrie ist.

\section{Tyndallometrie}

- Tyndall-Phänomen

\section{Tyndall-Phänomen}

T. Arndt

Synonym(e) Faraday-Tyndall-Effekt

Englischer Begriff Tyndall effect

Definition Die Beugung eines Lichtstrahls durch kolloidale Teilchen einer Kolloidlösung (Dispersion), sodass man den Lichtstrahl bei seitlicher Betrachtung innerhalb dieser Dispersion sehen kann, heißt Faraday-Tyndall-Effekt (kurz TyndallEffekt; s. Abbildung). Das Prinzip des Tyndall-Phänomens ist nachfolgend dargestellt:

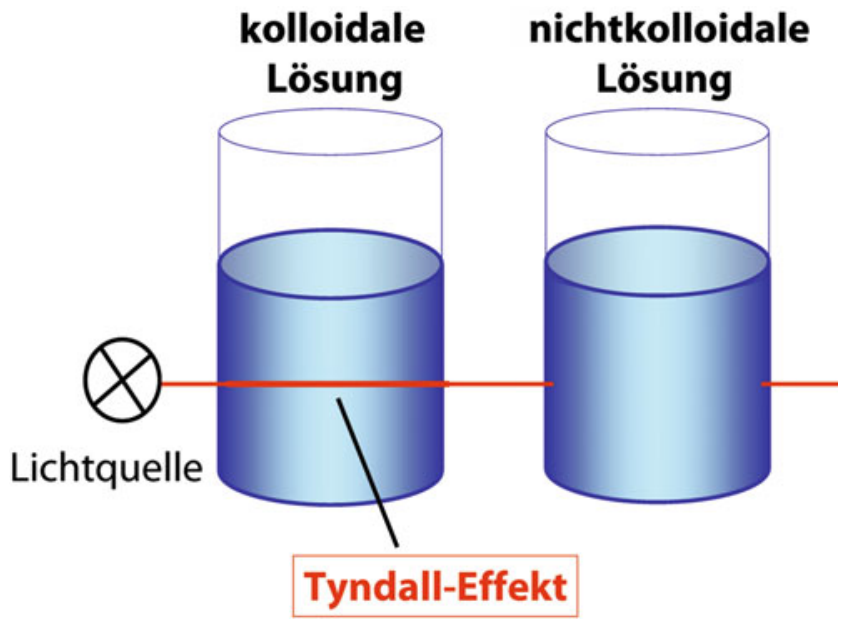

Beschreibung Die Teilchengröße von Kolloiden liegt unterhalb der Auflösungsgrenze eines Lichtmikroskops. Das Vorliegen kolloidaler Teilchen in einer Lösung (Dispersion) lässt sich aber bei Einfall eines ausreichend starken Lichtbündels und Betrachtung senkrecht zum Strahlungsgang nachweisen, wenn der Brechungsindex der Teilchen sich von dem des Dispersionsmittels unterscheidet. Der Eingangsstrahl wird dann als leuchtender „Kegel“ sichtbar. Die Intensität des den Lichtkegel bildenden Streulichtes wird im Wesentlichen durch die Größe und die Anzahl der kolloidalen Teilchen pro Volumeneinheit bestimmt. Bei konstanter Molekülgröße kann man daher diese Erscheinung zur Konzentrationsbestimmung nutzen. Die entsprechenden Analysenmethoden fasst man unter dem Begriff $>$ Immunnephelometrie zusammen. Dabei bestehen zwei Möglichkeiten der Messanordnung: Bestimmung der Differenz zwischen eintretendem 
und durch die Lichtstreuung abgeschwächtem, austretenden Licht $=\triangleright$ Immunturbidimetrie oder Trübungsmessung; Messung des Streulichts = Tyndallometrie, oft umgangssprachlich als Nephelometrie bezeichnet.

\section{Literatur}

Latscha HP, Linti GW, Klein HA (2004) Analytische Chemie ChemieBasiswissen III. Springer, Berlin/Heidelberg/New York

\section{Tyr}

- Tyrosin

\section{Tyramin}

A. M. Gressner und O. A. Gressner

Synonym(e) 4-Hydroxy-Phenylethylamin

\section{Englischer Begriff tyramine}

Definition Bei hochgradiger Leberinsuffizienz kommt es zu einer intrazerebralen Konzentrationszunahme des biogenen Amins Tyramin, das aufgrund seiner indirekten sympathomimetischen Wirkung (Noradrenalin freisetzung [ $>$ Katecholamine]), Hemmung der Noradrenalinsynthese und Präkursorfunktion für den falschen (inaktiven) Neurotransmitter $>$ Oktopamin Bedeutung in der Pathogenese der hepatogenen Enzephalopathie/Coma hepaticum hat.

Beschreibung Tyramin ist im Serum leberzirrhotischer Patienten aufgrund einer vermehrten bakteriellen Decarboxylierung des Tyrosins ( $\triangleright$ Tyrosin) im Intestinaltrakt und eines verminderten Abbaus in der Leber durch Monoaminooxidasen ( $>$ Monoaminooxidase im Serum) stark erhöht (s. Abbildung).

Entstehung von Tyramin durch intestinale bakterielle Decarboxylierung von Tyrosin:

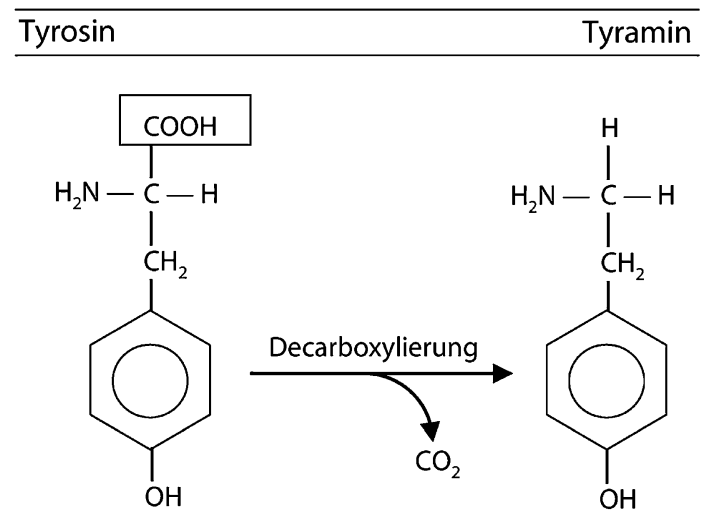

Die Hypertyraminämie ist vermutlich an der Pathogenese der hepatischen Enzephalopathie/Coma hepaticum beteiligt aufgrund der indirekten sympathomimetischen Wirkung mit Freisetzung von Noradrenalin, der Hemmwirkung auf die Noradrenalinsynthese und der Präkursorfunktion des Tyramins für den falschen (inaktiven) Neurotransmitter Oktopamin. Konzentrationen im Serum sind bei Zirrhotikern ohne Enzephalopathie etwa 2-fach, bei denen mit Enzephalopathie etwa 5-fach erhöht. Diagnostisch hat die Tyraminbestimmung gegenüber Oktopamin keine Vorteile.

Tyramin/Oktopamin sind pathogenetisch auch in den Bereich Cluster-Kopfschmerz/Migräne eingebunden.

\section{Literatur}

Hilger W, Zitting A, Albrecht J (1985) The brain octopamine and phenylethanolamine content in rats in thioacetamide-induced hepatogenic encephalopathy. Acta Neurol Scand 71(3):195-198

\section{Tyreoliberin-Test}

- TRH-Test

\section{Tyrosin}

\author{
A. C. Sewell
}

$\operatorname{Synonym(e)}$ Tyr

\section{Englischer Begriff tyrosine}

Definition Nicht essenzielle aromatische proteinogene Aminosäure. Der Name entstand, weil Tyr (griech. tyros: Käse) erstmals aus Kasein (Milch und Käse) durch Justus von Liebig (1803-1873) im Jahr 1846 isoliert wurde.

Struktur $>$ Aminosäuren.

Molmasse $181,2 \mathrm{~g}$.

Synthese - Verteilung - Abbau - Elimination Tyr entsteht aus > Phenylalanin durch die BH4-abhängige Hydroxylierung, katalysiert durch das Enzym Phenylalaninhydroxylase. Tyr wird abgebaut zu p-Hydroxyphenylpyruvat und weiter zu > Homogentisinsäure. Unter Wirkung von Homogentisatoxigenase entsteht Maleylacetoacetat, das weiter zu Fumarylacetoacetat umgewandelt wird. Der letzte Schritt spaltet Fumarylacetoacetat zu Fumarat und Acetoacetat. 
Funktion - Pathophysiologie Aus Tyr werden die $>$ Katecholamine Dopamin, Noradrenalin und Adrenalin synthetisiert. Die Schilddrüsenhormone T3 ( $\triangleright$ Triiodthyronin, gesamt, $\triangleright$ Triiodthyronin, freies) und T4 ( Thyroxin, gesamt) werden aus Tyr-Untereinheiten synthetisiert. Eine besondere Bedeutung hat Tyr in Proteinen, die an Signaltransduktionsprozessen beteiligt sind. Es fungiert als Empfänger von Phosphatgruppen, die durch Proteinkinasen (Rezeptor-Tyrosinkinasen) übertragen werden. Die Aktivität des Zielproteins wird dadurch verändert. Tyr ist Ausgangsstoff für die $>$ Neurotransmitterbildung. In Papaver somniferum ( $\triangleright$ Mohn) ist Tyr notwendig für die Morphinproduktion (s. a. > Morphin(derivate)). Außerdem ist Tyr Präkursor des Pigments $>$ Melanin.

Untersuchungsmaterial-Entnahmebedingungen Serum, Plasma, Liquor, Urin, Trockenblut.

Analytik $>$ Aminosäuren.

\section{Referenzbereiche $>$ Aminosäuren.}

Indikation Hypertyrosinämie.

Diagnostische Wertigkeit Bei der wichtigsten Stoffwechselstörung im Tyrosinabbau, der Hypertyrosinämie Typ I, handelt es sich um einen autosomal rezessiv vererbten Mangel der Fumarylacetoacetase. Es kommt zu einer Konzentrationserhöhung von Tyr und seiner Metabolite in allen Körperflüssigkeiten und Geweben. Die vor dem Enzymblock aufgestauten Metabolite hemmen verschiedene Enzyme und führen zu schwerer Leber- und Nierenschädigung.

\section{Literatur}

Duran M (2008) Amino acids. In: Blau N, Duran M, Gibson KM (Hrsg) Laboratory guide to the methods in biochemical genetics. Springer, Berlin, S 53-90

Kvittingen EA, Holme E (2000) Disorders of tyrosine metabolism. In: Fernandes J, Saudubray J-M, Van den Berghe G (Hrsg) Inborn metabolic diseases: diagnosis and treatment, 3. Aufl. Springer, Heidelberg/Berlin/New York, S 185-195

\section{Tyrosinphosphatase-Autoantikörper}

- Autoantikörper gegen Insulinoma-assoziiertes Antigen 2

TZ

> Thrombinzeit

\section{T-Zell-Differenzierung}

H. Baum

\section{Englischer Begriff T-cell differentiation}

Definition Differenzierung der T-Lymphozyten von der hämatopoetischen Stammzelle zu den Effektorzellen.

Beschreibung T-Zellen stammen von der hämatopoetischen Stammzelle $\mathrm{ab}$ und erhalten ihre spezifische Prägung zu immunkompetenten Zellen im Thymus. Die unreifste im Thymus nachweisbare Zelle der T-Reihe entspricht dabei der lymphatischen Vorläuferzelle des Knochenmarks. Innerhalb der Entwicklung im Thymus können dann 4 verschiedene Hauptgruppen an T-Zellen, den Thymozyten nachgewiesen werden. Diese Zellen unterscheiden sich in der Expression von CD4 und CD8. Die für beide Marker negativen Zellen (doppelt negativ) sind die unreifsten Thymozyten. Während dieser Reifungsphase wird der T-Zellrezeptor rearrangiert und an der Oberfläche exprimiert. Der Grad der Rezeptorexpression und Reifung kann dabei an der Co-Expression der Oberflächenmarker CD44 und/oder CD25 abgelesen werden. Nach dem Rearrangement des T-Zellrezeptors werden die Thymozyten positiv für CD4 und CD8 (doppelt positiv). Nur T-Lymphozyten ( $\triangleright \mathrm{T}$ Lymphozyt) (s. a. \ T-Lymphozyten, autoreaktive) mit einem für den Organismus nicht selbstgefährlichen T-Zellrezeptor und optimaler Antigenaffinität reifen dann weiter zu den einfach positiven CD4-positiven T-Helferzellen oder CD8-positiven zytotoxischen T-Lymphozyten aus. Alle anderen Thymozyten gehen durch $\triangleright$ Apoptose zugrunde.

\section{Literatur}

Bommhardt U, Beyer M, Hünig T et al (2004) Molecular and cellular mechanisms of T cell development. Cell Mol Life Sci 61:263-280

\section{T-Zelle}

- T-Lymphozyt

Interleukin-10 